Studying The Role of Estrogen Receptor Alpha in The Developmental Toxicity of Diethylstilbestrol Using A/ternative Testing Strategies 

Studying the role of estrogen receptor alpha in the developmental toxicity of diethylstilbestrol using alternative testing strategies 


\section{Thesis committee}

\section{Promoter}

Prof. Dr I.M.C.M. Rietjens

Professor of Toxicology

Wageningen University \& Research

\section{Co-promotor}

Dr J. Louisse

Researcher, Toxicology, Novel Foods \& Agrochains

Wageningen University \& Research

\section{Other members}

Prof. Dr A.H. Kersten, Wageningen University \& Research

Prof. Dr A. Piersma, National Institute for Public Health and the Environment (RIVM), Bilthoven

Prof. Dr M. van Duursen, VU University Amsterdam

Dr. H. Koëter, Orange House Partnership, Lucca, Italy

This research was conducted under the auspices of the Graduate School VLAG (Advanced studies in Food Technology, Agrobiotechnology, Nutrition and Health Sciences) 


\title{
Studying the role of estrogen receptor alpha in the developmental toxicity of diethylstilbestrol using alternative testing strategies
}

\author{
Aziza Hussein Bakheit Adam
}

Thesis

Submitted in fulfilment of the requirements of the degree of doctor at Wageningen University

by the authority of the Rector Magnificus

Prof. Dr A. P.J. Mol

in the presence of the

Thesis Committee appointed by the Academic Board

to be defended in public

on Monday 20 April 2020

at 1.30 p.m. in the Aula. 
Aziza Hussein Bakheit Adam

Studying the role of estrogen receptor alpha in the developmental toxicity of diethylstilbestrol using alternative testing strategies

pages 242

PhD thesis, Wageningen University, Wageningen, NL (2020)

With references, with summary in English

ISBN: 978-94-6395-369-6

DOI: https://doi.org/10.18174/518887 


\section{Table of Contents}

Chapter 1 General Introduction

$10-35$

Chapter 2 Estrogen receptor alpha (ER $\alpha)$-mediated coregulator binding

36-97 and gene expression discriminates the toxic ER $\alpha$ agonist diethylstilbestrol (DES) from the endogenous $E R \alpha$ agonist $17 \beta$-estradiol (E2)

Chapter 3 The in vivo developmental toxicity of diethylstilbestrol (DES) in rat evaluated by an alternative testing strategy

Chapter 4 Assessment of the in vitro developmental toxicity of $138-163$ diethylstilbestrol and estradiol in the zebrafish embryotoxicity test

Chapter 5 Physiologically based kinetic modelling-facilitated comparison $164-203$ of internal female dose levels of diethylstilbestrol and $17 \beta$ estradiol, to study a potential role of kinetics in the differences in their developmental toxicity

Chapter 6 General Discussion

Chapter 7 Summary

$228-233$

Appendix Acknowledgements

234-239

List of Publications

240-240

Curriculum Vitae

241-241

Overview of completed training activities

242-242 


\section{Abbreviations List}

\begin{tabular}{|c|c|}
\hline Abbreviation & Meaning \\
\hline DES & Diethylstilbestrol \\
\hline E2 & $17 \beta$-estradiol \\
\hline ERs & Estrogen Receptors \\
\hline ERE & Estrogen-Responsive Element \\
\hline ER $\alpha$ & Estrogen Receptor $\alpha$ \\
\hline ERß & Estrogen Receptor $\beta$ \\
\hline MIE & Molecular Initiating Event \\
\hline DBD & DNA-binding Domain \\
\hline ERE & Estrogen Responsive Element \\
\hline LBD & Ligand-binding Domain \\
\hline NR & Nuclear Receptor \\
\hline GST & Glutathione-S-transferase \\
\hline MARCoNI & Microarray Assay for Real-time Coregulator-Nuclear Receptor Interaction \\
\hline DNMTs & DNA Methyltransferases \\
\hline ECVAM & European Centre for the Validation of Alternative Methods \\
\hline EST & Embryonic Stem Cell Test \\
\hline MM & Limb Bud Micromass \\
\hline WEC & Rat Whole Embryo Culture \\
\hline mEST & Mouse Embryonic Stem Cell Test \\
\hline ZET & Zebrafish Embryo Toxicity Test \\
\hline GMS & General Morphology System \\
\hline PBK & Physiologically Based Kinetic \\
\hline ADME & Absorption, Distribution, Metabolism, and Excretion \\
\hline POD & Point of Departure \\
\hline BMD & Benchmark Dose BMD \\
\hline NCOA1 & Nuclear Receptor Coactivator 1 \\
\hline NRIP1 & Nuclear Receptor-Interacting Protein1 \\
\hline PNRC2 & Proline-rich Nuclear Receptor Coactivator 1 \\
\hline BDS & Biodetection Systems \\
\hline DMEM & Dulbecco's Modified Eagle Medium \\
\hline NEAA & Non-essential Amino Acids \\
\hline DCC-FCS & Dextran-Coated Charcoal-Treated Fetal Calf Serum \\
\hline DTT & Dithiothreitol \\
\hline CDTA & Diaminocyclohexane Tetraacetic Acid Monohydrate \\
\hline RLU & Relative Luminescence Units \\
\hline TR-FRET & Time-Resolved Fluorescence Resonance Energy Transfer \\
\hline TBS & Tris-buffered Saline TBS \\
\hline CCD & Charge Coupled Device \\
\hline MI & Modulation Index \\
\hline RNA-seq & Next Generation Sequencing \\
\hline RIN & RNA Integrity Number \\
\hline FDR & False Discovery Rate \\
\hline Cpdb & Consensus Path Database \\
\hline RT-qPCR & Real-time Quantitative Polymerase Chain Reaction \\
\hline TGF & Transforming Growth Factor \\
\hline RAR & Retinoid Acid Receptor \\
\hline
\end{tabular}




\begin{tabular}{|c|c|}
\hline ERR & Estrogen Related Receptor \\
\hline DMSO & Dimethyl Sulfoxide \\
\hline NADPH & Nicotinamide Adenine Dinucleotide Phosphate \\
\hline UDPGA & Uridine 5'-diphosphoglucuronic Acid \\
\hline PAP & Adenosine 3'-phosphate 5'-phosphosulfate \\
\hline acetyl CoA & Acetyl Coenzyme A \\
\hline RED & Rapid Equilibrium Dialysis \\
\hline PBS & Phosphate Buffered Saline \\
\hline EBs & Embryonic Bodies \\
\hline Papp & The apparent permeability coefficient \\
\hline Ka & Rate Constant \\
\hline QSAR & Quantitative Structure-activity Relationship \\
\hline PSA & Polar Surface Area \\
\hline QPPR & Quantitative Property-Property Relationship \\
\hline Pow & Octanol-water Partition Coefficient \\
\hline Clint & In vitro Intrinsic Clearance \\
\hline Km & Michaelis-Menten Constant \\
\hline$C_{\max }$ & Maximum Blood Concentration \\
\hline SC & Normalized Sensitivity Coefficients \\
\hline Fub & Fraction unbound \\
\hline BMR & Benchmark Response \\
\hline VLC & Fraction of Liver Tissue \\
\hline VRc & Fraction of Rapidly Perfused Tissue \\
\hline QLC & Fraction of Blood Flow to Liver \\
\hline QRc & Fraction of Blood Flow to Rapidly Perfused Tissue \\
\hline QSc & Fraction of Blood Flow to Slowly Perfused Tissue \\
\hline Papp, Caco-2 & Estimated in vivo Papp Value \\
\hline Vin & Intestine Volume for Intestinal Sub-compartment \\
\hline SAin & Intestinal Surface Area for Intestinal Sub-compartment \\
\hline Kin & Transfer Rate Within Intestinal Sub-compartments \\
\hline PR & Rapidly Perfused Tissue/blood Partition Coefficient \\
\hline PS & Slowly Perfused Tissue/blood Partition Coefficient \\
\hline ATRA & All-trans-Retinoic Acid \\
\hline EGME & Ethylene Glycol Monomethyl Ether \\
\hline EGEE & Ethylene Glycol Monoethyl Ether \\
\hline EGBE & Ethylene Glycol Monobutyl Ether \\
\hline EGPE & Ethylene Glycol Monophenyl Ether \\
\hline VEGFA & Vascular Endothelial Growth Factor \\
\hline ANGPT1 & Angiopoitin 1 \\
\hline Hpf & hours post fertilization \\
\hline TI & Teratogenicity Index \\
\hline LC50 & $50 \%$ lethal concentration \\
\hline EC50 & $50 \%$ effect concentration \\
\hline SEM & Standard Error of the Mean \\
\hline BMC & Benchmark Concentration \\
\hline BMR & Benchmark Response \\
\hline UGTs & UDP-glucuronosyltransferases \\
\hline ACN & Acetonitrile \\
\hline DESAD & National Cooperative Diethylstilbestrol Adenosis \\
\hline GA & Gestational Age \\
\hline
\end{tabular}


HDACs

GD

UGT

HUVECS
Histone Deacetylases

Gestational Days

Uridine 5'-diphospho-glucuronosyltransferase

Human Umbilical Vein Endothelial Cells 

CHAPTER 1

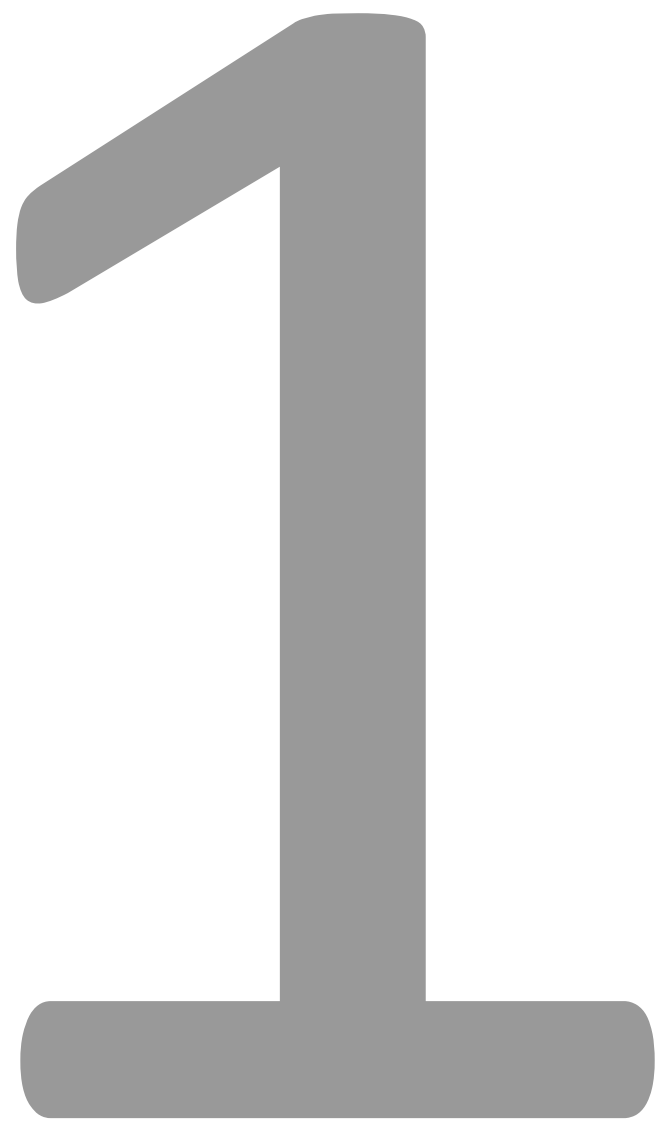


General Introduction 


\subsection{Background information}

Diethylstilbestrol (DES) is a synthetic estrogen that has been used between the 1940s to the 1970s by pregnant women to prevent miscarriages and premature delivery by stimulating the synthesis of estrogen and progesterone in the placenta (IARC, 2012; Newbold 2008; Reed and Fenton 2013). Moreover, DES has also been used for menopausal hormone therapy, for the prevention of postpartum breast engorgement, and it has also been used in the treatment of prostate cancer and of postmenopausal women with breast cancer (IARC, 2012). DES was also used for growth stimulation in livestock (IARC, 2012). DES was given to approximately 2 to 10 million pregnant women and between 1 and 2 million women have been prenatally exposed (Palmer et al., 2006; Reed \& Fenton, 2013). DES continued to be prescribed until 1971 when Greenwald et al. (1971) and Herbst et al. (1971) independently reported their findings of clear cell vaginal adenocarcinoma, an extremely rare form of cancer in young women that were exposed to DES in utero (Greenwald et al. 1971; Herbst et al. 1971).

These adverse effects reported for DES have not been reported for the endogenous estrogen $17 \beta$ estradiol (E2), raising the question what the differences are in the modes of action of these two estrogenic chemicals. Thus, the aim of this thesis was to investigate the differences in estrogenicity and developmental toxicity between DES and E2 using different in vitro and in silico approaches, focussing on the potential role of possible differences in ER $\alpha$-mediated changes in gene expression in the underlying mode of action.

\subsection{Adverse effects related to DES-exposure}

\subsubsection{Developmental and reproductive toxicity of DES}

Developmental toxicity is defined as any undesirable effect of a chemical on the development of an organism before and after birth, including malformation, growth retardation, embryo lethality, and malfunction (Pellizzer et al. 2005). DES use during pregnancy has been associated with multiple 
adverse health effects in the exposed females and their offspring including birth related problems, sub/infertility and cancer of reproductive tissues (Reed and Fenton 2013; Titus-Ernstoff et al. 2001). In detail, the birth related adverse effects in humans include spontaneous abortion, second trimester pregnancy loss, preterm delivery, stillbirth, and neonatal death (Reed and Fenton 2013). Animal studies showed that DES caused developmental toxicity, including embryonic death, resorptions and malformations (Cornwall et al. 1984; Nagao and Yoshimura 2009; Wardell et al. 1982). Mice that were exposed orally to DES during early and middle gestation showed decidual hypoplasia, subsequent placental haemorrhage (Nagao and Yoshimura 2009), and decreases in the physiological function of the placenta (Nagao et al., 2013). Similar results have been found in rats, including failure of uterine contraction accompanied by placental detachment and fetal death shown in rats that were exposed to DES (Clevenger et al. 1991; Zimmerman et al. 1991). It has been reported that in addition to developmental toxicity, DES can also induce reproductive toxicity. Reproductive effects were seen in both F1 animals exposed to DES in utero and in animals exposed postweaning (Odum et al. 2002). For example, DES was found to be a reproductive toxicant in female CD-1 mice decreasing the fertility, the number of litters, and the number of live pups per litter (Kawaguchi et al. 2009; Reel et al. 1985).

\subsubsection{DES and breast cancer}

It has been hypothesized that breast cancer risk is influenced by prenatal hormone levels (Sieri et al. 2009). The women who were exposed to DES in utero were shown to have an increased risk of breast cancer at the ages at which breast cancer becomes more common (Hatch et al. 1998; Hilakivi-Clarke 2014; Hoover et al. 2011; Palmer et al. 2006; Troisi et al. 2007). DES-exposed women aged $\geq 40$ years were estimated to have 1.9 times the risk of unexposed women of the same age. For women aged $\geq 50$ years, the estimated relative risk was even higher, but the relatively small number of cases made the age gradient imprecise. Furthermore, the highest relative risk was observed for the cohorts receiving the highest cumulative dose of DES (Palmer et al. 2006). The link between DES exposure 
and breast cancer has been shown also in animal studies. Animal studies showed that exposure of the animals to dose levels of DES similar to therapeutic dose levels given to pregnant women, increased the risk of developing mammary tumors in offspring (Boylan 1978; Boylan and Calhoon 1983; Hilakivi-Clarke 2014; Rothschild et al. 1987; Vassilacopoulou and Boylan 1993; Yoshikawa et al. 2008).

\subsection{Mechanisms of action of estrogen-like compounds}

Estrogens are steroid hormones that are primarily produced in the female ovaries. Estrogens influence the growth, differentiation and function of many target organs, such as the mammary gland, uterus, ovary, vagina, as well as testis and prostate (Heldring et al. 2007; Kuiper et al. 1996; Ogawa et al. 1998). They also play a role in bone maintenance, the central nervous system and the cardiovascular system (Gustafsson 2003). Estrogens exert their physiological effects mainly through activation of the nuclear estrogen receptors (ERs) in target cells, exerting their effects through upregulation of the transcription of estrogen-responsive element (ERE)-controlled genes. There are two main forms of the ER, estrogen receptor $\alpha(E R \alpha)$ and estrogen receptor $\beta$ (ER $\beta)$. ER $\alpha$ and ER $\beta$ have differential effects on the cell cycle in various estrogen-sensitive tissues. It has been reported that ER $\alpha$ activation in breast and uterus enhances cell proliferation, which is necessary for growth and maintenance of tissues (Harris 2007; Pearce and Jordan 2004; Thomas and Gustafsson 2011). ER $\beta$ has been shown to counteract the ER $\alpha$-mediated stimulation of cell proliferation (Sotoca et al. 2008; Thomas and Gustafsson 2011). In developmental and reproductive toxicology, the main attention goes out to the nuclear $E R \alpha$, as activation of nuclear ER $\alpha$ is the driving force behind adverse effects of estrogens in laboratory animals as has been shown in ER $\alpha$ knockout animals (Bocchinfuso and Korach 1997; Couse et al. 2001; Couse and Korach 1999; Couse and Korach 2004; Eddy et al. 1996; Prins et al. 2001). It has conclusively been shown that ER $\alpha$ is needed to induce adverse developmental effects in neonates including induction of malformations and phenotypic changes in the neonatal reproductive tracts of female and male mice (Couse et al. 2001; Couse and 
Korach 2004; Prins et al. 2001). Furthermore, ER $\alpha$-mediated adverse effects are considered relevant within regulatory frameworks, because binding to and activation of ER $\alpha$ is implicated as the molecular initiating event (MIE) in adverse outcome pathways on estrogenicity-related adverse endpoints (OECD, 2012).

ERs consist of several distinct functional regions (A-F) as illustrated in figure 1. The A/B region located in the $\mathrm{N}$-terminal part of the protein encompasses the activation function 1 (AF-1) domain responsible for ligand-independent transactivation. The most conserved domain among ERs is the DNA-binding domain (DBD) corresponding to the $C$ region, which is responsible for binding to a specific DNA sequence, called estrogen responsive element (ERE), in gene promoter regions of estrogen responsive genes. The $\mathrm{C}$-terminal protein part (E/F region) includes the ligand-binding domain (LBD) together with the ligand dependent transactivation domain AF-2 (Heldring et al. 2007; Klinge 2000). The nuclear ER $\alpha$ and ERß, like all other members of the nuclear receptor (NR) superfamily, are ligand-dependent transcription factors that work in concert with transcriptional coregulators to control target gene transcription (Klinge 2000).

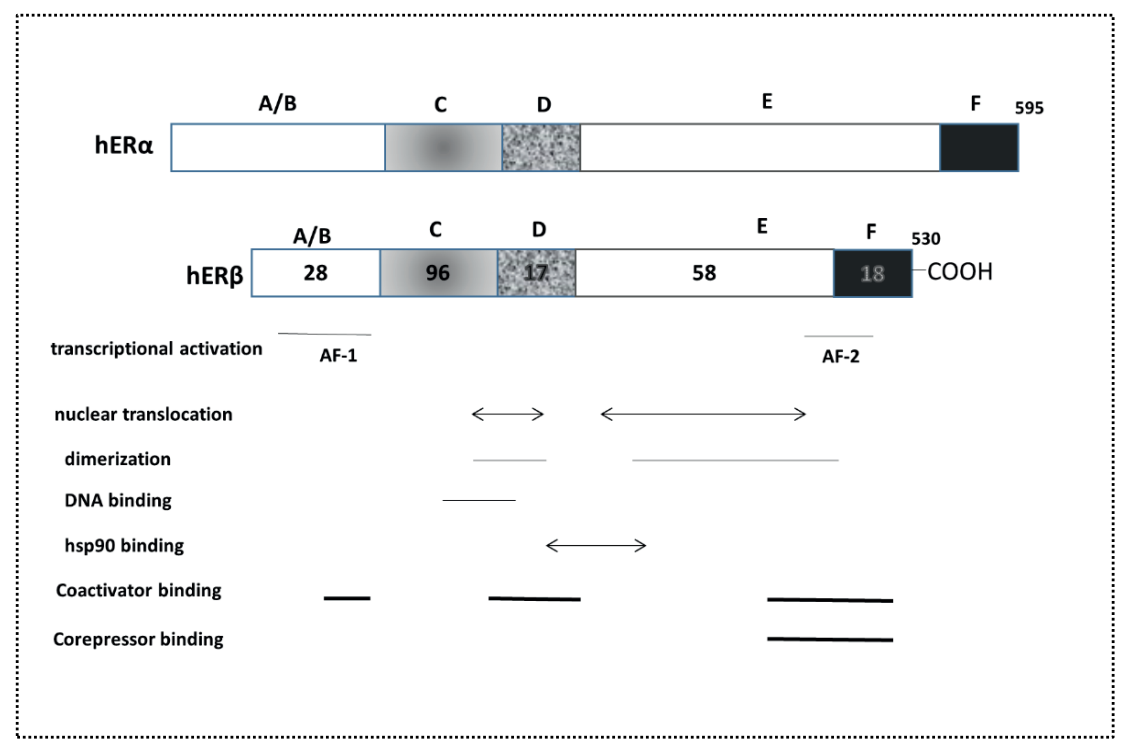


Figure 1. Schematic representation of the common structural and functional domains of ER a and ERB. The domains of the receptors are indicated, as are the regions responsible for nuclear translocation, dimerization, DNA binding, hsp90 binding, and interaction with co-activators and co-repressors (based on Klinge 2000).

Upon ligand binding to the ER, the LBD undergoes a conformational change that leads to receptor dimerization, translocation of the ER from the cytoplasm into the nucleus, and binding to the ERE followed by stimulation of estrogen-target gene transcription. Transcriptional activation mediated via the ERs is influenced by binding to transcriptional coregulators that can activate (e.g. nuclear receptor coactivator NCOA) or repress (e.g. nuclear receptor co-repressor NCOR) the gene transcription (Glass and Rosenfeld 2000; O'Malley and Kumar 2009). Previous research showed that overexpression or lack of certain ligand-dependent coregulators could affect the physiological outcome driven by a chemical (Hsia et al. 2010). Therefore, interaction of the NRs with coregulators is essential in the mode of action underlying the biological effects of chemicals activating the ERs. There are several methods that have been used to study these coregulator interactions with the NRs including Glutathione-S-transferase (GST)-pull down assays, yeast two hybrid assays or the Microarray Assay for Real-time Coregulator-Nuclear Receptor Interaction (MARCoNI) (Aarts et al. 2013; Foulds et al. 2013; Klein et al. 2000; Koppen et al. 2009).

These technologies assessing NR binding to coregulator peptides could add insights in the mode of action underlying the activity of the NRs and their ligands. In the present thesis the MARCoNI array technology was applied. This technology provides a high-throughput manner to rapidly and simultaneously assess ligand-modulated binding of NRs to 154 motifs derived from $>60$ different coregulators. Thus, by using this technique, broad coregulator binding profiles can be obtained (Aarts et al. 2013). The assay uses a PamChip plate consisting of 96 identical arrays, each array containing 155 immobilized nuclear receptor (NR) coregulator peptides harbouring either LXXLL (coactivator) or LXXX IXXXL (corepressor) sequences. The schematic overview of the assay is illustrated in figure 2. 


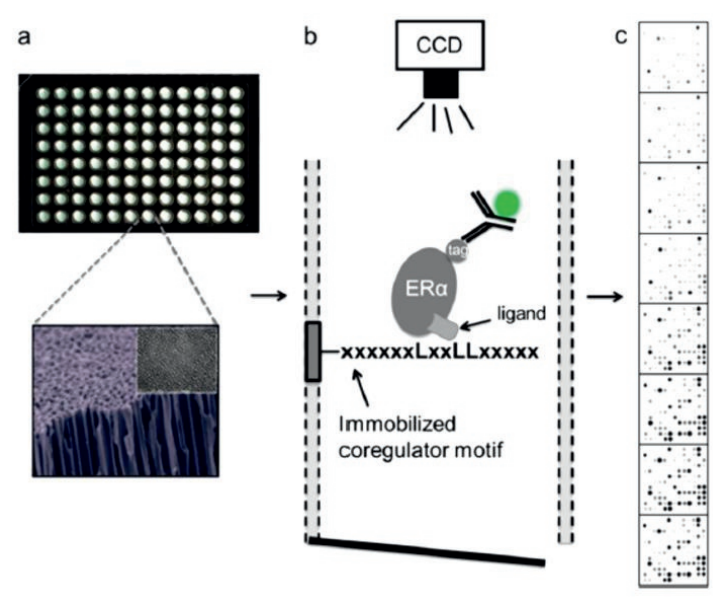

Figure 2. Schematic overview of the PamChip peptide microarray for nuclear receptor-coregulator interaction profiling. (a) PamChip-96 design. The PamChip plate consists of 96 identical arrays, each array containing 155 NR coregulator peptides (derived from both coactivators and corepressors) immobilized on a porous metal oxide carrier. (b) Ligand-modulated interaction of coregulator-derived peptides with ER $\alpha$-LBD. Depending on the presence of ligand, the ER $\alpha-L B D$ will bind to coregulator-derived peptides, which can be detected by fluorescent antibodies against the ER $\alpha-L B D$. (c) Images obtained with an increasing series of concentrations of a ligand. Figure adopted from Aarts et al. (2013).

Many steroidal and non-steroidal compounds bind to the ERs including endogenous, natural (phyto-) and synthetic estrogens (Pamplona-Silva et al. 2018; Smiley and Khalil 2009). The structural characteristics of these chemicals that are crucial for binding to these receptors include the phenolic ring(s), the molecular weight, and an optimal hydroxylation pattern (Anstead et al. 1997; Blair et al. 2000; Mombelli 2012; Hong et al. 2002; Lee and Barron 2017). Especially chemicals that resemble the endogenous female sex hormone $17 \beta$-estradiol (E2) can bind and activate the ERs with a similar or an even higher affinity. DES is an analogue of E2 and binds to both $E R \alpha$ and $E R \beta$ with a higher affinity compared to E2 (Blair et al., 2000; Bolger et al. 1998; Nikov et al. 2001). It has been reported that the molecular dimensions of DES are almost identical to those of E2 (see figure 3), particularly with regard to the distance between the terminal hydroxyl groups (Gonzalez et al. 2019). The length and breadth of both the steroid skeleton and the DES skeleton were shown to fit well into the receptorbinding pocket (Gonzalez et al. 2019). 


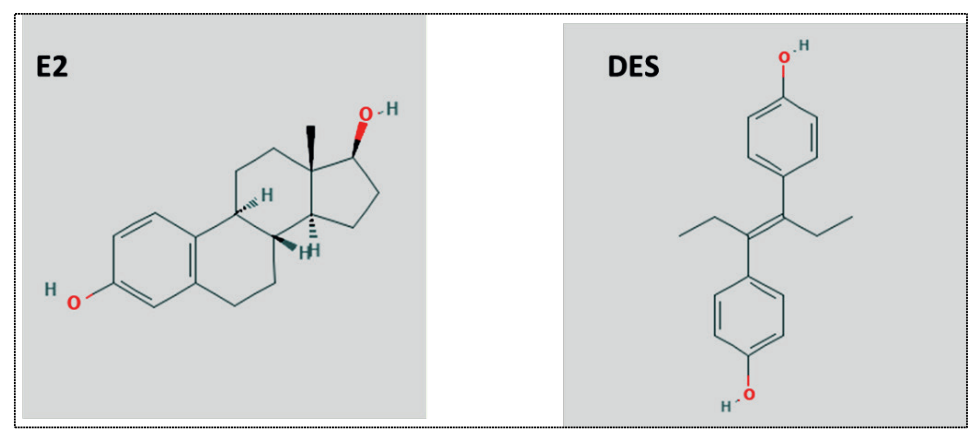

Figure 3. chemical structures of E2 and DES

ER $\alpha$ plays an important role in the developmental and reproductive toxicity of DES (Couse et al. 2001; Couse and Korach 2004; Prins et al. 2001). ER $\alpha$ functions as a ligand-dependent transcription factor that modulates gene transcription via direct recruitment to target gene chromatin. Studies suggest that alteration of ER $\alpha$-regulated changes in gene expression by DES is also mediated by epigenetic modification like DNA methylation, which has been reported to be in particular the case for genes related to developmental programming alteration (Bromer et al. 2009). It has been reported that female mice exposed to DES in utero had aberrant methylation in the promotor and intron of the hoxa10 gene, a gene of which an adequate expression is critical during embryonic development (Bromer et al. 2009). Thus, DES has a potential for causing epigenetic modifications which may play a role in its mode of action.

\subsection{Potential mode of action of DES}

\subsubsection{The role of estrogen receptor alpha in the developmental and reproductive toxicity effect of} DES

The mode of action of DES-induced adverse effects is largely unknown. Different studies indicated that a functional ER $\alpha$ is needed for DES-mediated activity including the DES-induced phenotypic changes in the reproductive tract, progressive proliferative lesions, and abnormal epithelial cell differentiation (Chen et al. 2012; Klotz et al. 2000). It has also been reported that ER $\alpha$ is needed to 
induce adverse developmental effects in neonates including induction of malformations and phenotypic changes in the neonatal reproductive tract of female and male mice (Couse et al. 2001; Couse and Korach 2004; Prins et al. 2001). This was concluded from experiments in ER $\alpha$ knock-out mice, in which exposure to DES, in contradiction to effects in wild-type mice, did not induce alteration in the weight of the seminal vesicle in the male and in the phenotype of the reproductive tract of the female, together with alteration of the expression of Hoxa10, Hoxa11, and Wnt7 genes. This provides clear evidence for a role for ER $\alpha$ in mediating the adverse effects of neonatal DES exposure in the reproductive tract.

\subsubsection{Epigenetic effect of DES}

Gene expression can also be altered as a consequence of epigenetic changes. Epigenetic regulation of gene expression includes methylation of gene promoter regions, histone modifications, deposition of certain histone variants along specific gene sequences and microRNA (miRNA) expression (Knight K 2015). A possibility of a transgenerational effect of DES has been under discussion. Some studies have found an increased risk of genital tract abnormalities in the children of women exposed to DES in utero (Colton and Greenberg 1982; Palmer et al. 2006). These inherent transmitted adverse effects of DES were hypothesized to occur through epigenetic changes (Titus-Ernstoff et al. 2006). In molecular mechanistic studies, genetic and epigenetic regulations have been implicated in DESinduced reproductive developmental abnormalities (LeBaron et al. 2010; Yamashita 2006). The developmental and reproductive abnormalities in the male and the female reproductive tracts induced by DES were reported to be likely induced through epigenetics changes, since it was demonstrated that DES has effects on DNA methylation and histone modifications (Newbold et al. 2006; Sato et al. 2009; Warita et al. 2010). As a well-characterized epigenetic modification, DNA methylation is important for gene regulation, transcriptional silencing, development, and tumorigenesis (Wu and Zhang 2010). In mammals, DNA methylation patterns are established during embryogenesis through the cooperation of DNA methyltransferases (DNMTs) and associated 
proteins. In utero DES exposure alters methylation patterns of several genes in estrogen's target tissues (müllerian system, uterus), including Hox genes (Block et al. 2000; Bromer et al. 2009), c-fox (Li et al. 2003), and Nsbp1 (Tang et al. 2008). Moreover, some researchers have revealed that gestational DES exposure affects cardiac structure/function in adult male mice and leads to increases in cardiac Dnmt3a expression and DNA methylation in the CpG island within the calsequestrin 2 promoter in the heart (Haddad et al. 2013).

\subsection{Alternative testing strategies for developmental toxicity}

The necessity of reduction, refinement and replacement (3Rs) of animal testing has stimulated the design and application of alternative assays for the hazard identification of developmental toxicants (Augustine-Rauch et al. 2010; Piersma 2006; Scialli 2008). Alternatives to animal testing in developmental toxicology have been the subject of three decades of research. Existing alternative methods for developmental toxicity testing vary from cell cultures, organ cultures, organ-on-a-chip concepts, whole embryo cultures to in silico simulation models (Augustine-Rauch et al. 2010; Lee et al. 2012; Piersma 2006; Spielmann 2009). Among the available alternative systems, three of them have been formally validated by the European Centre for the Validation of Alternative Methods (ECVAM). These are the embryonic stem cell test (EST) (Genschow et al. 2004), the limb bud micromass (MM) (Spielmann et al. 2004) and the rat whole embryo culture (WEC) (Piersma et al. 2004). Although these validated methods may decrease the number of laboratory animals used for developmental toxicity testing, their application is still largely restricted to screening purposes and for further prioritizing chemicals for in vivo testing.

\subsubsection{Mouse Embryonic Stem Cell Test (mEST)}

Embryonic stem cells were first derived from the inner cell mass of developing mouse blastocysts (Evans and Kaufman 1981; Martin 1981). These cells are able to self-renew as well as to differentiate into all cell types of the developing embryo (Keller 2005). Therefore, the differentiation of ESCs was 
further studied as a potential test for screening developmental toxic responses of chemicals. The basic protocol for the mEST was first described by Spielmann et al. (1997) who allowed mouse embryonic stem cells from the D3 cell line to aggregate in small drops of culture media. These aggregates (embryoid bodies) were formed on the lid of a petri dish in hanging drops and were cultured in this manner for three days. These embryoid bodies are cultured for an additional two days in suspension culture before being transferred to a 24-well culture dish where the cells are allowed to adhere and differentiate for an additional five days, making the total culture time 10 days. The cells differentiate to cardiomyocytes under these conditions, and the percentage of wells with beating cardiomyocytes are scored microscopically (see figure 4). This is the protocol that was utilized for the ECVAM validation with the test chemicals present for the entire 10 days of culture.
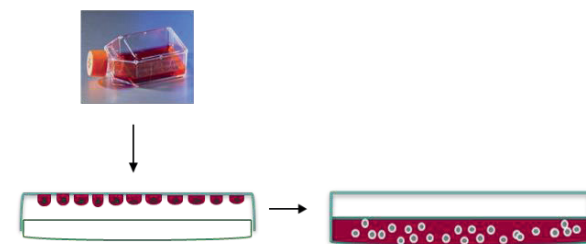

Day 0: undifferentiated single cell suspensions are cultured in hanging drops
Day 3: the formed cell aggregates, the EBs, are transferred and further cultured in supplemented cell culture medium
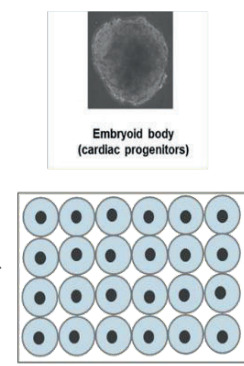

Day 5: single EBs are plated on tissue culture plates, in which they are differentiated into contracting cardiomyocytes
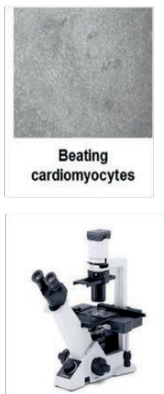

Day 10: The differentiated embryonic bodies evaluated under the microscope 
throughout embryonic development and rapid embryonic growth (Panzica-Kelly et al. 2015; Teraoka et al. 2003). Furthermore, in the early development of the zebrafish, the biological processes, such as signalling pathways, cell structure and anatomy, are similar to those in other vertebrates. Compared to the human genome, the zebrafish's genome is similar for $79 \%$ of the genes that are associated with human diseases (Howe et al. 2013; Sipes et al. 2011). Other advantages offered by this model include the low costs of maintaining a breeding stock and the need for only small amounts of drug substance for testing. In addition, the developing larvae are translucent and hence no complex, timeconsuming or expensive imaging systems are needed (Kimmel et al. 1995; Panzica-Kelly et al. 2015; Truong and Tanguay 2017). Thus the zebrafish appears to be well positioned to bridge the gap between in vitro and in vivo toxicity testing. Given these advantages, the Organisation for Economic Co-operation and Development (OECD) developed Test Guideline 236 (TG236) for using zebrafish for acute toxicity testing (OECD 2013) (see figure 5). This assay was adapted to the ZET assay to assess the developmental toxicity potential of chemicals. In the ZET, newly fertilized eggs (4-5 hour) are exposed to the test compounds and the development of the zebrafish embryos is observed over time and scored according to the general morphology system (GMS) (Beekhuijzen et al., 2015). The zebrafish are scored every 24 hours to up to 96 hour. The scoring includes; detachment of the tail, somite formation, eye development, movement, circulation, heartbeat, pigmentation of the head and the body, pigmentation of the tail, yolk extension, pectoral fin, protruding mouth and hatching (Beekhuijzen et al 2015). 


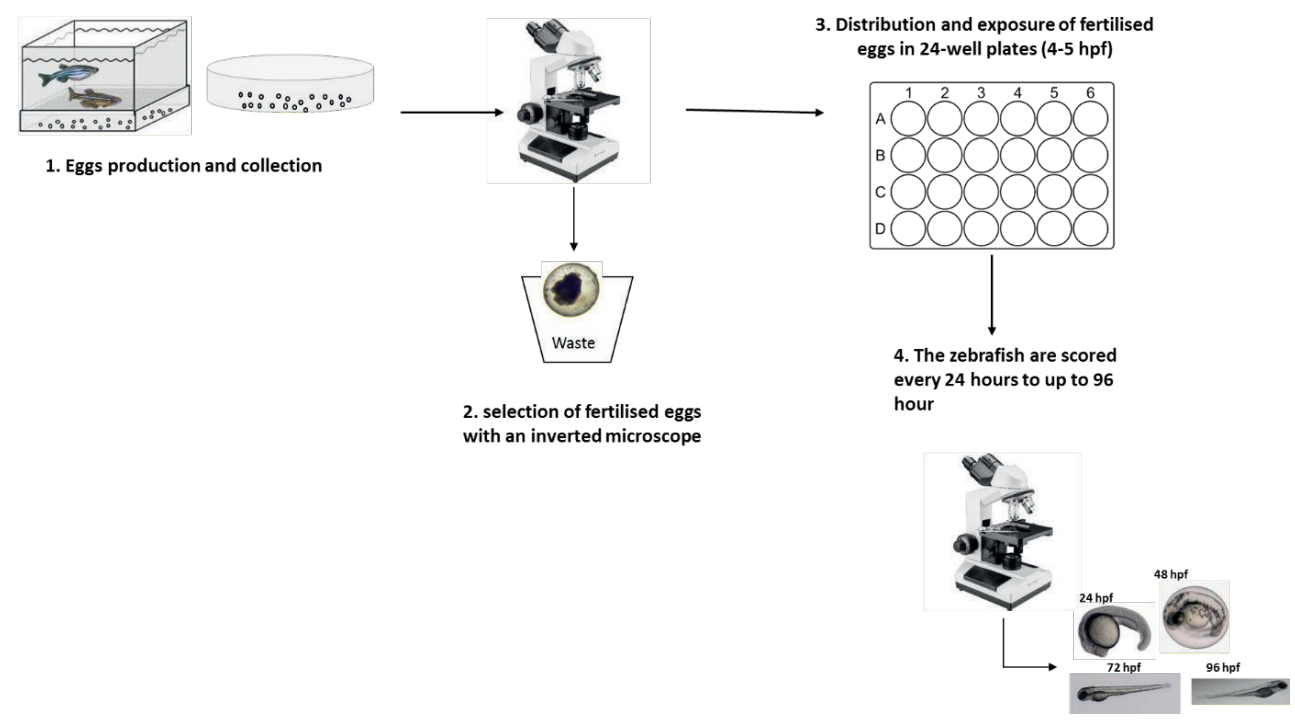

Figure 5. Scheme of the zebrafish embryo toxicity test procedure (from left to right): 1. production and collection of the eggs, 2. selection of fertilised eggs with an inverted microscope or binocular, 3. distribution of fertilised eggs into 24-well plates prepared with the respective test concentrations/controls and 4 . Scoring of the zebrafish embryo every 24 hours to up to 96 hpf. hpf = hours post-fertilisation.

\subsection{Translation of in vitro data to the in vivo situation using physiologically based kinetic}

\section{(PBK) modelling}

A PBK model is a set of mathematical equations that together describe the absorption, distribution, metabolism, and excretion (ADME) characteristics of a compound within an organism and can be used to relate external doses to internal (e.g., blood or tissue) concentrations (Chiu et al. 2007; Clewell and Clewell 2008). A PBK model is based on three types of parameters which include (1) physiological and anatomical parameters (e.g. cardiac output, tissue volumes and tissue blood flows), (2) physico chemical parameters (e.g. blood/ tissue partition coefficients) and (3) kinetic parameters (e.g. kinetic constants for metabolic reactions (Chiu et al. 2007; Clewell and Clewell 2008). The basic structure of a PBK model assumes that the whole body can be described as a set of basic compartments as illustrated in figure 6. PBK models describe the fate of the chemical (and its 
metabolite(s)) in the body in time after a certain dose of the chemical via a certain exposure route (e.g. oral, inhalation or dermal) in a certain species (e.g. rat, mice or human). As already indicated, PBK models can be used to translate external dose levels of a chemical into internal blood or tissue concentrations of the chemical (and its metabolite(s)). In addition PBK models can also be used to describe and quantify interindividual differences: such as between males and females, between adults and children, between non-pregnant and pregnant women, and/or between individuals with different genetic polymorphisms or different lifestyles (Rietjens et al. 2011). Moreover, PBK models can also be used in a reverse manner, translating internal blood or tissue concentrations of a chemical (and/or its metabolite(s)) into external dose levels of the chemical. This is called reverse dosimetry, in contrast to forward dosimetry where the models are used to predict internal concentrations resulting from defined external dose levels. In the reverse dosimetry approach, the concentrations causing toxicity in the in vitro model are considered equal to the blood or tissue concentrations that would cause toxicity in the in vivo situation. Then the corresponding dose level is calculated enabling definition of an in vivo dose-response curve based on an in vitro concentrationresponse curve. Thus, PBK models can be used to predict in vivo toxicity dose levels based on toxic effect concentrations obtained in in vitro assays to derive a point of departure (POD) for the risk assessment, such as a benchmark dose (BMD) or a lower confidence limit of the BMD, the BMDL (Louisse et al. 2010, 2017; Strikwold et al. 2013). In previous studies the approach was used to predict the developmental toxicity of glycol ethers, retinoic acid, a series of phenols, and tebuconazole (Li et al. 2017; Louisse et al. 2010, 2015; Strikwold et al. 2017). In the present thesis the approach was used to predict the in vivo dose-dependent developmental toxicity of DES. 


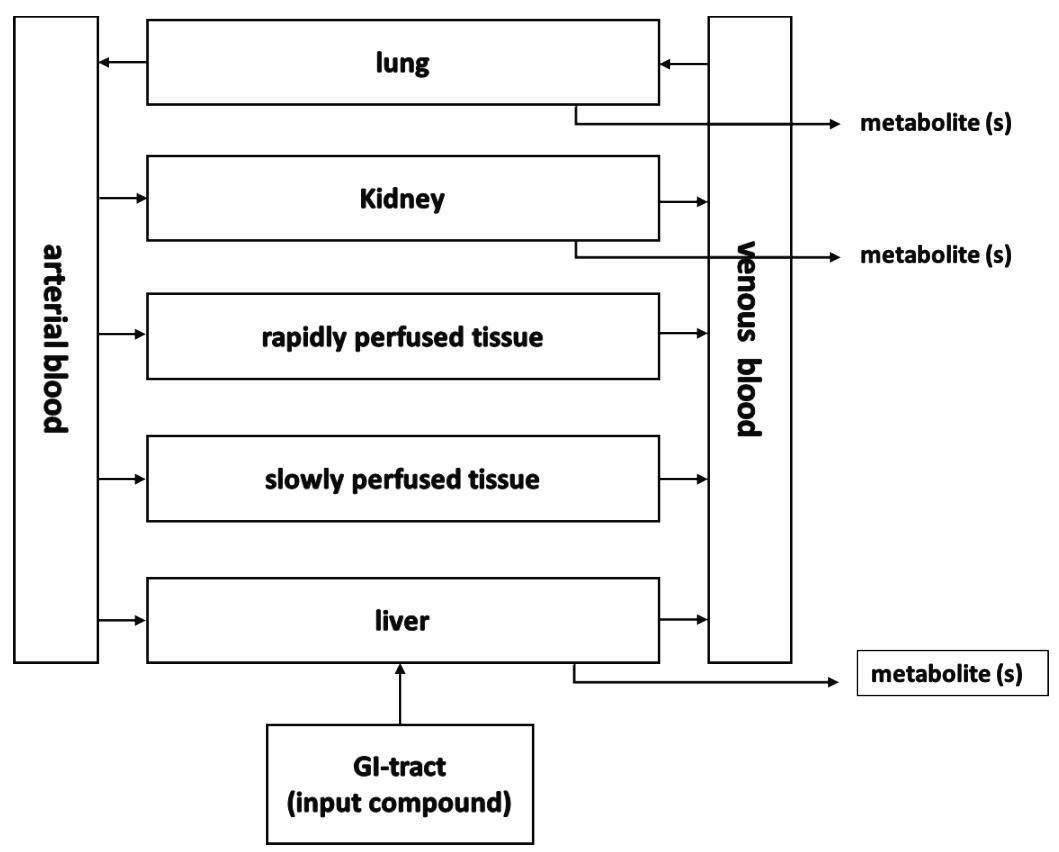

Figure 6. Schematic diagram of a PBK model for a compound that is absorbed upon oral intake and metabolized in liver, kidney and lung.

\subsection{Aim and outline of the thesis}

Despite the fact that many previous studies have reported on the similarity between DES and E2 in their chemical structure, their binding to the estrogen receptors, and their estrogen agonist activity, various adverse effects have been reported for DES, that have not been reported for E2. For some of these adverse effects clear evidence for a mode of action mediated through ER $\alpha$ was also provided (Couse et al. 2001; Couse and Korach 2004; Prins et al. 2001). Taking into account this apparent discrepancy between DES and E2, both activating ER $\alpha$ to a comparable level, the aim of this thesis was to investigate the differences between DES and E2 in different in vitro models, taking the potential role of ER $\alpha$ into account. 
In chapter $\mathbf{2}$ the potential differences in DES- and E2-dependent modulation of the interaction of ER $\alpha$ with coregulators was investigated using the MARCoNI technology and microarrays containing 154 unique nuclear receptor coregulator motifs of 64 different coregulators. Furthermore, the relative potency of the two compounds as ER $\alpha$ agonists was examined in a human osteosarcoma U2OS ER $\alpha$ reporter gene assay and in a proliferation assay of human ER $\alpha$ positive T47D breast cancer cells. Lastly, differences in DES- and E2- induced modulation of gene expression was quantified in T47D cells using next generation sequencing (RNA-seq) and transcriptome analysis. In chapter $\mathbf{3}$ the in vivo dose-dependent developmental toxicity caused by DES was predicted using a combination of an in vitro assay for developmental toxicity (ES-D3 cell differentiation assay) and PBK modelling-based reverse dosimetry. In addition, it was investigated whether the role of ER $\alpha$ observed in vivo could also be demonstrated for the in vitro developmental toxicity of DES. In chapter $\mathbf{4}$ the developmental toxicity of DES compared to E2 was assessed in the ZET. In addition, it was investigated whether the role of ER $\alpha$ could also be demonstrated for the in vitro developmental toxicity of DES in the ZET. In chapter $\mathbf{5}$ it was investigated to what extent the in vivo differences in developmental toxicity of E2 and DES may originate from differences in their kinetics and the actual internal dose levels of these two estrogens by comparing reported endogenous E2 concentrations during normal pregnancy with PBK model-predicted internal DES concentrations upon treatment of pregnant women with DES. Finally Chapter 6 provides the overall discussion of the thesis including future perspectives. 


\section{References}

Aarts JM, Wang S, Houtman R, et al. (2013) Robust array-based coregulator binding assay predicting ERalpha-agonist potency and generating binding profiles reflecting ligand structure. Chem Res Toxicol 26(3):336-46.

Anstead GM, Carlson KE, Katzenellenbogen JA (1997) The estradiol pharmacophore: ligand structureestrogen receptor binding affinity relationships and a model for the receptor binding site. Steroids 62(3):268-303.

Augustine-Rauch K, Zhang CX, Panzica-Kelly JM. In vitro developmental toxicology assays: A review of the state of the science of rodent and zebrafish whole embryo culture and embryonic stem cell assays. Birth Defects Res C Embryo Today 90(2):87-98.

Beekhuijzen, M., de Koning, C., Flores-Guillen, M. E., de Vries-Buitenweg, S., Tobor-Kaplon, M., van de Waart, B., and Emmen, H. (2015). From cutting edge to guideline: A first step in harmonization of the zebrafish embryotoxicity test (ZET) by describing the most optimal test conditions and morphology scoring system. Reproductive Toxicology 56: 64-76.

Blair RM, Fang H, Branham WS, et al. (2000) The estrogen receptor relative binding affinities of 188 natural and xenochemicals: structural diversity of ligands. Toxicological sciences : an official journal of the Society of Toxicology 54(1):138-53.

Blair RM, Fang $\mathrm{H}$, Branham WS, et al. The estrogen receptor relative binding affinities of 188 natural and xenochemicals: structural diversity of ligands. Toxicological sciences : an official journal of the Society of Toxicology 54(1):138-153.

Block K, Kardana A, Igarashi P, Taylor HS (2000) In utero diethylstilbestrol (DES) exposure alters Hox gene expression in the developing mullerian system. FASEB journal : official publication of the Federation of American Societies for Experimental Biology 14(9):1101-8.

Bocchinfuso WP, Korach KS (1997) Mammary gland development and tumorigenesis in estrogen receptor knockout mice. Journal of mammary gland biology and neoplasia 2(4):323-34.

Bolger R, Wiese TE, Ervin K, Nestich S, Checovich W. Rapid screening of environmental chemicals for estrogen receptor binding capacity. Environ Health Perspect 106(9):551-557.

Boylan ES (1978) Morphological and functional consequences of prenatal exposure to diethylstilbestrol in the rat. Biol Reprod 19(4):854-63.

Boylan ES, Calhoon RE (1983) Transplacental action of diethylstilbestrol on mammary carcinogenesis in female rats given one or two doses of 7,12-dimethylbenz(a)anthracene. Cancer research 43(10):4879-84.

Bromer JG, Wu J, Zhou Y, Taylor HS (2009) Hypermethylation of homeobox A10 by in utero diethylstilbestrol exposure: an epigenetic mechanism for altered developmental programming. Endocrinology 150(7):3376-82. 
Busquet F, Strecker R, Rawlings JM, et al. (2014) OECD validation study to assess intra- and interlaboratory reproducibility of the zebrafish embryo toxicity test for acute aquatic toxicity testing. Regulatory toxicology and pharmacology : RTP 69(3):496-511.

Cheedipudi S, Genolet O, Dobreva G (2014) Epigenetic inheritance of cell fates during embryonic development. Frontiers in genetics 5:19.

Chen M, Yeh CR, Chang HC, et al. (2012) Loss of epithelial oestrogen receptor alpha inhibits oestrogen-stimulated prostate proliferation and squamous metaplasia via in vivo tissue selective knockout models. The Journal of pathology 226(1):17-27.

Chiu WA, Barton HA, DeWoskin RS, et al. (2007) Evaluation of physiologically based pharmacokinetic models for use in risk assessment. J Appl Toxicol 27(3):218-37.

Clevenger WR, Cornwall GA, Carter MW, Bradshaw WS (1991) Diethylstilbestrol-induced perinatal lethality in the rat. I. Relationship to reduced maternal weight gain. Biology of reproduction 44(4):575-82.

Clewell RA, Clewell HJ, 3rd (2008) Development and specification of physiologically based pharmacokinetic models for use in risk assessment. Regulatory toxicology and pharmacology : RTP 50(1):129-43.

Colton T, Greenberg ER (1982) Epidemiologic Evidence for Adverse Effects of DES Exposure during Pregnancy. The American Statistician 36(3b):268-272.

Cornwall GA, Carter MW, Bradshaw WS (1984) The relationship between prenatal lethality or fetal weight and intrauterine position in rats exposed to diethylstilbestrol, zeranol, 3,4,3',4' tetrachlorobiphenyl, or cadmium. Teratology 30(3):341-349.

Couse JF, Dixon D, Yates M, et al. (2001) Estrogen receptor-alpha knockout mice exhibit resistance to the developmental effects of neonatal diethylstilbestrol exposure on the female reproductive tract. Developmental biology 238(2):224-38.

Couse JF, Korach KS (1999) Estrogen receptor null mice: what have we learned and where will they lead us? Endocrine reviews 20(3):358-417.

Couse JF, Korach KS (2004) Estrogen receptor-alpha mediates the detrimental effects of neonatal diethylstilbestrol (DES) exposure in the murine reproductive tract. Toxicology 205(1-2):55-63.

Eddy EM, Washburn TF, Bunch DO, et al. (1996) Targeted disruption of the estrogen receptor gene in male mice causes alteration of spermatogenesis and infertility. Endocrinology 137(11):4796-805.

Evans MJ, Kaufman MH. (1981) Establishment in culture of pluripotential cells from mouse embryos. Nature 292(5819): 154-6.

Foulds CE, Feng Q, Ding C, et al. (2013) Proteomic analysis of coregulators bound to ERalpha on DNA and nucleosomes reveals coregulator dynamics. Mol Cell 51(2):185-99.

Genschow, E., et al., (2004) Validation of the embryonic stem cell test in the international ECVAM validation study on three in vitro embryotoxicity tests. Altern Lab Anim 32(3): 209-44. 
Glass CK, Rosenfeld MG. (2000) The coregulator exchange in transcriptional functions of nuclear receptors. Genes \& development 14(2):121-141.

Gonzalez TL, Rae JM, Colacino JA, Richardson RJ (2019) Homology models of mouse and rat estrogen receptor-alpha ligand-binding domain created by in silico mutagenesis of a human template: molecular docking with 17ss-estradiol, diethylstilbestrol, and paraben analogs. Comput Toxicol 10:116.

Greenwald P, Barlow JJ, Nasca PC, Burnett WS (1971) Vaginal cancer after maternal treatment with synthetic estrogens. The New England journal of medicine 285(7):390-2.

Gustafsson JA (2003) What pharmacologists can learn from recent advances in estrogen signalling. Trends in pharmacological sciences 24(9):479-85.

Haddad R, Kasneci A, Mepham K, Sebag IA, Chalifour LE (2013) Gestational exposure to diethylstilbestrol alters cardiac structure/function, protein expression and DNA methylation in adult male mice progeny. Toxicology and applied pharmacology 266(1):27-37.

Harris HA (2007) Estrogen receptor-beta: recent lessons from in vivo studies. Molecular endocrinology 21(1):1-13.

Hatch EE, Palmer JR, Titus-Ernstoff L, et al. (1998) Cancer risk in women exposed to diethylstilbestrol in utero. JAMA 280(7):630-4.

Heldring N, Pike A, Andersson S, et al. (2007) Estrogen receptors: how do they signal and what are their targets. Physiological reviews 87(3):905-31.

Herbst AL, Ulfelder H, Poskanzer DC (1971) Adenocarcinoma of the vagina. Association of maternal stilbestrol therapy with tumor appearance in young women. The New England journal of medicine 284(15):878-81.

Hilakivi-Clarke L (2014) Maternal exposure to diethylstilbestrol during pregnancy and increased breast cancer risk in daughters. Breast cancer research : BCR 16(2):208.

Hill AJ, Teraoka H, Heideman W, Peterson RE (2005) Zebrafish as a model vertebrate for investigating chemical toxicity. Toxicological sciences : an official journal of the Society of Toxicology 86(1):6-19.

Hong $\mathrm{H}$, Tong $\mathrm{W}$, Fang $\mathrm{H}$, et al. (2002) Prediction of estrogen receptor binding for 58,000 chemicals using an integrated system of a tree-based model with structural alerts. Environmental health perspectives 110(1):29-36.

Hoover RN, Hyer M, Pfeiffer RM, et al. (2011) Adverse health outcomes in women exposed in utero to diethylstilbestrol. N Engl J Med 365(14):1304-14.

Howe K, Clark MD, Torroja CF, et al. (2013) The zebrafish reference genome sequence and its relationship to the human genome. Nature 496(7446):498-503.

Hsia EY, Goodson ML, Zou JX, Privalsky ML, Chen HW.(2010) Nuclear receptor coregulators as a new paradigm for therapeutic targeting. Advanced drug delivery reviews 62(13):1227-1237. 
IARC. (2012) A review of human carcinogens. Part A: Pharmaceuticals. IARC Working Group on the Evaluation of Carcinogenic Risks to Humans. International Agency for Research on Cancer 100:1-403.

Kawaguchi H, Miyoshi N, Miyamoto $\mathrm{Y}$, et al. (2009) Effects of exposure period and dose of diethylstilbestrol on pregnancy in rats. The Journal of veterinary medical science 71(10):1309-15.

Keller G. (2005) Embryonic stem cell differentiation: emergence of a new era in biology and medicine. Genes Dev 19(10): p. 1129-55.

Kimmel CB, Ballard WW, Kimmel SR, Ullmann B, Schilling TF (1995) Stages of embryonic development of the zebrafish. Dev Dyn 203(3):253-310.

Klein ES, Wang JW, Khalifa B, Gavigan SA, Chandraratna RA (2000) Recruitment of nuclear receptor corepressor and coactivator to the retinoic acid receptor by retinoid ligands. Influence of DNAheterodimer interactions. J Biol Chem 275(25):19401-8.

Klinge CM (2000) Estrogen receptor interaction with co-activators and co-repressors. Steroids 65(5):227-51.

Klotz DM, Hewitt SC, Korach KS, Diaugustine RP (2000) Activation of a uterine insulin-like growth factor I signaling pathway by clinical and environmental estrogens: requirement of estrogen receptor-alpha. Endocrinology 141(9):3430-3439.

Knight K (2015) A comparative perspective on epigenetics. Journal of Experimental Biology 2015 218: 1-5.

Koppen A, Houtman R, Pijnenburg D, Jeninga EH, Ruijtenbeek R, Kalkhoven E (2009) Nuclear receptor-coregulator interaction profiling identifies TRIP3 as a novel peroxisome proliferatoractivated receptor gamma cofactor. Mol Cell Proteomics 8(10):2212-26.

Kuiper GG, Enmark E, Pelto-Huikko M, Nilsson S, Gustafsson JA (1996) Cloning of a novel receptor expressed in rat prostate and ovary. Proceedings of the National Academy of Sciences of the United States of America 93(12):5925-30.

LeBaron MJ, Rasoulpour RJ, Klapacz J, Ellis-Hutchings RG, Hollnagel HM, Gollapudi BB (2010) Epigenetics and chemical safety assessment. Mutation research 705(2):83-95.

Lee HY., et al., (2012) Alternative models in developmental toxicology. Syst Biol Reprod Med 58(1): p. 10-22.

Lee S, Barron MG (2017) Structure-Based Understanding of Binding Affinity and Mode of Estrogen Receptor alpha Agonists and Antagonists. PloS one 12(1):e0169607.

Li H, Zhang M, Vervoort J, Rietjens IM, van Ravenzwaay B, Louisse J (2017) Use of physiologically based kinetic modeling-facilitated reverse dosimetry of in vitro toxicity data for prediction of in vivo developmental toxicity of tebuconazole in rats. Toxicol Lett 266:85-93.

Li S, Hansman R, Newbold R, Davis B, McLachlan JA, Barrett JC (2003) Neonatal diethylstilbestrol exposure induces persistent elevation of c-fos expression and hypomethylation in its exon-4 in mouse uterus. Molecular carcinogenesis 38(2):78-84. 
Louisse J, de Jong E, van de Sandt JJ et al (2010) The use of in vitro toxicity data and physiologically based kinetic modeling to predict dose-response curves for in vivo developmental toxicity of glycol ethers in rat and man. Toxicol Sci 118(2):470-484.

Martin GR. (1981) Isolation of a pluripotent cell line from early mouse embryos cultured in medium conditioned by teratocarcinoma stem cells. Proc Natl Acad Sci U S A 78(12): p. 7634-8.

Mombelli E. (2012) Evaluation of the OECD (Q)SAR application toolbox for the profiling of estrogen receptor binding affinities. SAR QSAR Environ. Res. 23, 37-57

Nagao T, Kagawa N, Saito Y, Komada M (2013) Developmental effects of oral exposure to diethylstilbestrol on mouse placenta. Journal of applied toxicology : JAT 33(11):1213-21.

Nagao T, Yoshimura S (2009) Early embryonic losses in mice induced by diethylstilbestrol. Congenit Anom 49(4):269-273.

Newbold RR (2008) Prenatal exposure to diethylstilbestrol (DES). Fertility and sterility 89(2 Suppl):e55-6.

Newbold RR, Padilla-Banks E, Jefferson WN (2006) Adverse effects of the model environmental estrogen diethylstilbestrol are transmitted to subsequent generations. Endocrinology 147(6 Suppl):S11-7.

Odum J, Lefevre PA, Tinwell H, et al. (2002) Comparison of the developmental and reproductive toxicity of diethylstilbestrol administered to rats in utero, lactationally, preweaning, or postweaning. Toxicological sciences : an official journal of the Society of Toxicology 68(1):147-63.

OECD. (2012) Test No. 455: Performance Based Test Guideline for Stably Transfected Transactivation In Vitro Assays to Detect Estrogen Receptor Agonists. OECD Publishing.

OECD. (2013). OECD Guidelines for Testing of Chemicals No.236: Fish Embryo Acute Toxicity (FET) Test. Adopted 26 July 2013.

Ogawa S, Inoue S, Watanabe T, et al. (1998) Molecular cloning and characterization of human estrogen receptor betacx: a potential inhibitor of estrogen action in human. Nucleic acids research 26(15):3505-12.

Palmer JR, Wise LA, Hatch EE, et al. (2006) Prenatal diethylstilbestrol exposure and risk of breast cancer. Cancer epidemiology, biomarkers \& prevention : a publication of the American Association for Cancer Research, cosponsored by the American Society of Preventive Oncology 15(8):1509-14.

Pamplona-Silva MT, Mazzeo DEC, Bianchi J, Marin-Morales MA (2018) Estrogenic Compounds: Chemical Characteristics, Detection Methods, Biological and Environmental Effects. Water Air Soil Poll 229(5).

Panzica-Kelly JM, Zhang CX, Augustine-Rauch KA (2015) Optimization and Performance Assessment of the Chorion-Off [Dechorinated] Zebrafish Developmental Toxicity Assay. Toxicological Sciences 146(1):127-134. 
Pearce ST, Jordan VC (2004) The biological role of estrogen receptors alpha and beta in cancer. Critical reviews in oncology/hematology 50(1):3-22.

Pellizzer C, Bremer S, Hartung T (2005) Developmental toxicity testing from animal towards embryonic stem cells. Altex 22(2):47-57.

Piersma AH. (2006) Alternative methods for developmental toxicity testing. Basic Clin Pharmacol Toxicol 98(5): 427-31.

Piersma, A.H., et al., (2004) Validation of the postimplantation rat whole-embryo culture test in the international ECVAM validation study on three in vitro embryotoxicity tests. Altern Lab Anim 32(3): 275-307.

Prins GS, Birch L, Couse JF, Choi I, Katzenellenbogen B, Korach KS (2001) Estrogen imprinting of the developing prostate gland is mediated through stromal estrogen receptor alpha: Studies with alpha ERKO and)beta ERKO mice. Cancer Res 61(20):7704-7705.

Reed CE, Fenton SE (2013) Exposure to diethylstilbestrol during sensitive life stages: a legacy of heritable health effects. Birth defects research Part C, Embryo today : reviews 99(2):134-46.

Reel JR, Lawton AD, Wolkowskityl R, Davis GW, Lamb JC (1985) Evaluation of a New Reproductive Toxicology Protocol Using Diethylstilbestrol (Des) as a Positive Control Compound. J Am Coll Toxicol $4(2): 147-162$.

Rietjens IM, Louisse J, Punt A (2011) Tutorial on physiologically based kinetic modeling in molecular nutrition and food research. Mol Nutr Food Res 55(6):941-56.

Rothschild TC, Boylan ES, Calhoon RE, Vonderhaar BK (1987) Transplacental effects of diethylstilbestrol on mammary development and tumorigenesis in female $\mathrm{ACl}$ rats. Cancer research 47(16):4508-16.

Sato K, Fukata H, Kogo Y, Ohgane J, Shiota K, Mori C (2009) Neonatal exposure to diethylstilbestrol alters expression of DNA methyltransferases and methylation of genomic DNA in the mouse uterus. Endocrine journal 56(1):131-9.

Scialli AR. (2008) The challenge of reproductive and developmental toxicology under REACH. Regul Toxicol Pharmacol 51(2): 244-50.

Sieri S, Krogh V, Bolelli G, et al. (2009) Sex hormone levels, breast cancer risk, and cancer receptor status in postmenopausal women: the ORDET cohort. Cancer epidemiology, biomarkers \& prevention: a publication of the American Association for Cancer Research, cosponsored by the American Society of Preventive Oncology 18(1):169-76.

Sipes NS, Padilla S, Knudsen TB (2011) Zebrafish: as an integrative model for twenty-first century toxicity testing. Birth defects research Part C, Embryo today : reviews 93(3):256-67.

Smiley DA, Khalil RA (2009) Estrogenic compounds, estrogen receptors and vascular cell signaling in the aging blood vessels. Current medicinal chemistry 16(15):1863-87. 
Sotoca AM, van den Berg H, Vervoort J, et al. (2008) Influence of cellular ERalpha/ERbeta ratio on the ERalpha-agonist induced proliferation of human T47D breast cancer cells. Toxicological sciences : an official journal of the Society of Toxicology 105(2):303-11.

Spielmann H. (2009) The way forward in reproductive/developmental toxicity testing. Altern Lab Anim 37(6): 641-56.

Spielmann, H., et al., (1997) The embryonic stem cell test (EST), an in vitro embryotoxicity test using two permanent mouse cell lines: 3 T3 fibroblasts and embryonic stem cells. In Vitro Toxicology 10: 119-127.

Spielmann, H., et al., (2004) Validation of the rat limb bud micromass test in the international ECVAM validation study on three in vitro embryotoxicity tests. Altern Lab Anim 32(3): p. 245-74.

Strikwold M, Spenkelink B, Woutersen RA, Rietjens IM, Punt A (2013) Combining in vitro embryotoxicity data with physiologically based kinetic (PBK) modelling to define in vivo dose response curves for developmental toxicity of phenol in rat and human. Arch Toxicol 87(9):17091723.

Strikwold M, Spenkelink B, de Haan LHJ, Woutersen RA, Punt A, Rietjens I (2017) Integrating in vitro data and physiologically based kinetic (PBK) modelling to assess the in vivo potential developmental toxicity of a series of phenols. Arch Toxicol 91(5):2119-2133

Tang WY, Newbold R, Mardilovich K, et al. (2008) Persistent hypomethylation in the promoter of nucleosomal binding protein 1 (Nsbp1) correlates with overexpression of Nsbp1 in mouse uteri neonatally exposed to diethylstilbestrol or genistein. Endocrinology 149(12):5922-31.

Teraoka H, Dong W, Hiraga T (2003) Zebrafish as a novel experimental model for developmental toxicology. Congenit Anom (Kyoto) 43(2):123-32.

Thomas C, Gustafsson JA (2011) The different roles of ER subtypes in cancer biology and therapy. Nature reviews Cancer 11(8):597-608.

Titus-Ernstoff L, Hatch EE, Hoover RN, et al. (2001) Long-term cancer risk in women given diethylstilbestrol (DES) during pregnancy. British journal of cancer 84(1):126-33.

Titus-Ernstoff L, Troisi R, Hatch EE, et al. (2006) Menstrual and reproductive characteristics of women whose mothers were exposed in utero to diethylstilbestrol (DES). Int J Epidemiol 35(4):862-868.

Troisi R, Hatch EE, Titus-Ernstoff L, et al. (2007) Cancer risk in women prenatally exposed to diethylstilbestrol. Int J Cancer 121(2):356-60.

Truong L, Tanguay RL (2017) Evaluation of Embryotoxicity Using the Zebrafish Model. Methods Mol Biol 1641:325-333.

Vassilacopoulou D, Boylan ES (1993) Mammary gland morphology and responsiveness to regulatory molecules following prenatal exposure to diethylstilbestrol. Teratog Carcinog Mutagen 13(2):59-74. 
Wardell RE, Seegmiller RE, Bradshaw WS (1982) Induction of prenatal toxicity in the rat by

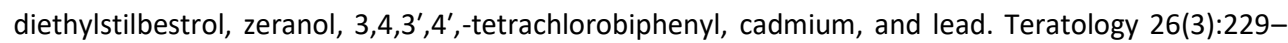
237.

Warita K, Mitsuhashi T, Sugawara T, et al. (2010) Direct effects of diethylstilbestrol on the gene expression of the cholesterol side-chain cleavage enzyme (P450scc) in testicular Leydig cells. Life sciences 87(9-10):281-5.

Wu SC, Zhang Y (2010) Active DNA demethylation: many roads lead to Rome. Nature reviews Molecular cell biology 11(9):607-20.

Yamashita S (2006) Expression of estrogen-regulated genes during development in the mouse uterus exposed to diethylstilbestrol neonatally. Current pharmaceutical design 12(12):1505-20.

Yoshikawa T, Kawaguchi H, Umekita $Y$, et al. (2008) Effects of neonatally administered low-dose diethylstilbestrol on the induction of mammary carcinomas and dysplasias induced by 7,12dimethylbenz [a] anthracene in female rats. In vivo 22(2):207-13.

Zimmerman SA, Clevenger WR, Brimhall BB, Bradshaw WS (1991) Diethylstilbestrol-induced perinatal lethality in the rat. II. Perturbation of parturition. Biology of reproduction 44(4):583-9. 
CHAPTER 2

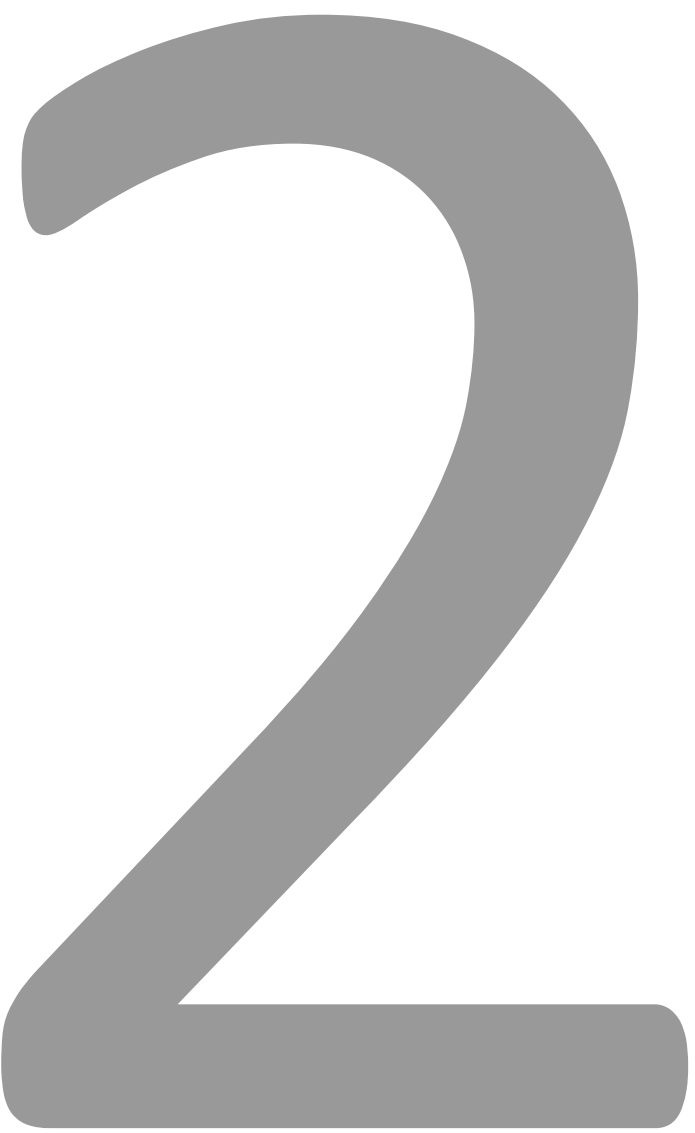


Estrogen receptor alpha (ER $\alpha)$-mediated coregulator binding and gene expression discriminates the toxic ER $\alpha$ agonist diethylstilbestrol (DES) from the endogenous ER $\alpha$ agonist $17 \beta$-estradiol (E2)

Aziza Hussein Bakheit Adam, Laura HJ de Haan, Ignacio Miro Estruch, Guido JEJ Hooiveld, Jochem Louisse and Ivonne MCM Rietjens 


\section{Abstract}

Diethylstilbestrol (DES) is a synthetic estrogen and proven human teratogen and carcinogen reported to act via the estrogen receptor $\alpha(E R \alpha)$. Since the endogenous ER $\alpha$ ligand $17 \beta$-estradiol (E2) does not show these adverse effects to a similar extent, we hypothesized that DES' interaction with the ER $\alpha$ differs from that of E2. The current study aimed to investigate possible differences between DES and E2 using in vitro assays that detect ER $\alpha$-mediated effects, including ER $\alpha$-mediated reporter gene expression, ER $\alpha$-mediated breast cancer cell (T47D) proliferation, and ER $\alpha$-coregulator interactions and gene expression in T47D cells. Results obtained indicate that DES and E2 activate ER $\alpha$-mediated reporter gene transcription and T47D cell proliferation in a similar way. However, significant differences between DES- and E2-induced binding of the ER $\alpha$ to 15 coregulator motifs and in transcriptomic signatures obtained in the T47D cells were observed. It is concluded that differences observed in binding of the ER $\alpha$ with several co-repressor motifs, in downregulation of genes involved in histone deacetylation and DNA methylation and in upregulation of CYP26A1 and CYP26B1 contribute to the differential effects reported for DES and E2. 


\section{Introduction}

Diethylstilbestrol (DES) is a synthetic estrogen that has been used from the 1940 s to the 1970 s to prevent premature delivery and fetal death by stimulating the synthesis of estrogen and progesterone in the placenta (IARC 2012). In addition, DES was used in hormonal therapy applied for the treatment of prostate and breast cancer (Giusti et al. 1995; IARC 2012; Reed and Fenton 2013). From 1971 onwards the use of DES was prohibited, since it was shown to induce rare reproductive tract cancers in women exposed in utero while no protective effect against miscarriage and premature delivery was actually observed (Titus-Ernstoff et al. 2001). Although DES has been discontinued since 1971, adverse health effects have later been discovered in women who had taken DES, as well as in their offspring including even subsequent generations. Adverse effects included breast cancer, clear cell adenocarcinoma of the vagina and cervix, abnormalities in the female genital tract, and abnormalities of the male reproductive tract (Colton and Greenberg 1982; Palmer et al. 2006).

DES is an analogue of the endogenous female sex hormone $17 \beta$-estradiol (E2) and binds to both the estrogen receptor $\alpha(E R \alpha)$ and estrogen receptor $\beta$ (ER $\beta)$ (Bolger et al. 1998; Nikov et al. 2001). It has been reported that the molecular dimensions of DES are almost identical to those of E2, particularly with regard to the distance between the terminal hydroxyl groups (Gonzalez et al. 2019) (Fig. 1). Molecular docking of E2 and DES into the ligand binding domain of ER $\alpha$ from mouse and rat revealed similar binding orientations and confirmed a role for the hydroxyl moieties in this interaction (Gonzalez et al. 2019). The ER $\alpha$ agonist action has generally been associated with stimulation of cell proliferation while ERß activation has been linked with suppression of cell proliferation and stimulation of apoptosis (Sotoca et al. 2008; Thomas and Gustafsson 2011). 


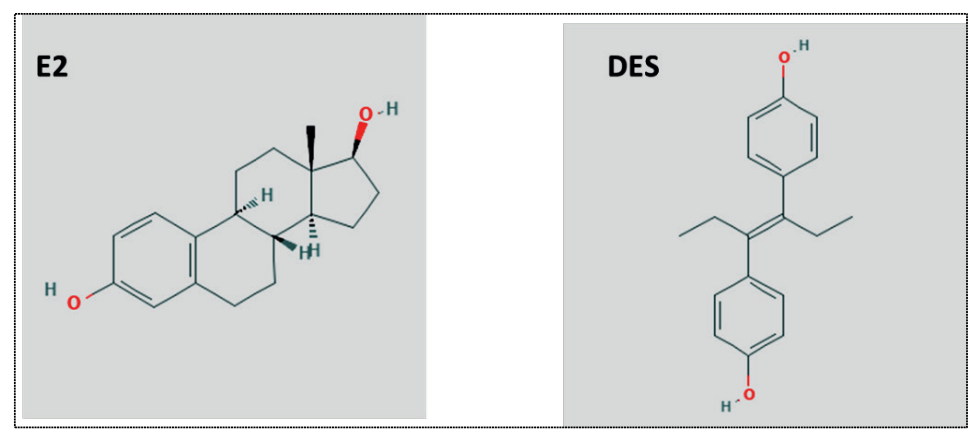

Figure 1. chemical structures for E2 and DES

The mode of action by which DES causes its adverse effects has not been unravelled yet. It has been reported that the ER $\alpha$ is required in the mediation of the proliferative response to DES in uterus and prostate epithelial cells in vivo (Chen et al. 2012; Klotz et al. 2000). Several studies have indicated that a functional ER $\alpha$ is needed for DES-mediated adverse effects, including phenotypic changes in the reproductive tract, and progressive proliferative lesions and abnormal epithelial cell differentiation in the prostate (Chen et al. 2012). This is apparent from studies in which these DESinduced adverse effects were observed in wild type mice, while the effects were absent in ER $\alpha$ knockout mice (Couse et al. 2001; Couse and Korach 2004; Prins et al. 2001). These studies suggest that DES elicits its adverse effects on the reproductive tract through an ER $\alpha$-mediated mechanism. It is of interest to note that the endogenous ER $\alpha$ agonist E2 does not induce the adverse effects that have been reported for DES to a similar extent. This points at the possible existence of essential differences between ER $\alpha$ activation by DES on the one hand and E2 on the other hand. Such differences upon ER $\alpha$ binding may be due to possible differential recruitment of coregulators, including both coactivators that interact with receptors and enhance their activation, as well as corepressors that interact with receptors and decrease their activation (Klinge 2000; McKenna et al. 1999).

So far, it has been reported that in the presence of DES the ER $\alpha$ interacts with coregulators NCOA1 (Nuclear receptor coactivator 1), NRIP1 (Nuclear receptor-interacting protein1) and PNRC2 (Proline- 
rich nuclear receptor coactivator 1), as indicated by binding to the coregulator motifs NCOA1_677_700, NRIP1_173_195 and PNRC2_118_139, respectively, using the MARCoNI (Microarray Assay for Real-time Coregulator-Nuclear receptor Interaction) technology (Wang et al. 2013). However, no extensive comparison has been carried out between the ER $\alpha$-coregulator interactions in the presence of DES compared to E2. This raises the question to what extent DESmediated coregulator recruitment to the ER $\alpha$ might be different from that of E2 and whether that could play a role in the differential biological effects of these two ER $\alpha$ agonists. The present study investigates the DES- and E2-dependent modulation of the interaction of ER $\alpha$ with coregulators using the MARCoNI technology and peptide microarrays containing 154 unique nuclear receptor coregulator motifs of 64 different coregulators. To provide further information on the possible differences between DES- and E2-induced ER $\alpha$-mediated effects the present study also assesses the relative potency of the two compounds as ER $\alpha$ agonists in a human osteosarcoma U2OS ER $\alpha$ reporter gene assay and in a proliferation assay of human ER $\alpha$ positive T47D breast cancer cells, and quantifies DES- and E2-induced modulation of gene expression in T47D cells using next generation sequencing (RNA-seq) and transcriptome analysis.

\section{Materials and methods}

\subsection{Cell lines and culture conditions}

The U2OS (human osteosarcoma) cell line, stably expressing ER $\alpha$ in addition to a $3 x$ estrogen responsive element and TATA box binding protein combined with a luciferase gene (3x ERE-TATAluciferase gene) was obtained from Biodetection Systems (BDS) (Amsterdam, The Netherlands). U2OS-ER $\alpha$ cells were grown in DMEM:F12, a 1:1 mixture of Dulbecco's modified Eagle medium (DMEM) and Ham's nutrient mixture F12 (Gibco, Bleiswijk, The Netherlands) supplemented with 10\% fetal bovine serum (FBS, Sigma-Aldrich, St. Louis, Missouri, United States), 0.5\% non-essential amino acids (NEAA) (Gibco, Bleiswijk, The Netherlands), $200 \mu / \mathrm{ml}$ geneticin G418 (Gibco, Bleiswijk, The Netherlands) and $50 \mu \mathrm{g} / \mathrm{ml}$ hygromycin (PAA Laboratories $\mathrm{GmbH}$, Pasching, Austria). T47D cells, 
obtained from the American Type Culture Collection (Manasssaa, VA, USA), were grown in 1:1 DMEM:F12/Glutamax culture medium supplemented with $10 \% \mathrm{FCS}$. All cells were incubated at $37^{\circ} \mathrm{C}$ and $5 \% \mathrm{CO}_{2}$ in a humidified atmosphere.

The T47D cell line is a generally applied model for studying ER $\alpha$ mediated effects, especially because the cells retain several key characteristics specific to the mammary epithelium (Holliday and Speirs 2011). Given that the adverse effects of DES are mediated through the ER $\alpha$ (Couse et al. 2001; Couse and Korach 2004; Prins et al. 2001) the T47D model was considered suitable to study potential differences in ER $\alpha$ mediated responses toward DES and E2.

The human breast cancer cell line MCF-7 (provided by the American Type Culture Collection (Manasssaa, VA, USA) was cultured in Dulbecco's Modified Eagle Medium DMEM/F12 (Gibco, Bleiswijk, The Netherlands) supplemented with $10 \%(\mathrm{v} / \mathrm{v})$ foetal bovine serum (PAA, Pasching, Austria), kept in a humidified atmosphere at $37^{\circ} \mathrm{C}$ and $5 \% \mathrm{CO}_{2}$ and subcultured when they reached $60-80 \%$ confluence.

\subsection{Reporter gene assay}

U2OS-ER $\alpha$ cells were seeded in 96-well white plates (PerkinElmer, Groningen, The Netherlands) at a density of $10^{5}$ cells/ml in phenol red free medium (DMEM/F12) supplemented with DCC-FCS (dextran-coated charcoal-treated fetal calf serum obtained from Gibco (Bleiswijk, The Netherlands) adding $100 \mu \mathrm{l} /$ well and the cells were incubated at $37{ }^{\circ} \mathrm{C}$ and $5 \% \mathrm{CO}_{2}$ in a humidified atmosphere. Twenty-four hours after seeding, medium was changed to phenol red free medium. Forty-eight hours after seeding, cells were exposed to the test compounds in triplicate, in phenol red free medium (DMEM/F12) supplemented with DCC-FCS. Exposure medium was prepared to reach the final concentration range of 0.1-100 pM for both DES (Sigma-Aldrich, Zwijndrecht, The Netherlands) and E2 (Sigma-Aldrich) using 200-times concentrated stock solution in DMSO (Acros, Geel, Belgium) diluted in the culture medium. The maximum concentration of DMSO in exposure medium was $0.5 \%$. After removing the medium from the wells, $100 \mu \mathrm{L}$ of exposure medium containing the test 
compound were added to the wells and the cells were incubated for another 24 hours at $37^{\circ} \mathrm{C}$ and $5 \% \mathrm{CO}_{2}$ in a humidified atmosphere. After 24 hours of exposure, cells were washed with $0.5 \times$ PBS and lysed with $30 \mu \mathrm{l}$ of hypotonic low-salt buffer containing $10 \mathrm{mM}$ Tris, $2 \mathrm{mM}$ dithiothreitol (DTT, Sigma-Aldrich) and $2 \mathrm{mM}$ 1,2-diaminocyclohexane tetraacetic acid monohydrate (CDTA, SigmaAldrich) $\mathrm{pH}$ 7.8. Plates were kept on ice for at least $30 \mathrm{~min}$ and subsequently stored at $-80{ }^{\circ} \mathrm{C}$ until analysis. One hour before measurement, plates were thawed on a plate shaker until they reached room temperature. Luciferase activity was determined using a luminometer (GloMax, Promega Corporation, USA). Data from the U2OS-ER $\alpha$ reporter gene assay were expressed in relative luminescence units (RLU), corrected for the corresponding background signal measured before luciferin induction. Effects obtained in the studies were expressed as a percentage of the maximum response obtained for E2 set at $100 \%$.

\subsection{Cell proliferation}

T47D cells were seeded in 96-well plates (Corning, NY, USA) at a cell density of $5 \times 10^{3}$ cells/well in phenol red free medium (DMEM/F12) supplemented with DCC-FCS and incubated at $37^{\circ} \mathrm{C}$ and $5 \%$ $\mathrm{CO}_{2}$ in a humidified atmosphere. Cells were allowed to attach and 24 hours later exposed to the test compounds (1 - $10000 \mathrm{pM}$ for both E2 and DES, final solvent control 0.5\% DMSO). After exposure for 72 hours, $20 \mu \mathrm{l} \mathrm{BrdU} \mathrm{labelling} \mathrm{solution} \mathrm{(containing} \mathrm{5-bromo-2'-deoxyuridine} \mathrm{in} \mathrm{PBS)} \mathrm{diluted} \mathrm{(10 \%} \mathrm{v/v)}$ in exposure medium, were added to the cells during the last 4 hours of exposure. Next, BrdU incorporation was measured by fixation-denaturation of the cells followed by incubation with BrdU detection antibodies and the corresponding substrate according to the manufacturer's guidelines (Roche, Manheim, Germany). Subsequently, colorimetric measurements were carried out at a wavelength of $370 \mathrm{~nm}$ with a Microplate Reader SpectraMax M2 (Molecular Devices, Sunnyvale CA, USA). Effects obtained were expressed as percentage of the maximum response obtained for E2 set at $100 \%$.

\subsection{Coregulator binding assay}


Ligand-modulated interaction of coregulators with ER $\alpha$ was assessed using a PamChip peptide microarray with 154 coregulator motifs of 66 different coregulators (PamGene International BV, Den Bosch, The Netherlands). Briefly, all incubations were performed on a PamStation (PamGene) at 20 ${ }^{\circ} \mathrm{C}$ using two cycles per minute, as described by Wang et al. (2013). Polyhistidine (His) tagged ER $\alpha$ ligand binding domain (amino acids 302-552, partly purified from Escherichia coli (E. coli) (Qiagen, Germantown, MD, USA, final concentration $10 \mathrm{nM}$ ) and His antibody penta-His Alexa Fluor 488 conjugate (Qiagen, Germantown, MD, USA, final concentration $25 \mathrm{nM}$ ) were diluted in time-resolved fluorescence resonance energy transfer (TR-FRET) reaction buffer containing $20 \mathrm{mM}$ Tris- $\mathrm{HCl}$ pH 7.5 (Tris: Sigma-Aldrich) (HCl: Merck, Darmstadt, Germany), $500 \mathrm{mM} \mathrm{NaCl}$ (Merck), $0.2 \%$ bovine serum albumin (BSA, Merck), and 0.05\% Tween 20 (Bio-Rad, Veenendaal, The Netherlands). All mixtures were kept on ice until transferred to the PamChip microarrays. The test compounds were predissolved in 50 times concentrated stock solutions in DMSO. The final concentrations of the test compounds ranged between $10^{-12}$ to $10^{-5} \mathrm{M}$, and the final DMSO concentration was $2 \%$. A reaction mixture with $2 \%$ DMSO served as negative control. Each array was blocked for 20 cycles using $25 \mu \mathrm{l}$ of blocking buffer (Tris-buffered saline) (TBS) (Bio-Rad) supplemented with 0.01\% Tween 20 (Bio-Rad) and $1 \%$ BSA. Later, the blocking buffer was removed by aspiration, and the reaction mixture containing the test compound at the required concentration was added to the PamChip microarray in a final volume of $25 \mu \mathrm{l}$. This reaction-ligand mixture was incubated (pumped up and down the porous microarray membrane containing the 154 different coregulator motifs) for 80 cycles. Subsequently, unbound receptor was removed by washing the arrays with $25 \mu$ IBS and finally a tiff image of each array was acquired by the charge coupled device (CCD) camera of the PamStation. Image analysis was performed using BioNavigator software (Version 62, PamGene International BV). Per array, the fluorescent signal of each spot, representative of ER binding to that particular coregulator motif, was quantified. For each spot the binding signal as median fluorescence signal minus background for each peptide was calculated. The modulation index (MI) for a saturating concentration was subsequently determined, by calculating the compound-induced log 10 -fold 
change of fluorescence in the presence of ligand over that in the presence of solvent only. As each array contains 154 unique coregulator motifs, each compound was characterized by a 154-point MI profile.

\subsection{Next generation sequencing (RNA-seq) and transcriptome analysis}

T47D cells were seeded in $25 \mathrm{~cm}^{2}$ flasks (Corning, NY, USA) at a density of $10^{5}$ cells $/ \mathrm{ml}$. Twenty-four hours after seeding, medium was changed for phenol red free medium supplemented with DCC-FCS. Forty-eight hours after seeding, cells were treated with $10 \mathrm{nM} \mathrm{E2,} 10 \mathrm{nM}$ DES or control (0.5\% DMSO) in duplicate, in phenol red free medium supplemented with DCC-FCS for 6 hours. Next, cells were lysed and total RNA was extracted and purified with the Quick RNA Miniprep kit (Zymo Research, Irvine, CA, USA) according to manufacturer's guidelines. For quality control, spectrophotometric analysis using a Nanodrop (ND-1000 Thermoscientific Wilmington, Delaware, USA) and RIN analysis 2100 Bioanalizer (Agilent Technologies California, EE. UU) were utilized. Only samples with RNA integrity number (RIN) values higher than 8 were accepted for analysis. RNA-seq library preparation and sequencing was commissioned to BaseClear BV (Leiden, The Netherlands). Briefly, strand-specific messenger RNA sequencing libraries for the Illumina (San Diego, CA, USA) platform were generated, multiplexed, clustered, and sequenced on an Illumina HiSeq 2500 with a single-read 50-cycle sequencing protocol (15 million reads per sample).

Colorimetric sequencing signals were translated into base calls using internal Illumina software (CASAVA). Subsequently, using the tool bcl2fastq2 (version 2.18), the per-cycle basecall (BCL) files were demultiplexed and converted into per-read FASTQ sequence files for downstream analysis. Next, reads containing PhiX control signal were removed by BaseClear BV using an in-house filtering protocol. In addition, reads containing (partial) adapters were clipped (up to minimum read length of 50bp). Finally, the quality of the FASTQ sequences was assessed by the tool FastQC (Andrews 2018) (version 0.11 .5 ), and enhanced by trimming off low-quality bases by setting the cut-off of the error probability limit of the modified-Mott algorithm (Ewing and Green 1998) to 0.02 . 
The RNA-seq reads were then used to quantify transcript abundances. To this end the tool Salmon (Patro et al. 2017) (version 0.8.2) was used to map the reads to the GRCh38.p10 genome assemblybased transcriptome sequences as annotated by the Ensembl genome database project (Zerbino et al. 2018) (Ensembl release v90). The obtained transcript abundance estimates and lengths were then imported in R using the package tximport (Soneson et al. 2015) (version 1.6.0), and summarized on the gene-level. Differential gene expression was determined using the package edgeR (Robinson et al. 2010) (version 3.20.5) utilizing the obtained estimated gene-level counts and offsets based on the transcript-level abundance estimates. The latter corrects for changes to the average transcript length across samples, and incorporation of such offsets has been reported to improve the accuracy of differential gene expression analysis (Soneson et al. 2015).

The complete RNA-seq dataset that was generated in this study consisted of 16 samples (8 treatments $\times 2$ replicates), including also samples from T47D cells exposed to a series of retinoids including all-trans-retinoic acid (AtRA) (Sigma), and the synthetic retinoids 4-[(5,6,7,8-tetrahydro5,5,8,8-tetramethyl-2-naphthalenyl)carbamoyl] benzoic acid (Am80)(Abcam, Cambridge, UK), 5(5,6,7,8-tetrahydro-5,5,8,8-tetramethyl-2-anthracenyl)-3-thiophenecarboxylic-acid (CD2314)(Tocris Bioscience, Bristol, UK), 3-fluoro-4-[[2-hydroxy-2-(5,5,8,8-tetramethyl-5,6,7,8,-tetrahydro-2naphthalenyl) acetyl]amino]-benzoic acid (BMS961)(Tocris Bioscience). Although not all treatments are of relevance to address the research question posed in this paper, all samples were included in the statistical analyses. This was done because this improves the empirical Bayes gene-wise dispersion (variability) estimates, which is advantageous when having two replicates per group (see below).

Before statistical analyses, nonspecific filtering of the count table was performed to increase detection power (Bourgon et al. 2010), based on the requirement that a gene should have an expression level greater than 10 counts, i.e. 0.65 count per million reads (cpm) mapped, for at least 2 libraries across all 16 samples. Differences in library size were adjusted by the trimmed mean of $\mathrm{M}$ - 
values normalization method (Robinson and Oshlack 2010). Differentially expressed genes were identified by using generalized linear models that incorporate empirical Bayes methods that permit the estimation of gene-specific biological variation, thereby improving testing power (Lun et al. 2016; McCarthy et al. 2012; Robinson and Smyth 2007). When indicated, thresholded hypotheses testing using a log2 fold-change of 0.6 was performed to identify robustly regulated genes, and genes regulated by a fold-change below this threshold were considered not to be biologically meaningful (McCarthy and Smyth 2009). In all cases, genes that satisfied the criterion of moderated $p$ value < 0.05 were considered to be significantly regulated. For the general overview as shown in the heatmap (Fig. 6A), only the criterion of false discovery rate (FDR) $<0.05$ (Benjamini and Hochberg 1995) in any of the 3 comparison was considered to select significantly regulated genes.

Gene ontology and pathway analysis were carried out using the Consensus Path Database (cpdb) tool (Kamburov et al. 2011). For NR pathway analysis, lists containing all cpdb and the top 100 genes of the NURSA data base Transcriptomine (Consensome) (Becnel et al. 2015) were also used. In all cases, only gene ontology and pathways with p-values lower than 0.05 were included for analysis. In addition, other web tools such as Heatmapper (Babicki et al. 2016), Interactivenn (Heberle et al. 2015) were used to create the heatmaps and Venn diagrams respectively.

\subsection{Gene expression (RT-qPCR) studies}

Real-time quantitative polymerase chain reaction (RT-qPCR) amplification reactions were carried out to confirm the genes that showed significant and biologically relevant expression in the RNA seq analysis. To this end T47D or MCF-7 cells were seeded in $25 \mathrm{~cm}^{2}$ flasks (Corning, NY, USA) using growth medium, which, after the cells reached $50-60 \%$ confluence, was replaced by phenol red free medium. Twenty-four hours later, cells were exposed to the test compounds in phenol red free medium for 6 hours. Following the exposure cell lysis was carried out using RLT Lysis buffer (Qiagen, Venlo, The Netherlands). Total RNA was extracted using QIAshredder and RNeasy kits (Qiagen, Venlo, The Netherlands) according to the manufacturer's instructions. Spectrophotometric analysis was 
performed using a Nanodrop (ND-1000 Thermoscientific Wilmington, Delaware, USA) to quantify and ensure the quality of the RNA. Next, RNA was converted into cDNA using the QuantiTect Reverse Transcription Kit (Qiagen, Venlo, The Netherlands). Expression of GAPDH (housekeeping gene) and HDAC7, HDAC11, HIST1H2BE, CPP26A1, CYP26B1, TFF1, AXIN2 and CXCL12 were quantified by RTqPCR using Rotor-Gene SYBR ${ }^{\circledR}$ Green Kit (Qiagen, Venlo, The Netherlands) and the Rotor-Gene 6000 cycler (Qiagen, Venlo, The Netherlands) following the manufacturer's protocol. To do so, this study made use of the QuantiTect Primer Assays Hs_GAPDH_1_SG, Hs_HDAC7_1_SG, Hs_HDAC11_1_SG, Hs_HIST1H2BE_1_SG, Hs_CYP26A1_1_SG and Hs_CYP26B1_1_SG, Hs_TFF1_1_SG, Hs_AXIN2_1_SG and Hs_CXCL12_1_SG (Qiagen, Venlo, The Netherlands).

\section{Results}

\subsection{Activation of ERa-mediated gene expression in the U2OS-ERa luciferase reporter gene assay and induction of T47D cell proliferation}

Treatment of human U2OS-ER $\alpha$ luciferase cells with DES and E2 resulted in concentration-dependent induction of luciferase expression (Fig.2A). Induction of ER $\alpha$-mediated luciferase expression by DES and E2 occurs at concentrations between 1 and $100 \mathrm{pM}$ in a similar manner. From the results obtained, the EC50 values for DES and E2 were determined (Table 1). The EC50 value is 3 -fold lower for E2 compared to that of DES, indicating a higher potency of E2 for induction of ER $\alpha$-mediated gene expression. In subsequent experiments the DES- and E2-induced ER $\alpha$-mediated proliferation of T47D human breast cancer cells was investigated. After 72 hours of exposure, both DES and E2 increased T47D cell proliferation in a concentration-dependent manner (Fig.2B). The EC50 values derived from these curves were two-fold lower for E2 than those for DES as presented in table 1. 


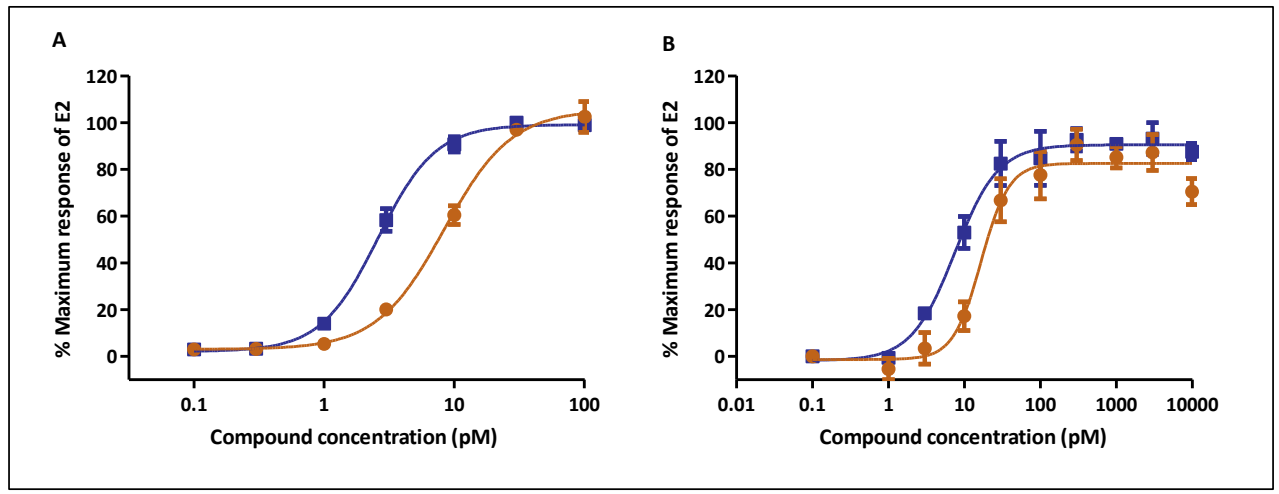

Figure 2. Concentration dependent ER $\alpha$-mediated induction of A) luciferase activity in U2OS-ER $\alpha$ reporter gene cells by E2 (blue) and DES (orange), and of B) T47D cell proliferation after 72 hours of exposure to E2 (blue) and $D E S$ (orange). Each data point represents the mean of three independent experiments $\pm S D$.

Table 1. EC50 values (95\% confidence intervals) (pM) of DES and E2 as derived from the data presented in Fig. 2.

\begin{tabular}{|l|l|l|}
\hline Assay & EC50 E2 (pM) & EC50 DES (pM) \\
\hline U2OS-ER $\alpha$ reporter gene expression & $2.5(2.3-2.9)$ & $8.4(7-9.9)$ \\
\hline T47D cell proliferation & $7.5(5.3-10.6)$ & $16.6(11.9-23.3)$ \\
\hline
\end{tabular}

\subsection{ER $\alpha$-mediated coregulator motif binding induced by DES and E2}

The ligand-induced interaction of the ligand binding domain of ER $\alpha$ (ER $\alpha$-LBD) with coregulator motifs was characterised in the MARCoNI coregulator binding assay, in order to evaluate and compare the capacity of DES and E2 to modulate ER $\alpha$-LBD binding to coregulator motifs. Most of the coregulator motifs showed an increased binding signal with increasing DES and E2 concentration (Supplementary material 1). As an example, Fig.3 presents the concentration-dependent induction by DES and E2 of the interaction of ER $\alpha$-LBD with NCOA1_1421_1441, NCOA1_677_700 and NCOA2_628_651. The observation of an increase in binding with increasing concentration of the model compounds is in line with the role of these compounds as receptor agonist and the function of these three coregulators as coactivators. The results reveal a similar concentration-dependent 
induction of ER $\alpha$-mediated coregulator motif binding for these three coregulators with the EC50 for E2 being about 1.5 fold lower than that of DES.

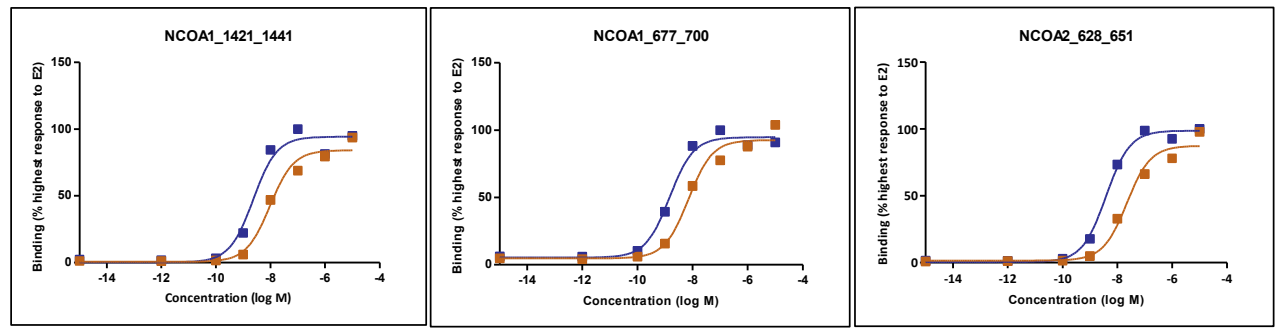

Figure 3. $E 2$ (blue) and DES (orange) concentration-dependent induction of ER $\alpha$-LBD binding to coregulator motifs (NCOA1_1421_1441, NCOA1_677_700 and NCOA2_628_651).

\subsubsection{Comparison of the effects of DES and E2 on coregulator motif binding to ERa}

The concentration-response data obtained for all 154 coregulator motifs present on the array show that for both E2 and DES, maximum responses were obtained at $10^{-6} \mathrm{M}$ (Fig.4; supplementary material 1). To compare DES-induced and E2-induced ER $\alpha$-coregulator interactions, the modulation index (MI) profile was determined (Fig. 4), defined as the log fold modulation of ligand-induced ER $\alpha$ LBD-mediated binding with different coregulator motifs in the presence of $10^{-6} \mathrm{M}$ DES or E2 compared to the solvent control. In this MI profile the changes in ER $\alpha$-LBD binding to the coregulator motifs are expressed relative to the solvent control (DMSO). Positive values on the $y$-axis present higher binding than the solvent control and negative values reflect lower binding. Binding patterns induced by DES and E2 appear to be overall quite similar, with the major difference being that for DES the MI values for a large number of coregulator motifs are lower than for E2 (Fig. 4). In a next step these differences were analysed to a further extent. 


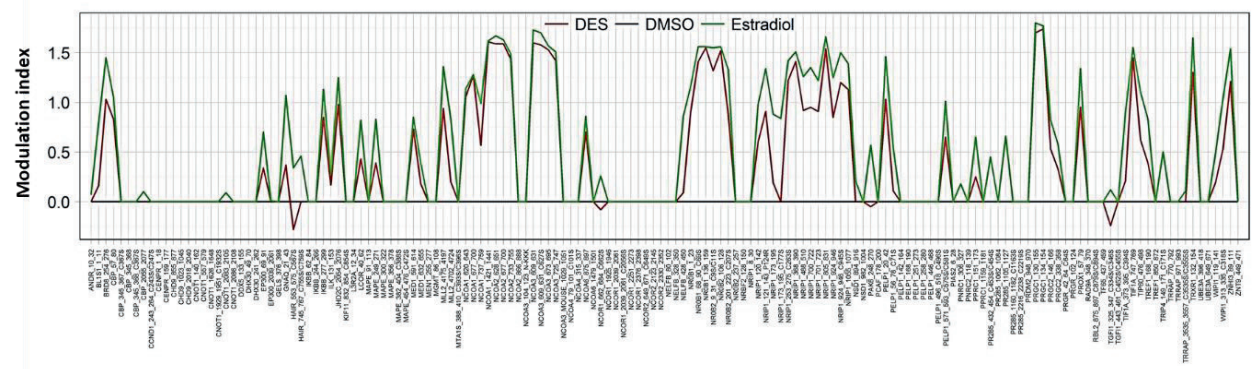

Figure 4. E2 (green) and DES (red) cause similar ER $\alpha-L B D$ coregulator binding patterns. The $M I$ represents the ligand-induced modulation of ER $\alpha$-LBD binding to coregulator motifs by DES and E2 both tested at $10^{-6} \mathrm{M}$, compared to the solvent control.

To further investigate to what extent coregulator binding may differentiate the ER $\alpha$ agonist action of DES and E2, the coregulator motifs that show concentration-response curves with a coefficient of determination $\left(R^{2}\right) \geq 0.8$ for at least either E2 or DES, were selected for further analysis. All the concentration-response curves with $R^{2} \geq 0.8$ are presented in supplementary material 1 with the response expressed as percentage of the highest response to E2 for the respective coregulator motif set at $100 \%$ and the effect of the solvent control at $0 \%$. This analysis reveals that 78 out of 154 coregulators motifs gave adequate concentration response curves with $\mathrm{R}^{2} \geq$ of 0.8 for E2 and/or DES. From these 78, 63 coregulators motifs gave adequate concentration-response curves for both DES and E2, while 14 show a response only for E2 and one only for DES. Concentration-response curves for 4 of the 15 coregulator motifs that show a differential response towards DES and E2 are presented in Fig. 5, while the concentrations-response curves for the other coregulators motifs are presented in supplementary material 1. 

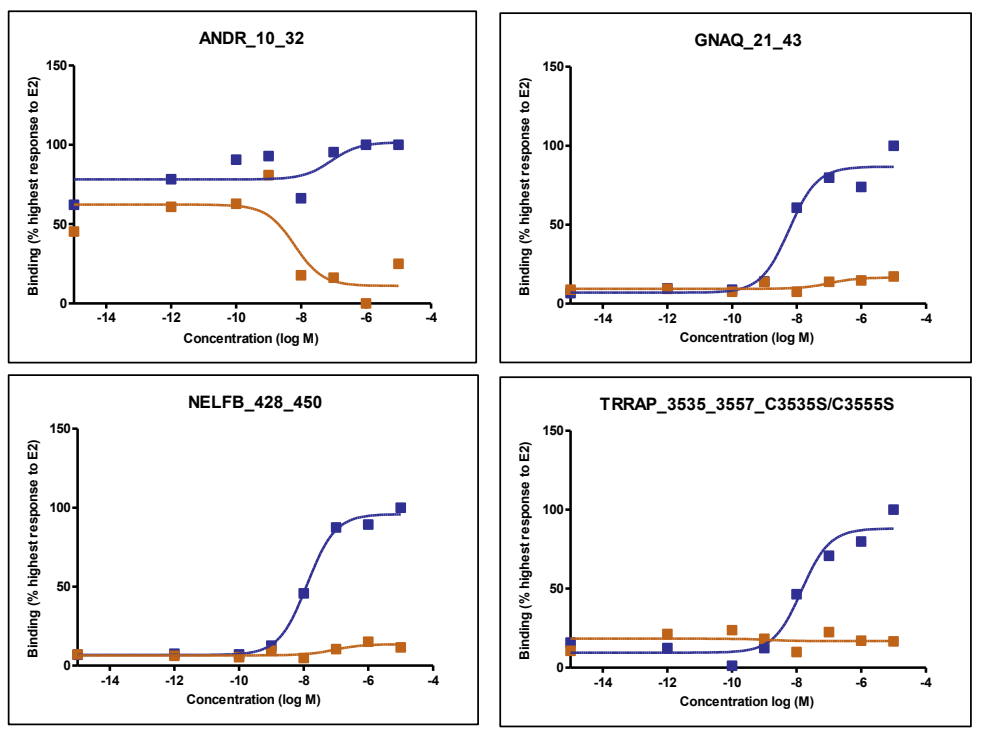

Figure 5. E2 (blue) and DES (orange) concentration-dependent induction of ER $\alpha$-LBD binding to coregulator motifs ANDR_10_32, GNAQ_21_43, NELFB_428_450 and TRRAP_3535_3557_C3535S/C3535S that show differences between $E 2$ and $D E S$.

Table 2 presents these 15 coregulator motifs and the biological function of the corresponding coregulator as far as these are known. The 15 coregulator motifs belong to 11 coregulators. The function of several of the coregulators of which a respective motif interacts specifically with E2 only are coactivators that enhance gene transcription (CBP, MLL2, NRIP1, TIF1A, TRIP4, TRRAP) while others act as co-repressors (NCOR1, NELFB, NRIP1, PAK6). Also of interest to note is that several of the coregulators of which a respective motif specifically responds to E2 and not to DES influence histone (de)acetylation. One coregulator motif, ANDR_10_32, responded only to DES showing a decrease in ER $\alpha$-LBD binding with increasing concentration of DES that was not observed with E2 as presented in Fig.5. The function of the corresponding coregulator ANDR of which motif ANDR_10_32 shows a DES-specific response is not known. However, given the decrease in binding upon DES interaction with the ER $\alpha$-LBD and the fact that it is an androgen receptor-related coregulator, suggests it may be an estrogen receptor co-repressor, resulting in activation of estrogen-related gene transcription upon its DES-induced release. To what extent such subtle differences in coregulator 
interactions might result in differences in gene transcription was investigated using next generation sequencing (RNA-seq) and transcriptome analysis.

Table 2. Overview of the 15 coregulator motifs that show a differential agonist-induced ER $\alpha$-dependent binding response for DES and E2.

\begin{tabular}{|c|c|c|c|c|}
\hline Coregulator motif & DES & E2 & Coregulator name/ family & Function \\
\hline ANDR_10_32 & + & - & $\begin{array}{l}\text { Androgen Receptor- } \\
\text { related coregulator }\end{array}$ & Unknown \\
\hline CBP_2055_2077 & - & + & CREB-binding protein & $\begin{array}{l}\text { Coactivator for nuclear receptors (NRs) } \\
\text { enhancing histone acetylation (Hung et } \\
\text { al. 2001; Vincek et al. 2018) }\end{array}$ \\
\hline GNAQ_21_43 & - & + & $\begin{array}{l}\text { Guanine nucleotide- } \\
\text { binding protein }\end{array}$ & Unknown \\
\hline MLL2_4702_4724 & - & + & $\begin{array}{l}\text { Myeloid/lymphoid or } \\
\text { mixed-lineage leukemia } \\
\text { protein } 2\end{array}$ & $\begin{array}{l}\text { Part of a complex that acts as } \\
\text { coactivator for estrogen receptor alpha } \\
\text { and shown to be a transcriptional } \\
\text { regulator of } \beta \text {-globin (Demers et al. } \\
2007 \text {; Mo et al. 2006). } \\
\text { MLL2 is also implicated in the regulation } \\
\text { of methylation of histone } 3 \text { at lysine } 4 \\
\text { (H3K4) (Zhao et al. 2016). }\end{array}$ \\
\hline $\begin{array}{l}\text { NCOR1_662_684_C6 } \\
62 S\end{array}$ & - & + & $\begin{array}{l}\text { Nuclear receptor } \\
\text { corepressor } 1\end{array}$ & $\begin{array}{l}\text { NCOR1 mediates transcriptional } \\
\text { repression by different nuclear } \\
\text { receptors. It is part of a complex which } \\
\text { promotes histone deacetylation and the } \\
\text { formation of repressive chromatin } \\
\text { structures (Cui et al. 2011; Yoon et al. } \\
2003 \text { ). }\end{array}$ \\
\hline NELFB_428_450 & - & + & \multirow{2}{*}{$\begin{array}{l}\text { Negative elongation factor } \\
\text { B }\end{array}$} & \multirow{2}{*}{$\begin{array}{l}\text { NELFB in complex negatively regulates } \\
\text { transcription elongation and causes } \\
\text { transcriptional repression (Narita et al. } \\
\text { 2003; Yamaguchi et al. 1999). }\end{array}$} \\
\hline NELFB_80_102 & - & + & & \\
\hline NRIP1_173_195 & - & + & \multirow{2}{*}{$\begin{array}{l}\text { Nuclear receptor- } \\
\text { interacting protein1 }\end{array}$} & \multirow{2}{*}{$\begin{array}{l}\text { NRIP1 can both co-activate and } \\
\text { corepress transcription mediated by } \\
\text { nuclear receptors including ERs (Castet } \\
\text { et al. 2004; Cavailles et al. 1995; } \\
\text { Subramaniam et al. 1999). }\end{array}$} \\
\hline $\begin{array}{l}\text { NRIP1_173_195_C17 } \\
\text { 7S }\end{array}$ & - & + & & \\
\hline
\end{tabular}




\begin{tabular}{|c|c|c|c|c|}
\hline PAK6_248_270 & - & + & $\begin{array}{l}\text { Serine/threonine-protein } \\
\text { kinase PAK6 }\end{array}$ & $\begin{array}{l}\text { PAK6 kinase plays a role in the } \\
\text { regulation of gene transcription. It is } \\
\text { reported to inhibit androgen receptor } \\
\text { and ER } \alpha \text {-mediated transcription by } \\
\text { phosphorylation of the DNA binding } \\
\text { domain (Lee et al. 2002; Zhang et al. } \\
2010 \text { ). }\end{array}$ \\
\hline $\begin{array}{l}\text { PR285_2216_2238_C } \\
22195\end{array}$ & - & + & \multirow{2}{*}{$\begin{array}{l}\text { Peroxisomal proliferator- } \\
\text { activated receptor A- } \\
\text { interacting complex } \\
\text { 285kDa protein PRIC285: } \\
\text { PPAR-alpha-interacting } \\
\text { complex protein } 285\end{array}$} & Unknown \\
\hline $\begin{array}{l}\text { PR285_432_454_C45 } \\
3 S / C 454 S\end{array}$ & - & + & & \\
\hline $\begin{array}{l}\text { TIF1A_373_395_C39 } \\
\text { 4S }\end{array}$ & - & + & $\begin{array}{l}\text { Transcription intermediary } \\
\text { factor 1-alpha } \\
\text { TRIM24: tripartite motif } \\
\text { containing } 24\end{array}$ & $\begin{array}{l}\text { TIF1A is a transcriptional coactivator } \\
\text { that interacts with numerous nuclear } \\
\text { receptors and coactivators and } \\
\text { modulates the transcription of target } \\
\text { genes. Furthermore, it is reported to } \\
\text { play a role in regulation of cell } \\
\text { proliferation and apoptosis by regulating } \\
\text { p53 level (Allton et al. 2009; Thenot et } \\
\text { al. 1997). }\end{array}$ \\
\hline $\begin{array}{l}\text { TRIP4_149_171_C17 } \\
\text { 1S }\end{array}$ & - & + & $\begin{array}{l}\text { Thyroid receptor- } \\
\text { interacting protein } 4\end{array}$ & $\begin{array}{l}\text { Acts as a transcriptional coactivator and } \\
\text { plays a role in different transactivation } \\
\text { of nuclear receptors including ERs and } \\
\text { thyroid hormone receptors (Kim et al. } \\
\text { 1999; Yoo et al. 2014). }\end{array}$ \\
\hline $\begin{array}{l}\text { TRRAP_3535_3557_C } \\
\text { 3535S/C3555S }\end{array}$ & - & + & $\begin{array}{l}\text { Transformation/transcripti } \\
\text { on domain-associated } \\
\text { protein }\end{array}$ & $\begin{array}{l}\text { Coactivator TRRAP is an adapter protein } \\
\text { complex that induces epigenetic } \\
\text { transcription activation by histone } \\
\text { acetyltransferase activity. It also plays a } \\
\text { role in transcription activation of proto- } \\
\text { oncogene MYC and tumor suppressor } \\
\text { genes p53 (Ard et al. 2002; Lang and } \\
\text { Hearing 2003; Liu et al. 2003; McMahon } \\
\text { et al. 1998). }\end{array}$ \\
\hline
\end{tabular}




\subsection{Transcriptome analysis of T47D cells exposed to DES and E2}

In a next step, the effects of DES and E2 on the gene expression in T47D cells was characterised using transcriptome analysis (RNA-seq) to better understand the potential differences between DES- and E2-induced ER $\alpha$ activation. An overview of the RNA-seq analysis of T47D cells exposed to DES and E2 is presented in Fig 6. The heatmap (Fig. 6A) provides a visual representation of the differences in gene expression between DES and E2 and the solvent control (DMSO). The results of a Principal Coordinates Analysis presented in Fig. $6 \mathrm{~B}$ also include the data from a series of retinoids tested in the same experiment thus showing clearly that DES- and E2-induced differential modulation of gene expression is different from that of the solvent control and also from the retinoids tested at the same time, while the differences between DES and E2 appear to be relatively small, albeit consistent.

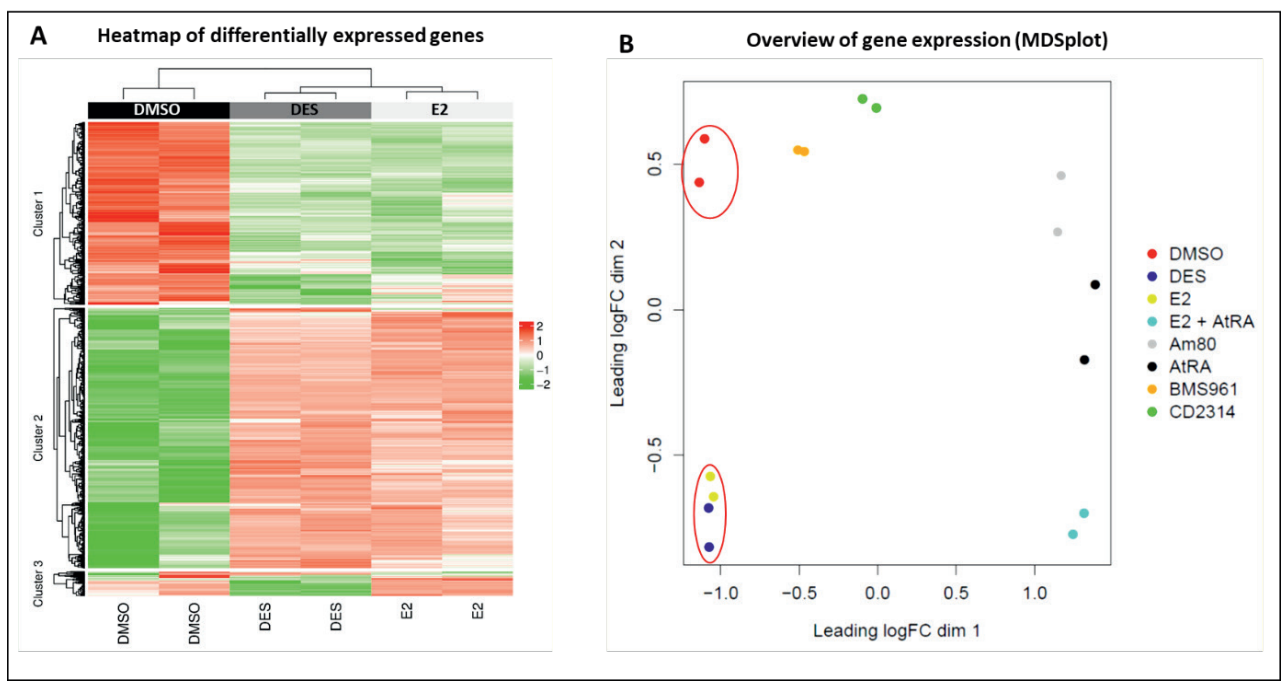

Figure 6. General overview of the RNA-seq assessment for T47D cells exposed to E2 or DES (10 nM) compared to the solvent control (DMSO) presented in A) a heatmap of differentially expressed genes significantly different (FDR<0.05) in at least 1 of the treatments. Red; high expressed genes, green; low expressed genes, and B) Principal Coordinates Analysis plot for E2, DES and the solvent control (DMSO) also including -to facilitate comparison- the data for 6 other treatment groups analysed in the same experiment, including all-trans retinoic acid (AtRA), and the synthetic retinoids 4-[(5,6,7,8-tetrahydro-5,5,8,8-tetramethyl-2-naphthalenyl)carbamoyl] benzoic acid (Am80), 5-(5,6,7,8-tetrahydro-5,5,8,8-tetramethyl-2-anthracenyl)-3-thiophenecarboxylic-acid (CD2314), 3-fluoro-4-[[2-hydroxy-2-(5,5,8,8-tetramethyl-5,6,7,8,-tetrahydro-2-naphthalenyl) acetyl]amino]benzoic acid (BMS961). 
Fig.7 shows the volcano plot presenting the total number of up- and down-regulated genes thus obtained and their overlap between DES and E2. The results obtained reveal that the total number of genes upregulated by E2 and DES are higher than the downregulated genes.

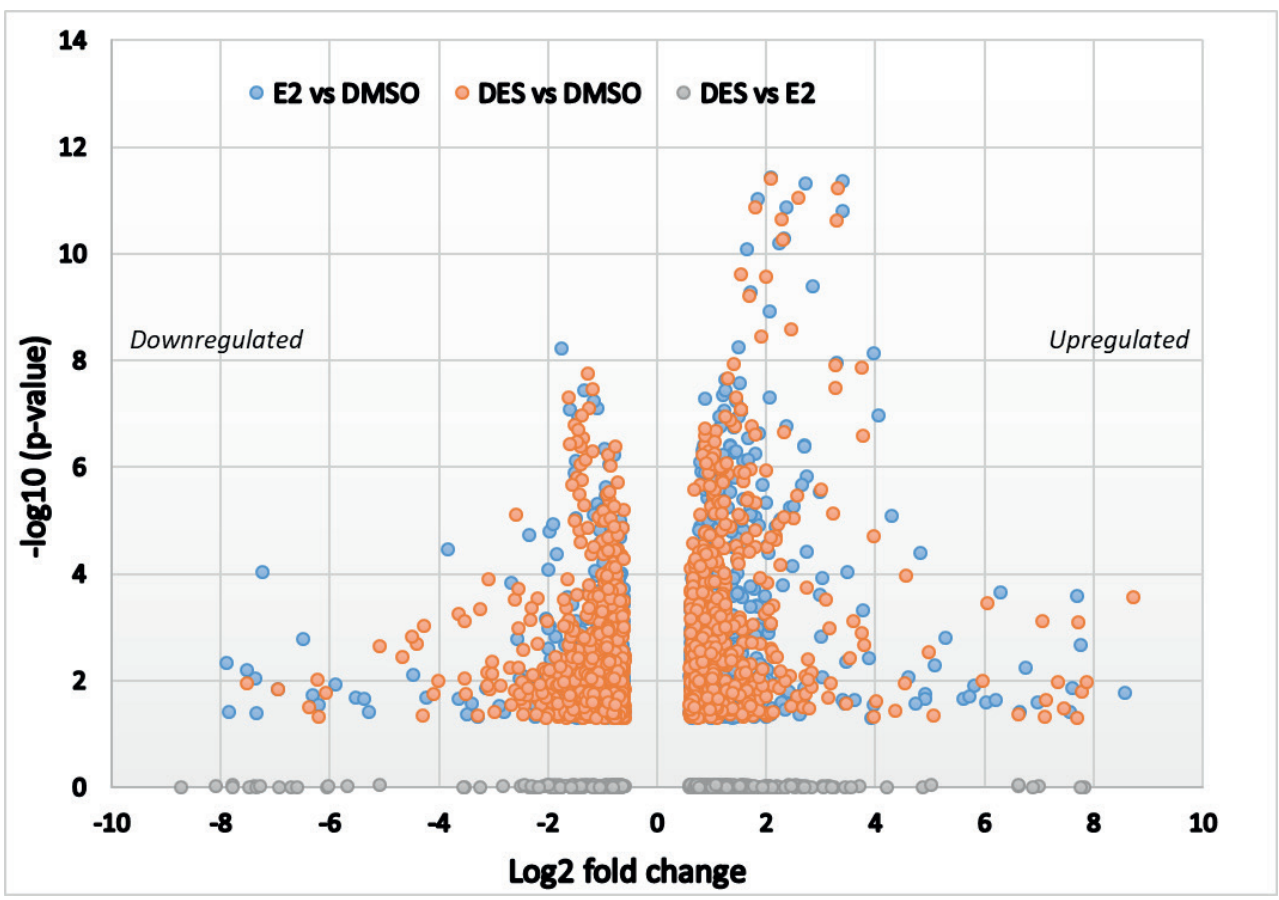

Figure 7. A volcano plot showing differential expressed genes (up-regulated and down-regulated). In the figure, each dot represents a gene showing the log2 fold-change and the -log10 (moderated p-value). Genes with significant expression changes (compared to DMSO) have a large magnitude fold change and high statistical significance (low p-value) The genes included in volcano plot are those with log2 FC $\geq 0.6$ and moderated $p$ value $<0.05$.

\subsubsection{Gene ontology (GO) and pathway analysis}

To gain insight into the biological meaning of the gene expression data, first a gene ontology overrepresentation analysis was performed using the consensus path database tool. For the gene ontology, the total number of genes regulated by DES and E2 compared to DMSO is presented based on their moderated $p$-value and their gene ratio to the total number of genes that are involved in a specific biological process. The overview of all biological process categories for the overrepresented genes by either DES versus DMSO or E2 versus DMSO is presented in supplementary material 2. This 
overview reveals that in spite of the relatively large number of DEGs specific for DES and E2 alone, DES and E2 show similar patterns with only small differences like those for the GO category gland development (only overrepresented in DES/E2 treatment) and response to the retinoid receptor (only overrepresented in DES/E2 treatment).

Next a pathway overrepresentation analysis, using the consensus path database tool and the NURSA database, was performed for the three groups of genes, E2- and DES-induced DEGs, and DEGs induced by either DES or E2 alone. Supplementary materials 3, 4 and 5 present the pathways analyses for these 3 DEG categories. It is clear from the pathway analysis of DEGs induced by both E2 and DES (supplementary material 3), that DES and E2 regulate pathways related to ER $\alpha$ network significantly with a very low $\mathrm{p}$ value. Furthermore, DES and E2 shared multiple pathways like mammary gland development, breast cancer and the estrogen receptor pathway. DEGs of interest that were specifically regulated by DES (supplementary material 4) appeared to relate especially to genes that relate to possible epigenetic effects, such as the relatively high level of downregulation of genes involved in histone modification and DNA methylation. Differential expression of three genes upon exposure of the cells to especially DES was confirmed by RT-qPCR. Fig.8 presents the results obtained corroborating the significant down-regulation of the expression of genes involved in histone deacetylation (like HDAC10 and HDAC7) and DNA methylation (HIST1H2BE) upon exposure to DES but not E2. Figure 8 reveal that DES (grey) downregulated these genes significantly compared to E2 (black). The differential expression of HDAC10, HDAC7 and DNA HIST1H2BE were validated using qPCR in T47D and moreover the differential expression of the HDAC10 and HDAC7 genes were also validated in the MCF-7 cell line (the data are presented in the supplementary material 7). 


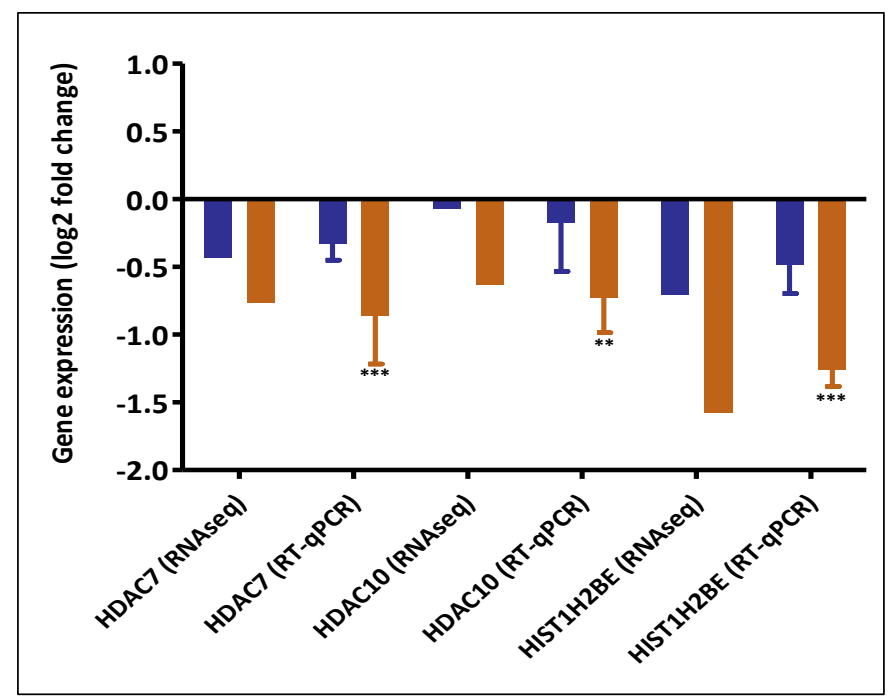

Figure 8. Example of genes that are significantly down-regulated by DES (orange) only that are involved in histone deacetylation and related DNA methylation. The expression was considered significant if log2 FC $>0.6$ and moderated $p$-value $<0.05$. For RT-qPCR results, bars represent average $\pm S E M$ from at least three independent experiments. For statistical analysis of the RT-qPCR data multiple paired t-tests were performed and differences were considered significant if $p$-value $<0.05$.

Pathway analysis for the genes that were regulated by E2 only (Supplementary material 5), revealed that most of these pathways relate to transforming growth factor (TGF) related pathways such as the $B M P$ signalling pathway, BMP2 signalling TGF-beta $M V, B M P$ signalling Dro and BMP receptor signalling.

\subsubsection{Analysis of differential gene expression in nuclear receptor pathways involved in developmental processes and toxicity}

To further elucidate gene expression results that may explain the differential developmental toxicity of DES and E2, pathways that relate to ER, retinoid acid receptor (RAR) and estrogen related receptor (ERR) related nuclear receptor signalling were analysed in more detail. First, the differential effects on genes related to ER signalling were evaluated (Fig.9). Fig.9A displays the log2 fold changes induced by DES and E2 for the transcription of genes known to play a role in ER-mediated pathways. In addition, Fig.9B shows RT-qPCR data focussing on selected ER-mediated gene that significant differences between DES and E2. As shown in the volcano plot and the bar graphs, almost all the 
genes that were differentially regulated by DES and E2 were regulated in a similar way by the two ER agonists. However, DES specifically down-regulated the E2-responsive gene AXIN2, an effect not observed upon E2 exposure. The expression of this gene is also validated in MCF-7 cells, showing also effect by DES not observed for E2, and the results are presented in the supplementary material 7.
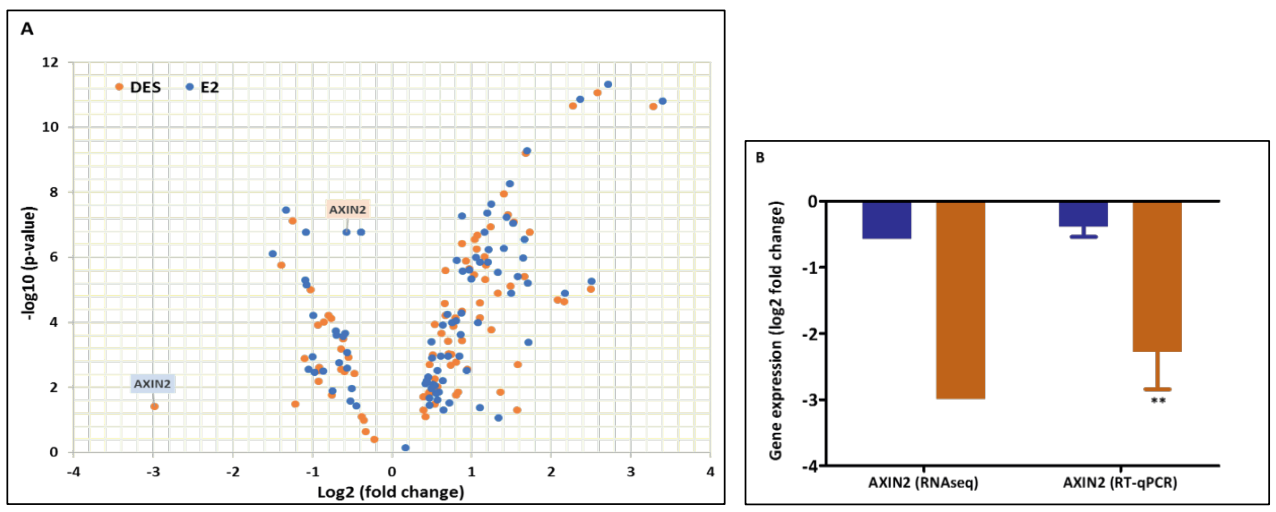

Figure 9. RNA-seq and RT-qPCR characterization of the effects of DES and E2 on gene expression associated with the ER pathway. Figure A displays a volcano plot showing all genes related to ER signalling presenting significant changes induced by at least one of the two compounds ( $\log 2$ FC $\geq 0.6$ and moderated $p$-value $<0.05$ ). Figure $B$ presents RT-qPCR data for AXIN2, an ER-mediated gene that showed large differences between DES (blue) and E2 (green). For the volcano plot, each dot represents a gene showing the log 2 fold-change and the log10 (moderated p-value). For RT-qPCR, results are expressed as log2 fold changes in relation to the solvent control. For $R T-q P C R$ results, bars represent average \pm SEM from at least three independent experiments. For statistical analysis of the RT-qPCR data multiple paired t-tests were performed and differences were considered significant if $p$-value $<0.05$.

Considering the important role of the retinoid receptors in developmental processes and toxicity (Kam et al. 2012; Mark et al. 2009; Rhinn and Dolle 2012), gene expression associated with the retinoid acid receptor (RAR) pathway was also analysed in more detail. Fig.10A displays the fold changes obtained upon exposure of T47D cells to DES and E2 for the transcription of genes known to play important roles in the RAR pathway based on the pathway database. In addition, Fig.10B presents RT-qPCR data focussing on selected RAR-mediated genes of which the expression was affected to a large extent by E2 and/or DES. Most RAR-dependent genes that regulated by E2 and/or DES in a similar manner. However, DES significantly upregulated CYP26A1 and CYP26B1 expression, an effect not observed at a significant level upon exposure of the T47D cells to E2 (Fig.10B). These 
genes also validated in MCF-7 cells, showing also an effect by DES not observed for E2, and the data are presented in the supplementary material 7.
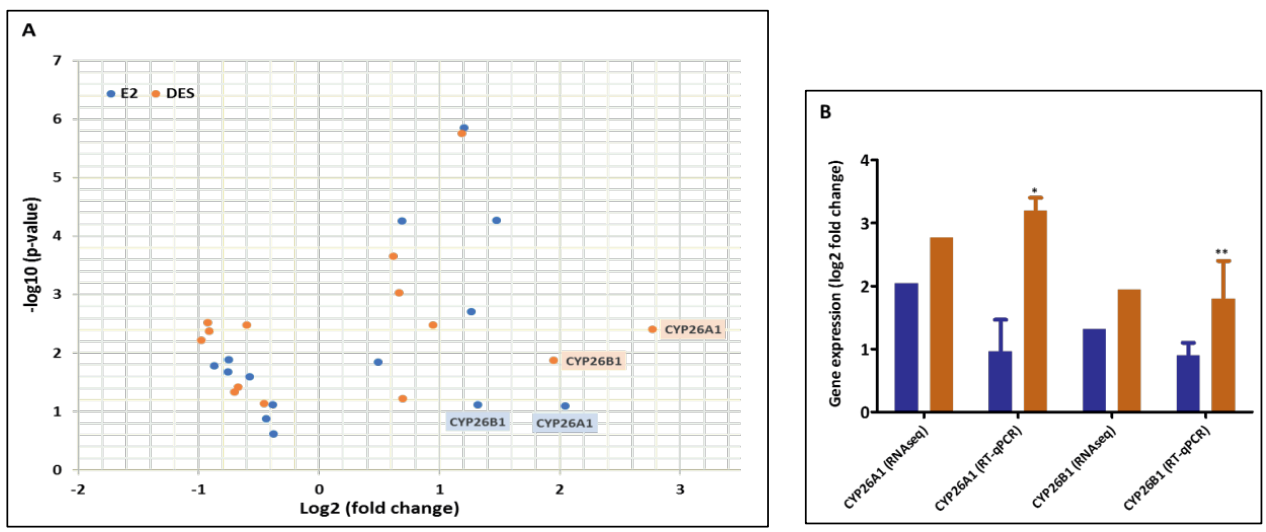

Figure 10. RNA-seq and RT-qPCR characterization of the effects of DES and E2 on gene expression associated with RAR pathways. Figure A displays A volcano plot showing all genes related to RAR signalling presenting significant changes induced by at least one of the two compounds. Figure $B$ presents RT-qPCR data for CYP26A1and CYP26B1 in RAR-mediated gene that showed high differences between DES (orange) and E2 (blue). For the volcano plot, each dot represents a gene showing the log2 fold-change and the -log10 (moderated $p$ value). For $R T-q P C R$, results are expressed as log 2 fold changes in relation to the solvent control. For RT-qPCR results are expressed as log 2 fold changes in relation to the solvent control. The change in expression is considered significant if $\log 2 F C>0.6$ and the $p$-value $<0.05$. For RT-qPCR results, bars represent average $\pm S E M$ from at least three independent experiments. For statistical analysis of the RT-qPCR data multiple paired $t$-tests were performed and differences were considered significant if $p$-value $<0.05$.

Finally, possible differential expression of ERRs pathways was evaluated in more detail. DES is known to interact with ERRs (Nam et al. 2003) while E2 is reported to not interact with ERRs. Supplementary material 6 presents the genes differentially affected by DES and E2 related to ERR signalling based on the pathway database. No significant differences between DES and E2 were found and it was concluded that the expression of the genes involved in this pathway is very similar upon DES and E2 exposure.

In summary, the results from the ontology and pathway analysis and from the RT-qPCR data indicate that there are subtle albeit interesting and significant differences between DES and E2 in transcriptomic signatures obtained in the T47D cell line. Furthermore, these subtle differences were also observed in the MCF-7 cell line. 


\section{Discussion}

Adverse effects of DES have been reported to be mediated via the ER $\alpha$ (Couse et al. 2001; Couse and Korach 2004; Prins et al. 2001). This suggests that studying the molecular events related to ER $\alpha$ is crucial to understand the potential mode of action underlying DES-induced adverse effects. Given however, that DES acts as an ER $\alpha$ agonist and thus via a mode of action potentially similar to the endogenous female hormone E2, it is of even more interest to elucidate the potential differences between DES- and E2-induced ER $\alpha$-mediated effects. The objective of this study was to assess whether DES and E2 differ in their ER $\alpha$-mediated responses, aiming to provide information on possible underlying differences in their mode of action and resulting potential developmental toxicity. To this end, the activities of DES and E2 were compared in a series of ER $\alpha$-related bioassays including the U2OS ER $\alpha$ reporter gene assay, T47D cell proliferation assay, ligand-induced ER $\alpha$ mediated coregulator interaction and gene expression profile in ER $\alpha$ positive T47D cells as well as ER $\alpha$ positive MCF-7 cells.

DES and E2 acted as ER $\alpha$ agonists in the U2OS-ER $\alpha$ cells (Fig.2A) and increased T47D proliferation (Fig.2B) in a similar manner, with the potency (reflected by the EC50) of E2 being only slightly higher than that of DES (Table 1). These results are consistent with results from ER $\alpha$ reporter gene and cell proliferation data for ER $\alpha$ positive cells reported in the literature (Kalach et al. 2005; Sotoca et al. 2008). However, the binding affinity of DES to ER $\alpha$ has been reported to be slightly greater than that of E2 (Blair et al. 2000; Bolger et al. 1998; Okulicz and Johnson 1987; Shelby et al. 1996).

Transcriptional activation mediated via the ER and other nuclear receptors is influenced by binding to transcriptional coregulators that can activate (eg. NCOA) or repress (NCOR) the gene transcription (Glass and Rosenfeld 2000; O'Malley and Kumar 2009). Previous research showed that overexpression or lack of certain ligand-dependent coregulators could affect the physiological outcome driven by a chemical (Hsia et al. 2010). Therefore, the interaction of the ER $\alpha$ with coregulators in the presence of DES and E2 was studied to obtain further insight in possible 
differences in their modes of action. Results obtained revealed that DES and E2 displayed similar responses with only a few, albeit significant, differences in the ligand-induced coregulator motif binding pattern to the ER $\alpha$-LBD. A high number of coactivator and corepressor motifs was found to interact with ER $\alpha$ in a DES and E2 concentration-dependent manner suggesting that a broad range of coregulator proteins is involved in ER $\alpha$ signalling induced by both agonists. However, 15 out of 154 coregulators motifs showed a marked difference in their response to DES and E2. These 15 coregulator motifs appear to belong to 11 coregulators including ANDR, CBP, GNAQ, MLL2, NCOR1, NELFB, NRIP1, PAK6, PR285, TRIP4 and TRRAP. Of these coregulator motifs, only ANDR_10_32 showed a DES-specific response while the other 14 bound to the ER $\alpha$-LBD in the presence of E2 and not in the presence of DES (Fig.5). Interestingly, in the presence of DES the ER $\alpha$-LBD bound to other coregulator motifs on the chip of CBP, MLL2, NCOR1, NRIP1 and PR285 than the coregulator motifs of the coregulators presented in Table 2 that specifically interacted with E2 alone. Together the data suggest a possible difference in ER $\alpha$-coregulator interaction between DES and E2. For the coregulator motifs present on the chip of the coregulators GNAQ, NELFB, PAK6, TRIP4 and TRRAP binding to the $E R \alpha$-LBD was only observed in the presence of E2 and not in the presence of DES, thus pointing at additional specific differences in coregulator binding upon binding of DES or E2 to the ER $\alpha$-LBD that have not been described in literature before. It is of interest to consider the role of these coregulators, although not all of them have been studied in detail so far.

The coregulator motif ANDR_10_32 responded only to DES, showing a decrease in ER $\alpha$-LBD binding with increasing concentration of DES that was not observed with E2. The function of the corresponding androgen receptor related coregulator (ANDR) is not known, but the loss of the interaction of this coregulator with ER $\alpha$ in the presence of DES, but not E2, might play a role in the reproductive tract effects of DES, since it has been reported that the androgen receptor plays a role in mediating DES-induced effects in prostatic enlargement (Gupta 2000). 
Another important finding was that binding of E2, but not of DES, to the ER $\alpha$, induced binding of motifs of the corepressors NELFB and PAK. Both PAK and NELFB are considered corepressors for ER $\alpha$ function reducing its transcriptional activities (Aiyar et al. 2004; Lee et al. 2002). Furthermore, a lack of NELFB expression in breast carcinoma may serve as a useful indicator for poor prognosis (Aiyar et al. 2007; Sun et al. 2008), thus pointing at a beneficial role for NELFB. The recruitment of the coregulator TRRA upon binding of E2 to ER $\alpha$ is consistent with the literature. It has been reported that E2 induces direct binding of ER $\alpha$ to TRRAP (Fujita et al. 2003). TRRAP has been reported to play different roles in cell cycle and histone transcription (DeRan et al. 2008; Ichim et al. 2014). The difference in recruitment of TRRAP by E2 and not by DES may thus contribute to the differential biological responses induced by the two ER $\alpha$ agonists. Other coregulator motifs and related coregulators that appeared to respond different to E2 and DES have not been studied in detail, so a clear role in the differential biological responses to DES and E2 is less obvious.

To further assess subtle differences in cellular responses induced by DES and E2, gene expression in DES- and E2-exposed ER $\alpha$ competent T47D cells were assessed using RNA seq. An initial view and Principal Coordinates Analysis of the general transcriptomes induced by the test compounds showed that DES and E2 clustered together and were clearly grouped apart from a series of retinoids, also known to cause developmental toxicity, tested in the same experiment (Fig. 6B). General comparison of the heatmaps confirmed that DES and E2 presented remarkably similar expression patterns and levels although close analysis of the data revealed minor, albeit significant differences as shown in the heatmap (Fig.6A).

The biological consequences of the genes that show specific regulation by either DES alone, or E2 alone, or genes that were regulated by both estrogens were evaluated in a subsequent pathway analysis. Interestingly pathway analysis for the genes regulated specifically by DES highlighted potential differential epigenetic effects induced by DES compared to E2, including effects on genes involved in histone modification and DNA methylation. Histone deacetylase related genes HDAC7, 
HDAC10 and HISTIH2BE were significantly downregulated by DES while not by E2 (Fig. 8). These findings are consistent with previous research that reported DES-induced histone deacetylation in the promoter region of P450scc in TTE1 Leydig cells, while E2 did not induce these changes (Warita et al. 2010). Furthermore, DES exposure resulted in expression of certain genes (HIST1H3E, HIST1H3D, HIST1H2BE, HIST1H2BG, HIST2H2AA3) involved in DNA methylation pathways while these genes did not show significant E2-induced regulation. These group of genes normally clusters together and highly expressed during the S-phase of the cell cycle (Harris et al. 1991). It has been reported that aberrant DNA methylation was implicated in DES-induced reproductive developmental abnormalities and tumor formation (Newbold et al. 2006; Sato et al. 2009). The differences observed in DES and E2 mediated induction of genes involved in epigenetic modes of action, observed to a substantially higher extent for DES than for E2, can add to the observations that DES mediated effects are transferred to subsequent generations via epigenetic modes of action (Doherty et al. 2010; Bromer et al. 2009).

Nuclear receptors act as ligand-inducible transcription factors by directly interacting with DNA response elements for the target genes. Therefore, nuclear receptor pathway analyses were performed to identify pathways potentially affected by E2 or/and DES through their interaction with ERs, RARs and ERRs, since these nuclear receptors may play a role in modes of action underlying developmental toxicity (Collins and Mao 1999; Couse and Korach 2004; Luo et al. 1997; Willhite et al. 1996). Both compounds regulated multiple ER-related genes in a similar way (Fig. 9A). These ERrelated genes were reported to play a role in ER-mediated regulation and can be target genes in breast cancer (Lin et al. 2004). From these estrogen responsive genes, the AXIN2 gene appeared to be strongly downregulated specifically by DES as compared to E2 (Fig. 9B). This gene is reported to play a role in regulation of $\beta$-actin and inhibit the Wnt signalling pathway (Jho et al. 2002). The Wnt signalling pathway is essential for the embryonic developmental processes (Yang 2012) and the inhibition of this pathway by AXIN was associated with developmental toxicity and malformation in zebrafish (Heisenberg et al. 2001; Zhang et al. 2016). 
Previous research has shown that DES can bind and activate estrogen related receptors (ERRs) (Nam et al. 2003), while E2 cannot. These receptors share high homology to ER $\alpha$ (Eudy et al. 1998; Giguere et al. 1988) and regulate the activity of the estrogen response element constitutively (Chen et al. 2001; Hong et al. 1999). Therefore, it was hypothesised that gene expression related to the ERR pathway might be influenced specifically by DES. However, the findings of the current study do not support this hypothesis. DES and E2 induced similar expression of ERR-related genes as presented in supplementary material 6 . This high similarity between DES and E2 in ERR pathways might be due the fact that ERs and ERRs share high homology and might regulate many of the same genes (Vanacker et al. 1999a; Vanacker et al. 1999b).

The gene expression profile related to the RAR pathway was studied in more detail based on the fact that DES induces developmental toxicity in human and animals, a process in which retinoid acid signalling and timing of RAR activation play an important role (Cornwall et al. 1984; Nagao and Yoshimura 2009; Reed and Fenton 2013; Wardell et al. 1982). Furthermore, several agonists for the retinoid receptors like all-trans-retinoic acid and retinol have been found to induce developmental toxicity and to have a relation to breast cancer (Collins and Mao 1999; Garattini et al. 2014; Liu et al. 2015; Tembe et al. 1996; Turton et al. 1992). Therefore, the DES- and E2-mediated effects on RARmediated gene expression was also characterised in more detail. The analysis revealed that DES induced expression of especially CYP26A1 and CYP26AB1 to a significantly higher extent than E2 (Fig 10B). These two genes are responsible for metabolism and elimination of retinoid acid (Loudig et al. 2000; Thatcher and Isoherranen 2009). DES-mediated upregulation of CYP26A1 and CYP26B1 gene expression, is in line with the effects reported for the developmental toxins flusilazole and retinoic acid which have been reported to increase the expression of these genes in a similar manner (Dimopoulou et al. 2016; Luijten et al. 2010). This effect may play an important role in the mode of action of DES in developmental toxicity. 
Finally it is important to note that concentrations used in the in vitro incubations were above physiological concentrations to be expected. However, the aim of the study was to detect potential mechanistic differences between DES and E2 induced ER $\alpha$ mediated cellular responses, in order to create hypotheses for potential mechanistic differences between these ER $\alpha$ agonists. The extent to which these differences will be detectable in an in vivo setting remains to be investigated.

Altogether, it is concluded that the present study reveals further insight in possible modes of action underlying the differential biological effects of DES and E2. While effects of these two estrogens on $E R \alpha$-mediated gene expression in an ER $\alpha$ reporter gene assay and on ER $\alpha$-mediated cell proliferation were similar, coregulator binding and gene expression studies revealed subtle but significant differences. The studies on DES- and E2-induced coregulator binding to ER $\alpha$-LBD showed differences for 15 coregulator motifs and gene expression analysis revealed effects of DES on genes related to epigenetic regulation and developmental processes that were not observed for E2. These observations point at subtle differences in the estrogenic response that ultimately may contribute to their differential biological effects.

\section{Conflict of interest statement}

The authors declare that there are no conflicts of interest.

\section{Acknowledgments}

The authors are grateful to bio-detection systems (BDS) for use of U2OS-ER $\alpha$ CALUX cells. 


\section{References}

Aiyar SE, Cho H, Lee J, Li R. Concerted transcriptional regulation by BRCA1 and COBRA1 in breast cancer cells. International journal of biological sciences. 2007;3(7):486-492.

Aiyar SE, Sun JL, Blair AL, et al. Attenuation of estrogen receptor alpha-mediated transcription through estrogen-stimulated recruitment of a negative elongation factor. Genes \& development. 2004;18(17):2134-2146.

Allton K, Jain AK, Herz HM, et al. Trim24 targets endogenous p53 for degradation. Proceedings of the National Academy of Sciences of the United States of America. 2009;106(28):11612-11616.

Andrews S. Babraham Bioinformatics - FastQC A Quality Control tool for High Throughput Sequence Data. . 2018, Accessed November 9, 2018.

Ard PG, Chatterjee C, Kunjibettu S, Adside LR, Gralinski LE, McMahon SB. Transcriptional regulation of the mdm2 oncogene by p53 requires TRRAP acetyltransferase complexes. Molecular and cellular biology. 2002;22(16):5650-5661.

Babicki S, Arndt D, Marcu A, et al. Heatmapper: web-enabled heat mapping for all. Nucleic acids research. 2016;44(W1):W147-153.

Becnel LB, Darlington YF, Ochsner SA, et al. Nuclear Receptor Signaling Atlas: Opening Access to the Biology of Nuclear Receptor Signaling Pathways. PloS one. 2015;10(9):e0135615.

Benjamini Y, Hochberg Y. Controlling the False Discovery Rate - a Practical and Powerful Approach to Multiple Testing. J R Stat Soc B. 1995;57(1):289-300.

Blair RM, Fang H, Branham WS, et al. The estrogen receptor relative binding affinities of 188 natural and xenochemicals: structural diversity of ligands. Toxicological sciences : an official journal of the Society of Toxicology. 2000;54(1):138-153.

Bolger R, Wiese TE, Ervin K, Nestich S, Checovich W. Rapid screening of environmental chemicals for estrogen receptor binding capacity. Environ Health Perspect. 1998;106(9):551-557.

Bourgon R, Gentleman R, Huber W. Independent filtering increases detection power for highthroughput experiments. Proceedings of the National Academy of Sciences of the United States of America. 2010;107(21):9546-9551.

Bromer JG, Wu J, Zhou Y, Taylor HS. Hypermethylation of homeobox A10 by in utero diethylstilbestrol exposure: an epigenetic mechanism for altered developmental programming. Endocrinology. 2009;150:3376-82.

Castet A, Boulahtouf A, Versini G, et al. Multiple domains of the Receptor-Interacting Protein 140 contribute to transcription inhibition. Nucleic acids research. 2004;32(6):1957-1966. 
Cavailles V, Dauvois S, L'Horset F, et al. Nuclear factor RIP140 modulates transcriptional activation by the estrogen receptor. The EMBO journal. 1995;14(15):3741-3751.

Chen $\mathrm{M}$, Yeh CR, Chang HC, et al. Loss of epithelial oestrogen receptor alpha inhibits oestrogenstimulated prostate proliferation and squamous metaplasia via in vivo tissue selective knockout models. The Journal of pathology. 2012;226(1):17-27.

Chen S, Zhou D, Yang C, Sherman M. Molecular basis for the constitutive activity of estrogen-related receptor alpha-1. The Journal of biological chemistry. 2001;276(30):28465-28470.

Collins MD, Mao GE. Teratology of retinoids. Annual review of pharmacology and toxicology. 1999;39:399-430.

Colton T, Greenberg ER. Epidemiologic Evidence for Adverse-Effects of Des Exposure during Pregnancy. Am Stat. 1982;36(3):268-272.

Cornwall GA, Carter MW, Bradshaw WS. The relationship between prenatal lethality or fetal weight and intrauterine position in rats exposed to diethylstilbestrol, zeranol, 3,4,3',4'-tetrachlorobiphenyl, or cadmium. Teratology. 1984;30(3):341-349.

Couse JF, Dixon D, Yates M, et al. Estrogen receptor-alpha knockout mice exhibit resistance to the developmental effects of neonatal diethylstilbestrol exposure on the female reproductive tract. Developmental biology. 2001;238(2):224-238.

Couse JF, Korach KS. Estrogen receptor-alpha mediates the detrimental effects of neonatal diethylstilbestrol (DES) exposure in the murine reproductive tract. Toxicology. 2004;205(1-2):55-63.

Cui J, Yang Y, Zhang C, et al. FBI-1 functions as a novel AR co-repressor in prostate cancer cells. Cellular and molecular life sciences : CMLS. 2011;68(6):1091-1103.

Demers C, Chaturvedi CP, Ranish JA, et al. Activator-mediated recruitment of the MLL2 methyltransferase complex to the beta-globin locus. Molecular cell. 2007;27(4):573-584.

DeRan M, Pulvino M, Greene E, Su C, Zhao J. Transcriptional activation of histone genes requires NPAT-dependent recruitment of TRRAP-Tip60 complex to histone promoters during the G1/S phase transition. Molecular and cellular biology. 2008;28(1):435-447.

Dimopoulou M, Verhoef A, van Ravenzwaay B, Rietjens IM, Piersma AH. Flusilazole induces spatiotemporal expression patterns of retinoic acid-, differentiation- and sterol biosynthesis-related genes in the rat Whole Embryo Culture. Reproductive toxicology. 2016;64:77-85.

Doherty LF, Bromer JG, Zhou Y, Aldad TS, Taylor HS. In utero exposure to diethylstilbestrol (DES) or bisphenol-A (BPA) increases EZH2 expression in the mammary gland: an epigenetic mechanism linking endocrine disruptors to breast cancer. Horm Cancer. 2010;1:146-55.

Eudy JD, Yao S, Weston MD, et al. Isolation of a gene encoding a novel member of the nuclear receptor superfamily from the critical region of Usher syndrome type lla at 1q41. Genomics. 1998;50(3):382-384. 
Ewing B, Green P. Base-calling of automated sequencer traces using phred. II. Error probabilities. Genome research. 1998;8(3):186-194.

Fujita T, Kobayashi Y, Wada O, et al. Full activation of estrogen receptor alpha activation function-1 induces proliferation of breast cancer cells. The Journal of biological chemistry. 2003;278(29):2670426714.

Garattini E, Bolis M, Garattini SK, et al. Retinoids and breast cancer: from basic studies to the clinic and back again. Cancer treatment reviews. 2014;40(6):739-749.

Giguere V, Yang N, Segui P, Evans RM. Identification of a new class of steroid hormone receptors. Nature. 1988;331(6151):91-94.

Giusti RM, Iwamoto K, Hatch EE. Diethylstilbestrol revisited: a review of the long-term health effects. Annals of internal medicine. 1995;122(10):778-788.

Glass CK, Rosenfeld MG. The coregulator exchange in transcriptional functions of nuclear receptors. Genes \& development. 2000;14(2):121-141.

Gonzalez TL, Rae JM, Colacino JA, Richardson RJ. Homology models of mouse and rat estrogen receptor- $\alpha$ ligand-binding domain created by in silico mutagenesis of a human template: Molecular docking with $17 \beta$-estradiol, diethylstilbestrol, and paraben analogs. Computational Toxicology. 2019;10:1-16

Gupta C. The role of estrogen receptor, androgen receptor and growth factors in diethylstilbestrolinduced programming of prostate differentiation. Urological research. 2000;28(4):223-229.

Harris ME, Bohni R, Schneiderman MH, Ramamurthy L, Schumperli D, Marzluff WF. Regulation of histone mRNA in the unperturbed cell cycle: evidence suggesting control at two posttranscriptional steps. Molecular and cellular biology. 1991;11(5):2416-2424.

Heberle H, Meirelles GV, da Silva FR, Telles GP, Minghim R. InteractiVenn: a web-based tool for the analysis of sets through Venn diagrams. BMC bioinformatics. 2015;16:169.

Heisenberg CP, Houart C, Take-Uchi M, et al. A mutation in the Gsk3-binding domain of zebrafish Masterblind/Axin1 leads to a fate transformation of telencephalon and eyes to diencephalon. Genes \& development. 2001;15(11):1427-1434.

Hong $\mathrm{H}$, Yang L, Stallcup MR. Hormone-independent transcriptional activation and coactivator binding by novel orphan nuclear receptor ERR3. The Journal of biological chemistry. 1999;274(32):22618-22626.

Hsia EY, Goodson ML, Zou JX, Privalsky ML, Chen HW. Nuclear receptor coregulators as a new paradigm for therapeutic targeting. Advanced drug delivery reviews. 2010;62(13):1227-1237.

Hung HL, Kim AY, Hong W, Rakowski C, Blobel GA. Stimulation of NF-E2 DNA binding by CREB-binding protein (CBP)-mediated acetylation. The Journal of biological chemistry. 2001;276(14):10715-10721. 
IARC. A review of human carcinogens. Part A: Pharmaceuticals. IARC Working Group on the Evaluation of Carcinogenic Risks to Humans. International Agency for Research on Cancer, 2012 100:1-403.

Ichim G, Mola M, Finkbeiner MG, Cros MP, Herceg Z, Hernandez-Vargas H. The histone acetyltransferase component TRRAP is targeted for destruction during the cell cycle. Oncogene. 2014;33(2):181-192.

Jho EH, Zhang T, Domon C, Joo CK, Freund JN, Costantini F. Wnt/beta-catenin/Tcf signaling induces the transcription of Axin2, a negative regulator of the signaling pathway. Molecular and cellular biology. 2002;22(4):1172-1183.

Kalach JJ, Joly-Pharaboz MO, Chantepie J, et al. Divergent biological effects of estradiol and diethylstilbestrol in the prostate cancer cell line MOP. The Journal of steroid biochemistry and molecular biology. 2005;96(2):119-129.

Kam RK, Deng $\mathrm{Y}$, Chen $\mathrm{Y}$, Zhao $\mathrm{H}$. Retinoic acid synthesis and functions in early embryonic development. Cell \& bioscience. 2012;2(1):11.

Kamburov A, Pentchev K, Galicka H, Wierling C, Lehrach H, Herwig R. ConsensusPathDB: toward a more complete picture of cell biology. Nucleic acids research. 2011;39(Database issue):D712-717.

Kim HJ, Yi JY, Sung HS, et al. Activating signal cointegrator 1, a novel transcription coactivator of nuclear receptors, and its cytosolic localization under conditions of serum deprivation. Molecular and cellular biology. 1999;19(9):6323-6332.

Klinge CM. Estrogen receptor interaction with co-activators and co-repressors. Steroids. 2000;65(5):227-251.

Klotz DM, Hewitt SC, Korach KS, Diaugustine RP. Activation of a uterine insulin-like growth factor I signaling pathway by clinical and environmental estrogens: requirement of estrogen receptor-alpha. Endocrinology. 2000;141(9):3430-3439.

Lang SE, Hearing P. The adenovirus E1A oncoprotein recruits the cellular TRRAP/GCN5 histone acetyltransferase complex. Oncogene. 2003;22(18):2836-2841.

Lee SR, Ramos SM, Ko A, et al. AR and ER interaction with a p21-activated kinase (PAK6). Molecular endocrinology. 2002;16(1):85-99.

Lin CY, Strom A, Vega VB, et al. Discovery of estrogen receptor alpha target genes and response elements in breast tumor cells. Genome biology. 2004;5(9):R66.

Liu RZ, Garcia E, Glubrecht DD, Poon HY, Mackey JR, Godbout R. CRABP1 is associated with a poor prognosis in breast cancer: adding to the complexity of breast cancer cell response to retinoic acid. Molecular cancer. 2015;14:129. 
Liu X, Tesfai J, Evrard YA, Dent SY, Martinez E. c-Myc transformation domain recruits the human STAGA complex and requires TRRAP and GCN5 acetylase activity for transcription activation. The Journal of biological chemistry. 2003;278(22):20405-20412.

Loudig O, Babichuk C, White J, Abu-Abed S, Mueller C, Petkovich M. Cytochrome P450RAI(CYP26) promoter: a distinct composite retinoic acid response element underlies the complex regulation of retinoic acid metabolism. Molecular endocrinology. 2000;14(9):1483-1497.

Luijten M, van Beelen VA, Verhoef A, et al. Transcriptomics analysis of retinoic acid embryotoxicity in rat postimplantation whole embryo culture. Reproductive toxicology. 2010;30(2):333-340.

Lun AT, Chen Y, Smyth GK. It's DE-licious: A Recipe for Differential Expression Analyses of RNA-seq Experiments Using Quasi-Likelihood Methods in edgeR. Methods in molecular biology. 2016;1418:391-416.

Luo J, Sladek R, Bader JA, Matthyssen A, Rossant J, Giguere V. Placental abnormalities in mouse embryos lacking the orphan nuclear receptor ERR-beta. Nature. 1997;388(6644):778-782.

Mark M, Ghyselinck NB, Chambon P. Function of retinoic acid receptors during embryonic development. Nuclear receptor signaling. 2009;7:e002.

McCarthy DJ, Chen Y, Smyth GK. Differential expression analysis of multifactor RNA-Seq experiments with respect to biological variation. Nucleic acids research. 2012;40(10):4288-4297.

McCarthy DJ, Smyth GK. Testing significance relative to a fold-change threshold is a TREAT. Bioinformatics. 2009;25(6):765-771.

McKenna NJ, Lanz RB, O'Malley BW. Nuclear receptor coregulators: cellular and molecular biology. Endocrine reviews. 1999;20(3):321-344.

McMahon SB, Van Buskirk HA, Dugan KA, Copeland TD, Cole MD. The novel ATM-related protein TRRAP is an essential cofactor for the c-Myc and E2F oncoproteins. Cell. 1998;94(3):363-374.

Mo R, Rao SM, Zhu YJ. Identification of the MLL2 complex as a coactivator for estrogen receptor alpha. The Journal of biological chemistry. 2006;281(23):15714-15720.

Nagao T, Yoshimura S. Early embryonic losses in mice induced by diethylstilbestrol. Congenital anomalies. 2009;49(4):269-273.

Nam K, Marshall P, Wolf RM, Cornell W. Simulation of the different biological activities of diethylstilbestrol (DES) on estrogen receptor alpha and estrogen-related receptor gamma. Biopolymers. 2003;68(1):130-138.

Narita T, Yamaguchi Y, Yano K, et al. Human transcription elongation factor NELF: identification of novel subunits and reconstitution of the functionally active complex. Molecular and cellular biology. 2003;23(6):1863-1873. 
Newbold RR, Padilla-Banks E, Jefferson WN. Adverse effects of the model environmental estrogen diethylstilbestrol are transmitted to subsequent generations. Endocrinology. 2006;147(6 Suppl):S1117.

Nikov GN, Eshete M, Rajnarayanan RV, Alworth WL. Interactions of synthetic estrogens with human estrogen receptors. The Journal of endocrinology. 2001;170(1):137-145.

Okulicz WC, Johnson LD. The relative binding affinity of diethylstilbestrol to uterine nuclear estrogen receptor: effect of serum and serum albumin. Proceedings of the Society for Experimental Biology and Medicine Society for Experimental Biology and Medicine. 1987;185(4):478-483.

O'Malley BW, Kumar R. Nuclear receptor coregulators in cancer biology. Cancer research. 2009;69(21):8217-8222.

Palmer JR, Wise LA, Hatch EE, et al. Prenatal diethylstilbestrol exposure and risk of breast cancer. Cancer epidemiology, biomarkers \& prevention : a publication of the American Association for Cancer Research, cosponsored by the American Society of Preventive Oncology. 2006;15(8):15091514.

Patro R, Duggal G, Love MI, Irizarry RA, Kingsford C. Salmon provides fast and bias-aware quantification of transcript expression. Nature methods. 2017;14(4):417-419.

Prins GS, Birch L, Couse JF, Choi I, Katzenellenbogen B, Korach KS. Estrogen imprinting of the developing prostate gland is mediated through stromal estrogen receptor alpha: studies with alphaERKO and betaERKO mice. Cancer research. 2001;61(16):6089-6097.

Reed CE, Fenton SE. Exposure to diethylstilbestrol during sensitive life stages: a legacy of heritable health effects. Birth defects research Part C, Embryo today : reviews. 2013;99(2):134-146.

Rhinn M, Dolle P. Retinoic acid signalling during development. Development. 2012;139(5):843-858.

Robinson MD, McCarthy DJ, Smyth GK. edgeR: a Bioconductor package for differential expression analysis of digital gene expression data. Bioinformatics. 2010;26(1):139-140.

Robinson MD, Oshlack A. A scaling normalization method for differential expression analysis of RNAseq data. Genome biology. 2010;11(3):R25.

Robinson MD, Smyth GK. Moderated statistical tests for assessing differences in tag abundance. Bioinformatics. 2007;23(21):2881-2887.

Sato K, Fukata H, Kogo Y, Ohgane J, Shiota K, Mori C. Neonatal exposure to diethylstilbestrol alters expression of DNA methyltransferases and methylation of genomic DNA in the mouse uterus. Endocrine journal. 2009;56(1):131-139.

Shelby MD, Newbold RR, Tully DB, Chae K, Davis VL. Assessing environmental chemicals for estrogenicity using a combination of in vitro and in vivo assays. Environ Health Perspect. 1996;104(12):1296-1300. 
Soneson C, Love MI, Robinson MD. Differential analyses for RNA-seq: transcript-level estimates improve gene-level inferences. F1000Research. 2015;4:1521.

Sotoca AM, Van den Berg H, Vervoort J, et al. Influence of cellular ERalpha/ERbeta ratio on the ERalpha-agonist induced proliferation of human T47D breast cancer cells. Toxicological sciences : an official journal of the Society of Toxicology. 2008;105(2):303-311.

Subramaniam N, Treuter E, Okret S. Receptor interacting protein RIP140 inhibits both positive and negative gene regulation by glucocorticoids. The Journal of biological chemistry. 1999;274(25):18121-18127.

Sun J, Watkins G, Blair AL, et al. Deregulation of cofactor of BRCA1 expression in breast cancer cells. Journal of cellular biochemistry. 2008;103(6):1798-1807.

Tembe EA, Honeywell R, Buss NE, Renwick AG. All-trans-retinoic acid in maternal plasma and teratogenicity in rats and rabbits. Toxicology and applied pharmacology. 1996;141(2):456-472.

Thatcher JE, Isoherranen N. The role of CYP26 enzymes in retinoic acid clearance. Expert opinion on drug metabolism \& toxicology. 2009;5(8):875-886.

Thenot S, Henriquet C, Rochefort H, Cavailles V. Differential interaction of nuclear receptors with the putative human transcriptional coactivator hTIF1. Journal of Biological Chemistry. 1997;272(18):12062-12068.

Thomas C, Gustafsson JA. The different roles of ER subtypes in cancer biology and therapy. Nature reviews Cancer. 2011;11(8):597-608.

Titus-Ernstoff L, Hatch EE, Hoover RN, et al. Long-term cancer risk in women given diethylstilbestrol (DES) during pregnancy. British journal of cancer. 2001;84(1):126-133.

Turton JA, Willars GB, Haselden JN, Ward SJ, Steele CE, Hicks RM. Comparative teratogenicity of nine retinoids in the rat. International journal of experimental pathology. 1992;73(5):551-563.

Vanacker JM, Bonnelye E, Chopin-Delannoy S, Delmarre C, Cavailles V, Laudet V. Transcriptional activities of the orphan nuclear receptor ERR alpha (estrogen receptor-related receptor-alpha). Molecular endocrinology. 1999a;13(5):764-773.

Vanacker JM, Pettersson K, Gustafsson JA, Laudet V. Transcriptional targets shared by estrogen receptor- related receptors (ERRs) and estrogen receptor (ER) alpha, but not by ERbeta. The EMBO journal. 1999b;18(15):4270-4279.

Vincek AS, Patel J, Jaganathan A, et al. Inhibitor of CBP Histone Acetyltransferase Downregulates p53 Activation and Facilitates Methylation at Lysine 27 on Histone H3. Molecules. 2018;23(8).

Wang S, Houtman R, Melchers D, et al. A 155-plex high-throughput in vitro coregulator binding assay for (anti-)estrogenicity testing evaluated with 23 reference compounds. Altex. 2013;30(2):145-157. 
Wardell RE, Seegmiller RE, Bradshaw WS. Induction of prenatal toxicity in the rat by diethylstilbestrol, zeranol, 3,4,3',4',-tetrachlorobiphenyl, cadmium, and lead. Teratology. 1982;26(3):229-237.

Warita K, Mitsuhashi T, Sugawara T, et al. Direct effects of diethylstilbestrol on the gene expression of the cholesterol side-chain cleavage enzyme (P450scc) in testicular Leydig cells. Life sciences. 2010;87(9-10):281-285.

Willhite CC, Dawson MI, Reichert U. Receptor-selective retinoid agonists and teratogenic activity. Drug metabolism reviews. 1996;28(1-2):105-119.

Yamaguchi Y, Takagi T, Wada T, et al. NELF, a multisubunit complex containing RD, cooperates with DSIF to repress RNA polymerase II elongation. Cell. 1999;97(1):41-51.

Yang Y. Wnt signaling in development and disease. Cell \& bioscience. 2012;2(1):14.

Yoo HM, Kang SH, Kim JY, et al. Modification of ASC1 by UFM1 is crucial for ERalpha transactivation and breast cancer development. Molecular cell. 2014;56(2):261-274.

Yoon HG, Chan DW, Reynolds AB, Qin J, Wong J. N-CoR mediates DNA methylation-dependent repression through a methyl $C p G$ binding protein Kaiso. Molecular cell. 2003;12(3):723-734.

Zerbino DR, Achuthan P, Akanni W, et al. Ensembl 2018. Nucleic acids research. 2018;46(D1):D754D761.

Zhang $\mathrm{H}$, Yao Y, Chen Y, et al. Crosstalk between AhR and wnt/beta-catenin signal pathways in the cardiac developmental toxicity of PM2.5 in zebrafish embryos. Toxicology. 2016;355-356:31-38.

Zhang M, Siedow M, Saia G, Chakravarti A. Inhibition of p21-activated kinase 6 (PAK6) increases radiosensitivity of prostate cancer cells. The Prostate. 2010;70(8):807-816.

Zhao MH, Liang S, Kim NH, Cui XS. MLL2 is essential for porcine embryo development in vitro. In vitro cellular \& developmental biology Animal. 2016;52(6):699-704. 


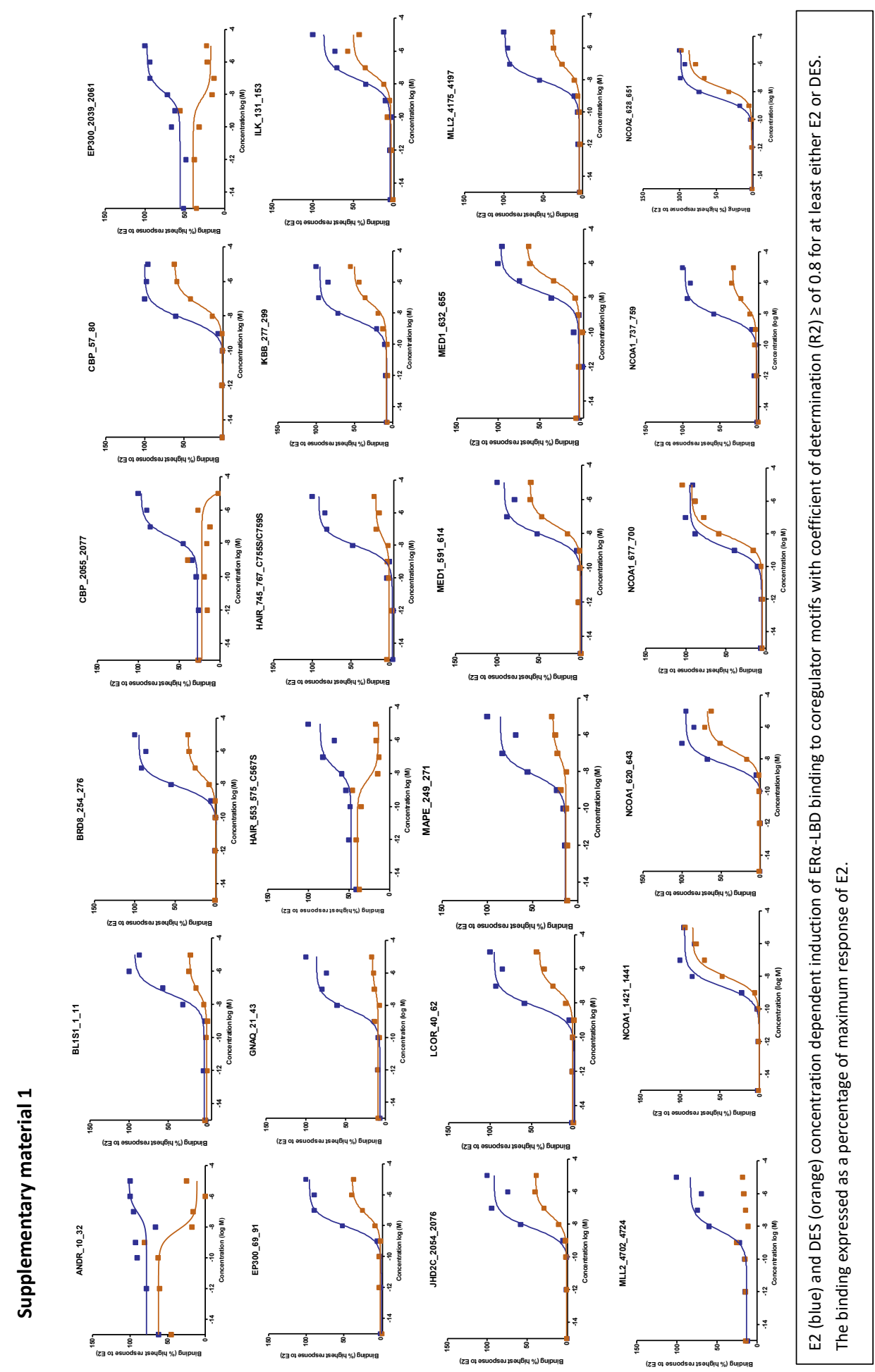




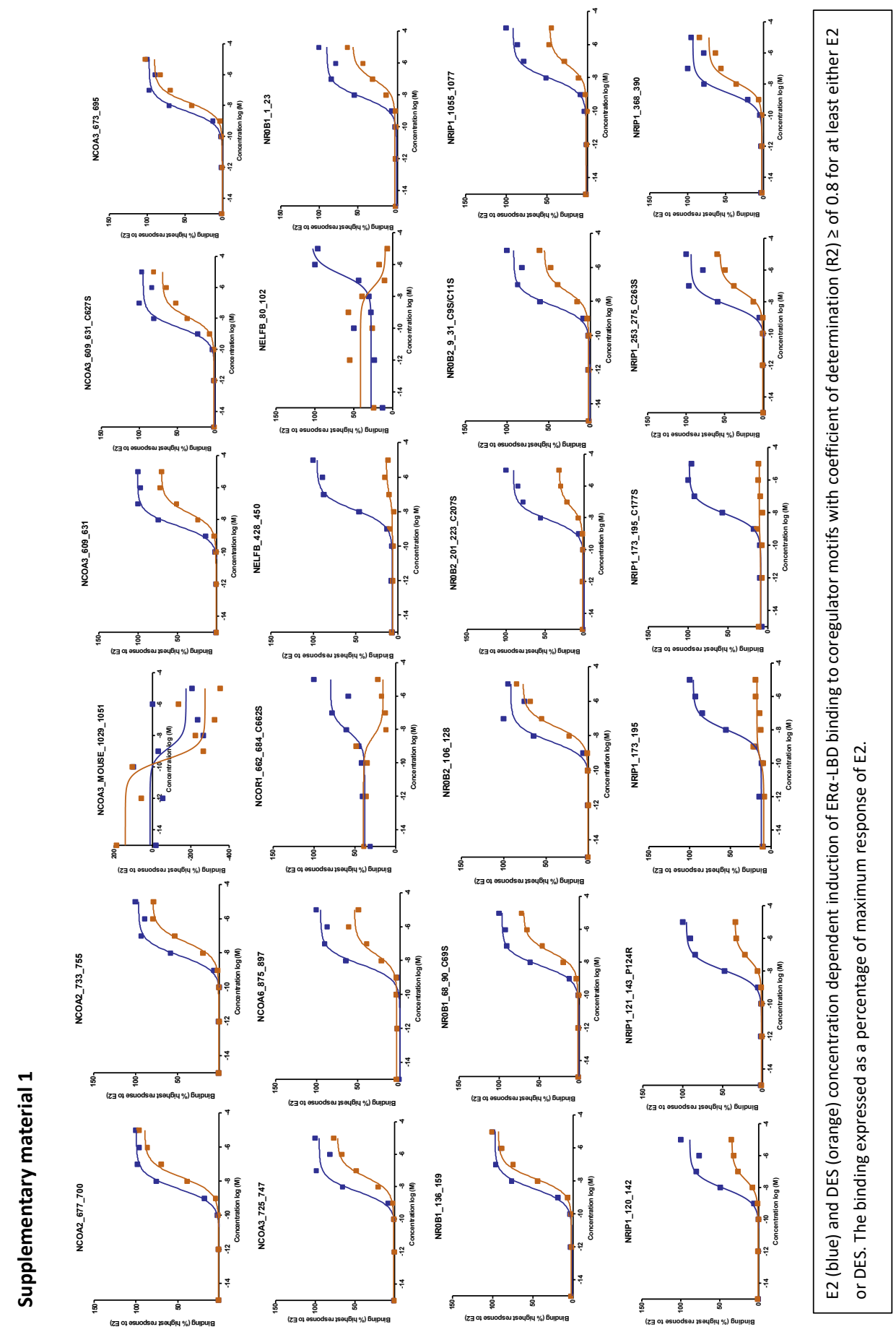




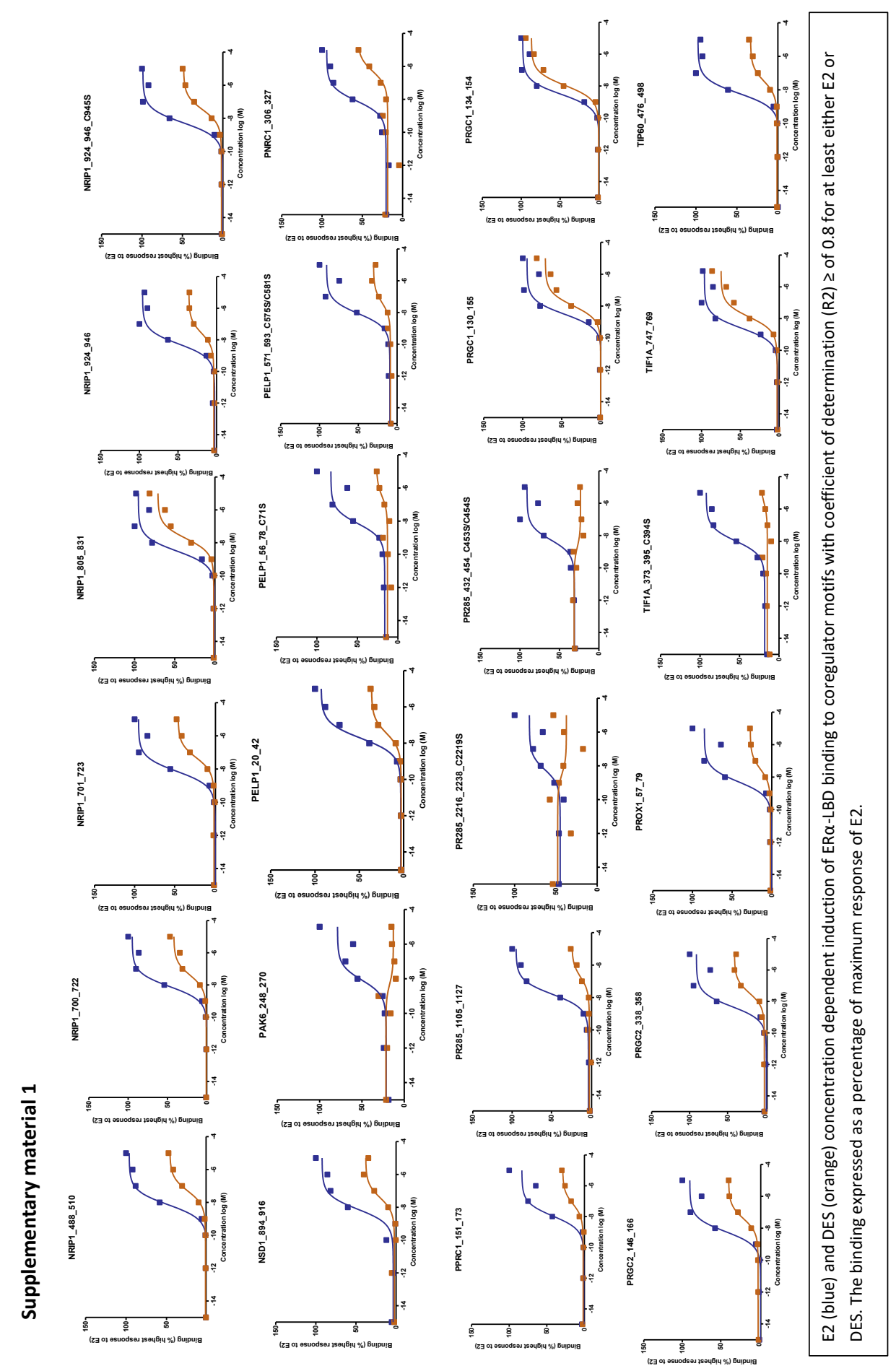




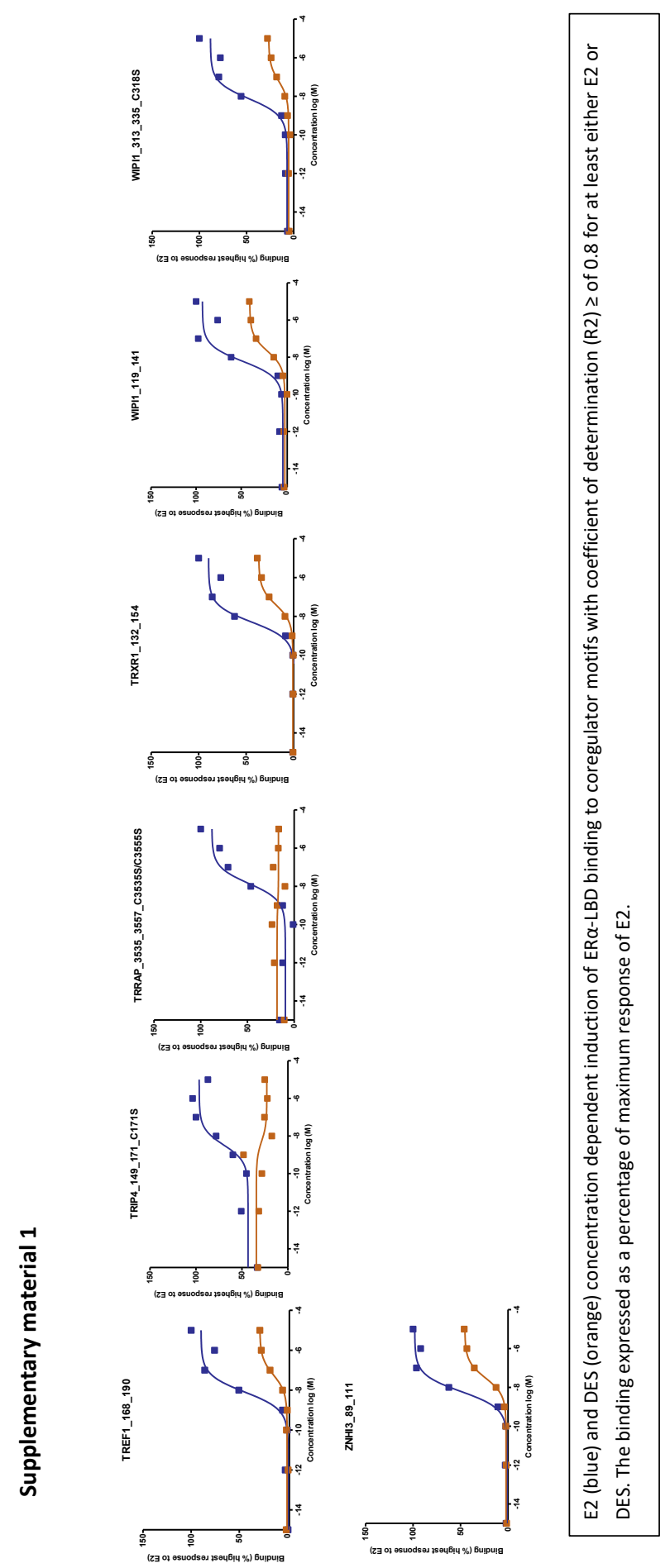




\section{Supplementary material $2 \quad$ Overrepresented GO-BP categories}

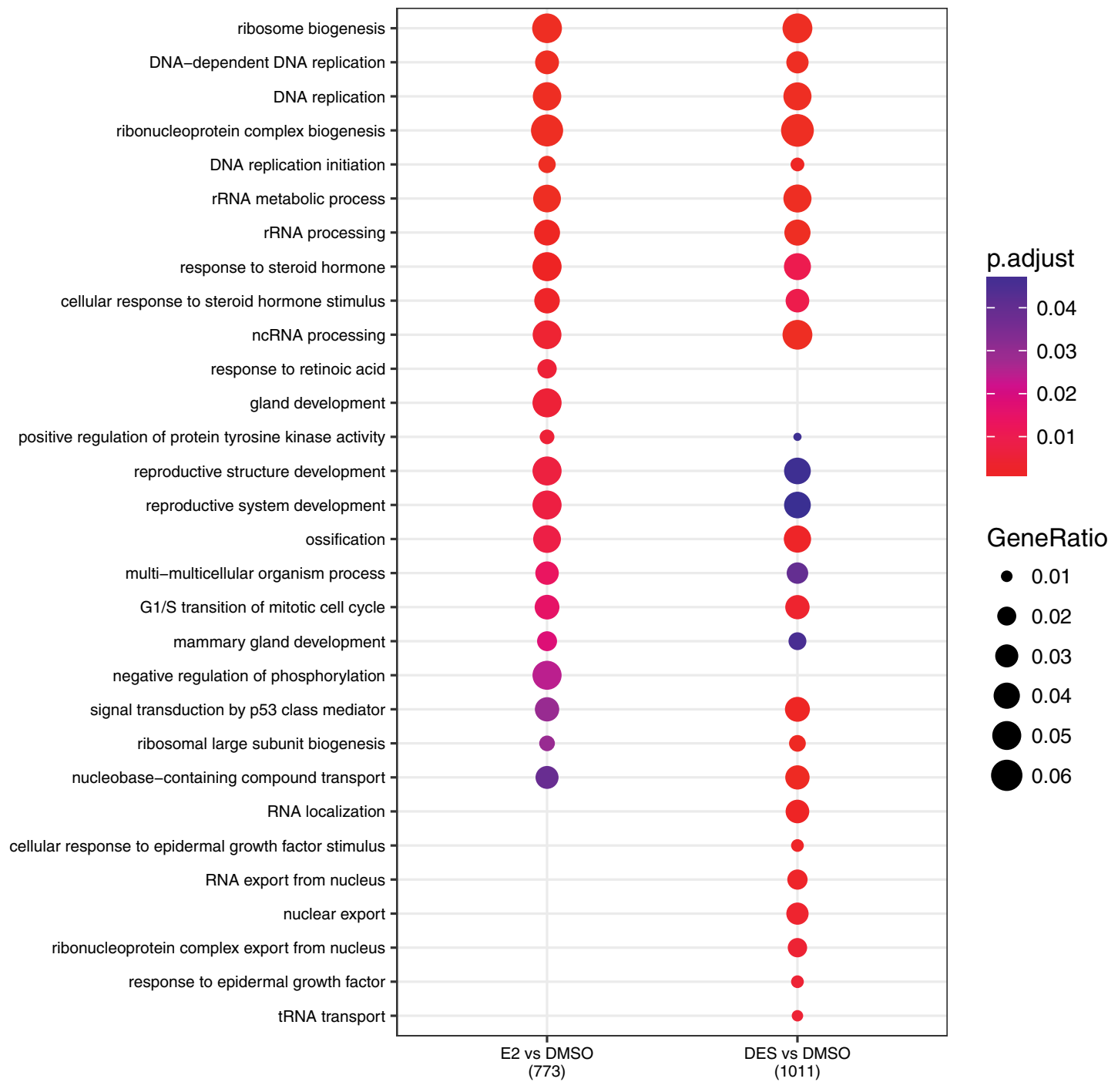




\section{Supplementary material 3}

Pathway analysis for the genes that expressed by E2 and DES

\begin{tabular}{|c|c|c|c|c|}
\hline Pathway name & $\begin{array}{l}\text { set } \\
\text { size }\end{array}$ & $\begin{array}{l}\text { candidates } \\
\text { contained }\end{array}$ & $\begin{array}{l}\text { p- } \\
\text { value }\end{array}$ & $\begin{array}{l}\text { pathway } \\
\text { source }\end{array}$ \\
\hline $\begin{array}{l}\text { Transcriptional regulation by the AP-2 (TFAP2) family of } \\
\text { transcription factors }\end{array}$ & 42 & $10(23.8 \%)$ & $\begin{array}{l}7.58 \mathrm{E} \\
-07\end{array}$ & Reactome \\
\hline Adipogenesis & 131 & $16(12.2 \%)$ & $\begin{array}{l}6.05 E \\
-06\end{array}$ & $\begin{array}{l}\text { Wikipath } \\
\text { ways }\end{array}$ \\
\hline Validated nuclear estrogen receptor alpha network & 65 & $11(16.9 \%)$ & $\begin{array}{l}7.67 \mathrm{E} \\
-06\end{array}$ & PID \\
\hline rRNA processing & 67 & $11(16.7 \%)$ & $\begin{array}{l}8.94 \mathrm{E} \\
-06\end{array}$ & Reactome \\
\hline rRNA modification in the nucleus and cytosol & 61 & $10(16.7 \%)$ & $\begin{array}{l}2.29 \mathrm{E} \\
-05 \\
\end{array}$ & Reactome \\
\hline rRNA processing in the nucleus and cytosol & 61 & $10(16.7 \%)$ & $\begin{array}{l}2.29 \mathrm{E} \\
-05\end{array}$ & Reactome \\
\hline Notch-mediated HES/HEY network & 51 & $9(17.6 \%)$ & $\begin{array}{l}3.67 E \\
-05\end{array}$ & PID \\
\hline HIF-1-alpha transcription factor network & 67 & $10(14.9 \%)$ & $\begin{array}{l}6.14 \mathrm{E} \\
-05 \\
\end{array}$ & PID \\
\hline RAF-independent MAPK1/3 activation & 23 & $6(26.1 \%)$ & $\begin{array}{l}7.63 E \\
-05 \\
\end{array}$ & Reactome \\
\hline TGF-beta Signaling Pathway & 132 & $14(10.6 \%)$ & $\begin{array}{l}0.000 \\
111 \\
\end{array}$ & $\begin{array}{l}\text { Wikipath } \\
\text { ways }\end{array}$ \\
\hline Aryl Hydrocarbon Receptor & 46 & $8(17.4 \%)$ & $\begin{array}{l}0.000 \\
111 \\
\end{array}$ & $\begin{array}{l}\text { Wikipath } \\
\text { ways }\end{array}$ \\
\hline ID signaling pathway & 16 & $5(31.2 \%)$ & $\begin{array}{l}0.000 \\
121\end{array}$ & $\begin{array}{l}\text { Wikipath } \\
\text { ways }\end{array}$ \\
\hline $\begin{array}{l}\text { TFAP2 (AP-2) family regulates transcription of growth factors } \\
\text { and their receptors }\end{array}$ & 16 & $5(31.2 \%)$ & $\begin{array}{l}0.000 \\
121\end{array}$ & Reactome \\
\hline $\begin{array}{l}\text { TFAP2 (AP-2) family regulates transcription of other } \\
\text { transcription factors }\end{array}$ & 4 & $3(75.0 \%)$ & $\begin{array}{l}0.000 \\
138\end{array}$ & Reactome \\
\hline HIF-2-alpha transcription factor network & 36 & $7(19.4 \%)$ & $\begin{array}{l}0.000 \\
144\end{array}$ & PID \\
\hline Notch Signaling Pathway & 61 & $9(14.8 \%)$ & $\begin{array}{l}0.000 \\
157\end{array}$ & $\begin{array}{l}\text { Wikipath } \\
\text { ways }\end{array}$ \\
\hline ID & 26 & $6(23.1 \%)$ & $\begin{array}{l}0.000 \\
16 \\
\end{array}$ & NetPath \\
\hline Ectoderm Differentiation & 142 & $14(9.9 \%)$ & $\begin{array}{l}0.000 \\
241 \\
\end{array}$ & $\begin{array}{l}\text { Wikipath } \\
\text { ways }\end{array}$ \\
\hline Transcriptional activity of SMAD2-SMAD3-SMAD4 heterotrimer & 5 & $3(60.0 \%)$ & $\begin{array}{l}0.000 \\
336 \\
\end{array}$ & $\begin{array}{l}\text { Wikipath } \\
\text { ways }\end{array}$ \\
\hline TFAP2 (AP-2) family regulates transcription of cell cycle factors & 5 & $3(60.0 \%)$ & $\begin{array}{l}0.000 \\
336 \\
\end{array}$ & Reactome \\
\hline G1 to $S$ cell cycle control & 68 & $9(13.2 \%)$ & $\begin{array}{l}0.000 \\
363\end{array}$ & $\begin{array}{l}\text { Wikipath } \\
\text { ways }\end{array}$ \\
\hline TGF-beta signaling pathway - Homo sapiens (human) & 84 & $10(11.9 \%)$ & $\begin{array}{l}0.000 \\
416 \\
\end{array}$ & KEGG \\
\hline Bladder Cancer & 31 & $6(19.4 \%)$ & $\begin{array}{l}0.000 \\
446 \\
\end{array}$ & $\begin{array}{l}\text { Wikipath } \\
\text { ways }\end{array}$ \\
\hline IL17 signaling pathway & 31 & $6(19.4 \%)$ & $\begin{array}{l}0.000 \\
446\end{array}$ & $\begin{array}{l}\text { Wikipath } \\
\text { ways }\end{array}$ \\
\hline Activation of the TFAP2 (AP-2) family of transcription factors & 13 & $4(30.8 \%)$ & $\begin{array}{l}0.000 \\
65\end{array}$ & Reactome \\
\hline Signaling by NOTCH1 & 6 & $3(50.0 \%)$ & $\begin{array}{l}0.000 \\
655\end{array}$ & $\begin{array}{l}\text { Wikipath } \\
\text { ways }\end{array}$ \\
\hline
\end{tabular}




\begin{tabular}{|c|c|c|c|c|}
\hline Nuclear Receptors Meta-Pathway & 316 & $22(7.0 \%)$ & $\begin{array}{l}0.000 \\
767\end{array}$ & $\begin{array}{l}\text { Wikipath } \\
\text { ways }\end{array}$ \\
\hline Mitotic G1-G1/S phases & 92 & $10(10.9 \%)$ & $\begin{array}{l}0.000 \\
86\end{array}$ & Reactome \\
\hline $\begin{array}{l}\text { TGF-B Signaling in Thyroid Cells for Epithelial-Mesenchymal } \\
\text { Transition }\end{array}$ & 14 & $4(28.6 \%)$ & $\begin{array}{l}0.000 \\
886\end{array}$ & $\begin{array}{l}\text { Wikipath } \\
\text { ways }\end{array}$ \\
\hline IL6-mediated signaling events & 48 & $7(14.6 \%)$ & $\begin{array}{l}0.000 \\
905\end{array}$ & PID \\
\hline tumor suppressor arf inhibits ribosomal biogenesis & 24 & $5(20.8 \%)$ & $\begin{array}{l}0.000 \\
95\end{array}$ & BioCarta \\
\hline Breast cancer - Homo sapiens (human) & 146 & $13(8.9 \%)$ & $\begin{array}{l}0.001 \\
05\end{array}$ & KEGG \\
\hline Vitamin D Receptor Pathway & 184 & $15(8.2 \%)$ & $\begin{array}{l}0.001 \\
05\end{array}$ & $\begin{array}{l}\text { Wikipath } \\
\text { ways }\end{array}$ \\
\hline $\begin{array}{l}\text { TFAP2A acts as a transcriptional repressor during retinoic acid } \\
\text { induced cell differentiation }\end{array}$ & 7 & $3(42.9 \%)$ & $\begin{array}{l}0.001 \\
12\end{array}$ & Reactome \\
\hline Hepatitis C and Hepatocellular Carcinoma & 50 & $7(14.0 \%)$ & $\begin{array}{l}0.001 \\
16\end{array}$ & $\begin{array}{l}\text { Wikipath } \\
\text { ways }\end{array}$ \\
\hline Pancreatic cancer - Homo sapiens (human) & 66 & $8(12.1 \%)$ & $\begin{array}{l}0.001 \\
38\end{array}$ & KEGG \\
\hline Oncostatin_M & 39 & $6(15.4 \%)$ & $\begin{array}{l}0.001 \\
58\end{array}$ & NetPath \\
\hline Hippo signaling pathway - Homo sapiens (human) & 154 & $13(8.5 \%)$ & $\begin{array}{l}0.001 \\
61\end{array}$ & KEGG \\
\hline Spinal Cord Injury & 117 & $11(9.4 \%)$ & $\begin{array}{l}0.001 \\
62\end{array}$ & $\begin{array}{l}\text { Wikipath } \\
\text { ways }\end{array}$ \\
\hline Ribosome biogenesis in eukaryotes - Homo sapiens (human) & 106 & $10(10.0 \%)$ & $\begin{array}{l}0.001 \\
64 \\
\end{array}$ & KEGG \\
\hline Neural Crest Differentiation & 101 & $10(9.9 \%)$ & $\begin{array}{l}0.001 \\
77\end{array}$ & $\begin{array}{l}\text { Wikipath } \\
\text { ways }\end{array}$ \\
\hline Constitutive Signaling by NOTCH1 HD+PEST Domain Mutants & 54 & $7(13.0 \%)$ & $\begin{array}{l}0.001 \\
84\end{array}$ & Reactome \\
\hline Signaling by NOTCH1 HD+PEST Domain Mutants in Cancer & 54 & $7(13.0 \%)$ & $\begin{array}{l}0.001 \\
84\end{array}$ & Reactome \\
\hline Signaling by NOTCH1 in Cancer & 54 & $7(13.0 \%)$ & $\begin{array}{l}0.001 \\
84\end{array}$ & Reactome \\
\hline Constitutive Signaling by NOTCH1 PEST Domain Mutants & 54 & $7(13.0 \%)$ & $\begin{array}{l}0.001 \\
84\end{array}$ & Reactome \\
\hline Signaling by NOTCH1 PEST Domain Mutants in Cancer & 54 & $7(13.0 \%)$ & $\begin{array}{l}0.001 \\
84\end{array}$ & Reactome \\
\hline Bladder cancer - Homo sapiens (human) & 41 & $6(14.6 \%)$ & $\begin{array}{l}0.002 \\
06\end{array}$ & KEGG \\
\hline Endoderm Differentiation & 71 & $8(11.3 \%)$ & $\begin{array}{l}0.002 \\
22\end{array}$ & $\begin{array}{l}\text { Wikipath } \\
\text { ways }\end{array}$ \\
\hline Glucocorticoid Receptor Pathway & 71 & $8(11.3 \%)$ & $\begin{array}{l}0.002 \\
22\end{array}$ & $\begin{array}{l}\text { Wikipath } \\
\text { ways }\end{array}$ \\
\hline $\begin{array}{l}\text { regulation of map kinase pathways through dual specificity } \\
\text { phosphatases }\end{array}$ & 9 & $3(33.3 \%)$ & $\begin{array}{l}0.002 \\
56\end{array}$ & BioCarta \\
\hline Interleukin-11 Signaling Pathway & 44 & $6(13.6 \%)$ & $\begin{array}{l}0.002 \\
98\end{array}$ & $\begin{array}{l}\text { Wikipath } \\
\text { ways }\end{array}$ \\
\hline Pathways in cancer - Homo sapiens (human) & 397 & $24(6.0 \%)$ & $\begin{array}{l}0.003 \\
06\end{array}$ & KEGG \\
\hline Validated targets of C-MYC transcriptional repression & 75 & $8(10.7 \%)$ & $\begin{array}{l}0.003 \\
14\end{array}$ & PID \\
\hline $\begin{array}{l}\text { Mammary gland development pathway - Involution (Stage } 4 \text { of } \\
\text { 4) }\end{array}$ & 10 & $3(30.0 \%)$ & $\begin{array}{l}0.003 \\
56\end{array}$ & $\begin{array}{l}\text { Wikipath } \\
\text { ways }\end{array}$ \\
\hline
\end{tabular}




\begin{tabular}{|c|c|c|c|c|}
\hline ATF-2 transcription factor network & 61 & $7(11.5 \%)$ & $\begin{array}{l}0.003 \\
72\end{array}$ & PID \\
\hline Aryl Hydrocarbon Receptor Pathway & 46 & $6(13.0 \%)$ & $\begin{array}{l}0.003 \\
74\end{array}$ & $\begin{array}{l}\text { Wikipath } \\
\text { ways }\end{array}$ \\
\hline Osteoclast differentiation - Homo sapiens (human) & 132 & $11(8.4 \%)$ & $\begin{array}{l}0.003 \\
93\end{array}$ & KEGG \\
\hline Regulation of nuclear SMAD2/3 signaling & 79 & $8(10.3 \%)$ & 0.004 & PID \\
\hline Integrated Pancreatic Cancer Pathway & 170 & $13(7.6 \%)$ & $\begin{array}{l}0.004 \\
05\end{array}$ & $\begin{array}{l}\text { Wikipath } \\
\text { ways }\end{array}$ \\
\hline NOTCH1 Intracellular Domain Regulates Transcription & 48 & $6(12.5 \%)$ & $\begin{array}{l}0.004 \\
64\end{array}$ & Reactome \\
\hline Interleukin-6 signaling & 11 & $3(27.3 \%)$ & $\begin{array}{l}0.004 \\
78\end{array}$ & Reactome \\
\hline VEGFA-VEGFR2 Signaling Pathway & 236 & $16(6.8 \%)$ & 0.005 & $\begin{array}{l}\text { Wikipath } \\
\text { ways }\end{array}$ \\
\hline HTLV-I infection - Homo sapiens (human) & 258 & $17(6.6 \%)$ & $\begin{array}{l}0.005 \\
14\end{array}$ & KEGG \\
\hline Oncostatin M Signaling Pathway & 65 & $7(10.8 \%)$ & $\begin{array}{l}0.005 \\
31\end{array}$ & $\begin{array}{l}\text { Wikipath } \\
\text { ways }\end{array}$ \\
\hline rac1 cell motility signaling pathway & 38 & $5(13.9 \%)$ & $\begin{array}{l}0.006 \\
1 \\
\end{array}$ & BioCarta \\
\hline Adenosine $\mathrm{P} 1$ receptors & 4 & $2(50.0 \%)$ & $\begin{array}{l}0.006 \\
19\end{array}$ & Reactome \\
\hline cyclins and cell cycle regulation & 23 & $4(17.4 \%)$ & $\begin{array}{l}0.006 \\
21\end{array}$ & BioCarta \\
\hline Nuclear Receptor transcription pathway & 51 & $6(11.8 \%)$ & $\begin{array}{l}0.006 \\
28\end{array}$ & Reactome \\
\hline Cell Cycle & 103 & $9(8.7 \%)$ & $\begin{array}{l}0.006 \\
77\end{array}$ & $\begin{array}{l}\text { Wikipath } \\
\text { ways }\end{array}$ \\
\hline IL2 signaling events mediated by PI3K & 37 & $5(13.5 \%)$ & $\begin{array}{l}0.006 \\
86\end{array}$ & PID \\
\hline $\begin{array}{l}\text { Signaling pathways regulating pluripotency of stem cells - Homo } \\
\text { sapiens (human) }\end{array}$ & 142 & $11(7.7 \%)$ & $\begin{array}{l}0.007 \\
18\end{array}$ & KEGG \\
\hline Small cell lung cancer - Homo sapiens (human) & 86 & $8(9.3 \%)$ & $\begin{array}{l}0.007 \\
23\end{array}$ & KEGG \\
\hline Physiological and Pathological Hypertrophy of the Heart & 24 & $4(16.7 \%)$ & $\begin{array}{l}0.007 \\
26\end{array}$ & $\begin{array}{l}\text { Wikipath } \\
\text { ways }\end{array}$ \\
\hline $\begin{array}{l}\text { mechanism of gene regulation by peroxisome proliferators via } \\
\text { ppara }\end{array}$ & 53 & $6(11.3 \%)$ & $\begin{array}{l}0.007 \\
57\end{array}$ & BioCarta \\
\hline Nuclear Receptors & 38 & $5(13.2 \%)$ & $\begin{array}{l}0.007 \\
7\end{array}$ & $\begin{array}{l}\text { Wikipath } \\
\text { ways }\end{array}$ \\
\hline Cell cycle - Homo sapiens (human) & 124 & $10(8.1 \%)$ & $\begin{array}{l}0.007 \\
72\end{array}$ & KEGG \\
\hline Proteoglycans in cancer - Homo sapiens (human) & 205 & $14(6.8 \%)$ & $\begin{array}{l}0.007 \\
85\end{array}$ & KEGG \\
\hline Estrogen Receptor Pathway & 13 & $3(23.1 \%)$ & $\begin{array}{l}0.007 \\
89\end{array}$ & $\begin{array}{l}\text { Wikipath } \\
\text { ways }\end{array}$ \\
\hline melatonin degradation I & 13 & $3(23.1 \%)$ & $\begin{array}{l}0.007 \\
89\end{array}$ & $\begin{array}{l}\text { HumanCy } \\
\text { c }\end{array}$ \\
\hline NOTCH2 intracellular domain regulates transcription & 13 & $3(23.1 \%)$ & $\begin{array}{l}0.007 \\
89\end{array}$ & Reactome \\
\hline G1/S Transition & 70 & $7(10.0 \%)$ & $\begin{array}{l}0.007 \\
96\end{array}$ & Reactome \\
\hline IL-7 Signaling Pathway & 25 & $4(16.0 \%)$ & $\begin{array}{l}0.008 \\
42\end{array}$ & $\begin{array}{l}\text { Wikipath } \\
\text { ways }\end{array}$ \\
\hline
\end{tabular}




\begin{tabular}{|c|c|c|c|c|}
\hline Alpha9 beta1 integrin signaling events & 25 & $4(16.0 \%)$ & $\begin{array}{l}0.008 \\
42 \\
\end{array}$ & PID \\
\hline cell cycle: g1/s check point & 25 & $4(16.0 \%)$ & $\begin{array}{l}0.008 \\
42\end{array}$ & BioCarta \\
\hline segmentation clock & 25 & $4(16.0 \%)$ & $\begin{array}{l}0.008 \\
42\end{array}$ & BioCarta \\
\hline AP-1 transcription factor network & 71 & $7(9.9 \%)$ & $\begin{array}{l}0.008 \\
59 \\
\end{array}$ & PID \\
\hline Signaling by NOTCH & 108 & $9(8.4 \%)$ & $\begin{array}{l}0.008 \\
63 \\
\end{array}$ & Reactome \\
\hline Generic Transcription Pathway & 861 & $41(4.8 \%)$ & $\begin{array}{l}0.009 \\
58 \\
\end{array}$ & Reactome \\
\hline superpathway of melatonin degradation & 14 & $3(21.4 \%)$ & $\begin{array}{l}0.009 \\
8\end{array}$ & $\begin{array}{l}\text { HumanCy } \\
\text { c }\end{array}$ \\
\hline Notch signaling pathway & 57 & $6(10.7 \%)$ & $\begin{array}{l}0.009 \\
87\end{array}$ & PID \\
\hline Signaling by NOTCH1 & 74 & $7(9.6 \%)$ & $\begin{array}{l}0.009 \\
95 \\
\end{array}$ & Reactome \\
\hline Sulindac Metabolic Pathway & 5 & $2(40.0 \%)$ & $\begin{array}{l}0.010 \\
1 \\
\end{array}$ & $\begin{array}{l}\text { Wikipath } \\
\text { ways }\end{array}$ \\
\hline GRB7 events in ERBB2 signaling & 5 & $2(40.0 \%)$ & $\begin{array}{l}0.010 \\
1 \\
\end{array}$ & Reactome \\
\hline miR-517 relationship with ARCN1 and USP1 & 5 & $2(40.0 \%)$ & $\begin{array}{l}0.010 \\
1 \\
\end{array}$ & $\begin{array}{l}\text { Wikipath } \\
\text { ways }\end{array}$ \\
\hline Transcriptional regulation of pluripotent stem cells & 5 & $2(40.0 \%)$ & $\begin{array}{l}0.010 \\
1 \\
\end{array}$ & $\begin{array}{l}\text { Wikipath } \\
\text { ways }\end{array}$ \\
\hline tRNA modification in the mitochondrion & 5 & $2(40.0 \%)$ & $\begin{array}{l}0.010 \\
1 \\
\end{array}$ & Reactome \\
\hline DNA Damage Response (only ATM dependent) & 110 & $9(8.2 \%)$ & $\begin{array}{l}0.010 \\
3 \\
\end{array}$ & $\begin{array}{l}\text { Wikipath } \\
\text { ways }\end{array}$ \\
\hline EGF-Ncore & 57 & $6(10.5 \%)$ & $\begin{array}{l}0.010 \\
7 \\
\end{array}$ & Signalink \\
\hline Interleukin- 6 family signaling & 27 & $4(14.8 \%)$ & $\begin{array}{l}0.011 \\
1 \\
\end{array}$ & Reactome \\
\hline Canonical and Non-canonical Notch signaling & 27 & $4(14.8 \%)$ & $\begin{array}{l}0.011 \\
1 \\
\end{array}$ & $\begin{array}{l}\text { Wikipath } \\
\text { ways }\end{array}$ \\
\hline Signaling by Interleukins & 373 & $21(5.6 \%)$ & $\begin{array}{l}0.011 \\
4 \\
\end{array}$ & Reactome \\
\hline $\begin{array}{l}\text { inactivation of gsk3 by akt causes accumulation of b-catenin in } \\
\text { alveolar macrophages }\end{array}$ & 42 & $5(11.9 \%)$ & $\begin{array}{l}0.011 \\
7\end{array}$ & BioCarta \\
\hline IL-2 Signaling Pathway & 42 & $5(11.9 \%)$ & $\begin{array}{l}0.011 \\
7\end{array}$ & $\begin{array}{l}\text { Wikipath } \\
\text { ways }\end{array}$ \\
\hline Integrated Cancer Pathway & 15 & $3(20.0 \%)$ & 0.012 & $\begin{array}{l}\text { Wikipath } \\
\text { ways }\end{array}$ \\
\hline ErbB receptor signaling network & 15 & $3(20.0 \%)$ & 0.012 & PID \\
\hline Mesodermal Commitment Pathway & 153 & $11(7.2 \%)$ & $\begin{array}{l}0.012 \\
2 \\
\end{array}$ & $\begin{array}{l}\text { Wikipath } \\
\text { ways }\end{array}$ \\
\hline Reelin signaling pathway & 28 & $4(14.3 \%)$ & $\begin{array}{l}0.012 \\
6\end{array}$ & PID \\
\hline TGF_beta_Receptor & 176 & $12(6.9 \%)$ & $\begin{array}{l}0.012 \\
9\end{array}$ & NetPath \\
\hline IL-6 signaling pathway & 43 & $5(11.6 \%)$ & $\begin{array}{l}0.012 \\
9\end{array}$ & $\begin{array}{l}\text { Wikipath } \\
\text { ways }\end{array}$ \\
\hline Signaling by PDGF & 331 & $19(5.8 \%)$ & $\begin{array}{l}0.012 \\
9\end{array}$ & Reactome \\
\hline
\end{tabular}




\begin{tabular}{|c|c|c|c|c|}
\hline Axon guidance - Homo sapiens (human) & 177 & $12(6.8 \%)$ & $\begin{array}{l}0.013 \\
5\end{array}$ & KEGG \\
\hline Cyclin E associated events during G1/S transition & 29 & $4(13.8 \%)$ & $\begin{array}{l}0.014 \\
3\end{array}$ & Reactome \\
\hline $\begin{array}{l}\text { Amplification and Expansion of Oncogenic Pathways as } \\
\text { Metastatic Traits }\end{array}$ & 16 & $3(18.8 \%)$ & $\begin{array}{l}0.014 \\
4\end{array}$ & $\begin{array}{l}\text { Wikipath } \\
\text { ways }\end{array}$ \\
\hline let-7 inhibition of ES cell reprogramming & 16 & $3(18.8 \%)$ & $\begin{array}{l}0.014 \\
4\end{array}$ & $\begin{array}{l}\text { Wikipath } \\
\text { ways }\end{array}$ \\
\hline Osteoclast Signaling & 16 & $3(18.8 \%)$ & $\begin{array}{l}0.014 \\
4\end{array}$ & $\begin{array}{l}\text { Wikipath } \\
\text { ways }\end{array}$ \\
\hline IL-6 signaling & 6 & $2(33.3 \%)$ & $\begin{array}{l}0.014 \\
8\end{array}$ & $\mathrm{INOH}$ \\
\hline deregulation of cdk5 in alzheimers disease & 6 & $2(33.3 \%)$ & $\begin{array}{l}0.014 \\
8\end{array}$ & BioCarta \\
\hline E2F transcription factor network & 79 & $7(8.9 \%)$ & 0.015 & PID \\
\hline Leptin & 62 & $6(9.7 \%)$ & $\begin{array}{l}0.015 \\
9\end{array}$ & NetPath \\
\hline p73 transcription factor network & 81 & $7(8.8 \%)$ & 0.016 & PID \\
\hline Dopaminergic Neurogenesis & 30 & $4(13.3 \%)$ & 0.016 & $\begin{array}{l}\text { Wikipath } \\
\text { ways }\end{array}$ \\
\hline Interleukin-3, 5 and GM-CSF signaling & 226 & $14(6.2 \%)$ & $\begin{array}{l}0.016 \\
8\end{array}$ & Reactome \\
\hline Proton Pump Inhibitor Pathway, Pharmacodynamics & 46 & $5(10.9 \%)$ & 0.017 & $\begin{array}{l}\text { PharmGK } \\
\text { B }\end{array}$ \\
\hline Endochondral Ossification & 64 & $6(9.5 \%)$ & $\begin{array}{l}0.017 \\
1\end{array}$ & $\begin{array}{l}\text { Wikipath } \\
\text { ways }\end{array}$ \\
\hline Signaling by EGFR & 319 & $18(5.7 \%)$ & $\begin{array}{l}0.017 \\
9\end{array}$ & Reactome \\
\hline MAPK1/MAPK3 signaling & 206 & $13(6.3 \%)$ & 0.018 & Reactome \\
\hline Wnt Signaling Pathway and Pluripotency & 101 & $8(7.9 \%)$ & 0.018 & $\begin{array}{l}\text { Wikipath } \\
\text { ways }\end{array}$ \\
\hline Presenilin action in Notch and Wnt signaling & 47 & $5(10.6 \%)$ & $\begin{array}{l}0.018 \\
5\end{array}$ & PID \\
\hline Heart Development & 47 & $5(10.6 \%)$ & $\begin{array}{l}0.018 \\
5\end{array}$ & $\begin{array}{l}\text { Wikipath } \\
\text { ways }\end{array}$ \\
\hline Signaling by Leptin & 208 & $13(6.3 \%)$ & $\begin{array}{l}0.019 \\
4\end{array}$ & Reactome \\
\hline TarBasePathway & 18 & $3(16.7 \%)$ & $\begin{array}{l}0.019 \\
9\end{array}$ & $\begin{array}{l}\text { Wikipath } \\
\text { ways }\end{array}$ \\
\hline Monoamine Transport & 32 & $4(12.5 \%)$ & 0.02 & $\begin{array}{l}\text { Wikipath } \\
\text { ways }\end{array}$ \\
\hline wnt signaling pathway & 32 & $4(12.5 \%)$ & 0.02 & BioCarta \\
\hline White fat cell differentiation & 32 & $4(12.5 \%)$ & 0.02 & $\begin{array}{l}\text { Wikipath } \\
\text { ways }\end{array}$ \\
\hline miR-148a-miR-31-FIH1-HIF1Ît-Notch signaling in glioblastoma & 7 & $2(28.6 \%)$ & $\begin{array}{l}0.020 \\
3 \\
\end{array}$ & $\begin{array}{l}\text { Wikipath } \\
\text { ways }\end{array}$ \\
\hline Interleukin receptor SHC signaling & 210 & $13(6.2 \%)$ & $\begin{array}{l}0.020 \\
8\end{array}$ & Reactome \\
\hline Wnt Signaling Pathway & 66 & $6(9.1 \%)$ & 0.021 & $\begin{array}{l}\text { Wikipath } \\
\text { ways }\end{array}$ \\
\hline Renal cell carcinoma - Homo sapiens (human) & 67 & $6(9.1 \%)$ & 0.021 & KEGG \\
\hline NHR & 49 & $5(10.2 \%)$ & $\begin{array}{l}0.021 \\
8\end{array}$ & Signalink \\
\hline Signaling by NOTCH2 & 33 & $4(12.1 \%)$ & 0.022 & Reactome \\
\hline
\end{tabular}




\begin{tabular}{|c|c|c|c|c|}
\hline & & & 2 & \\
\hline EPHA forward signaling & 33 & $4(12.1 \%)$ & $\begin{array}{l}0.022 \\
2\end{array}$ & PID \\
\hline EGFR Inhibitor Pathway, Pharmacodynamics & 67 & $6(9.0 \%)$ & $\begin{array}{l}0.022 \\
5\end{array}$ & $\begin{array}{l}\text { PharmGK } \\
\text { B }\end{array}$ \\
\hline Rac1-Pak1-p38-MMP-2 pathway & 67 & $6(9.0 \%)$ & $\begin{array}{l}0.022 \\
5\end{array}$ & $\begin{array}{l}\text { Wikipath } \\
\text { ways }\end{array}$ \\
\hline VEGFR2 mediated cell proliferation & 213 & $13(6.1 \%)$ & 0.023 & Reactome \\
\hline Phase 4 - resting membrane potential & 19 & $3(15.8 \%)$ & $\begin{array}{l}0.023 \\
1\end{array}$ & Reactome \\
\hline VEGFA-VEGFR2 Pathway & 282 & $16(5.7 \%)$ & $\begin{array}{l}0.023 \\
5\end{array}$ & Reactome \\
\hline EPHA-mediated growth cone collapse & 34 & $4(11.8 \%)$ & $\begin{array}{l}0.024 \\
5\end{array}$ & Reactome \\
\hline $\begin{array}{l}\text { Resolution of D-loop Structures through Holliday Junction } \\
\text { Intermediates }\end{array}$ & 35 & $4(11.8 \%)$ & $\begin{array}{l}0.024 \\
5\end{array}$ & Reactome \\
\hline Downstream signal transduction & 307 & $17(5.6 \%)$ & $\begin{array}{l}0.024 \\
6\end{array}$ & Reactome \\
\hline TP53 Regulates Transcription of Cell Cycle Genes & 51 & $5(9.8 \%)$ & $\begin{array}{l}0.025 \\
5\end{array}$ & Reactome \\
\hline Interleukin-2 signaling & 217 & $13(6.0 \%)$ & $\begin{array}{l}0.026 \\
3\end{array}$ & Reactome \\
\hline $\begin{array}{l}\text { Synthesis of epoxy (EET) and dihydroxyeicosatrienoic acids } \\
\text { (DHET) }\end{array}$ & 8 & $2(25.0 \%)$ & $\begin{array}{l}0.026 \\
5\end{array}$ & Reactome \\
\hline Interleukin-17 signaling & 8 & $2(25.0 \%)$ & $\begin{array}{l}0.026 \\
5\end{array}$ & Reactome \\
\hline IL-6-type cytokine receptor ligand interactions & 20 & $3(15.0 \%)$ & $\begin{array}{l}0.026 \\
5\end{array}$ & Reactome \\
\hline MAPK family signaling cascades & 240 & $14(5.9 \%)$ & $\begin{array}{l}0.026 \\
6\end{array}$ & Reactome \\
\hline Androgen receptor signaling pathway & 89 & $7(7.9 \%)$ & 0.027 & $\begin{array}{l}\text { Wikipath } \\
\text { ways }\end{array}$ \\
\hline RET signaling & 219 & $13(6.0 \%)$ & $\begin{array}{l}0.028 \\
1\end{array}$ & Reactome \\
\hline Signaling by VEGF & 290 & $16(5.5 \%)$ & $\begin{array}{l}0.029 \\
5\end{array}$ & Reactome \\
\hline Resolution of D-Loop Structures & 37 & $4(11.1 \%)$ & $\begin{array}{l}0.029 \\
6 \\
\end{array}$ & Reactome \\
\hline downregulated of mta-3 in er-negative breast tumors & 21 & $3(14.3 \%)$ & $\begin{array}{l}0.030 \\
2\end{array}$ & BioCarta \\
\hline Methionine De Novo and Salvage Pathway & 21 & $3(14.3 \%)$ & $\begin{array}{l}0.030 \\
2\end{array}$ & $\begin{array}{l}\text { Wikipath } \\
\text { ways }\end{array}$ \\
\hline Cytokine Signaling in Immune system & 487 & $24(4.9 \%)$ & $\begin{array}{l}0.030 \\
9 \\
\end{array}$ & Reactome \\
\hline RAF/MAP kinase cascade & 200 & $12(6.0 \%)$ & $\begin{array}{l}0.031 \\
6 \\
\end{array}$ & Reactome \\
\hline SHC1 events in EGFR signaling & 200 & $12(6.0 \%)$ & $\begin{array}{l}0.031 \\
6\end{array}$ & Reactome \\
\hline SOS-mediated signalling & 200 & $12(6.0 \%)$ & $\begin{array}{l}0.031 \\
6 \\
\end{array}$ & Reactome \\
\hline GRB2 events in EGFR signaling & 200 & $12(6.0 \%)$ & $\begin{array}{l}0.031 \\
6 \\
\end{array}$ & Reactome \\
\hline IL2-mediated signaling events & 54 & $5(9.3 \%)$ & $\begin{array}{l}0.031 \\
7\end{array}$ & PID \\
\hline Circadian Clock & 38 & $4(10.8 \%)$ & 0.032 & Reactome \\
\hline
\end{tabular}




\begin{tabular}{|c|c|c|c|c|}
\hline & & & 3 & \\
\hline Activation of ATR in response to replication stress & 37 & $4(10.8 \%)$ & $\begin{array}{l}0.032 \\
3 \\
\end{array}$ & Reactome \\
\hline Chronic myeloid leukemia - Homo sapiens (human) & 73 & $6(8.2 \%)$ & $\begin{array}{l}0.032 \\
6\end{array}$ & KEGG \\
\hline Adrenoceptors & 9 & $2(22.2 \%)$ & $\begin{array}{l}0.033 \\
3 \\
\end{array}$ & Reactome \\
\hline Synthesis of (16-20)-hydroxyeicosatetraenoic acids (HETE) & 9 & $2(22.2 \%)$ & $\begin{array}{l}0.033 \\
3 \\
\end{array}$ & Reactome \\
\hline MAPK1 (ERK2) activation & 9 & $2(22.2 \%)$ & $\begin{array}{l}0.033 \\
3 \\
\end{array}$ & Reactome \\
\hline Metabolism of ingested SeMet, Sec, MeSec into H2Se & 9 & $2(22.2 \%)$ & $\begin{array}{l}0.033 \\
3 \\
\end{array}$ & Reactome \\
\hline TGF-beta Receptor Signaling & 55 & $5(9.1 \%)$ & 0.034 & $\begin{array}{l}\text { Wikipath } \\
\text { ways }\end{array}$ \\
\hline ErbB Signaling Pathway & 55 & $5(9.1 \%)$ & 0.034 & $\begin{array}{l}\text { Wikipath } \\
\text { ways }\end{array}$ \\
\hline Signalling to p38 via RIT and RIN & 204 & $12(5.9 \%)$ & 0.036 & Reactome \\
\hline ARMS-mediated activation & 204 & $12(5.9 \%)$ & 0.036 & Reactome \\
\hline Viral carcinogenesis - Homo sapiens (human) & 203 & $12(5.9 \%)$ & 0.036 & KEGG \\
\hline Regulation of lipolysis in adipocytes - Homo sapiens (human) & 56 & $5(8.9 \%)$ & $\begin{array}{l}0.036 \\
4\end{array}$ & KEGG \\
\hline Non-small cell lung cancer - Homo sapiens (human) & 56 & $5(8.9 \%)$ & $\begin{array}{l}0.036 \\
4 \\
\end{array}$ & KEGG \\
\hline Sudden Infant Death Syndrome (SIDS) Susceptibility Pathways & 159 & $10(6.3 \%)$ & $\begin{array}{l}0.037 \\
1 \\
\end{array}$ & $\begin{array}{l}\text { Wikipath } \\
\text { ways }\end{array}$ \\
\hline Frs2-mediated activation & 205 & $12(5.9 \%)$ & $\begin{array}{l}0.037 \\
2 \\
\end{array}$ & Reactome \\
\hline Cyclin D associated events in G1 & 39 & $4(10.3 \%)$ & $\begin{array}{l}0.038 \\
3 \\
\end{array}$ & Reactome \\
\hline G1 Phase & 39 & $4(10.3 \%)$ & $\begin{array}{l}0.038 \\
3 \\
\end{array}$ & Reactome \\
\hline Signaling events regulated by Ret tyrosine kinase & 39 & $4(10.3 \%)$ & $\begin{array}{l}0.038 \\
3 \\
\end{array}$ & PID \\
\hline O-glycosylation of TSR domain-containing proteins & 39 & $4(10.3 \%)$ & $\begin{array}{l}0.038 \\
3 \\
\end{array}$ & Reactome \\
\hline IL11 & 23 & $3(13.0 \%)$ & $\begin{array}{l}0.038 \\
4 \\
\end{array}$ & NetPath \\
\hline Sympathetic Nerve Pathway (Neuroeffector Junction) & 23 & $3(13.0 \%)$ & $\begin{array}{l}0.038 \\
4 \\
\end{array}$ & $\begin{array}{l}\text { PharmGK } \\
\text { B }\end{array}$ \\
\hline ctcf: first multivalent nuclear factor & 23 & $3(13.0 \%)$ & $\begin{array}{l}0.038 \\
4 \\
\end{array}$ & BioCarta \\
\hline Prolactin Signaling Pathway & 76 & $6(7.9 \%)$ & $\begin{array}{l}0.038 \\
6 \\
\end{array}$ & $\begin{array}{l}\text { Wikipath } \\
\text { ways }\end{array}$ \\
\hline Acute myeloid leukemia - Homo sapiens (human) & 57 & $5(8.8 \%)$ & $\begin{array}{l}0.038 \\
8 \\
\end{array}$ & KEGG \\
\hline Prolonged ERK activation events & 207 & $12(5.8 \%)$ & $\begin{array}{l}0.039 \\
6 \\
\end{array}$ & Reactome \\
\hline NCAM signaling for neurite out-growth & 231 & $13(5.7 \%)$ & $\begin{array}{l}0.040 \\
7 \\
\end{array}$ & Reactome \\
\hline Organic cation transport & 11 & $2(20.0 \%)$ & $\begin{array}{l}0.040 \\
7 \\
\end{array}$ & Reactome \\
\hline MAPK3 (ERK1) activation & 10 & $2(20.0 \%)$ & $\begin{array}{l}0.040 \\
7 \\
\end{array}$ & Reactome \\
\hline
\end{tabular}




\begin{tabular}{|c|c|c|c|c|}
\hline LIF signaling & 10 & $2(20.0 \%)$ & $\begin{array}{l}0.040 \\
7\end{array}$ & $\mathrm{INOH}$ \\
\hline methionine salvage cycle III & 10 & $2(20.0 \%)$ & $\begin{array}{l}0.040 \\
7\end{array}$ & $\begin{array}{l}\text { HumanCy } \\
\text { c }\end{array}$ \\
\hline $\begin{array}{l}\text { overview of telomerase protein component gene htert } \\
\text { transcriptional regulation }\end{array}$ & 10 & $2(20.0 \%)$ & $\begin{array}{l}0.040 \\
7\end{array}$ & BioCarta \\
\hline Signaling by FGFR3 fusions in cancer & 10 & $2(20.0 \%)$ & $\begin{array}{l}0.040 \\
7\end{array}$ & Reactome \\
\hline EV release from cardiac cells and their functional effects & 10 & $2(20.0 \%)$ & $\begin{array}{l}0.040 \\
7\end{array}$ & $\begin{array}{l}\text { Wikipath } \\
\text { ways }\end{array}$ \\
\hline RORA activates gene expression & 10 & $2(20.0 \%)$ & $\begin{array}{l}0.040 \\
7\end{array}$ & Reactome \\
\hline $\begin{array}{l}\text { Negative regulation of activity of TFAP2 (AP-2) family } \\
\text { transcription factors }\end{array}$ & 10 & $2(20.0 \%)$ & $\begin{array}{l}0.040 \\
7\end{array}$ & Reactome \\
\hline IL6 & 77 & $6(7.8 \%)$ & $\begin{array}{l}0.040 \\
8\end{array}$ & NetPath \\
\hline Negative regulation of MAPK pathway & 40 & $4(10.0 \%)$ & $\begin{array}{l}0.041 \\
5\end{array}$ & Reactome \\
\hline IL-5 Signaling Pathway & 40 & $4(10.0 \%)$ & $\begin{array}{l}0.041 \\
5 \\
\end{array}$ & $\begin{array}{l}\text { Wikipath } \\
\text { ways }\end{array}$ \\
\hline tRNA modification in the nucleus and cytosol & 40 & $4(10.0 \%)$ & $\begin{array}{l}0.041 \\
5\end{array}$ & Reactome \\
\hline Signalling to RAS & 209 & $12(5.8 \%)$ & $\begin{array}{l}0.042 \\
1\end{array}$ & Reactome \\
\hline $\begin{array}{l}\text { Glycosaminoglycan biosynthesis - heparan sulfate / heparin - } \\
\text { Homo sapiens (human) }\end{array}$ & 24 & $3(12.5 \%)$ & $\begin{array}{l}0.042 \\
8\end{array}$ & KEGG \\
\hline Kit receptor signaling pathway & 59 & $5(8.5 \%)$ & 0.044 & $\begin{array}{l}\text { Wikipath } \\
\text { ways }\end{array}$ \\
\hline SHP2 signaling & 59 & $5(8.5 \%)$ & 0.044 & PID \\
\hline Preimplantation Embryo & 59 & $5(8.5 \%)$ & 0.044 & $\begin{array}{l}\text { Wikipath } \\
\text { ways }\end{array}$ \\
\hline G2/M Checkpoints & 121 & $8(6.7 \%)$ & $\begin{array}{l}0.044 \\
2\end{array}$ & Reactome \\
\hline Cell Differentiation - meta & 60 & $5(8.3 \%)$ & $\begin{array}{l}0.046 \\
8\end{array}$ & $\begin{array}{l}\text { Wikipath } \\
\text { ways }\end{array}$ \\
\hline Rap1 signaling pathway - Homo sapiens (human) & 212 & $12(5.7 \%)$ & $\begin{array}{l}0.047 \\
5\end{array}$ & KEGG \\
\hline Nucleotide GPCRs & 11 & $2(18.2 \%)$ & $\begin{array}{l}0.048 \\
7\end{array}$ & $\begin{array}{l}\text { Wikipath } \\
\text { ways }\end{array}$ \\
\hline Signaling mediated by p38-gamma and p38-delta & 12 & $2(18.2 \%)$ & $\begin{array}{l}0.048 \\
7\end{array}$ & PID \\
\hline il22 soluble receptor signaling pathway & 11 & $2(18.2 \%)$ & $\begin{array}{l}0.048 \\
7\end{array}$ & BioCarta \\
\hline cxcr4 signaling pathway & 11 & $2(18.2 \%)$ & $\begin{array}{l}0.048 \\
7\end{array}$ & BioCarta \\
\hline Signaling by FGFR4 in disease & 11 & $2(18.2 \%)$ & $\begin{array}{l}0.048 \\
7 \\
\end{array}$ & Reactome \\
\hline cardiac protection against ros & 12 & $2(18.2 \%)$ & $\begin{array}{l}0.048 \\
7\end{array}$ & BioCarta \\
\hline $\begin{array}{l}\text { POU5F1 (OCT4), SOX2, NANOG repress genes related to } \\
\text { differentiation }\end{array}$ & 11 & $2(18.2 \%)$ & $\begin{array}{l}0.048 \\
7\end{array}$ & Reactome \\
\hline Axon guidance & 487 & $23(4.8 \%)$ & $\begin{array}{l}0.049 \\
1\end{array}$ & Reactome \\
\hline Developmental Biology & 748 & $33(4.4 \%)$ & $\begin{array}{l}0.049 \\
4\end{array}$ & Reactome \\
\hline
\end{tabular}




\begin{tabular}{|l|l|l|l|l|}
\hline Coregulation of Androgen receptor activity & 61 & $5(8.2 \%)$ & $\begin{array}{l}0.049 \\
7\end{array}$ & PID \\
\hline Notch & 62 & $5(8.2 \%)$ & $\begin{array}{l}0.049 \\
7\end{array}$ & NetPath \\
\hline
\end{tabular}




\section{Supplementary material 4}

\section{Pathway analyses of the genes that expressed by DES only}

\begin{tabular}{|c|c|c|c|c|}
\hline Pathway name & $\begin{array}{l}\text { set } \\
\text { size }\end{array}$ & $\begin{array}{l}\text { candidates } \\
\text { contained }\end{array}$ & p-value & $\begin{array}{l}\text { pathway } \\
\text { source }\end{array}$ \\
\hline Electron Transport Chain & 103 & $12(11.7 \%)$ & 1.43E-05 & $\begin{array}{l}\text { Wikipathway } \\
\text { s }\end{array}$ \\
\hline Oxidative phosphorylation - Homo sapiens (human) & 133 & $13(9.8 \%)$ & $4.23 \mathrm{E}-05$ & KEGG \\
\hline Parkinson,s disease - Homo sapiens (human) & 142 & $13(9.2 \%)$ & $8.36 \mathrm{E}-05$ & KEGG \\
\hline Transmembrane transport of small molecules & 628 & $32(5.1 \%)$ & 0.0002 & Reactome \\
\hline $\begin{array}{l}\text { Respiratory electron transport, ATP synthesis by } \\
\text { chemiosmotic coupling, and heat production by } \\
\text { uncoupling proteins. }\end{array}$ & 126 & $11(8.8 \%)$ & $\begin{array}{l}0.00041 \\
1\end{array}$ & Reactome \\
\hline $\begin{array}{l}\text { The citric acid (TCA) cycle and respiratory electron } \\
\text { transport }\end{array}$ & 171 & $13(7.6 \%)$ & $\begin{array}{l}0.00049 \\
8\end{array}$ & Reactome \\
\hline Oxidative phosphorylation & 61 & $7(11.5 \%)$ & $\begin{array}{l}0.00098 \\
5\end{array}$ & $\begin{array}{l}\text { Wikipathway } \\
\text { s }\end{array}$ \\
\hline Respiratory electron transport & 103 & $9(8.8 \%)$ & 0.00134 & Reactome \\
\hline Exercise-induced Circadian Regulation & 48 & $6(12.5 \%)$ & 0.00144 & $\begin{array}{l}\text { Wikipathway } \\
\text { s }\end{array}$ \\
\hline Stimuli-sensing channels & 104 & $9(8.7 \%)$ & 0.00153 & Reactome \\
\hline Multifunctional anion exchangers & 10 & $3(30.0 \%)$ & 0.00182 & Reactome \\
\hline Mineral absorption - Homo sapiens (human) & 52 & $6(11.5 \%)$ & 0.00219 & KEGG \\
\hline Allograft rejection - Homo sapiens (human) & 38 & $5(13.5 \%)$ & 0.00254 & KEGG \\
\hline Graft-versus-host disease - Homo sapiens (human) & 41 & $5(12.2 \%)$ & 0.00401 & KEGG \\
\hline Endosomal/Vacuolar pathway & 13 & $3(23.1 \%)$ & 0.0041 & Reactome \\
\hline Glycerolipid metabolism - Homo sapiens (human) & 59 & $6(10.2 \%)$ & 0.00417 & KEGG \\
\hline Neural Crest Differentiation & 101 & $8(7.9 \%)$ & 0.00476 & $\begin{array}{l}\text { Wikipathway } \\
\text { s }\end{array}$ \\
\hline Type I diabetes mellitus - Homo sapiens (human) & 43 & $5(11.6 \%)$ & 0.00493 & KEGG \\
\hline GPR40 PATHWAY & 14 & $3(21.4 \%)$ & 0.00512 & $\begin{array}{l}\text { Wikipathway } \\
\text { s }\end{array}$ \\
\hline Insulin secretion - Homo sapiens (human) & 85 & $7(8.2 \%)$ & 0.00657 & KEGG \\
\hline $\begin{array}{l}\text { Transport of inorganic cations/anions and amino } \\
\text { acids/oligopeptides }\end{array}$ & 107 & $8(7.5 \%)$ & 0.00673 & Reactome \\
\hline Alcoholism - Homo sapiens (human) & 180 & $11(6.1 \%)$ & 0.00743 & KEGG \\
\hline Ion channel transport & 209 & $12(5.7 \%)$ & 0.00856 & Reactome \\
\hline mechanism of acetaminophen activity and toxicity & 6 & $2(33.3 \%)$ & 0.00943 & BioCarta \\
\hline Autoimmune thyroid disease - Homo sapiens (human) & 53 & $5(9.6 \%)$ & 0.011 & KEGG \\
\hline HDACs deacetylate histones & 94 & $7(7.4 \%)$ & 0.0112 & Reactome \\
\hline $\begin{array}{l}\text { Formation of the beta-catenin:TCF transactivating } \\
\text { complex }\end{array}$ & 95 & $7(7.4 \%)$ & 0.0112 & Reactome \\
\hline NrCAM interactions & 7 & $2(28.6 \%)$ & 0.013 & Reactome \\
\hline Proton-coupled monocarboxylate transport & 7 & $2(28.6 \%)$ & 0.013 & Reactome \\
\hline Binding of TCF/LEF:CTNNB1 to target gene promoters & 7 & $2(28.6 \%)$ & 0.013 & Reactome \\
\hline Alzheimer,s disease - Homo sapiens (human) & 171 & $10(5.8 \%)$ & 0.0139 & KEGG \\
\hline Glutathione metabolism & 20 & $3(15.0 \%)$ & 0.0143 & $\begin{array}{l}\text { Wikipathway } \\
\text { s }\end{array}$ \\
\hline Wnt-beta-catenin Signaling Pathway in Leukemia & 20 & $3(15.0 \%)$ & 0.0143 & $\begin{array}{l}\text { Wikipathway } \\
\text { s }\end{array}$ \\
\hline RNA degradation - Homo sapiens (human) & 77 & $6(7.8 \%)$ & 0.0149 & KEGG \\
\hline
\end{tabular}




\begin{tabular}{|c|c|c|c|c|}
\hline $\begin{array}{l}\text { ERCC6 (CSB) and EHMT2 (G9a) positively regulate rRNA } \\
\text { expression }\end{array}$ & 79 & $6(7.7 \%)$ & 0.0158 & Reactome \\
\hline Complex I biogenesis & 57 & $5(8.8 \%)$ & 0.016 & Reactome \\
\hline CDC6 association with the ORC:origin complex & 8 & $2(25.0 \%)$ & 0.017 & Reactome \\
\hline $\begin{array}{l}\text { Recognition and association of DNA glycosylase with site } \\
\text { containing an affected pyrimidine }\end{array}$ & 8 & $2(25.0 \%)$ & 0.017 & Reactome \\
\hline Cleavage of the damaged pyrimidine & 8 & $2(25.0 \%)$ & 0.017 & Reactome \\
\hline Depyrimidination & 8 & $2(25.0 \%)$ & 0.017 & Reactome \\
\hline Histidine catabolism & 8 & $2(25.0 \%)$ & 0.017 & Reactome \\
\hline Allograft Rejection & 80 & $6(7.5 \%)$ & 0.0177 & $\begin{array}{l}\text { Wikipathway } \\
\text { s }\end{array}$ \\
\hline Phagosome - Homo sapiens (human) & 154 & $9(5.9 \%)$ & 0.0185 & KEGG \\
\hline Homologous recombination - Homo sapiens (human) & 41 & $4(9.8 \%)$ & 0.0213 & KEGG \\
\hline sphingosine and sphingosine-1-phosphate metabolism & 9 & $2(22.2 \%)$ & 0.0215 & HumanCyc \\
\hline $\begin{array}{l}\text { Antigen Presentation: Folding, assembly and peptide } \\
\text { loading of class I MHC }\end{array}$ & 24 & $3(12.5 \%)$ & 0.0235 & Reactome \\
\hline Histidine metabolism - Homo sapiens (human) & 24 & $3(12.5 \%)$ & 0.0235 & KEGG \\
\hline Meiotic recombination & 65 & $5(7.8 \%)$ & 0.0252 & Reactome \\
\hline TRP channels & 25 & $3(12.0 \%)$ & 0.0262 & Reactome \\
\hline Glycogen synthesis & 10 & $2(20.0 \%)$ & 0.0264 & Reactome \\
\hline Base-Excision Repair, AP Site Formation & 10 & $2(20.0 \%)$ & 0.0264 & Reactome \\
\hline RNA Polymerase I Promoter Opening & 66 & $5(7.7 \%)$ & 0.0267 & Reactome \\
\hline Tacrolimus/Cyclosporine Pathway, Pharmacodynamics & 44 & $4(9.1 \%)$ & 0.0269 & PharmGKB \\
\hline Integrins in angiogenesis & 66 & $5(7.6 \%)$ & 0.0283 & PID \\
\hline DNA methylation & 68 & $5(7.5 \%)$ & 0.03 & Reactome \\
\hline Signaling by Rho GTPases & 434 & $18(4.2 \%)$ & 0.0315 & Reactome \\
\hline Gamma-glutamyl-transpeptidase deficiency & 11 & $2(18.2 \%)$ & 0.0317 & SMPDB \\
\hline 5-oxoprolinase deficiency & 11 & $2(18.2 \%)$ & 0.0317 & SMPDB \\
\hline Gamma-Glutamyltransferase Deficiency & 11 & $2(18.2 \%)$ & 0.0317 & SMPDB \\
\hline Glutathione Metabolism & 11 & $2(18.2 \%)$ & 0.0317 & SMPDB \\
\hline Glutathione Synthetase Deficiency & 11 & $2(18.2 \%)$ & 0.0317 & SMPDB \\
\hline 5-Oxoprolinuria & 11 & $2(18.2 \%)$ & 0.0317 & SMPDB \\
\hline Spinal Cord Injury & 117 & $7(6.0 \%)$ & 0.0329 & $\begin{array}{l}\text { Wikipathway } \\
\text { s }\end{array}$ \\
\hline $\begin{array}{l}\text { Activated PKN1 stimulates transcription of AR (androgen } \\
\text { receptor) regulated genes KLK2 and KLK3 }\end{array}$ & 70 & $5(7.2 \%)$ & 0.0335 & Reactome \\
\hline Synthesis of IP3 and IP4 in the cytosol & 28 & $3(10.7 \%)$ & 0.0353 & Reactome \\
\hline $\begin{array}{l}\text { Resolution of D-loop Structures through Synthesis- } \\
\text { Dependent Strand Annealing (SDSA) }\end{array}$ & 28 & $3(10.7 \%)$ & 0.0353 & Reactome \\
\hline SLC-mediated transmembrane transport & 286 & $13(4.6 \%)$ & 0.0356 & Reactome \\
\hline il-2 receptor beta chain in $\mathrm{t}$ cell activation & 48 & $4(8.3 \%)$ & 0.0356 & BioCarta \\
\hline Longevity regulating pathway - Homo sapiens (human) & 94 & $6(6.4 \%)$ & 0.0357 & KEGG \\
\hline Bile secretion - Homo sapiens (human) & 71 & $5(7.0 \%)$ & 0.0372 & KEGG \\
\hline SIRT1 negatively regulates rRNA Expression & 72 & $5(7.0 \%)$ & 0.0372 & Reactome \\
\hline $\begin{array}{l}\text { Glycerophospholipid metabolism - Homo sapiens } \\
\text { (human) }\end{array}$ & 95 & $6(6.3 \%)$ & 0.0373 & KEGG \\
\hline antigen processing and presentation & 12 & $2(16.7 \%)$ & 0.0374 & BioCarta \\
\hline Generic Transcription Pathway & 861 & $31(3.6 \%)$ & 0.038 & Reactome \\
\hline
\end{tabular}




\begin{tabular}{|c|c|c|c|c|}
\hline Cocaine addiction - Homo sapiens (human) & 49 & $4(8.2 \%)$ & 0.038 & KEGG \\
\hline Antigen processing-Cross presentation & 49 & $4(8.2 \%)$ & 0.038 & Reactome \\
\hline Dectin-2 family & 29 & $3(10.3 \%)$ & 0.0386 & Reactome \\
\hline triacylglycerol biosynthesis & 29 & $3(10.3 \%)$ & 0.0386 & HumanCyc \\
\hline Axon guidance - Homo sapiens (human) & 177 & $9(5.1 \%)$ & 0.0405 & KEGG \\
\hline TP53 Regulates Transcription of Cell Cycle Genes & 13 & $2(15.4 \%)$ & 0.0435 & $\begin{array}{l}\text { Wikipathway } \\
\text { s }\end{array}$ \\
\hline Familial lipoprotein lipase deficiency & 13 & $2(15.4 \%)$ & 0.0435 & SMPDB \\
\hline Glycerolipid Metabolism & 13 & $2(15.4 \%)$ & 0.0435 & SMPDB \\
\hline Glycerol Kinase Deficiency & 13 & $2(15.4 \%)$ & 0.0435 & SMPDB \\
\hline D-glyceric acidura & 13 & $2(15.4 \%)$ & 0.0435 & SMPDB \\
\hline $\begin{array}{l}\text { multiple antiapoptotic pathways from igf-1r signaling } \\
\text { lead to bad phosphorylation }\end{array}$ & 13 & $2(15.4 \%)$ & 0.0435 & BioCarta \\
\hline Methotrexate Pathway, Pharmacokinetics & 13 & $2(15.4 \%)$ & 0.0435 & PharmGKB \\
\hline $\begin{array}{l}\text { Transcriptional misregulation in cancer - Homo sapiens } \\
\text { (human) }\end{array}$ & 180 & $9(5.0 \%)$ & 0.0443 & KEGG \\
\hline Fatty acid, triacylglycerol, and ketone body metabolism & 153 & $8(5.3 \%)$ & 0.045 & Reactome \\
\hline role of mef2d in t-cell apoptosis & 31 & $3(9.7 \%)$ & 0.0458 & BioCarta \\
\hline Potassium Channels & 100 & $6(6.0 \%)$ & 0.046 & Reactome \\
\hline PRC2 methylates histones and DNA & 77 & $5(6.6 \%)$ & 0.0476 & Reactome \\
\hline Condensation of Prophase Chromosomes & 77 & $5(6.6 \%)$ & 0.0476 & Reactome \\
\hline CD4 T cell receptor signaling-JNK cascade & 53 & $4(7.5 \%)$ & 0.0485 & $\mathrm{INOH}$ \\
\hline Oxidative Stress Induced Senescence & 129 & $7(5.5 \%)$ & 0.0495 & Reactome \\
\hline $\begin{array}{l}\text { Antigen processing and presentation - Homo sapiens } \\
\text { (human) }\end{array}$ & 77 & $5(6.5 \%)$ & 0.0499 & KEGG \\
\hline Irinotecan Pathway & 14 & $2(14.3 \%)$ & 0.0499 & $\begin{array}{l}\text { Wikipathway } \\
\text { s }\end{array}$ \\
\hline CDT1 association with the CDC6:ORC:origin complex & 14 & $2(14.3 \%)$ & 0.0499 & Reactome \\
\hline Repression of WNT target genes & 14 & $2(14.3 \%)$ & 0.0499 & Reactome \\
\hline
\end{tabular}




\section{Supplementary material 5}

Pathway analyses of the genes that expressed by E2 only

\begin{tabular}{|c|c|c|c|c|}
\hline Pathway name & $\begin{array}{l}\text { Set } \\
\text { size }\end{array}$ & $\begin{array}{l}\text { Candidate } \\
\text { conttained }\end{array}$ & p-value & $\begin{array}{l}\text { Pathway } \\
\text { source }\end{array}$ \\
\hline HDMs demethylate histones & 52 & $5(9.6 \%)$ & $\begin{array}{l}0.0017 \\
6\end{array}$ & Reactome \\
\hline BMP Signalling Pathway & 19 & $3(15.8 \%)$ & $\begin{array}{l}0.0037 \\
3\end{array}$ & HumanCyc \\
\hline Lipid storage and perilipins in skeletal muscle & 6 & $2(33.3 \%)$ & $\begin{array}{l}0.0040 \\
5\end{array}$ & $\begin{array}{l}\text { Wikipathway } \\
\text { s }\end{array}$ \\
\hline $\begin{array}{l}\text { Hormone-sensitive lipase (HSL)-mediated triacylglycerol } \\
\text { hydrolysis }\end{array}$ & 20 & $3(15.0 \%)$ & $\begin{array}{l}0.0043 \\
4\end{array}$ & Reactome \\
\hline Signaling by BMP & 22 & $3(13.6 \%)$ & $\begin{array}{l}0.0057 \\
2\end{array}$ & Reactome \\
\hline Collagen biosynthesis and modifying enzymes & 70 & $5(7.1 \%)$ & $\begin{array}{l}0.0064 \\
3\end{array}$ & Reactome \\
\hline Glycosphingolipid metabolism & 46 & $4(8.7 \%)$ & $\begin{array}{l}0.0073 \\
3\end{array}$ & Reactome \\
\hline Vitamin C (ascorbate) metabolism & 8 & $2(25.0 \%)$ & $\begin{array}{l}0.0073 \\
9\end{array}$ & Reactome \\
\hline Collagen chain trimerization & 47 & $4(8.5 \%)$ & $\begin{array}{l}0.0079 \\
1 \\
\end{array}$ & Reactome \\
\hline Synaptic Vesicle Pathway & 51 & $4(7.8 \%)$ & 0.0105 & $\begin{array}{l}\text { Wikipathway } \\
\text { s }\end{array}$ \\
\hline $\begin{array}{l}\text { Resolution of D-loop Structures through Synthesis- } \\
\text { Dependent Strand Annealing (SDSA) }\end{array}$ & 28 & $3(10.7 \%)$ & 0.0113 & Reactome \\
\hline Interaction between L1 and Ankyrins & 30 & $3(10.0 \%)$ & 0.0137 & Reactome \\
\hline Ligand-independent caspase activation via DCC & 11 & $2(18.2 \%)$ & 0.014 & Reactome \\
\hline BMP2 signaling TGF-beta MV & 56 & $4(7.1 \%)$ & 0.0145 & $\mathrm{INOH}$ \\
\hline Ovarian Infertility Genes & 31 & $3(9.7 \%)$ & 0.0149 & $\begin{array}{l}\text { Wikipathway } \\
\text { s }\end{array}$ \\
\hline Mucin type O-glycan biosynthesis - Homo sapiens (human) & 31 & $3(9.7 \%)$ & 0.0149 & KEGG \\
\hline Viral myocarditis - Homo sapiens (human) & 59 & $4(6.9 \%)$ & 0.0163 & KEGG \\
\hline $\mathrm{P} 2 \mathrm{Y}$ receptors & 12 & $2(16.7 \%)$ & 0.0167 & Reactome \\
\hline Bone Morphogenic Protein (BMP) Signalling and Regulation & 12 & $2(16.7 \%)$ & 0.0167 & $\begin{array}{l}\text { Wikipathway } \\
\text { s }\end{array}$ \\
\hline Protein digestion and absorption - Homo sapiens (human) & 90 & $5(5.6 \%)$ & 0.0179 & KEGG \\
\hline BMP signaling Dro & 34 & $3(8.8 \%)$ & 0.0192 & $\mathrm{INOH}$ \\
\hline $\begin{array}{l}\text { Resolution of D-loop Structures through Holliday Junction } \\
\text { Intermediates }\end{array}$ & 35 & $3(8.8 \%)$ & 0.0192 & Reactome \\
\hline $\begin{array}{l}\text { Depolarization of the Presynaptic Terminal Triggers the } \\
\text { Opening of Calcium Channels }\end{array}$ & 13 & $2(15.4 \%)$ & 0.0195 & Reactome \\
\hline The activation of arylsulfatases & 13 & $2(15.4 \%)$ & 0.0195 & Reactome \\
\hline Collagen formation & 94 & $5(5.3 \%)$ & 0.0211 & Reactome \\
\hline Synaptic vesicle cycle - Homo sapiens (human) & 63 & $4(6.3 \%)$ & 0.0215 & KEGG \\
\hline Resolution of D-Loop Structures & 37 & $3(8.3 \%)$ & 0.0223 & Reactome \\
\hline IL5-mediated signaling events & 14 & $2(14.3 \%)$ & 0.0225 & PID \\
\hline $\begin{array}{l}\text { TP53 regulates transcription of several additional cell death } \\
\text { genes whose specific roles in p53-dependent apoptosis } \\
\text { remain uncertain }\end{array}$ & 14 & $2(14.3 \%)$ & 0.0225 & Reactome \\
\hline triacylglycerol degradation & 14 & $2(14.3 \%)$ & 0.0225 & HumanCyc \\
\hline Synthesis of PE & 14 & $2(14.3 \%)$ & 0.0225 & Reactome \\
\hline
\end{tabular}




\begin{tabular}{|c|c|c|c|c|}
\hline Adipogenesis & 131 & $6(4.6 \%)$ & 0.0233 & $\begin{array}{l}\text { Wikipathway } \\
\text { s }\end{array}$ \\
\hline HIF-1-alpha transcription factor network & 67 & $4(6.0 \%)$ & 0.0262 & PID \\
\hline Metabolism of nucleotides & 100 & $5(5.0 \%)$ & 0.0268 & Reactome \\
\hline Nucleotide-like (purinergic) receptors & 16 & $2(12.5 \%)$ & 0.029 & Reactome \\
\hline $\begin{array}{l}\text { Deregulation of Rab and Rab Effector Genes in Bladder } \\
\text { Cancer }\end{array}$ & 16 & $2(12.5 \%)$ & 0.029 & $\begin{array}{l}\text { Wikipathway } \\
\text { s }\end{array}$ \\
\hline BMP receptor signaling & 41 & $3(7.3 \%)$ & 0.0314 & PID \\
\hline Bile Acid Biosynthesis & 17 & $2(11.8 \%)$ & 0.0325 & SMPDB \\
\hline 27-Hydroxylase Deficiency & 17 & $2(11.8 \%)$ & 0.0325 & SMPDB \\
\hline Congenital Bile Acid Synthesis Defect Type II & 17 & $2(11.8 \%)$ & 0.0325 & SMPDB \\
\hline Cerebrotendinous Xanthomatosis (CTX) & 17 & $2(11.8 \%)$ & 0.0325 & SMPDB \\
\hline Zellweger Syndrome & 17 & $2(11.8 \%)$ & 0.0325 & SMPDB \\
\hline Familial Hypercholanemia (FHCA) & 17 & $2(11.8 \%)$ & 0.0325 & SMPDB \\
\hline Congenital Bile Acid Synthesis Defect Type III & 17 & $2(11.8 \%)$ & 0.0325 & SMPDB \\
\hline Primary bile acid biosynthesis - Homo sapiens (human) & 17 & $2(11.8 \%)$ & 0.0325 & KEGG \\
\hline TGF-Core & 42 & $3(7.1 \%)$ & 0.0334 & Signalink \\
\hline Protein-protein interactions at synapses & 73 & $4(5.5 \%)$ & 0.0345 & Reactome \\
\hline Transmembrane transport of small molecules & 628 & $17(2.7 \%)$ & 0.0354 & Reactome \\
\hline Homologous DNA Pairing and Strand Exchange & 43 & $3(7.0 \%)$ & 0.0354 & Reactome \\
\hline JAK-STAT & 43 & $3(7.0 \%)$ & 0.0354 & $\begin{array}{l}\text { Wikipathway } \\
\text { s }\end{array}$ \\
\hline Estrogen metabolism & 18 & $2(11.1 \%)$ & 0.0361 & $\begin{array}{l}\text { Wikipathway } \\
\text { s }\end{array}$ \\
\hline ABC transporters in lipid homeostasis & 18 & $2(11.1 \%)$ & 0.0361 & Reactome \\
\hline Other glycan degradation - Homo sapiens (human) & 18 & $2(11.1 \%)$ & 0.0361 & KEGG \\
\hline Lipid digestion, mobilization, and transport & 110 & $5(4.5 \%)$ & 0.0381 & Reactome \\
\hline PRC2 methylates histones and DNA & 77 & $4(5.3 \%)$ & 0.0391 & Reactome \\
\hline Glucose transport & 45 & $3(6.7 \%)$ & 0.0398 & Reactome \\
\hline Growth hormone receptor signaling & 19 & $2(10.5 \%)$ & 0.04 & Reactome \\
\hline HH-Core & 19 & $2(10.5 \%)$ & 0.04 & Signalink \\
\hline Calcium Regulation in the Cardiac Cell & 149 & $6(4.0 \%)$ & 0.0402 & $\begin{array}{l}\text { Wikipathway } \\
\text { s }\end{array}$ \\
\hline RNA degradation - Homo sapiens (human) & 77 & $4(5.2 \%)$ & 0.0408 & KEGG \\
\hline Globo Sphingolipid Metabolism & 20 & $2(10.0 \%)$ & 0.0439 & $\begin{array}{l}\text { Wikipathway } \\
\text { s }\end{array}$ \\
\hline sprouty regulation of tyrosine kinase signals & 20 & $2(10.0 \%)$ & 0.0439 & BioCarta \\
\hline Hippo signaling pathway - Homo sapiens (human) & 154 & $6(3.9 \%)$ & 0.0447 & KEGG \\
\hline Allograft Rejection & 80 & $4(5.0 \%)$ & 0.0458 & $\begin{array}{l}\text { Wikipathway } \\
\text { s }\end{array}$ \\
\hline Asymmetric localization of PCP proteins & 21 & $2(9.5 \%)$ & 0.048 & Reactome \\
\hline Toxoplasmosis - Homo sapiens (human) & 118 & $5(4.2 \%)$ & 0.0491 & KEGG \\
\hline
\end{tabular}




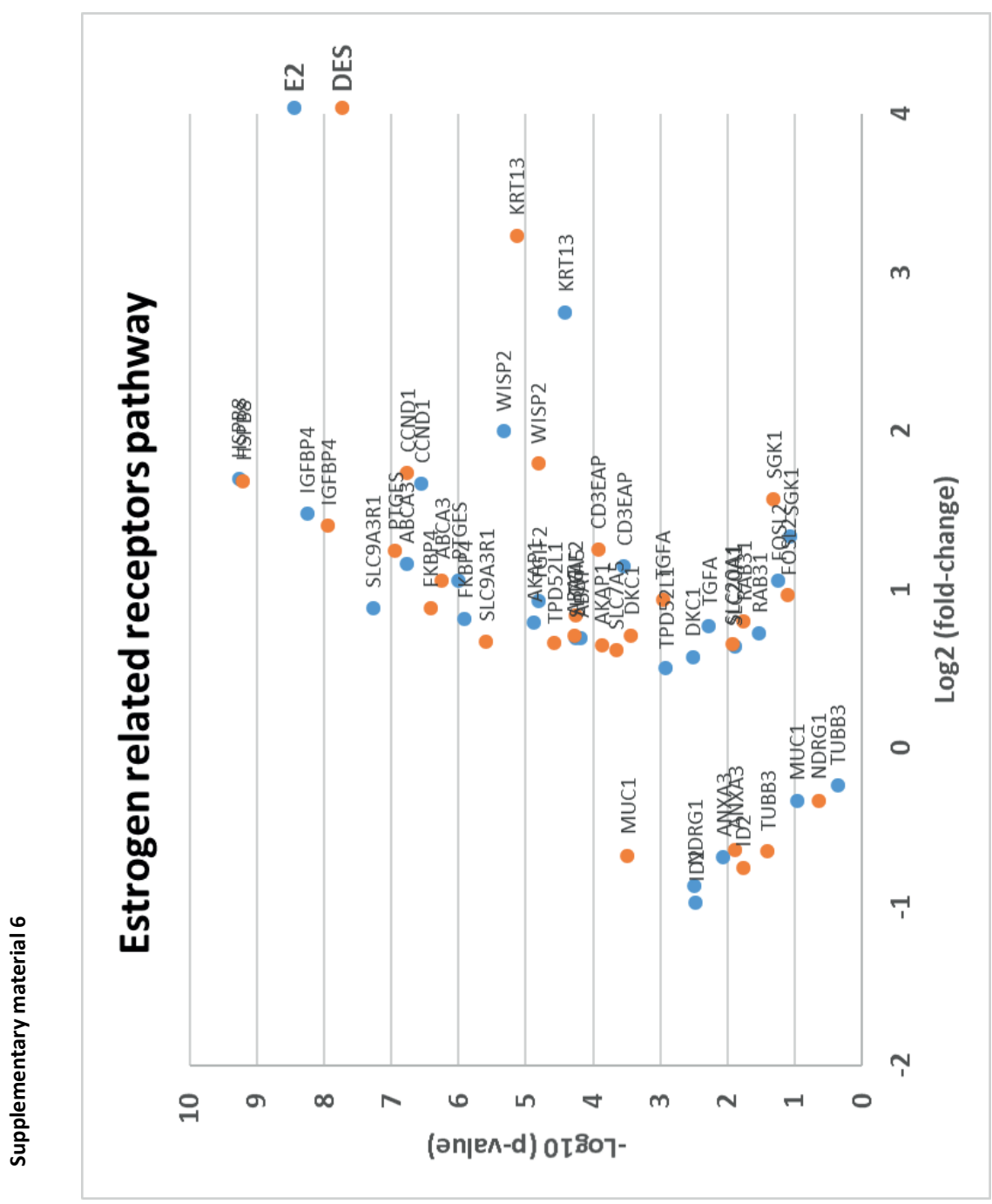




\section{Supplementary material 7}

\section{The genes that are validated in MCF-7 cells}

- Histone modification-related genes

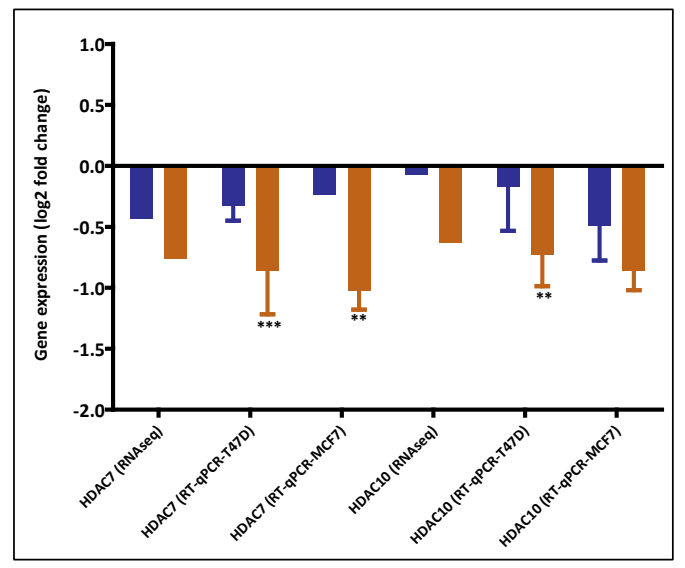

RNA-seq and RT-qPCR characterization of the effects of DES (orange) and E2 (blue) on gene expression associated with RAR pathways. For RT-qPCR results are expressed as log 2 fold changes in relation to the solvent control, bars represent average \pm SEM from at least three independent experiments. For statistical analysis of the RT-qPCR data multiple paired t-tests were performed and differences were considered significant if $p$-value $<0.05$.

- RAR-related genes

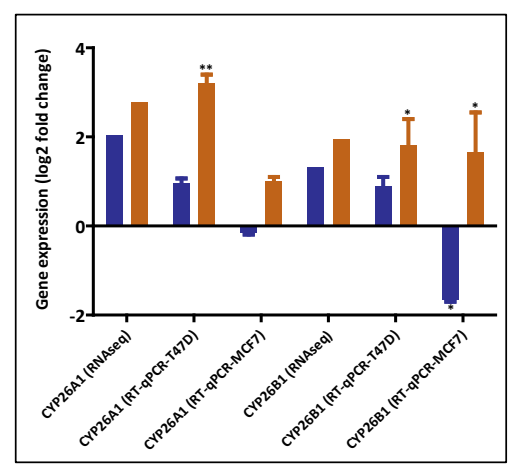

RNA-seq and RT qPCR characterization of the effects of DES ( and E 2 blue) on gene expression associated with RAR pathways For RT qPCR results are expressed as log 2 fold changes in relation to the solvent control, bars represent average SEM from at least three independent experiments For statistical analysis of the RT qPCR data multiple paired t tests were performed and differences were considered significant if $p$ value $<0.05$. 
- ER-related genes

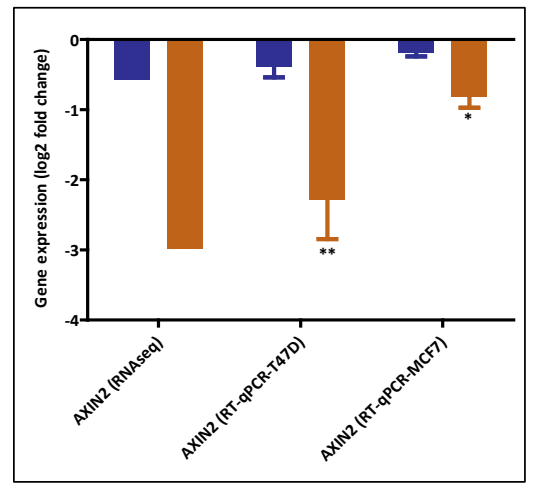

RNA-seq and RT qPCR characterization of the effects of DES (and E 2 blue) on gene expression associated with RAR pathways For RT qPCR results are expressed as log 2 fold changes in relation to the solvent control, bars represent average SEM from at least three independent experiments For statistical analysis of the RT qPCR data multiple paired t tests were performed and differences were considered significant if $p$ value 005 
CHAPTER 3

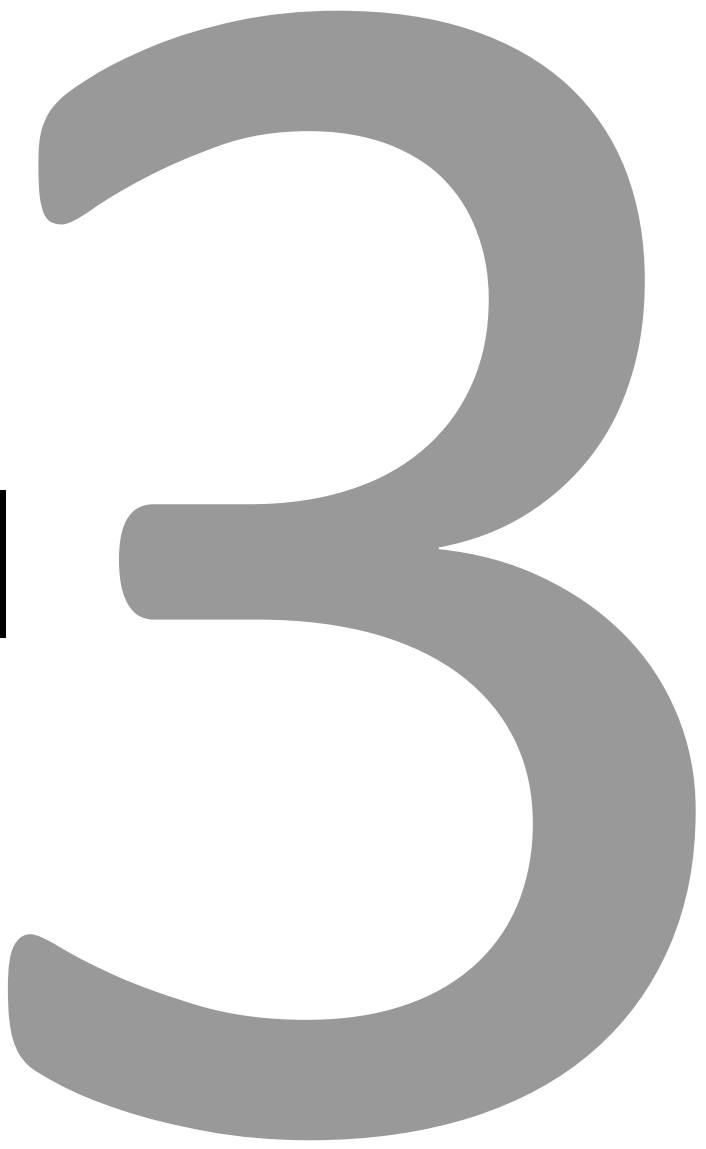




\section{The in vivo developmental toxicity of diethylstilbestrol (DES) in rat evaluated by an alternative testing strategy}

Aziza Hussein Bakheit Adam, Mengying Zhang, Laura HJ de Haan, Bennard van Ravenzwaay, Jochem Louisse and Ivonne MCM Rietjens 


\section{Abstract}

In the present study, we evaluated an alternative testing strategy to quantitatively predict the in vivo developmental toxicity of the synthetic hormone diethylstilbestrol (DES). To this end a physiologically based kinetic (PBK) model was defined that was subsequently used to translate concentrationresponse data for the in vitro developmental toxicity of DES, obtained in the ES-D3 cell differentiation assay, into predicted in vivo dose-response data for developmental toxicity. Previous studies showed that the PBK model facilitated reverse dosimetry approach is a useful approach to quantitatively predict the developmental toxicity of several developmental toxins. The results obtained in the present study show that the PBK model adequately predicted DES blood concentrations in rats. Further studies revealed that DES tested positive in the ES-D3 differentiation assay and that DES-induced inhibition of the ES-D3 cell differentiation could be counteracted by the estrogen receptor alpha $(E R \alpha)$ antagonist fulvestrant, indicating that the in vitro ES-D3 cell differentiation assay was able to mimic the role of ER $\alpha$ reported in the mode of action underlying the developmental toxicity of DES in vivo. In spite of this, combining these in vitro data with the PBK model did not adequately predict the in vivo developmental toxicity of DES in a quantitative way. It is concluded that although the EST qualifies DES as a developmental toxin and detects the role of ER $\alpha$ in this process, the ES-D3 cell differentiation assay of the EST apparently does not adequately capture the processes underlying DES induced developmental toxicity in vivo. 


\section{Introduction}

The development of reliable non-animal based testing strategies is of main interests in current human safety testing of chemicals. Especially the development of in vitro testing strategies in which adverse effects of chemicals on cells in culture can be detected are considered promising. However, data derived from in vitro models are as such inadequate for risk assessment since risk assessment requires in vivo dose-response data from which points of departure (PODs) can be derived for defining safe exposure levels, whereas in vitro models provide information on concentrationresponse relationships. Therefore, in order to use in vitro data for risk assessment, in vitro concentration-response curves need to be translated to in vivo dose-response curves. This translation can be achieved through so called physiologically based kinetic (PBK) modelling-facilitated reverse dosimetry approach. A PBK model is a set of mathematical equations that together describe the absorption, distribution, metabolism, and excretion (ADME) characteristics of a compound within an organism and can be used to relate external doses to internal (e.g. blood or tissue) concentrations. In the reverse dosimetry approach the concentrations causing toxicity in the in vitro model are considered equal to the blood or tissue concentrations that would cause toxicity in the in vivo situation. As such, PBK models can be used to predict in vivo toxicity dose levels based on toxic effect concentrations obtained in in vitro assays to derive a point of departure (POD) for risk assessment, such as a benchmark dose (BMD) or a lower confidence limit of the BMD, the BMDL (Louisse et al. 2017; Louisse et al. 2010; Strikwold et al. 2013).

Previously we have shown that reverse dosimetry of in vitro developmental toxicity data obtained in the ES-D3 differentiation assay of the embryonic stem cell test (EST) can result in an adequate quantitative prediction of in vivo dose-dependent developmental toxicity for a wide range of compounds including glycol ethers, retinoic acid, a series of phenols and tebuconazole (Li et al. 2017; Louisse et al. 2015; Louisse et al. 2010; Strikwold et al. 2017). 
To further explore the potential applicability of the reverse dosimetry approach, examples with more chemicals with diverse physico-chemical properties and modes of action are needed. The present study assesses whether the developmental toxicity of the xeno-estrogen diethylstilbestrol (DES) can be predicted using PBK modelling-based reverse dosimetry approach.

DES is a synthetic estrogen that was first produced for hormonal therapy in 1938 (IARC 2012). DES was prescribed to pregnant women to prevent potential miscarriages and premature delivery, by acting as an estrogen analogue (IARC 2012). However, DES use during pregnancy showed no preventive effect against miscarriages and it even caused adverse health effects in these women, such as breast cancer, and in their children and grandchildren, such as cell adenocarcinoma of the cervix and vagina in daughters and cancer of the testis in sons (Giusti et al. 1995; IARC 2012). Moreover, animal studies showed that DES caused developmental toxicity, including embryonic death and resorptions (Cornwall et al. 1984; Nagao and Yoshimura 2009; Wardell et al. 1982). Considering the underlying mode of action for adverse effects of DES, it has been reported that the estrogen receptor alpha $(E R \alpha)$ is needed to induce adverse developmental effects in neonates including induction of malformations and phenotypic changes in the neonatal reproductive tracts of female and male mice (Couse et al. 2001; Couse and Korach 2004; Prins et al. 2001). This was concluded from experiments in ER $\alpha$ knock-out mice, in which exposure to DES no longer induced alteration of the expression of Hoxa10, Hoxa11 and Wnt7 genes, or alteration in the weight of the seminal vesicle in the male and in the phenotype of the reproductive tract of the female, providing clear evidence for a role for ER $\alpha$ in mediating the adverse effects of neonatal DES exposure in the reproductive tract.

The aim of the present study was to assess whether the in vivo dose-dependent developmental toxicity caused by DES can be estimated using a combination of an in vitro assay for developmental toxicity and PBK modelling-based reverse dosimetry. In addition, it was investigated whether the role of ER $\alpha$ observed in vivo could also be demonstrated for the in vitro developmental toxicity of DES. To 
this end, in vitro concentration-response data for DES were quantified in the ES-D3 cell differentiation assay of the EST and a PBK model for DES in the rat was developed. In a next step the PBK model was used to translate the in vitro EST data to predicted in vivo dose-response data for developmental toxicity of DES that were subsequently compared with available literature data from in vivo studies reporting developmental toxicity of DES. Finally, DES was tested in the ES-D3 cell differentiation assay in the presence of the ER $\alpha$ antagonist fulvestrant, to investigate whether with respect to the reported role of ER $\alpha$ in DES-induced disturbance of development, the in vitro model mimics the in vivo situation.

\section{Materials and Methods}

\subsection{Materials}

Dimethyl sulfoxide (DMSO) was purchased from Acros Organics (Geel, Belgium). DES, reduced nicotinamide adenine dinucleotide phosphate (NADPH), uridine 5'-diphosphoglucuronic acid (UDPGA), adenosine 3'-phosphate 5'-phosphosulfate (PAPS) lithium salt hydrate, acetyl coenzyme A (acetyl CoA) sodium salt, alamethicin, magnesium chloride, sodium phosphate, sodium chloride and rat serum were purchased from Sigma-Aldrich (Zwijndrecht, the Netherlands). Pooled male and female Sprague-Dawley rat liver S9 fractions were purchased from Tebu-bio (Heerhugowaard, the Netherlands). Rapid equilibrium dialysis (RED) devices were purchased from Thermo Fisher Scientific (Bleiswijk, the Netherlands). Phosphate-buffered saline (PBS) was purchased from Invitrogen (Breda, the Netherlands).

\subsection{Cell line and culture conditions}

The murine mouse embryonic stem (ES-D3) cell line was purchased from ATCC/LGC (Wesel, Germany). The cells were maintained in low osmo Dulbecco's modified Eagle's medium (low osmo DMEM, GE Healthcare life sciences, Logan, Utah, USA) in $75 \mathrm{~cm}^{2}$ polystyrene cell culture flasks (Corning, The Netherlands), supplemented with $15 \%$ heat-inactivated ES cell qualified fetal calf 
serum (ATCC/LGC, Wesel, Germany), $50 \mathrm{U} / \mathrm{ml}$ penicillin with $50 \mu \mathrm{g} / \mathrm{ml}$ streptomycin (Invitrogen, Breda, The Netherlands), $2 \mathrm{mM} \mathrm{L-glutamine} \mathrm{(Invitrogen),} \mathrm{at} 37{ }^{\circ} \mathrm{C}$ and $5 \% \mathrm{CO}_{2}$ in a humidified atmosphere. Cells were kept undifferentiated with $1000 \mathrm{U} / \mathrm{ml}$ murine leukemia inhibiting factor (LIF, Sigma-Aldrich, Steinheim, Germany) and sub-cultured every 2-3 days using non-enzymatic cell dissociation solution (Sigma-Aldrich) to detach the cells.

\subsection{Cytotoxicity assay with ES-D3 cells}

Cytotoxicity of DES was determined using the WST-1 assay. This assay measures the formation of the water-soluble formazan product from WST-1 by mitochondrial succinate-tetrazolium reductase enzymes in non-exposed cells (control) and cells exposed to the test compound. ES-D3 cells were exposed to DES (Sigma-Aldrich) for the duration of 3 and 5 days. Briefly, cells were seeded in 96-well plates (Greiner bio-one, Alphen aan den Rijn, The Netherlands) at a concentration of $1 \times 10^{4}$ cells $/ \mathrm{ml}$ in $100 \mu \mathrm{l}$ culture medium in the absence of LIF and incubated for 1 day to allow cell adherence. Then, the cells were exposed to DES or fulvestrant at concentrations up to $100 \mu \mathrm{M}$ in triplicate (final solvent concentration $0.2 \% \mathrm{DMSO}$ ) and subsequently cultured for 3 or 5 days at $37^{\circ} \mathrm{C}$ and $5 \% \mathrm{CO}_{2}$ in a humidified atmosphere. The solvent DMSO (0.2\%) was used as a negative control and $5 \mu \mathrm{M} 5$ fluorouracil served as a positive control in all cytotoxicity assays. After exposure for 3 or 5 days, $20 \mu \mathrm{l}$ WST-1 reagent (Roche, Woerden, The Netherlands) were added to each well and plates were incubated for an additional $3 \mathrm{~h}$. Then, absorbance was measured at $450 \mathrm{~nm}$ using a SpectraMax M2 (Molecular Devices, Sunnyvale, USA). Three independent experiments were performed. The cell viability was expressed as percentage of the solvent control, with the solvent control set at $100 \%$. Cytotoxicity data were analysed for significant effects compared to the solvent control using one way analysis of variance (ANOVA) in GraphPad Prism 5.04 software.

\subsection{Differentiation assay with ES-D3 cells}

Differentiation assay was performed to detect the effect of DES on the differentiation of ES-D3 cells into contracting cardiomyocytes. On day 1 , droplets of $20 \mu \mathrm{l}$ cell suspension $\left(3.75 \times 10^{4}\right.$ cells $\left./ \mathrm{ml}\right)$ 
were placed as hanging drops, containing the test compound (DES) at concentrations ranging from 0.3 to $100 \mu \mathrm{M}$ (final solvent concentration as $0.2 \% \mathrm{DMSO}$ ), on the inner side of the lid of a 96 -well plate. Sterile lids of Eppendorf tubes were placed on the corner wells of the plates to prevent contact of the drops with the plate. The wells of the 96 -well plate were filled with $200 \mu$ l phosphate buffered saline (PBS, Invitrogen), and the plate was sealed with microspore tape (3M, Neuss, Germany) to prevent evaporation of the hanging drops. Plates were incubated for 3 days at $37{ }^{\circ} \mathrm{C}$ and $5 \% \mathrm{CO}_{2}$ in a humidified atmosphere. In the drops, cells formed embryonic bodies (EBs), which were transferred to non-tissue culture-treated Petri dishes (diameter $6 \mathrm{~cm}$, Greiner) containing $5 \mathrm{ml}$ of medium with the test compound at the relevant test concentration. On day 5, the EBs were transferred to wells of a 24-well plate (one EB per well) containing $1 \mathrm{ml}$ of medium with test compound. On day 10, the number of wells containing contracting cardiomyocytes was determined by visual inspection using a light microscope. A solvent control (0.2 \% DMSO in culture medium) was included in each experiment. Tests were accepted for further analysis if at least 21 of the 24 wells of the solvent control contained contracting cardiomyocytes. Three independent experiments were performed. The results were expressed as percentage of the solvent control, with the solvent control set at $100 \%$.

To assess whether effects on ES-D3 cell differentiation were mediated via the ER $\alpha$, also studies were performed in which the effects of DES on the differentiation of ES-D3 cells into contracting cardiomyocytes was assessed in the presence of the ER $\alpha$ antagonist fulvestrant. To that end, first a concentration of fulvestrant was determined that did not affect ES-D3 cell differentiation by itself, which was then applied in the co-exposure studies. Final solvent concentrations in these studies was also $0.2 \%$ DMSO.

\subsection{Development of a PBK model of DES in rats}

The previously developed PBK model of E2 and BPA (Zhang et al. 2018) was used as the starting point to develop the PBK model that describes the kinetics of DES in rats. The schematic representation of the model was shown in Fig. 1. The PBK model includes individual compartments for blood, fat, 
intestine, liver, rapidly perfused tissue and slowly perfused tissue. The physiological and anatomical parameter values were taken from literature (Brown et al. 1997) and are presented in Table 1. To describe the intestinal transition of DES, the intestine compartment was divided into 7 subcompartments. The transition in the small intestine was assumed to be the same for all the subcompartments. The apparent permeability coefficient ( $P_{\text {app }}$ value) was used to derive the absorption rate constant $(\mathrm{ka})$ for uptake of the parent compound from the intestines into the liver. This input $P_{\text {app }}$ value was estimated based on the quantitative structure-activity relationship (QSAR) approach of Hou et al. (Hou et al. 2004). The chemical-dependent input parameter of this approach was the polar surface area (PSA), which is 40.46 for DES. The in vitro Log $P_{\text {app }}$ value can be estimated using the formula: $\log \left(P_{\text {app, in vitro }}\right)=-4.28-0.011 \times$ PSA. This value was used to calculate the in vivo $P_{\text {app }}$ value using the following equation: $\log P_{\text {app, in vivo }}=0.6836 \times \log P_{\text {app, in vitro }}-0.5579$ (Sun et al. 2002). Then the absorption rate constant (ka, L/hr) was estimated by using the in vivo $P_{a p p}$ value (expressed in $\mathrm{dm} / \mathrm{hr}$ ) times the respected intestine surface area $\left(\mathrm{SA}\right.$, in $\mathrm{dm}^{2}$ ) of each sub-compartment (Zhang et al. 2018).

The tissue/blood partition coefficients of DES were estimated based on the quantitative propertyproperty relationship (QPPR) approach of DeJongh et al. (DeJongh et al. 1997). The input parameter of this approach was the octanol-water partition coefficient $\left(\mathrm{P}_{\mathrm{ow}}\right)$, the Log $\mathrm{P}_{\text {ow }}$ of DES is 5.07 (Selassie et al. 1999). The estimated partition coefficients are presented in Table 1.

The assumption was made that the estrogenic effects of DES are caused by the parent compound, not by the metabolites (Korach et al. 1989), and the clearance was resulted from hepatic clearance only, not by the renal clearance. The hepatic metabolism of the parent compound was determined in rat liver S9 fractions (Zhang et al. 2018), as described below. The PBK model code was described in Supplementary Material 1 . The PBK model equations were coded and numerically integrated in Berkeley Madonna 8.0.1 (UC Berkeley, CA, USA), using the Rosenbrock's algorithm for stiff systems. 


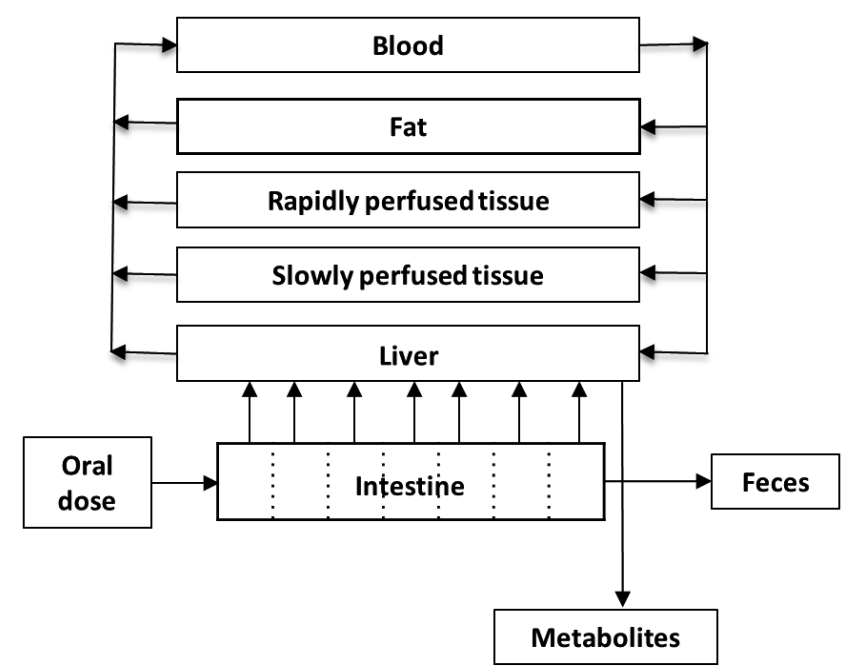

Fig. 11 Schematic diagram of the PBK model for DES in rats.

\subsection{Determination of the model parameter value for hepatic clearance}

The in vitro intrinsic clearance $\left(\mathrm{CL}_{\text {int }}\right)$ was determined using a substrate depletion approach, and these data were scaled to in vivo to describe the hepatic clearance of the parent compound in the PBK model. The $\mathrm{CL}_{\text {int }}$ of DES was determined in incubations with male or female Sprague-Dawley rat liver S9 fractions in the presence of relevant co-factors (NADPH, UDPGA, PAPS and acetyl CoA) for phase I and II metabolism. Our previous study has shown that the $\mathrm{CL}_{\text {int }}$ value obtained from incubations with $\mathrm{S} 9$ and all co-factors together in one mixture is similar to the sum of $\mathrm{CL}_{\text {int }}$ values derived from incubations for individual reactions (with individual co-factors) (Zhang et al. 2018). Therefore, in the current study, we determined $\mathrm{CL}_{\text {int }}$ of DES by incubating the substance with all cofactors together in one mixture, in the presence of liver S9 fraction from male or female SpragueDawley rats. Incubations with female rats were performed to obtain kinetic parameters for the PBK model when used to predict developmental toxicity. However, since the in vivo kinetic data on DES that were used for evaluation of the PBK model were obtained in male rats, also the kinetic 
parameters for clearance in male rats were determined. One requirement of the substrate depletion approach is that the initial concentration of the parent compound should be below the MichaelisMenten constant $(\mathrm{Km})$ for the respective conversions. In the current study, the test concentration of DES was $3 \mu \mathrm{M}$, which is 25.6 -fold below the lowest $\mathrm{Km}$ value reported for the metabolism of DES by liver microsomes of rats (Roy et al. 1992). To determine the hepatic clearance, $3 \mu \mathrm{M}$ DES (final concentration) was incubated with $0.5 \mathrm{mg} / \mathrm{ml}$ liver S9, $3 \mathrm{mM} \mathrm{NADPH}, 5 \mathrm{mM}$ UDPGA, $0.2 \mathrm{mM}$ PAPS, $0.5 \mathrm{mM}$ acetyl CoA, $5 \mathrm{mM} \mathrm{MgCl}$ and $0.025 \mathrm{mg} / \mathrm{ml}$ alamethicin in $0.1 \mathrm{M}$ potassium phosphate buffer (pH 7.4). The total incubation volume was $200 \mu \mathrm{L}$. The incubation time points were $0,1,2,3,4,5,7$, $8.5,10,15,20,25,30$ and $45 \mathrm{~min}$. To terminate the reaction, $100 \mu \mathrm{L}$ cold acetonitrile (ACN) were added to the mixture and the Eppendorf tubes were put on ice for $30 \mathrm{~min}$. Subsequently, tubes were centrifuged at 15,000 rpm for $10 \mathrm{~min}$ (CT 15RE, Hitachi Koki Co., Ltd) and the supernatant was collected for UPLC analysis. For each incubation time point, a corresponding control incubated in the absence of co-factors was included. For all incubations three independent replicates were performed.

The ratio of remaining DES between incubation samples ( $\left.\mathrm{C}_{\text {compound }}\right)$ and the corresponding control (incubation without co-factors, $\mathrm{C}_{\text {control }}$ ) was calculated for all the incubation time points. The elimination curve of the parent compound $\left[\ln \left(C_{\text {compound }} / C_{\text {control }}\right)\right]$ against incubation time was derived. The elimination rate constant $\left(k, \min ^{-1}\right)$, which is the absolute value of the slope of the linear part of the elimination curve, was used to calculate the in vitro clearance $\left(\mathrm{CL}_{\text {int, in vitro }}\right)$ using the following equation: $\mathrm{CL}_{\text {int, in vitro }}(\mu \mathrm{L} / \mathrm{min} / \mathrm{mg}$ protein $)=$ incubation volume $(\mu \mathrm{L}) /$ protein amount in the mixture $(\mathrm{mg}) \times$ elimination rate constant $\left(\mathrm{k}, \mathrm{min}^{-1}\right)$ (Obach 1999; Sjogren et al. 2009). The in vitro $\mathrm{CL}_{\text {int }}$ value of the parent compound was then scaled to the whole liver, assuming the S9 protein concentration in rat liver to be $87 \mathrm{~g}$ protein/kg liver (Chiu and Ginsberg 2011).

\subsection{Ultra-Performance Liquid Chromatography (UPLC) analysis}


A UPLC H_Class system (Waters Acquity) equipped with a Waters BEH C18 $(1.7 \mu \mathrm{m}, 2.1 \times 50 \mathrm{~mm})$ column was used. The temperature was set at $40{ }^{\circ} \mathrm{C}$ for the column and $5{ }^{\circ} \mathrm{C}$ for the samples. The injection volume was $3.5 \mu \mathrm{L}$ and the flow rate was $0.45 \mathrm{ml} / \mathrm{min}$. The mobile phase consisted of nanopure water as solvent $A$ and $A C N$ as solvent $B$. The gradient started at $65 \%$ solvent $A$, changed to $50 \%$ solvent $A$ in the next $2 \mathrm{~min}$, decreased to $0 \%$ solvent $A$ in $1 \mathrm{~min}$ and was kept at these conditions for another $2 \mathrm{~min}$. Then the gradient was changed to the initial conditions in $2 \mathrm{~min}$ and kept at these conditions for $1 \mathrm{~min}$. The total running time was $8 \mathrm{~min}$. The quantification of DES in each incubation was achieved by integrating the peak area at $245 \mathrm{~nm}$ and comparison to the peak areas of a calibration curve made using the commercially available reference compound.

\subsection{PBK model evaluation}

To evaluate the performance of the PBK model developed, the predicted time-dependent blood concentrations of DES were compared to the time-dependent blood concentrations of DES in rats reported in the literature upon intravenous and oral exposure (Ako 2011; Thompson and Klaassen 1985).

A sensitivity analysis was performed to locate the influential parameters of the PBK model on the model prediction of the maximum blood concentration $\left(C_{\max }\right)$ of DES. As described in a previous study (Evans and Andersen 2000), normalized sensitivity coefficients (SC) were calculated according to the following equation: $S C=\left(C^{\prime}-C\right) /\left(P^{\prime}-P\right) \times(P / C)$, with $C$ and $C^{\prime}$ representing the initial and modified value of the model output, and $P$ and $P^{\prime}$ the initial and modified parameter value. A $5 \%$ increase of parameter value was chosen to assess the effect of a change in parameter on the prediction of $C_{\max }$. Each parameter was individually analysed by changing one parameter value at a time and keeping the others the same. Also, the total tissue fraction and blood flow fraction should be kept as 1 . The sensitivity analysis was conducted for oral exposure to a single dose of $4 \mathrm{mg} / \mathrm{kg}$ bw DES, which was the dose applied in the in vivo kinetic study of Ako (Ako 2011). 


\subsection{Translation of in vitro concentration-response data into predicted in vivo dose-response data} using PBK modelling-based reverse dosimetry

The PBK modelling-based reverse dosimetry approach was used to quantitatively predict the dose levels that are required to reach concentrations of DES in blood that were applied in the in vitro differentiation assay. It is assumed that the toxicity is induced by the fraction unbound $\left(\mathrm{f}_{\mathrm{ub}}\right)$ of the parent compound. To take differences in the unbound fraction in the in vitro incubation medium and in vivo blood into account, the $f_{u b}$ values of DES in vitro and in vivo were determined by rapid equilibrium dialysis (RED).

\subsection{Determination of fraction unbound of DES in rat serum and in in vitro medium}

Rapid equilibrium dialysis (RED) was performed to determine the $f_{u b}$ of DES in the in vitro assay medium of the cell differentiation assay and in rat serum by following the protocol described by Waters et al. (Waters et al. 2008). The assay medium of the ES-D3 cell differentiation assay contained $15 \%$ FCS. $300 \mu \mathrm{L}$ sample containing $5 \mu \mathrm{M}$ of DES (final concentration) in the in vitro assay medium or in rat serum were added to the plasma chamber and $500 \mu \mathrm{L}$ PBS were added to the buffer chamber. After a 5 -hour incubation at $37^{\circ} \mathrm{C}$ at $250 \mathrm{rpm}$ on an orbital shaker, the system reaches equilibrium (van Liempd et al. 2011). Then $25 \mu \mathrm{L}$ of post-dialysis samples were collected from the plasma chamber and the buffer chamber in different tubes. According to the manufactural protocol, $25 \mu \mathrm{L}$ of buffer (PBS) were added to the samples from the plasma chamber and the same volume of assay medium or rat serum was added to the samples taken from the buffer chamber. This was done to equalize the samples with respect to the protein concentration for analysis. To precipitate the protein and release the compound, $300 \mu \mathrm{L}$ cold $\mathrm{ACN} /$ nanopure water (90/10) was added to all the samples. The samples were put on ice for $30 \mathrm{~min}$ and subsequently centrifuged for $15 \mathrm{~min}$ at $15,000 \times \mathrm{g}$ (CT 15RE, Hitachi Koki Co., Ltd). The supernatants were collected for UPLC analysis to quantify the concentration of DES in each chamber. The fraction unbound $\left(f_{u b}\right)$ can be calculated based on the 
equation: $f_{u b}=$ (concentration in buffer chamber / concentration in plasma chamber) (Waters et al. 2008). All the measurements were performed in triplicate in three independent studies.

\subsection{PBK modelling-based reverse dosimetry}

The in vivo dose-dependent developmental toxicity was assumed to depend on the maximum blood concentration $\left(C_{\max }\right)$ of DES. The in vitro effect concentrations were corrected for differences in protein binding with the in vivo situation, using the results of the analysis of $f_{u b}$ described above. For reverse dosimetry, the in vitro unbound concentration ( $\mathrm{C}_{\mathrm{ub}}$, in vitro $)$ was set equal to the in vivo

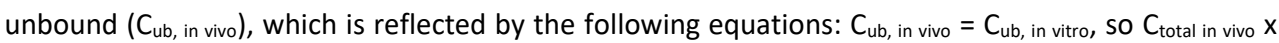

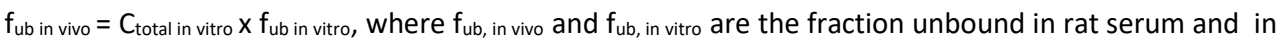
the in vitro assay medium determined from the RED assay. Then the nominal blood concentration in rat can be described as: $C_{\text {total in vivo }}=C_{u b \text {, in vivo }} / f_{u b \text {, in vivo }}=C_{u b \text {, in vitro }} / f_{u b \text {, in vivo }}=\left(C_{\text {total, in vitro }} \times f_{u b \text {, in vitro }}\right) / f_{u b \text {, }}$

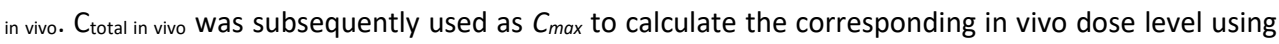
the PBK model. Performing this exercise for all the in vitro test concentrations, the in vitro concentration-response curve was translated into predicted in vivo dose-response curve.

\subsection{Evaluation of the quantitative prediction of dose-dependent developmental toxicity of DES}

To evaluate the quantitative prediction of the developmental toxicity of DES by using the developed PBK modelling-based reverse dosimetry approach, the predicted dose-response data derived from the in vitro differentiation assay were compared with the dose-response data derived from in vivo development toxicity studies (Cornwall et al. 1984; Wardell et al. 1982).

Furthermore, the benchmark dose (BMD) values derived from the predicted dose-response data were compared with the BMD values obtained from in vivo toxicity data. The BMD analysis was performed using the exponential model for dichotomous data of PROAST software from The National Institute for Public Health and the Environment of the Netherlands (RIVM) version 38.9 (Slop 2002). The benchmark response (BMR) was defined as a $10 \%$ change compared to the control. The lower 
(BMDL) and upper (BMDU) limits of the $95 \%$ confidence interval on the $\mathrm{BMD}_{10}$ can be derived from the software only when the data can be adequately modelled. The BMD analyses were performed on the predicted dose-response data obtained from the in vitro differentiation assay and the in vivo developmental toxicity data reported in the literature. In vitro EST data were analysed using the same BMD approach, fitting the concentration-response curve to determine the concentration associated with a BMR of $50 \%$. A $50 \%$ change in the number of beating EBs was selected as the BMR to calculate the benchmark concentrations for the differentiation $\left(\mathrm{BMC}_{50}\right)$.

\section{Results}

\subsection{Cytotoxicity and inhibition of ES-D3 cell differentiation by DES}

To study the in vitro developmental toxicity of DES, the effect of the compound on the differentiation of ES-D3 cells into contracting cardiomyocytes was evaluated. First, the WST-1 assay upon both three-day and five-day exposure was performed to evaluate the cytotoxic effects of DES on the ES-D3 cells (Fig. 2). The DES concentrations tested were non-cytotoxic up to $3 \mu \mathrm{M}$ as determined in the three-day and five-day cytotoxicity assay. Starting from $10 \mu \mathrm{M}$ the cell viability started to decrease.

Regarding the differentiation effect, DES induced a concentration-dependent inhibition of the differentiation of the ES-D3 cells into contracting cardiomyocytes (Fig. 3) at concentrations that were not yet cytotoxic, indicating that inhibitory effects on the differentiation of EBs are not due to cytotoxicity of DES. 


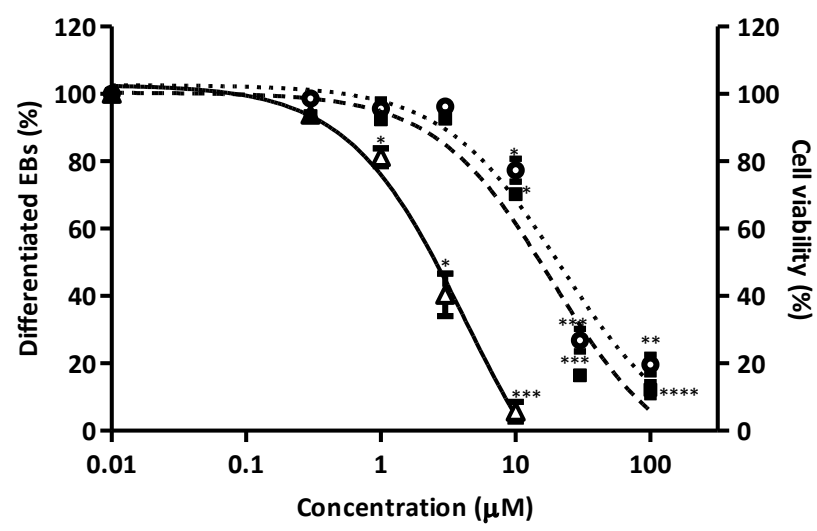

Fig. 2 Concentration-dependent effects of DES on cell viability upon three-day (o) and five-day (-) exposure and on ES-D3 cell differentiation ( $\Delta)$. The figure presents data from three independent experiments. For the statistical analysis, ${ }^{* * * *} p<0.0001 ;{ }^{* * *} p<0.001{ }^{* *} p<0.01 ;{ }^{*} p<0.05$.

\subsection{Effect of the ER $\alpha$ antagonist fulvestrant on DES-induced inhibition of ES-D3 cell differentiation}

Cytotoxicity and ES-D3 differentiation assays were performed to evaluate the toxicity and the inhibition of ES-D3 differentiation by the ER $\alpha$ antagonist fulvestrant. The results indicate that fulvestrant is not cytotoxic up to $100 \mu \mathrm{M}$ (Fig. 3A). Fulvestrant also caused a concentrationdependent inhibition of ES-D3 cell differentiation into contracting cardiomyocytes (Fig. 3A). Based on these results a concentration of $150 \mathrm{nM}$ fulvestrant was selected to investigate the effect of the ER $\alpha$ antagonist on DES-induced inhibition of ES-D3 differentiation because at this concentration fulvestrant did not interfere with the differentiation of the ES-D3 cells while $150 \mathrm{nM}$ is considerably higher than the IC50 for binding of fulvestrant to the ER of 0.8 to $0.9 \mathrm{nM}$ as reported in the literature (Wakeling et al. 1991; Weir et al. 2016). Figure 3B reveals that DES-induced inhibition of ESD3 cell differentiation is counteracted by the ER $\alpha$-antagonist fulvestrant at $150 \mathrm{nM}$. 

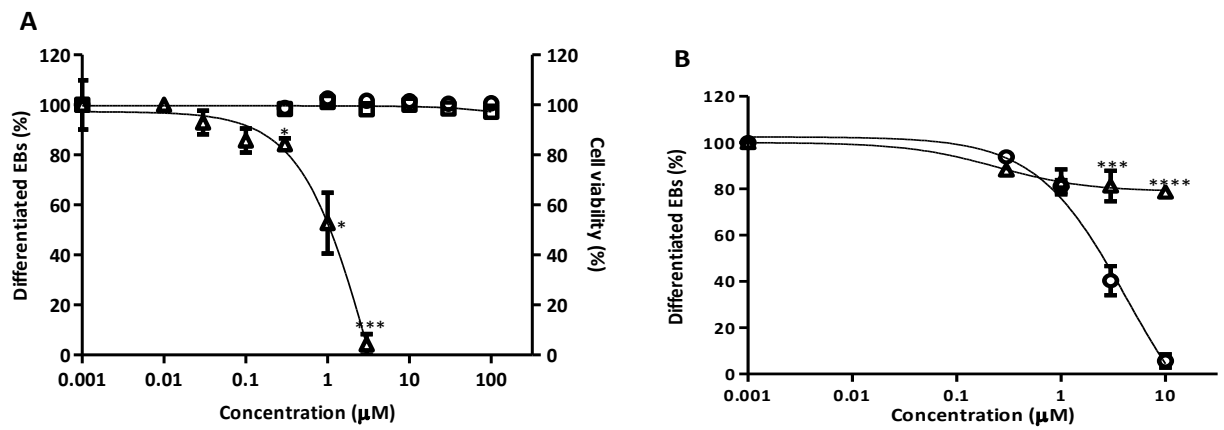

Fig. 3 A) Concentration-dependent effects of fulvestrant on cell viability upon three-day (open circle) and fiveday (open square) exposure and on inhibition of ES-D3 cell differentiation (open triangle). B) Effect of fulvestrant on DES-induced inhibition of ES-D3 cell differentiation. ES-D3 cells were exposed to DES in the absence (o) or presence $(\Delta)$ of $150 \mathrm{nM}$ fulvestrant $(n=3)$. For the statistical analysis, $* * * * p<0.0001 ; * * * p<$ $0.001 ; * *<0.01 ; * p<0.05$.

\subsection{Development of a PBK model for DES in rats}

The developed PBK model code is presented in supplementary material 1 . The values for physiological and anatomical parameters were taken from literature (Brown et al. 1997), and are presented in Table 1.

The apparent permeability coefficient $\left(P_{\text {app }}\right)$ value was estimated by using the QSAR approach of Hou

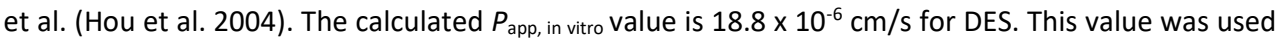
to estimate the in vivo Papp value, which was used to describe the uptake of DES from the intestines to the liver from the 7 sub-compartments of the intestines.

The hepatic clearance was considered the driving clearance process determining the body clearance of DES. The in vitro hepatic $\mathrm{CL}_{\text {int }}$ value of DES was determined by incubating the parent compound with co-factors of phase I and phase II metabolism together with male or female rat liver S9 in one mixture. The depletion curves are presented in supplementary material 2 and the hepatic $\mathrm{CL}_{\text {int }}$ values were listed in Table 1. 
Table 3. Parameters used in the PBK model for DES

\begin{tabular}{|c|c|}
\hline Parameters & Values \\
\hline \multicolumn{2}{|l|}{ Physiological parameters } \\
\hline Body weight (kg) & 0.25 \\
\hline \multicolumn{2}{|l|}{ Tissue volumes (\% of body weight) } \\
\hline Liver & 3.4 \\
\hline Fat & 7.0 \\
\hline Rapidly perfused tissue & 9.8 \\
\hline Slowly perfused tissue & 72.4 \\
\hline Blood & 7.4 \\
\hline Cardiac output $\left(\mathrm{L} \cdot \mathrm{h}^{-1} \cdot \mathrm{kg} \mathrm{bw}^{-0.74}\right)$ & 15 \\
\hline \multicolumn{2}{|c|}{ Tissue blood flows (\% of cardiac output) } \\
\hline Liver & 25.0 \\
\hline Fat & 7.0 \\
\hline Rapidly perfused tissue & 51.0 \\
\hline Slowly perfused tissue & 17.0 \\
\hline \multicolumn{2}{|l|}{ Tissue/blood partition coefficients } \\
\hline Liver & 8.0 \\
\hline Fat & 209.0 \\
\hline Rapidly perfused tissue & 8.0 \\
\hline Slowly perfused tissue & 1.6 \\
\hline \multicolumn{2}{|l|}{ In vitro clearance $\left(C L_{\text {int }}\right)$} \\
\hline Male $\mathrm{Cl}_{\text {int }}(\mu \mathrm{l} / \mathrm{min} / \mathrm{mg}$ protein) & $588.8 \pm 4.0$ \\
\hline Female $\mathrm{Cl}_{\text {int }}(\mu \mathrm{l} / \mathrm{min} / \mathrm{mg}$ protein) & $448.2 \pm 10.4$ \\
\hline
\end{tabular}




\subsection{PBK model evaluation}

To evaluate the model predictions, the predicted time-dependent blood concentrations of DES were compared with available in vivo kinetic data reported in the literature. Figure 4 presents the timedependent blood concentration of DES obtained from the in vivo studies (symbols) and the predicted time-dependent blood concentration curves (lines) upon intravenous (IV) (Fig. 4A) or oral (Fig. 4B) administration. The difference of maximum blood concertation $\left(C_{\max }\right)$ upon oral administration between the prediction and the in vivo kinetics data was 2.3 -fold. This comparison reveals that the developed PBK model can predict the blood concentration of DES upon IV and oral exposure quite well.

B

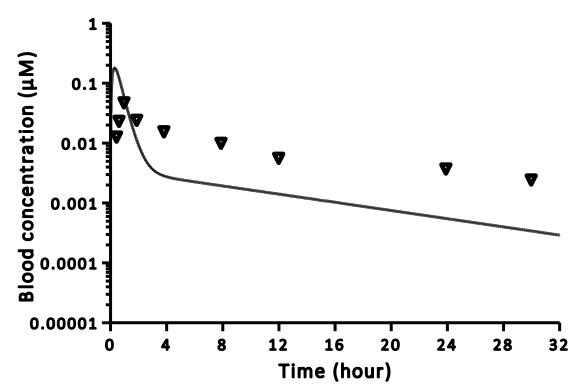

A

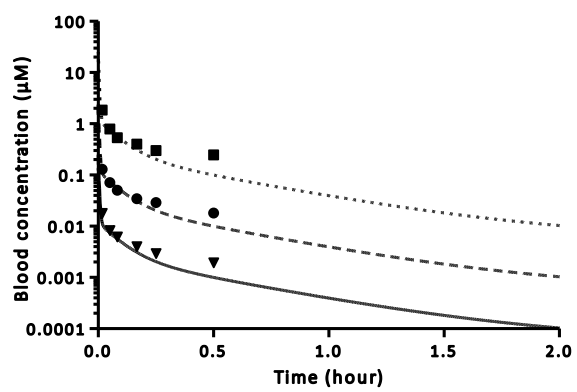

Fig. 4 A) Blood concentration of DES in rats upon intravenous administration. Symbols represent the average blood concentrations from the in vivo study of Thompson and Klaassen (Thompson and Klaassen 1985). Lines represent PBK model-based predictions of blood concentrations. Dose levels are as follows: $0.005 \mathrm{mg} / \mathrm{kg} \mathrm{bw}$ (reversed triangles, straight line); $0.05 \mathrm{mg} / \mathrm{kg}$ bw (circles, dashed line); $0.5 \mathrm{mg} / \mathrm{kg}$ bw (squares, dotted line). B) Blood concentration of DES in rats upon oral administration. Symbols represent the average blood concentrations when rats were exposed to a dose of $4 \mathrm{mg} / \mathrm{kg}$ bw/day as reported in the in vivo study of Ako (Ako 2011). Lines represent PBK model-based predictions of blood concentrations.

For further evaluation of the model a sensitivity analysis was performed. This sensitivity analysis was performed for the prediction of the $C_{\max }$ upon oral exposure to a single oral dose of $4 \mathrm{mg} / \mathrm{kg}$ bw DES, 
which was used in the in vivo kinetic data of Ako (Ako 2011). The normalized sensitivity coefficients (SC) with an absolute value higher than 0.1 are displayed in Figure 5. The results indicate that among all the influential parameters, the prediction of the $C_{\max }$ of DES in the PBK model is most sensitive to the fraction of liver tissue (VLc), the fraction of blood flow to the liver (QLc), parameters of intestines, the estimated in vivo $P_{a p p}$ value and the hepatic clearance (CLintS9).

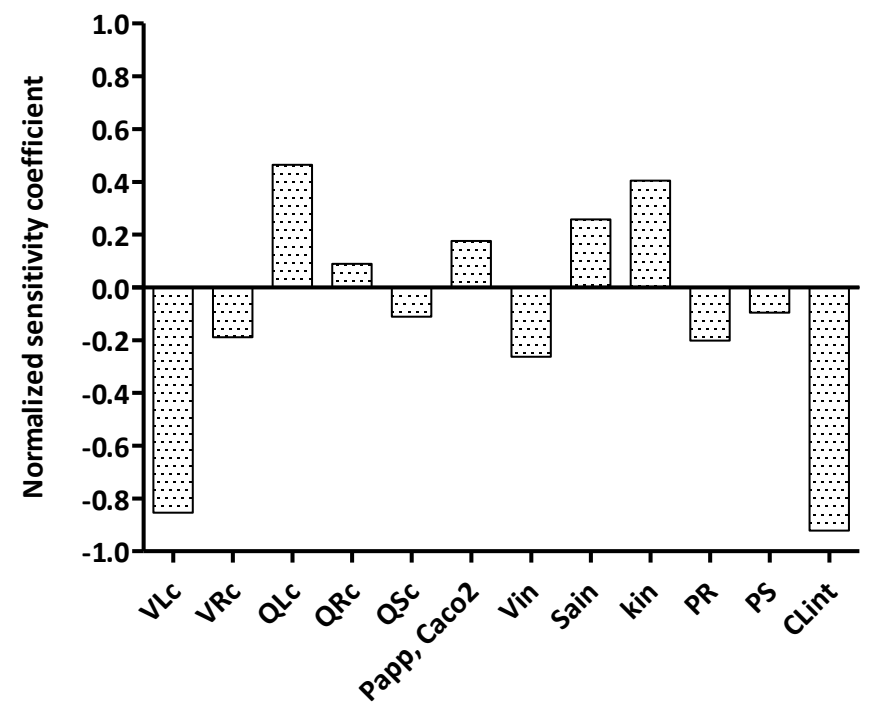

Fig. 5 Normalized sensitivity coefficients of the PBK model parameters for the predicted $C_{\max }$ of DES in blood after oral administration of $4 \mathrm{mg} / \mathrm{kg}$ bw which was tested in the in vivo kinetic study (Ako 2011). All model parameters with a normalized sensitivity coefficient with an absolute value higher than 0.1 are shown. VLc = fraction of liver tissue, $V R c=$ fraction of rapidly perfused tissue, $Q L c=$ fraction of blood flow to liver, $Q R c=$ fraction of blood flow to rapidly perfused tissue, QSC = fraction of blood flow to slowly perfused tissue, Papp, Caco-2 = estimated in vivo $P_{a p p}$ value, Vin = intestine volume for intestinal sub-compartment, SAin = intestinal surface area for intestinal sub-compartment, $k$ in $=$ transfer rate within intestinal sub-compartments, $P R=$ rapidly perfused tissue/blood partition coefficient, $P S=$ slowly perfused tissue/blood partition coefficient and CLint = experimental hepatic clearance of DES.

\subsection{Translation of the in vitro concentration-response data into quantitatively predicted in vivo} dose-response data 
The $f_{u b}$ of DES in ES-D3 culture medium was $0.90 \pm 0.09$ and it was $0.65 \pm 0.06$ in rat serum. These values were used to correct for the differences in fraction unbound between in vivo and in vitro.

The in vitro concentration-response curves from the ES-D3 differentiation assay were translated into in vivo dose-response curves using PBK modelling-based reverse dosimetry approach. Data from two in vivo developmental toxicity studies of DES reported in the literature were used to evaluate the predictions and are presented in table 3.1 and 3.2 in the supplementary material 3 . The predicted dose-response curve (Fig. 6, straight line) was compared with the in vivo dose-response curves derived from in vivo developmental toxicity studies reported in literature (Fig. 6, dashed lines). It can be concluded that the prediction based on in vitro ES-D3 differentiation assay data underestimates the in vivo developmental toxicity of DES by 3-4 orders of magnitude.

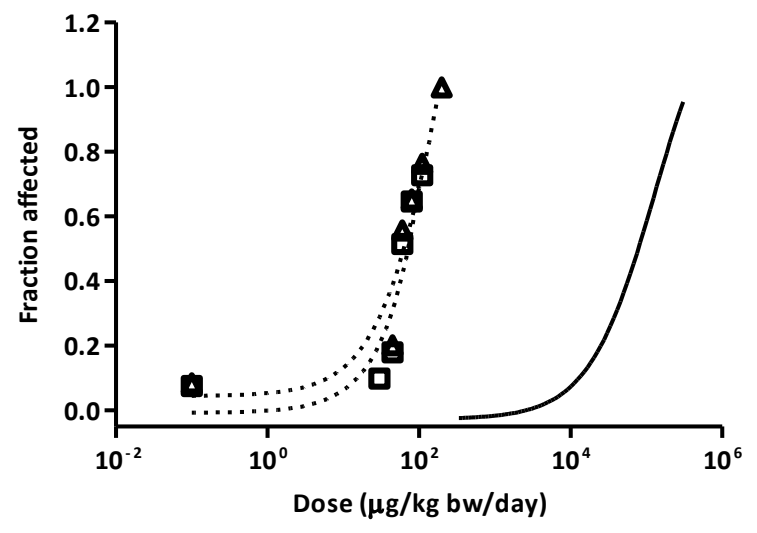

Fig. 6 Predicted (straight line) and reported dose-response data for developmental toxicity of DES in rats reported in literature (squares and triangles with dashed lines) (Cornwall et al. 1984; Wardell et al. 1982), respectively. Predicted dose-response data were obtained using PBK modelling-facilitated reverse dosimetry approach based on data obtained from the ES-D3 cell differentiation assay.

\subsection{Evaluation of the prediction of dose-dependent developmental toxicity of DES}

In the next step a BMD analysis using the PROAST software was performed on the predicted doseresponse data and on the in vivo toxicity data, resulting in the BMD values presented in Fig. 7. The 
$\mathrm{BMR}$ was defined as a $10 \%$ change compared to control and the $\mathrm{BMD}_{10}, \mathrm{BMDL}_{10}$ and $\mathrm{BMDU}_{10}$ values were obtained. The $B M D$ range between $B M D L_{10}$ and $B M D U_{10}$ is represented as a box and the $B M D_{10}$ value is shown as the vertical line in the box (Fig. 7). The predicted $B M D_{10}$ value of $D E S$ is 372 to 700 fold higher than the $\mathrm{BMD}_{10}$ values derived from the in vivo studies, while the $\mathrm{BMDL}_{10}$ is 202 to 442 and $\mathrm{BMDU}_{10} 707$ to 1107 fold higher than the $\mathrm{BMDL}_{10}$ and $\mathrm{BMDU}_{10}$ values derived from the in vivo studies. These results indicate that the developed PBK modelling-based reverse dosimetry approach of the in vitro ES-D3 differentiation assay under predicts the developmental toxicity of DES in rats by up to about 3 to 4 orders of magnitude. The detailed results of the BMD analyses can be found in the supplementary material 3 in table 3.3, 3.4 and 3.6.

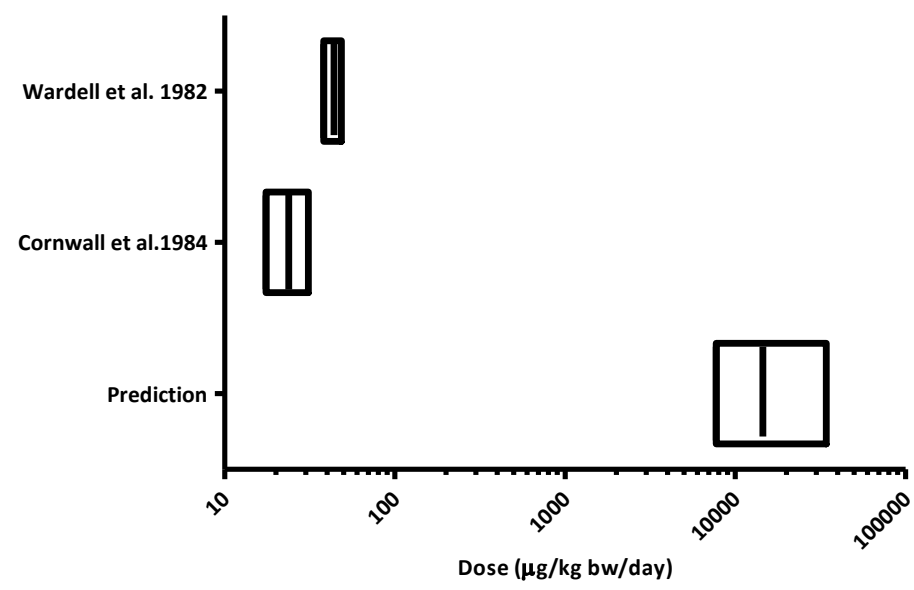

Fig. 7 Comparison of the $B M D_{10}$ values (including $B M D L_{10}$ and $B M D U_{10}$ values) derived from the predicted doseresponse curve and from in vivo dose-response data for developmental toxicity of DES in rats. Predicted doseresponse data were obtained by PBK modelling-based reverse dosimetry approach based on in vitro data from the ES-D3 cell differentiation assay and in vivo data were obtained from developmental toxicity assay studies reported in the literature (Cornwall et al. 1984; Wardell et al. 1982). BMD analysis was performed using the $B M R$ as a $10 \%$ response change as compared to the control using PROAST. The results are presented as a box representing the range between the $B M D L_{10}$ and $B M D U_{10}$ values, giving the $B M D_{10}$ values as a vertical line in the box. 


\subsection{Comparison of different compounds inducing inhibition of embryonic stem cell differentiation}

\section{and developmental toxicity in experimental animals}

To obtain further insight in possible reasons underlying the inability to quantitatively predict the in vivo developmental toxicity of DES based on data from the EST and PBK modelling-based reverse dosimetry approach, the $\mathrm{BMC}_{50}$ values obtained in the EST for different classes of developmental toxins were compared with their in vivo $\mathrm{BMD}_{10}$ values (Fig. 8). Such data were available for retinoids (ATRA: all-trans-retinoic acid, 13-cis-RA and acitretin), antifungal compounds (tebuconazole, propiconazole, prothioconazole, ketoconazole and fenarimol), phenols ( $p$-methylketophenol and $p$ fluorophenol) and glycol ethers (EGME: ethylene glycol monomethyl ether, EGEE: ethylene glycol monoethyl ether, EGBE: ethylene glycol monobutyl ether and EGPE: ethylene glycol monophenyl ether (de Jong et al. 2009; Li et al. 2017; Louisse et al. 2010; Strikwold et al. 2017). The figure 8 also includes the data for DES, showing that DES is out of line with the other developmental toxins. Based on the data shown in figure $8 \mathrm{~A}$, the $\mathrm{BMC}_{50}$ in the EST for the developmental toxins, excluding DES, correlated $\left(\mathrm{R}^{2}=0.62\right)$ with the $\mathrm{BMD}_{10}$ derived from the in vivo developmental toxicity data for these compounds. Plotting DES in this figure illustrates that the EST underestimates the developmental toxicity of DES, providing a $\mathrm{BMC}_{50}$ that is about $10^{4}$ fold higher than what would be predicted based on the obtained correlation. Taking into account the kinetics of these compounds, figure 7B presents the correlation between the in vivo $\mathrm{BMD}_{10}$ and predicted $\mathrm{BMD}_{10}$ for $\mathrm{p}$-methylketophenol, $\mathrm{p}$ heptyloxyphenol, p-flurophenol, EGPE, EGBE, EGEE, EGME, ATRA and DES. When taking kinetics into account, the correlation improves $\left(R^{2}=0.69\right.$, excluding $\left.D E S\right)$. With this new correlation DES is still 3orders of magnitude out of line. Based on the fact that the developed PBK model predicted the kinetics of DES quite well (fig. 4), and the fact that DES is 3-orders of magnitude off line as compared to other model compounds when taking kinetics into account (Fig. 8B), it is concluded that the inability to predict the in vivo developmental toxicity by the PBK modelling-based reverse dosimetry of the in vitro data from the ES-D3 cell differentiation assay is likely to be due to the inability of this assay to accurately detect the developmental toxicity of DES in vivo in a quantitative way. 

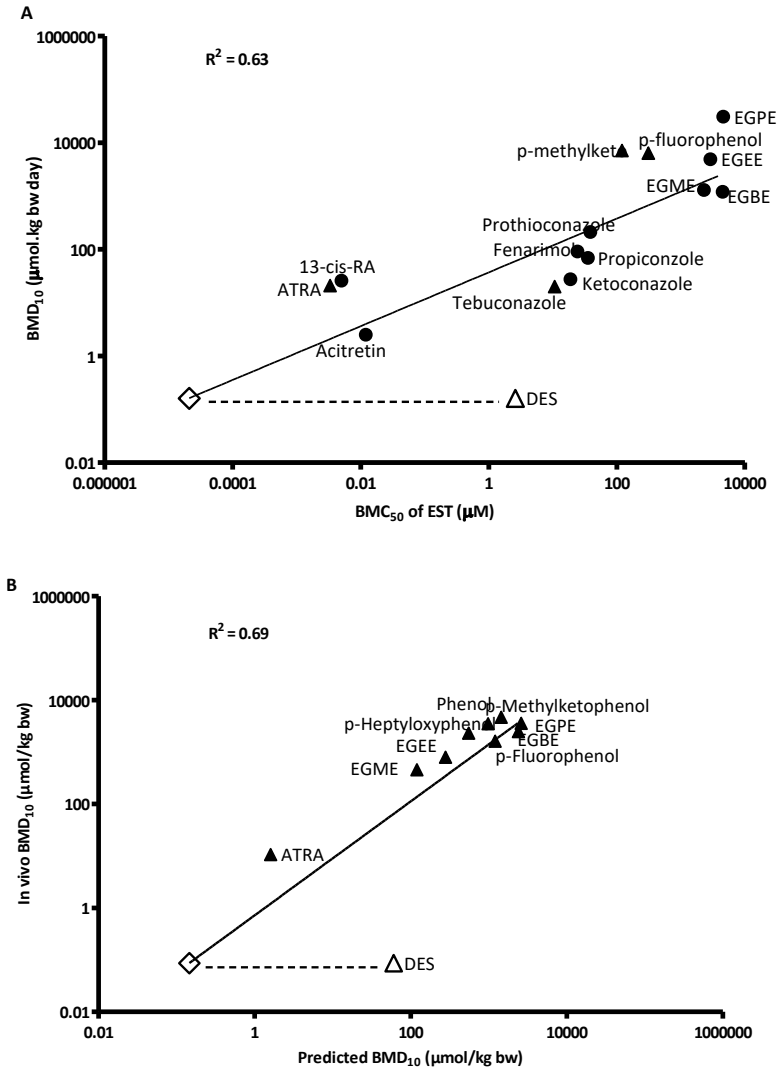

Fig. 8 Comparison between in vivo $B M D_{10}$ values for developmental toxicity for $\left.A\right) B M C_{50}$ values in the ES-D3 cell differentiation assay and $B$ ) predicted $B M D_{10}$ values for DES and other developmental toxins for which ES-D3 cell differentiation assay data are available, including retinoids (ATRA: all-trans-retinoic acid, 13-cis-RA and Acitretin) (Louisse et al. 2011), antifungal compounds (tebuconazole, propiconazole, prothioconazole, ketoconazole and fenarimol) (Li et al. 2015), phenols (p-methylketophenol and p-fluorophenol) (Strikwold et al. 2017), and glycol ethers (EGEE: ethylene glycol monoethyl ether, EGME: ethylene glycol monomethyl ether, EGBE: ethylene glycol monobutyl ether and EGPE: ethylene glycol monophenyl ether) (de Jong et al. 2009). Compounds with the black triangle symbols are the compounds that previously gave good predictions with the PBK modelling-facilitated reverse dosimetry (Li et al. 2017; Louisse et al. 2015; Louisse et al. 2010; Strikwold et al. 2017). The white triangle present the results of DES from the present study, while the white diamond presents the value that would have been in line with the other compounds. Correlations presented are calculated excluding the value for DES.

\section{Discussion}

The aim of the present study was to develop an in vitro and in silico-based PBK model for DES and assess whether the in vivo developmental toxicity of DES can be quantitatively predicted by PBK modelling-facilitated reverse dosimetry of in vitro toxicity data obtained in the ES-D3 cell 
differentiation assay. Furthermore, it was investigated whether the ES-D3 differentiation assay for developmental toxicity reflects the role of ER $\alpha$ in the mode of action underlying DES-induced adverse effects on development. To this end, the effect of DES in the ES-D3 cell differentiation assay in the presence or absence of the ER $\alpha$ antagonist fulvestrant was characterised, a PBK model for DES was developed and evaluated and results obtained for the developmental toxicity of DES in vitro were translated to in vivo dose-response curves using PBK modelling-facilitated reverse dosimetry.

The previous studies demonstrated that PBK modelling-facilitated reverse dosimetry of data obtained in the ES-D3 cell differentiation assay of the EST could adequately predict developmental toxicity for glycol ethers, retinoic acid, a series of phenols and tebuconazole (Li et al. 2017; Louisse et al. 2010, 2015, Strikwold et al. 2017). The results of the present study reveal that the approach cannot quantitatively predict the reported in vivo developmental toxicity of DES, since predicted dose-response curves appeared to occur at dose levels that were about three-to-four orders of magnitude higher than what is actually observed in vivo (Cornwall et al. 1984; Wardell et al. 1982). Comparison of the results for DES to those previously obtained for other developmental toxins reveals that DES deviates from the other toxins, in that the in vitro ES-D3 cell differentiation assay seems to be relatively less sensitive than what would be expected based on its in vivo developmental toxicity (Fig. 8a). In addition, when kinetics are taken into account, the predicted data for DES are three orders of magnitude out of line with what was observed for other developmental toxins (Fig. 8b). This deviation for DES might be due to the fact that the ES-D3 cell differentiation assay does not capture the full sensitivity of the developing organism underlying the developmental toxicity of DES in vivo. For DES, the ES-D3 differentiation assay appeared to capture some aspects of its developmental toxicity, since DES inhibited ES-D3 cell differentiation at non-cytotoxic concentrations, and there was a role for ER $\alpha$ in the underlying mode of action. The latter was shown by the fact that the ER $\alpha$ antagonist fulvestrant counteracted the in vitro developmental toxicity of DES in the ES-D3 cell differentiation assay. In spite of this, the ES-D3 cell differentiation assay did not provide a basis for an adequate PBK model-facilitated reverse dosimetry-based prediction of the in vivo 
developmental toxicity in a quantitative way. This may due to the fact that the ES-D3 cell differentiation assay captures only early stages of development, while the major adverse effects induced by DES may occur apparent only later during development, and/or that developmental stages affected by DES are not involved in the processes reflected in the ES-D3 cell differentiation of the EST. The inadequacy of the PBK model-facilitated reverse dosimetry approach to correctly predict the in vivo developmental toxicity of DES is likely due to the inability of the ES-D3 cell differentiation assay to display full sensitivity for DES induced developmental toxicity. The PBK model adequately predicted reported in vivo DES blood concentrations upon dosing $0.0005,0.005$, and $0.05 \mathrm{mg} / \mathrm{kg}$ bw DES intravenously (Thompson and Klaassen 1985) and $4 \mathrm{mg} / \mathrm{kg}$ bw upon oral dosing (Ako 2011). The fact that DES deviates from the comparison of the EST BMC50 to the in vivo BMD10 for developmental toxicity (Fig. 8a) also when taking kinetics into account (Fig. 8b) corroborates this conclusion.

As concluded above, this is most likely due to the inability of the ES-D3 cell differentiation assay to fully reflect the in vivo developmental toxicity of DES. A possible explanation for this might be that, the ES-D3 cell differentiation assay lacks the complex biological system and the metabolic capacity of intact organisms (Spielmann et al. 2006). In addition, it is suitable only for the early developmental stages (Pera and Trounson 2004).

The results of the present study show that the ES-D3 differentiation assay was able to represent the role of ER $\alpha$ in the developmental toxicity of DES. Activation and disruption of the ER $\alpha$ pathway might contribute to disruption of embryonic development (Bondesson et al. 2015; Greco et al. 1993), and it has been reported that ER $\alpha$ is essential for DES-induced effects, including phenotypic changes in the reproductive tract (malformed reproductive tract) and alterations of the expression of genes that are involved in regulation of the embryonic development as measured in neonates that have been exposed prenatally and neonatally (Block et al. 2000; Couse et al. 2001; Couse and Korach 2004; Ma et al. 1998; Miller et al. 1998). However, other mechanisms may be involved, as well. Literature 
indicates that epigenetic changes could be one of the main modes of action of DES-induced adverse effects, which can be passed on to the next generations. It has been reported that the sons and daughters of women who were exposed in utero to DES also showed increased numbers of birth defects, showing transgenerational effects that may be epigenetically regulated (Titus-Ernstof et al. 2010). Furthermore, the role of epigenetics in developmental toxicity of DES follows for example from the fact that it has been reported that female mice exposed to DES in utero had aberrant methylation in the promotor and intron of the hoxa10 gene, a gene of which an adequate expression is critical during embryonic development (Bromer et al. 2009). Possibly, adverse developmental effects which are mediated via epigenetic changes cannot be adequately captured by the ES-D3 cell differentiation assay. Moreover, there are other potential mechanisms of action proposed for teratogenic chemicals (Wani et al. 2017). For example, formation of reactive oxygen species (Parman et al. 1999), which may be captured by the ES-D3 cell differentiation assay, and inhibition of angiogenesis (D'Amato et al. 1994), which is not captured by the ES-D3 cell differentiation assay. Yamashita et al. 2013 reported that DES induces downregulation of the angiogenesis factors VEGFA (vascular endothelial growth factor) and ANGPT1 (angiopoitin 1) in neonates that have been exposed in utero (Yamashita et al. 2013). This may be another important mechanism underlying DES-induced developmental toxicity, which is not captured by the ES-D3 cell differentiation assay.

The fact that other than only ER $\alpha$-mediated pathways contribute to DES-induced developmental toxicity is supported also by the fact that the endogenous estrogen $17 \beta$-estradiol (E2), also able to activate $E R \alpha$, is not reported to be a developmental toxin in vivo and did not induce developmental toxicity in the ES-D3 cell differentiation assay (only effects were observed at cytotoxic concentrations; data presented in the Supplementary materials 4 Fig. 4.1. Further studies will be necessary to define the mode(s) of action underlying the developmental toxicity of DES and to what extent these modes of action are detected in the ES-D3 differentiation assay of the EST. With this knowledge, in vitro endpoints and readout parameters may be selected that cover these modes of 
action, to include these endpoints in a test battery for in vitro developmental toxicity testing, to also cover chemicals with a mode of action similar to that of DES.

Altogether, it is concluded that although it was shown that the EST assay detects the in vitro developmental toxicity of DES and an adequate PBK model for description of DES kinetics was developed, combining these in vitro and in silico approaches could not predict the in vivo developmental toxicity of DES in a quantitative way. The inability of the EST to fully reflect DESmediated developmental toxicity hampers adequate translation from the in vitro to the in vivo situation, probably due to the fact that the ES-D3 cell differentiation assay does not reflect the full mode of action underlying DES-induced developmental toxicity.

\section{Acknowledgements}

This work was supported by Wageningen university and BASF SE.

\section{Conflicts of interests}

The authors declare that there are no conflicts of interest. 


\section{References:}

Ako RA (2011) Pharmacokinetics/pharmacodynamics (PK/PD) of oral diethylstilbestrol (DES) in recurrent prostate cancer patients and of oral dissolving film (ODF)-DES in Rats. University of Houston, Houston

Block K, Kardana A, Igarashi P, Taylor HS (2000) In utero diethylstilbestrol (DES) exposure alters Hox gene expression in the developing mullerian system. FASEB J 14(9):1101-1108

Bondesson M, Hao R, Lin CY, Williams C, Gustafsson JA (2015) Estrogen receptor signaling during vertebrate development. Biochim Biophys Acta 1849(2):142-151.

Bromer JG, Wu J, Zhou Y, Taylor HS (2009) Hypermethylation of homeobox A10 by in utero diethylstilbestrol exposure: an epigenetic mechanism for altered developmental programming. Endocrinology 150(7):3376-3382.

Brown RP, Delp MD, Lindstedt SL, Rhomberg LR, Beliles RP (1997) Physiological parameter values for physiologically based pharmacokinetic models. Toxicol Ind Health 13(4):407-484.

Chiu WA, Ginsberg GL (2011) Development and evaluation of a harmonized physiologically based pharmacokinetic (PBPK) model for perchloroethylene toxicokinetics in mice, rats, and humans. Toxicol Appl Pharmacol 253(3):203-234. https://doi.org/10.1016/j.taap.2011.03.020

Cornwall GA, Carter MW, Bradshaw WS (1984) The relationship between prenatal lethality or fetal weight and intrauterine position in rats exposed to diethylstilbestrol, zeranol, 3,4,3',4'tetrachlorobiphenyl, or cadmium. Teratology 30(3):341-349.

Couse JF, Korach KS (2004) Estrogen receptor-alpha mediates the detrimental effects of neonatal diethylstilbestrol (DES) exposure in the murine reproductive tract. Toxicology 205(1-2):55-63.

Couse JF, Dixon D, Yates M et al (2001) Estrogen receptor-alpha knockout mice exhibit resistance to the developmental effects of neonatal diethylstilbestrol exposure on the female reproductive tract. Dev Biol 238(2):224-238.

D'Amato RJ, Loughnan MS, Flynn E, Folkman J (1994) Thalidomide is an inhibitor of angiogenesis. Proc Natl Acad Sci USA 91(9):4082-4085

de Jong E, Louisse J, Verwei M et al (2009) Relative developmental toxicity of glycol ether alkoxy acid metabolites in the embryonic stem cell test as compared with the in vivo potency of their parent compounds. Toxicol Sci 110(1):117-124.

DeJongh J, Verhaar HJ, Hermens JL (1997) A quantitative property-property relationship (QPPR) approach to estimate in vitro tissue-blood partition coefficients of organic chemicals in rats and humans. Arch Toxicol 72(1):17-25 
Evans MV, Andersen ME (2000) Sensitivity analysis of a physiological model for 2,3,7,8tetrachlorodibenzo-p-dioxin (TCDD): assessing the impact of specific model parameters on sequestration in liver and fat in the rat. Toxicol Sci 54(1):71-80

Giusti RM, Iwamoto K, Hatch EE (1995) Diethylstilbestrol revisited: a review of the long-term health effects. Ann Intern Med 122(10):778-788

Greco TL, Duello TM, Gorski J (1993) Estrogen receptors, estradiol, and diethylstilbestrol in early development: the mouse as a model for the study of estrogen receptors and estrogen sensitivity in embryonic development of male and female reproductive tracts. Endocr Rev 14(1):59-71

Hou TJ, Zhang W, Xia K, Qiao XB, Xu XJ (2004) ADME evaluation in drug discovery. 5. Correlation of Caco-2 permeation with simple molecular properties. J Chem Inf Comput Sci 44(5):1585-1600.

IARC (2012) A review of human carcinogens. Part A: Pharmaceuticals. IARC Working Group on the Evaluation of Carcinogenic Risks to Humans, 100:1-403. PMID: 23189749

Korach KS, Chae K, Levy LA, Duax WL, Sarver PJ (1989) Diethylstilbestrol metabolites and analogs. Stereochemical probes for the estrogen receptor binding site. J Biol Chem 264(10):5642-5647

Li H, Rietjens IMCM, Louisse J et al (2015) Use of the ES-D3 cell differentiation assay, combined with the BeWo transport model, to predict relative in vivo developmental toxicity of antifungal compounds. Toxicol in vitro 29(2):320-328.

Li H, Zhang M, Vervoort J, Rietjens IMCM, van Ravenzwaay B, Louisse J (2017) Use of physiologically based kinetic modeling-facilitated reverse dosimetry of in vitro toxicity data for prediction of in vivo developmental toxicity of tebuconazole in rats. Toxicol Lett 266:85-93.

Louisse J, de Jong E, van de Sandt JJ et al (2010) The use of in vitro toxicity data and physiologically based kinetic modeling to predict dose-response curves for in vivo developmental toxicity of glycol ethers in rat and man. Toxicol Sci 118(2):470-484.

Louisse J, Gonen S, Rietjens IMCM, Verwei M (2011) Relative developmental toxicity potencies of retinoids in the embryonic stem cell test compared with their relative potencies in in vivo and two other in vitro assays for developmental toxicity. Toxicol Lett 203(1):1-8.

Louisse J, Bosgra S, Blaauboer BJ, Rietjens IMCM, Verwei M (2015) Prediction of in vivo developmental toxicity of all-trans-retinoic acid based on in vitro toxicity data and in silico physiologically based kinetic modeling. Arch Toxicol 89(7):1135-1148.

Louisse J, Beekmann K, Rietjens IMCM (2017) Use of physiologically based kinetic modeling-based reverse dosimetry to predict in vivo toxicity from in vitro data. Chem Res Toxicol 30(1):114-125.

Ma L, Benson GV, Lim H, Dey SK, Maas RL (1998) Abdominal B (AbdB) Hoxa genes: regulation in adult uterus by estrogen and progesterone and repression in mullerian duct by the synthetic estrogen diethylstilbestrol (DES). Dev Biol 197(2):141-154. 
Miller C, Degenhardt K, Sassoon DA (1998) Fetal exposure to DES results in de-regulation of Wnt7a during uterine morphogenesis. Nat Genet 20(3):228-230.

Nagao T, Yoshimura S (2009) Early embryonic losses in mice induced by diethylstilbestrol. Congenit Anom 49(4):269-273.

Obach RS (1999) Prediction of human clearance of twenty-nine drugs from hepatic microsomal intrinsic clearance data: an examination of in vitro half-life approach and nonspecific binding to microsomes. Drug Metab Dispos Biol Fate Chem 27(11):1350-1359

Parman T, Wiley MJ, Wells PG (1999) Free radical-mediated oxidative DNA damage in the mechanism of thalidomide teratogenicity. Nat Med 5(5):582-585.

Pera MF, Trounson AO (2004) Human embryonic stem cells: prospects for development. Development 131(22):5515-5525.

Prins GS, Birch L, Couse JF, Choi I, Katzenellenbogen B, Korach KS (2001) Estrogen imprinting of the developing prostate gland is mediated through stromal estrogen receptor alpha: studies with alphaERKO and betaERKO mice. Can Res 61(16):6089-6097

Roy D, Bernhardt A, Strobel HW, Liehr JG (1992) Catalysis of the oxidation of steroid and stilbene estrogens to estrogen quinone metabolites by the beta-naphthoflavone-inducible cytochrome P450 IA family. Arch Biochem Biophys 296(2):450-456

Selassie CD, Shusterman AJ, Kapur S, Verma RP, Zhang LT, Hansch C (1999) On the toxicity of phenols to fast growing cells. A QSAR model for a radical-based toxicity. J Chem Soc Perk T 2(12):2729-2733.

Sjogren E, Lennernas H, Andersson TB, Grasjo J, Bredberg U (2009) The multiple depletion curves method provides accurate estimates of intrinsic clearance (CLint), maximum velocity of the metabolic reaction (Vmax), and Michaelis constant $(\mathrm{Km})$ : accuracy and robustness evaluated through experimental data and Monte Carlo simulations. Drug Metab Dispos 37(1):47-58.

Slob W (2018) PROAST: software for dose-response modeling and benchmark dose analysis. RIVM. http://www.rivm.nl/en/Library/Scientific/Models/PROAST

Spielmann H, Seiler A, Bremer S, et al (2006) The practical application of three validated in vitro embryotoxicity tests. The report and recommendations of an ECVAM/ZEBET workshop (ECVAM workshop 57). Alternatives to laboratory animals: ATLA 34(5):527-538

Strikwold M, Spenkelink B, Woutersen RA, Rietjens IMCM, Punt A (2013) Combining in vitro embryotoxicity data with physiologically based kinetic (PBK) modelling to define in vivo doseresponse curves for developmental toxicity of phenol in rat and human. Arch Toxicol 87(9):17091723.

Strikwold M, Spenkelink B, de Haan LHJ, Woutersen RA, Punt A, Rietjens IMCM (2017) Integrating in vitro data and physiologically based kinetic (PBK) modelling to assess the in vivo potential developmental toxicity of a series of phenols. Arch Toxicol 91(5):2119-2133. https://doi.org/10.1007/s00204-016-1881-x 
Sun D, Lennernas H, Welage LS et al (2002) Comparison of human duodenum and Caco-2 gene expression profiles for 12,000 gene sequences tags and correlation with permeability of 26 drugs. Pharm Res 19(10):1400-1416

Thompson TN, Klaassen CD (1985) Hepatic presystemic elimination of diethylstilbestrol by rats and effect of pretreatment with inducers of UDP-glucuronosyltransferase. J Toxicol Environ Health 16(34):615-629.

Titus-Ernstoff L, Troisi R, Hatch EE et al (2010) Birth defects in the sons and daughters of women who were exposed in utero to diethylstilbestrol (DES). Int J Androl 33(2):377-384.

van Liempd S, Morrison D, Sysmans L, Nelis P, Mortishire-Smith R (2011) Development and validation of a higher-throughput equilibrium dialysis assay for plasma protein binding. J Lab Autom 16(1):5667.

Wakeling AE, Dukes M, Bowler J (1991) A potent specific pure antiestrogen with clinical potential. Can Res 51(15):3867-3873

Wani TH, Chakrabarty A, Shibata N, Yamazaki H, Guengerich FP, Chowdhury G (2017) The dihydroxy metabolite of the teratogen thalidomide causes oxidative DNA damage. Chem Res Toxicol 30(8):1622-1628.

Wardell RE, Seegmiller RE, Bradshaw WS (1982) Induction of prenatal toxicity in the rat by

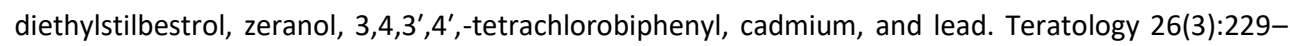
237.

Waters NJ, Jones R, Williams G, Sohal B (2008) Validation of a rapid equilibrium dialysis approach for the measurement of plasma protein binding. J Pharm Sci 97(10):4586-4595.

Weir HM, Bradbury RH, Lawson M et al (2016) AZD9496: an oral estrogen receptor inhibitor that blocks the growth of ER-positive and ESR1-mutant breast tumors in preclinical models. Can Res 76(11):3307-3318.

Yamashita S, Kudo A, Kawakami H, Okada Y (2013) Mechanisms of angiogenic suppression in uteri exposed to diethylstilbestrol neonatally in the mouse. Biol Reprod 88(5):116.

Zhang M, van Ravenzwaay B, Fabian E, Rietjens IMCM, Louisse J (2018) Towards a generic physiologically based kinetic model to predict in vivo uterotrophic responses in rats by reverse dosimetry of in vitro estrogenicity data. Arch Toxicol 92(3):1075-1088. 


\section{Supplementary material 1. PBK model for DES, built with in vitro model and in silico data}

Species: Rat

; Physiological parameters

; ; tissue volumes

$\mathrm{BW}=0.250 \mathrm{Kg} ;$ body weight rat (variable, dependent on study)

$\mathrm{VFc}=0.07$

; fraction of fat tissue

reference: (Brown et al., 1997).

$\mathrm{VLC}=0.034$

; fraction of liver tissue

reference: (Brown et al., 1997).

$\mathrm{VBc}=0.074$

; fraction of blood

$\mathrm{VRc}=0.098$

; fraction of rapidly perfused tissue

reference: (Brown et al., 1997).

$\mathrm{VSc}=0.724$

; fraction of slowly perfused tissue

reference: (Brown et al., 1997).

$\mathrm{VF}=\mathrm{VFc} * \mathrm{BW}$

$\{\mathrm{L}$ or $\mathrm{Kg}\}$

reference: (Brown et al., 1997).

$\mathrm{VL}=\mathrm{VLC} * \mathrm{BW}$

$\{\mathrm{L}$ or $\mathrm{Kg}\}$

; volume of fat tissue (calculated)

$\mathrm{VB}=\mathrm{VBC} * \mathrm{BW}$

$\{\mathrm{L}$ or $\mathrm{Kg}\}$

$\mathrm{VR}=\mathrm{VRc} * \mathrm{BW}$

$\{\mathrm{L}$ or $\mathrm{Kg}\}$

$\mathrm{VS}=\mathrm{VSC} \mathrm{BW}^{*}$

$\{\mathrm{L}$ or $\mathrm{Kg}\}$

; volume of liver tissue (calculated)

; volume of blood (calculated)

; volume of richly perfused tissue (calculated) ; volume of slowly perfused tissue (calculated)

;blood flow rates

$\mathrm{QC}=15^{*} \mathrm{BW}^{\wedge} 0.74$

$\mathrm{QFC}=0.07$

$\mathrm{QLC}=0.25$

$\mathrm{QRC}=0.51$

al., 1997).

QSC $=0.17$

al., 1997).

$\mathrm{QF}=\mathrm{QFc} * \mathrm{QC}$

$\{\mathrm{L} / \mathrm{hr}\}$; cardiac output

; fraction of blood flow to fat

; fraction of blood flow to liver

; fraction of blood flow to rapidly perfused tissue

; fraction of blood flow to slowly perfused tissue

$\{\mathrm{L} / \mathrm{hr}\} \quad ;$ blood flow to fat tissue (calculated)

$\{\mathrm{L} / \mathrm{hr}\}$; blood flow to liver tissue (calculated)

$\{\mathrm{L} / \mathrm{hr}\} \quad$; blood flow to rapidly perfused tissue (calculated)

$\{\mathrm{L} / \mathrm{hr}\} \quad$; blood flow to slowly perfused tissue (calculated)

$\mathrm{QR}=\mathrm{QRC} * \mathrm{QC}$

$Q S=Q S C^{*} Q C$

reference: (Brown et al., 1997).

reference: (Brown et al., 1997).

reference: (Brown et al., 1997).

reference: (Brown et

reference: (Brown et

; Intestinal lumen volumes, surfaces, absorption rates, transfer rates

PappCaco2 $=-4.73$

;Log Papp, calculation based on QSAR of Hou et al. (2004)

; Log (Papp,in vivo $)=0.6836 * \log ($ PappCaco-2) -0.5579

reference: (Sun et al. 2002)

$\mathrm{Papp}=10^{\wedge}(0.6836 * \mathrm{PappCaco2}-0.5579) * 3600 / 10$

;apparent intestinal permeability coefficient in vivo $\{\mathrm{cm} / \mathrm{hr}\}$

Vin $=0.0012$

SAin $=0.134$

kin $=4.17$

;kabin1 $=$ Papp*SAin

Vin1 = Vin

SAin1 $=$ SAin

kabin1 $=$ Papp*SAin1

kin1 $=$ kin

$\operatorname{Vin} 2=$ Vin

SAin2 $=$ SAin

kabin2 $=$ Papp $*$ SAin2

$\operatorname{kin} 2=$ kin

Vin3 $=$ Vin
; volume for each compartment of intestines $\{L\}$

; surface area $\{\mathrm{dm} 2\}$

; transfer rate to next compartment within the intestines $\{/ \mathrm{hr}\}$

; absorption rate constant $\{\mathrm{L} / \mathrm{hr}\}$

; volume of intestine compartment $1\{\mathrm{~L}\}$

; surface area of intestine compartment 1 ddm2\}

; absorption rate constant of intestine compartment $1\{\mathrm{~L} / \mathrm{hr}\}$

; transfer rate to intestine compartment $2\{/ \mathrm{hr}\}$

; volume of intestine compartment $2\{\mathrm{~L}\}$

; surface area of intestine compartment $2\{\mathrm{dm} 2\}$

; absorption rate constant of intestine compartment $2\{\mathrm{~L} / \mathrm{hr}\}$

; transfer rate to intestine compartment $3 \quad$ /hr $\}$

; volume of intestine compartment $3\{\mathrm{~L}\}$ 


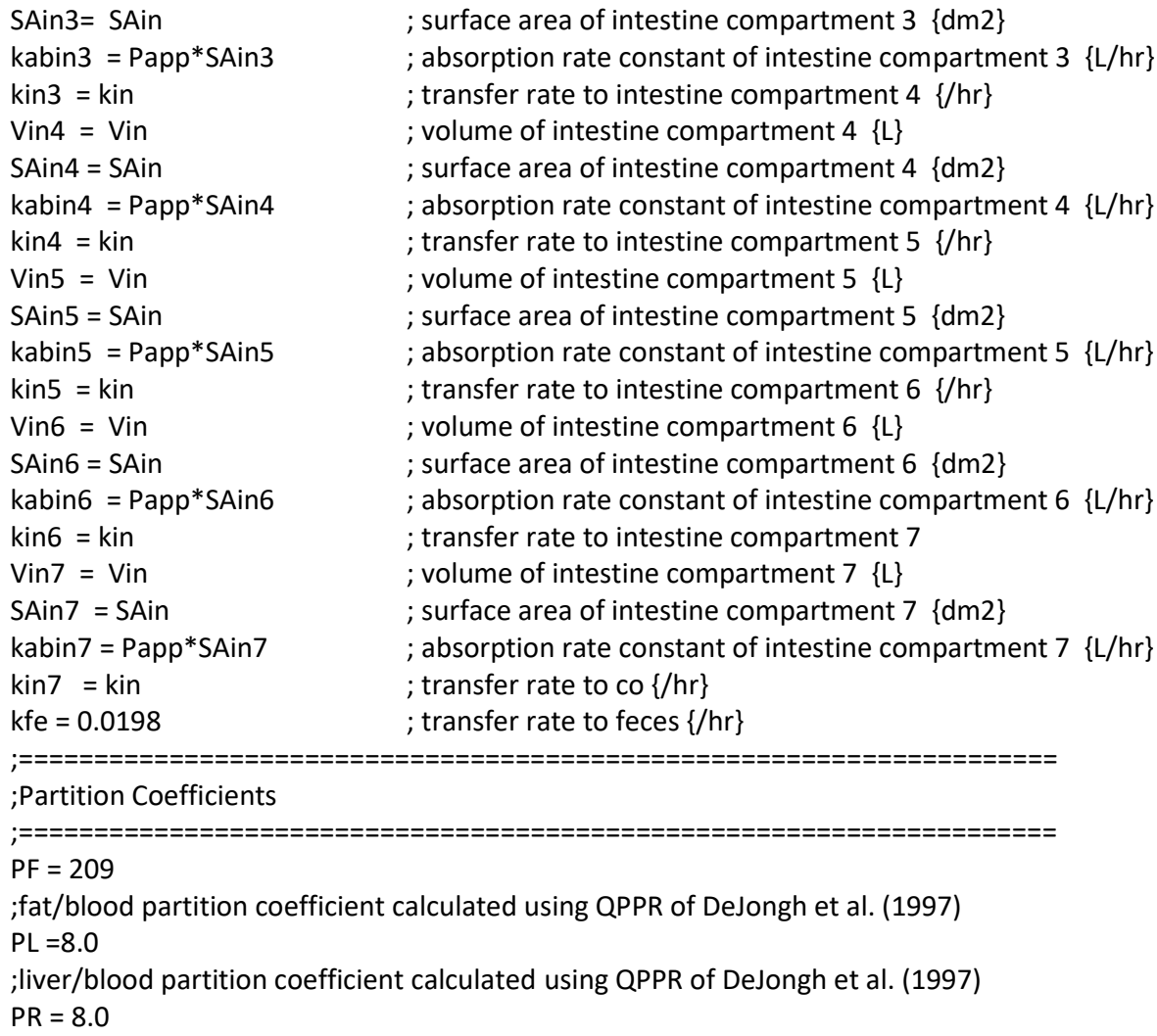

; $================$
;Partition Coefficients

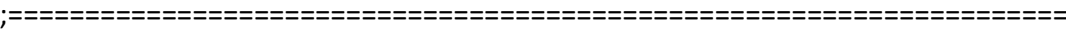

$\mathrm{PF}=209$

;fat/blood partition coefficient calculated using QPPR of DeJongh et al. (1997)

$\mathrm{PL}=8.0$

;liver/blood partition coefficient calculated using QPPR of DeJongh et al. (1997)

$\mathrm{PR}=8.0$

; rapidly perfused tissue/blood partition coefficient calculated using QPPR of DeJongh et al. (1997)

PS $=1.6$

;slowly perfused tissue/blood partition coefficient calculated using QPPR of DeJongh et al. (1997)

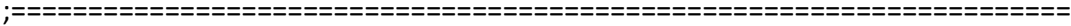

;Kinetic parameters

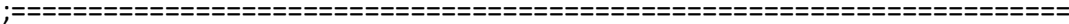

;Metabolism liver

;metabolism of diethylstilbestrol, scaled to maximum rate of metabolism

$\begin{array}{lll}\text { CLint }=S 9 P * V L *(C L i n t S 9 * 60 * 1 E-6) & \{\mathrm{L} / \mathrm{hr}\} & ; \text { Hepatic clearance } \\ \text { CLintS9 }=448.2 & \{\mathrm{ul} / \mathrm{min} / \mathrm{mg} \text { protein }\} & ; \text { Hepatic clearance derived from S9 fraction; } \\ & & ; \text { male: } 588.8 \\ \mathrm{S9P}=87 * 1000 & \{\mathrm{mg} / \mathrm{kg}\} & ; \text { female: } 448.2 \\ & & ; \text { mg protein in } \mathrm{kg} \text { liver } \\ & \text {;reference: (Chiu and Ginsberg, 2011) }\end{array}$

; Run settings

; ;Molecular weight

$\mathrm{MW}=268.35$

;oral dose

ODOSEmg1 $=0.25 \quad\{\mathrm{mg} / \mathrm{kg}$ bw $\} \quad ;$ ODOSEmg1 $=$ given oral dose in $\mathrm{mg} / \mathrm{kg}$ bw

ODOSEumol2 = ODOSEmg $1 * 1 \mathrm{E}-3 / \mathrm{MW} * 1 \mathrm{E} 6 \quad\{\mathrm{umol} / \mathrm{kg} \mathrm{bw}\}$

;ODOSEumol2 = given oral dose recalculated to $\mathrm{umol} / \mathrm{kg}$ bw

ODOSEumol = ODOSEumol $2 * \mathrm{BW} ; \quad$;ODOSEumol $=$ umol given oral 


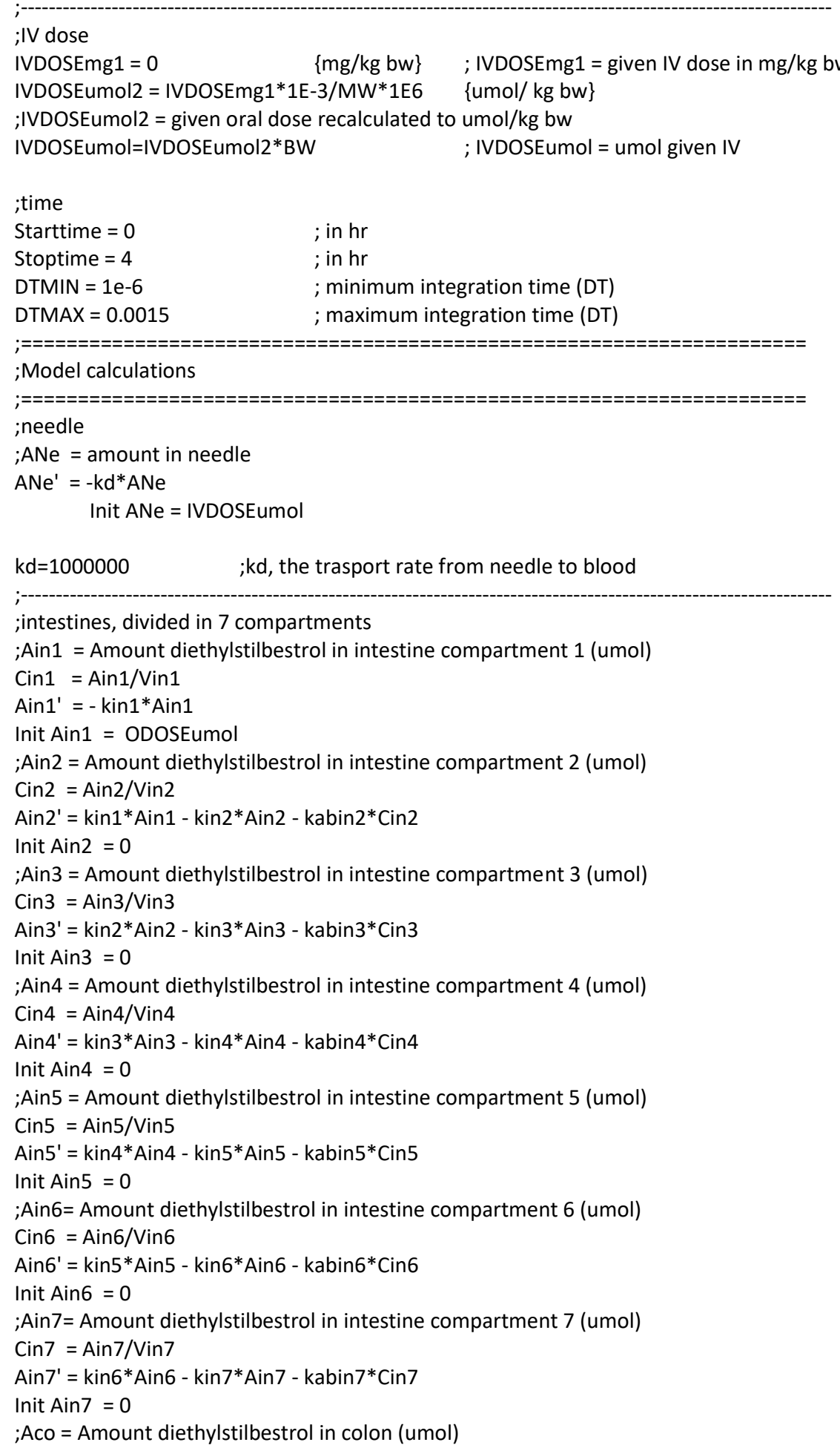




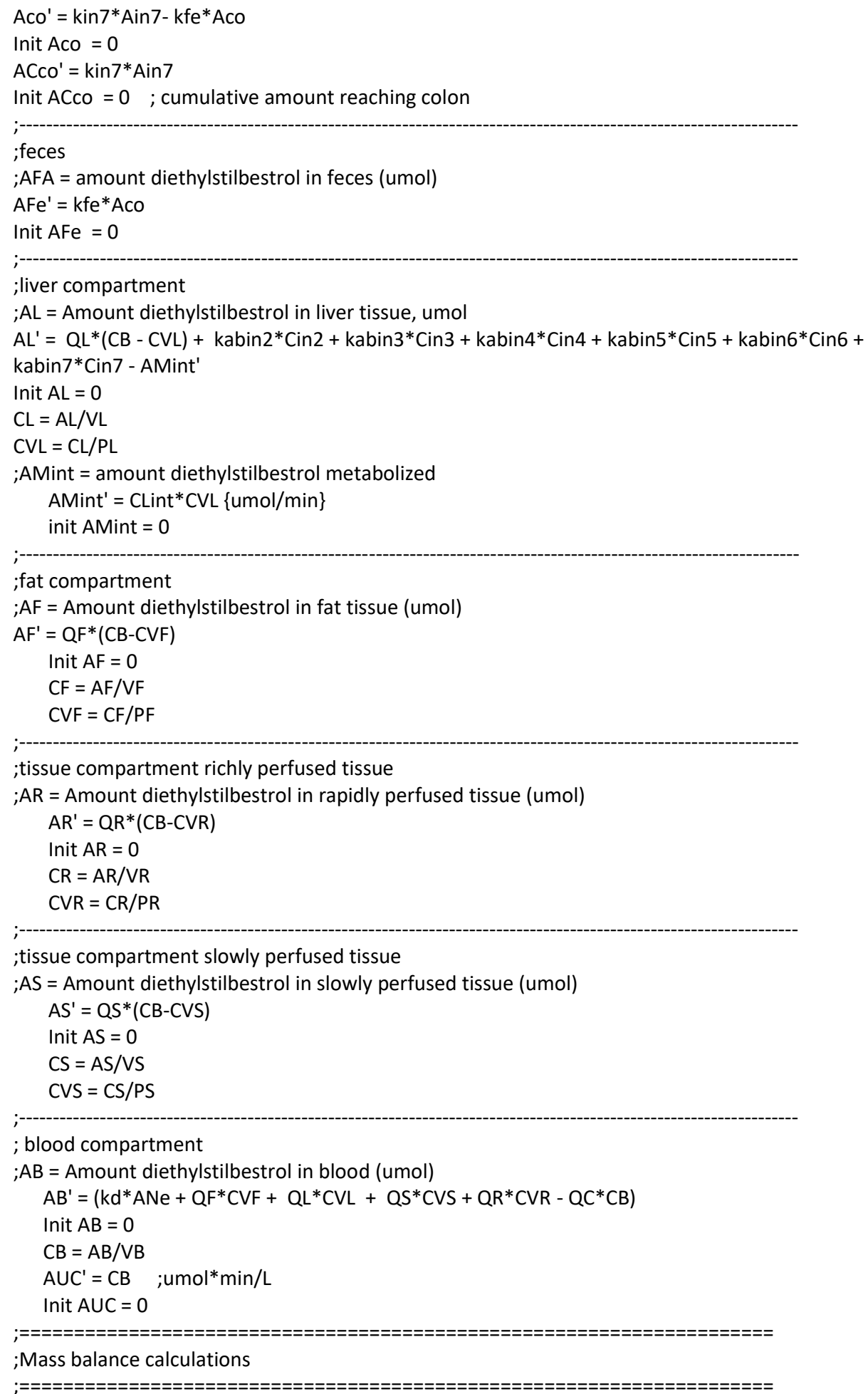


Total $=$ ODOSEumol + IVDOSEumol

Calculated $=$ Ain1 + Ain2 + Ain3 + Ain4 $+A i n 5+A i n 6+A i n 7+A c o+A F e+A L+A M i n t+A F+A S+A R$

$+\mathrm{AB}+\mathrm{ANe}$

ERROR $=(($ Total-Calculated $) /$ Total $+1 \mathrm{E}-30) * 100$

MASSBBAL=Total-Calculated +1

\section{Supplementary material 2. Results of hepatic clearance of DES}

To determine the hepatic clearance (CLint) of DES, substrate depletion approach was used. The CLint of the parent compound from phase I and phase II metabolism was determined in incubations liver S9 fraction from both male (fig. 1A) and female (fig. 1B) Sprague Dawley rats, in the presence of the relevant co-factors NADPH, UDPGA, PAPS and acetyl CoA.
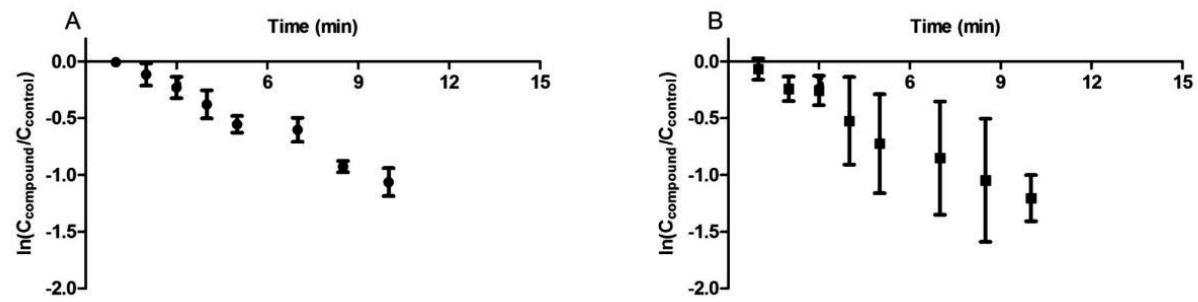

Fig. 1. The substrate depletion curves of DES. Symbols represent the average $\operatorname{In}\left(C_{\text {compound }} / C_{\text {control }}\right)$ at different incubation time points. The parent compound DES was incubated with male (A) and female (B) Sprague-Dawley rats liver S9 fraction together with co-factors NADPH, UDPGA, PAPS and acetyl.

\section{Supplementary material 3. BMD analysis}

BMD analyses were performed using the exponential model for continuous data in the PROAST software from The National Institute for Public Health and the Environment of the of the Netherlands (RIVM) version 38.9 (Slop 2002). The in vivo development toxicity data obtained from Wardell et al. and Cornwall et al. were presented in table 3.1 and 3.2, respectively. The BMD results of these two in vivo datasets were shown in table 3.3 and 3.4, respectively. The predicted dose-response data using the PBK modelling-based reverse dosimetry on in vitro EST assay data were shown in table 3.5 and the BMD results were shown in table 3.6. 
Table 3.1 In vivo data used for BMD modeling of developmental toxicity of DES exposure in female SpragueDawley rats (Wardell et al. 1982).

\begin{tabular}{|c|c|c|}
\hline Dose $(\boldsymbol{\mu g} / \mathbf{k g ~} \mathbf{b w})$ & Total number of fetuses & Number of dead fetuses \\
\hline 0 & 716 & 54 \\
\hline 30 & 112 & 11 \\
\hline 45 & 128 & 23 \\
\hline 60 & 97 & 50 \\
\hline 80 & 113 & 73 \\
\hline 110 & 66 & 48 \\
\hline
\end{tabular}

Table 3.2 In vivo data used for BMD modeling of developmental toxicity of DES exposure in female SpragueDawley rats (Cornwall et al. 1984).

\begin{tabular}{|c|c|c|c|}
\hline Dose $(\boldsymbol{\mu g} / \mathbf{k g} \mathbf{b w})$ & Number of litters & $\begin{array}{c}\text { Average number of } \\
\text { resorptions per litter }\end{array}$ & SD Standard deviation \\
\hline 0 & 36 & 3.0 & 2.8 \\
\hline 45 & 20 & 4.1 & 5.4 \\
\hline 60 & 7 & 3.9 & 3.9 \\
\hline 80 & 10 & 6.5 & 1.8 \\
\hline 110 & 6 & 4.6 & 0 \\
\hline 200 & 4 & 4 & \\
\hline
\end{tabular}

Table 3.3 Results from the BMD analysis using PROAST software on incidences of prenatal resorptions in female rats exposed to DES by oral exposure on gestation days 6 to 18 for the total number of fetuses (Wardell et al. 1982). The table presents the benchmark dose (BMD10), the 95\% benchmark dose lower confidence limit (BMDL10) and the 95\% benchmark dose upper confidence limit (BMDU10) values for a BMR of 10\% as extra risk with characteristics of the model fit.

\begin{tabular}{|c|c|c|c|c|c|}
\hline Model & loglik & Accepted & BMDL & BMDU & BMD \\
\hline Exponential & -468.01 & yes & 38.2 & 48.5 & 43.7 \\
\hline
\end{tabular}

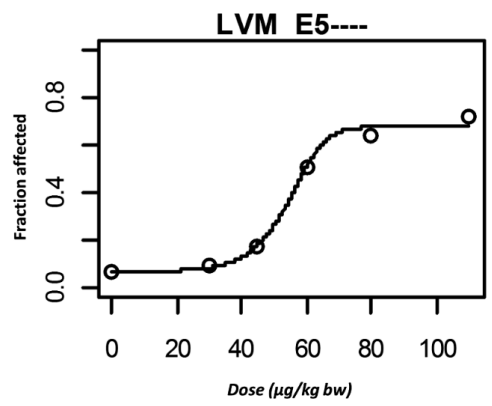


Table 3.4 Results from the BMD analysis using PROAST software on incidences of prenatal resorptions in female rats exposed to DES by oral exposure on gestation days (GD) 6 to 18 for the total number of litters (Cornwall et al. 1984). The table presents the benchmark dose (BMD10), the 95\% benchmark dose lower confidence limit (BMDL10) and the 95\% benchmark dose upper confidence limit (BMDU10) values for a BMR of 10\% asextra risk with characteristics of the model fit.

\begin{tabular}{|c|c|c|c|c|c|}
\hline Model & loglik & Accepted & BMDL & BMDU & BMD \\
\hline Exponential & -35.87 & yes & 17.5 & 31 & 23.3 \\
\hline
\end{tabular}

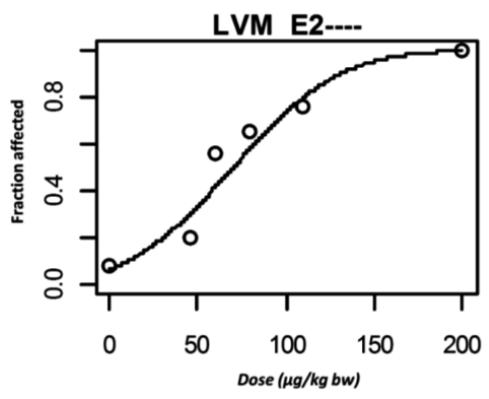

Table 3.5 Predicted dose-response data of DES used for BMD analysis. These response is shown as differentiated embryonic bodies compared to the solvent control

\begin{tabular}{|c|c|c|c|}
\hline Dose $(\boldsymbol{\mu g} / \mathbf{k g} \mathbf{b w})$ & Numbers & Average of response & Standard deviation \\
\hline 300 & 24 & 24 & 0 \\
\hline 9200 & 24 & 22.5 & 0.8 \\
\hline 30600 & 24 & 17.8 & 0.5 \\
\hline 91700 & 24 & 6.5 & 1 \\
\hline 305500 & 24 & 1.2 & 1.2 \\
\hline
\end{tabular}

Table 3.6 Results from the BMD analysis using PROAST software of the predicted dose-response data of DES using PBK modelling-based reverse dosimetry approach based on the EST assay data. The table presents the benchmark dose $\left(B M D_{10}\right)$, the 95\% benchmark dose lower confidence limit (BMDL ${ }_{10}$ ) and the $95 \%$ benchmark dose upper confidence limit $\left(B M D U_{10}\right)$ values for a $B M R$ of $10 \%$ as extra risk with characteristics of the model fit.

\begin{tabular}{|c|c|c|c|c|c|}
\hline Model & loglik & Accepted & BMDL & BMDU & BMD \\
\hline Exponential & -38.66 & yes & 7730 & 34300 & 16300 \\
\hline
\end{tabular}




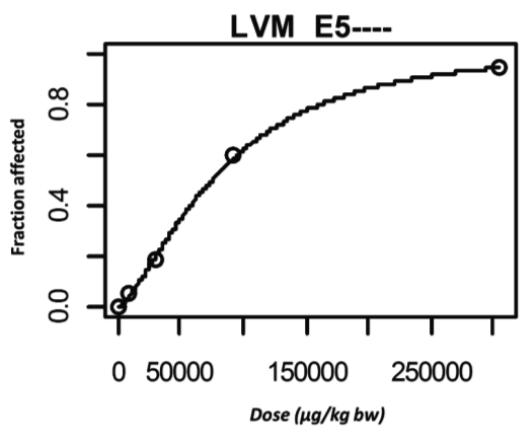

\section{Supplementary material 4. Cytotoxicity and inhibition of ES-D3 cell differentiation by E2}

To study the in vitro developmental toxicity of E2, the effect of the compound on the differentiation of ES-D3 cells into contracting cardiomyocytes was evaluated. First, the WST-1 assay upon both three-day and five-day exposure was performed to evaluate the cytotoxic effects of E2 on the ES-D3 cells. The E2 concentrations tested were non-cytotoxic up to $10 \mu \mathrm{M}$ as determined in the three-day and five-day cytotoxicity assay. Starting from $30 \mu \mathrm{M}$ the cell viability started to decrease. Regarding the differentiation effect, E2 does not inhibit the differentiation of the ES-D3 cells into contracting cardiomyocytes (Fig. 4.1) at concentrations that were not yet cytotoxic, indicating that inhibitory effects on the differentiation of EBs are due to cytotoxicity of E2.

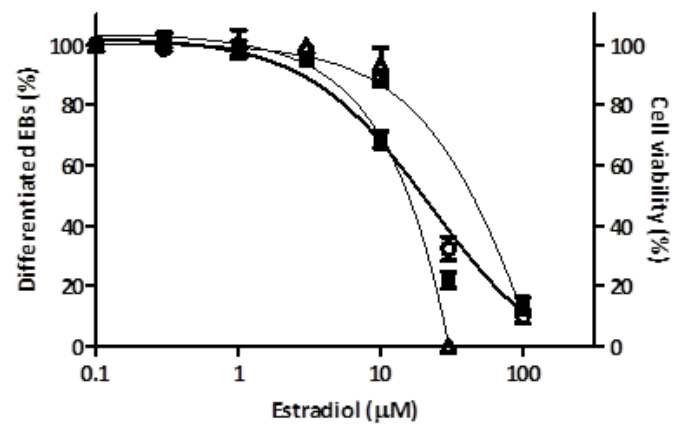

Fig. 4.1 Concentration-dependent effects of E2 on cell viability upon three-day (o) and five-day (-) exposure and on ES-D3 cell differentiation ( $\Delta)$. The figure presents data from three independent experiments. 
CHAPTER 4 


\section{Assessment of the in vitro developmental toxicity of diethylstilbestrol and estradiol in the zebrafish embryotoxicity test}

Aziza Hussein Bakheit Adam, Lenny Kamelia, Laura HJ de Haan, Jochem Louisse and Ivonne MCM Rietjens 


\section{Abstract}

The present study investigated the developmental toxicity of DES in the zebrafish embyotoxicity test (ZET). This was done to investigate whether the ZET would better capture the developmental toxicity of DES than the embryonic stem cells test (EST) that was previously shown to underpredict the DESinduced developmental toxicity as compared to in vivo data, potentially because the EST does not capture late events in the developmental process. The ZET results showed DES-induced growth retardation, cumulative mortality and malformations (i.e. induction of pericardial edema) in zebrafish embryos while the endogenous ER $\alpha$ agonist $17 \beta$-estradiol (E2) showed only growth retardation and cumulative mortality with lower potency compared to DES. Furthermore, the DES-induced pericardial edema formation in zebrafish embryos could be counteracted by co-exposure with fulvestrant, indicating that the ZET captures the role of ER $\alpha$ in the mode of action underlying this developmental toxicity. Altogether, it is concluded that the ZET differentiates DES from E2 with respect to their developmental toxicity effects, while confirming the role of ER $\alpha$ in the developmental toxicity of DES. Furthermore, comparison to in vivo data revealed that, like the EST, in a quantitative way also the ZET did not capture the relatively high in vivo potency of DES as a developmental toxicant. 


\section{Introduction}

Diethylstilbestrol (DES) is a synthetic hormone that was first prescribed in the period of 1938 to 1971 for pregnant women to prevent miscarriage and premature delivery, for menstrual problems and for cancer treatment (Herbst and Anderson, 2015; Reed and Fenton, 2013). However, while these claimed beneficial effects were not observed, adverse effects were reported including spontaneous abortion, second trimester pregnancy loss, preterm delivery, neonatal death, sub-/infertility and cancer of reproductive tissues in neonates, all pointing at developmental toxicity (IARC, 2012; Newbold, 2004; Reed and Fenton, 2013). Subsequent in vivo animal studies confirmed the developmental toxicity of DES including the induction of embryonic death, resorptions and morphological changes in mice and rats (Cornwall et al., 1984; Nagao et al., 2013; Nagao and Yoshimura, 2009; Odum et al., 2002).

It was also shown that the estrogen receptor alpha $(E R \alpha)$ is involved in the mode-of-action underlying DES-induced malformations and phenotypic changes in the reproductive tract in male and female mice neonates, while this effect was not observed in ER $\alpha$ knockout mice (Couse et al., 2004; Couse and Korach, 2004; Prins et al., 2001). The role of ER $\alpha$ in DES-mediated developmental toxicity was also confirmed in our recent in vitro developmental toxicity study in which DES tested positive in the ES-D3 cell differentiation assay of the embryonic stem cell test (EST) and this DES-induced inhibition of ES-D3 cell differentiation into beating cardiomyocytes could be counteracted by the ER $\alpha$ antagonist fulvestrant (Adam et al., 2019a). However, when correlating EST data to in vivo developmental toxicity data for DES and other developmental toxicants, the EST appeared to largely underpredict the developmental toxicity of DES (Adam et al., 2019a). Thus, it was concluded that although the EST did capture ER $\alpha$-mediated adverse developmental effects of DES in vitro, it apparently did not adequately capture all processes underlying DES-induced developmental toxicity. A possible explanation for this might be that the ES-D3 cell differentiation assay of the EST lacks the complex biological system and the metabolic capacity of an intact organism (Spielmann et al., 2006), 
and may only be suitable for detection of adverse effects in the early developmental stages (Pera and Trounson, 2004).

Such late developmental effects may in theory be better reflected by the zebrafish embryotoxicity test (ZET). The ZET is one of the most recent in vitro alternative assays for developmental toxicity testing and is often used in addition to the validated embryonic stem cell test (EST), the rat limb bud micromass test (MM) and the rat postimplantation whole embryo culture (WEC) (Busquet et al., 2014: Genschow et al., 2004; Hill et al., 2005; Lee et al., 2012; Piersma et al., 2004; Spielmann et al., 2004). The use of zebrafish embryos as developmental toxicity in vitro model is facilitated by the transparency of the organism throughout embryonic development and a rapid embryonic growth (Panzica-Kelly et al., 2012). Furthermore, development of the zebrafish embryos is considered to be very similar to the embryogenesis in vertebrates including humans (Sipes et al., 2011).

The aim of the present study was to assess the developmental toxicity of DES in the ZET, and to compare the effects obtained for this synthetic ER $\alpha$ agonist with the effects of the endogenous ER $\alpha$ agonist $17 \beta$-estradiol (E2). In addition, it was investigated whether the role of $E R \alpha$, observed in vivo and in the EST, could also be demonstrated for the in vitro developmental toxicity of DES in the ZET. To this end, the in vitro embryotoxicity of DES was quantified in the ZET in the absence and presence of the ER $\alpha$ antagonist fulvestrant.

\section{Materials and methods}

\subsection{Materials}

Diethylstilbestrol (DES; CAS no. 56-53-1), estradiol (E2; CAS no. 50-28-2), fulvestrant (CAS no. 129453-61-8) and 3,4-dichloroaniline (CAS no. 95-76-1) were purchased from Sigma-Aldrich (Zwijndrecht, The Netherlands). Dimethyl sulfoxide (DMSO) was purchased from Acros Organics (Geel, Belgium).

\subsection{Zebrafish maintenance and embryo collections}


The wild-type adult zebrafish (Danio rerio) $A B$ line was obtained from the research facility Carus, Wageningen University and Research (Wageningen, The Netherlands) and maintained in a flowthrough aquarium system at $27^{\circ} \mathrm{C}$ with 14 hours light/10 hours dark cycle. The zebrafish embryos were obtained via spawning groups by placing adult males and females with a ratio of 1:2 in spawning tanks 4-5 hours before the beginning of the dark cycle on the day before the test. Spawned eggs were collected, rinsed with egg water (prepared by dissolving 40 gram Instant Ocean ${ }^{\circledR}$ sea salt (Blacksburg, Virginia, USA) in 1 litre distilled water, $\mathrm{pH}$ was adjusted to $7-8$ and incubated at $26^{\circ} \mathrm{C}$ until further steps. The egg water was also used as the assay medium for the zebrafish embryotoxicity test. Collected eggs were examined under a stereomicroscope, and embryos that developed normally and reached the blastula stage were selected for subsequent experiments while embryos that showed anomalies were discarded. These maintenance and selection criteria are based on the OECD guideline 236 for fish embryo acute toxicity (OECD, 2013).

\subsection{Zebrafish embryotoxicity test (ZET)}

The ZET was initiated at 4-5 hours post fertilization (hpf) at the gastrulation period and ended at 96 hpf, as this covers the entire organogenesis in a zebrafish embryo (Beekhuijzen et al., 2015; OECD, 2013). The zebrafish embryo exposure was performed in 24-well plates (Greiner Bio-one, Frickenhausen, Germany), sealed with a self-adhesive film cover (Sigma-Aldrich, Zwijndrecht, The Netherlands). Twenty wells of the 24-well plate were used for exposure to one concentration of test compound and the other four wells were used for the internal plate control. Exposure medium was prepared by mixing 400 times concentrated stock solutions of the test compounds (dissolved in DMSO) with egg water. The exposure medium was then transferred into 20 wells of the 24-well plate, at $2 \mathrm{ml}$ exposure medium/well, and for the internal plate control, $2 \mathrm{ml}$ egg water was added into each of the four remaining wells. The zebrafish embryos ( 1 embryo per well) were added after filling the wells with either exposure medium or egg water. The plate was then sealed with selfadhesive film cover to prevent evaporation of test compound throughout the exposure period (up to $96 \mathrm{hpf})$. All samples were tested at a range of final concentrations up to $100 \mu \mathrm{M}$ in egg water. Solvent 
controls (0.25\% DMSO), positive controls ( $4 \mathrm{\mu g} / \mathrm{ml} \mathrm{3,4-dichloroaniline)} \mathrm{and} \mathrm{negative} \mathrm{controls} \mathrm{(egg}$ water only) were included in each independent experiment. Plates were incubated at $26^{\circ} \mathrm{C}$ with a photo period of 14 hours light:10 hours dark. Embryos were scored every 24 hours ( $t=0$ is $0 \mathrm{hpf}$ ) for developmental abnormalities and cumulative mortality using an inverted microscope until $96 \mathrm{hpf}$, based on the extended general morphological scoring (GMS) system described by Beekhuijzen et al., (2015). Deviation from normal developmental stages, for example incomplete detachment of tail, incomplete development of eyes, fin, and mouth, unhatched embryos, will result in a lower total GMS value corresponding to a certain extent of developmental retardation. The GMS used for the exposure time window of 0-96 hpf is based on the $96 \mathrm{hpf}$ endpoints, as described in detail by Beekhuijzen et al. (2015). The ZET was considered valid if the following was observed: $\leq 1$ dead embryo (out of 4 ) in the internal plate control of every exposed-plate; $\leq 3$ dead embryos (out of 24) in the negative control plate (at least $87.5 \%$ survival rate); $\leq 2$ dead embryos (out of 20 ) in the solvent control plate $(0.25 \% \mathrm{v} / \mathrm{v}$ DMSO); $\leq 14$ live embryos (out of 20 ) in the positive control plate (4 $\mu \mathrm{g} / \mathrm{ml}$ 3,4-dicholoaniline; exposure to positive control should result in a minimum of $30 \%$ mortality by $96 \mathrm{hpf}$ ). An embryo was considered dead when it was coagulated (dead milky white embryo appearing dark under the microscope) after $24 \mathrm{hr}$. If the somites did not form after 48 hours, the embryos were also considered dead, and when the heartbeat was absent after 48,72 and $96 \mathrm{hrs}$ the embryo was considered dead as well. In addition to the GMS, the observed teratogenicity endpoints that include malformation of the body shape, head, heart, sacculi and yolk deformation were also listed and scored (Beekhuijzen et al., 2015; Kamelia et al., 2019). At least four independent experiments were performed for each test compound.

To assess whether DES or E2 are teratogenic compounds, the teratogenicity index (TI) approach was used. Within the ZET, the $\mathrm{TI}$ is defined as the ratio between the $50 \%$ lethal concentration (LC50) and the $50 \%$ effect concentration (EC50) based on the teratogenic endpoints described by Beekhuijzen et al. (2015) and Selderslaghs et al. (2012)). The list of teratogenic endpoints described by Beekhuijzen et al. (2015) and Selderslaghs et al. (2012) is presented in the supplementary materials. 
To assess whether the observed developmental toxicity in the ZET was mediated via the ER $\alpha$, studies in which the effects of DES on zebrafish embryo development were assessed, were performed in the absence or presence of the ER $\alpha$ antagonist fulvestrant. To that end, first a concentration of fulvestrant that did not affect development of zebrafish embryo by itself was determined, which was then applied in the co-exposure studies. Final solvent concentrations in these studies was also $0.25 \%$ v/v DMSO.

\subsection{Data analysis}

Figures of concentration-response curves for the effect of test compounds in the ZET were made using GraphPad Prism 5.0. Data were fitted to a sigmoid concentration-response curve with three parameters. For this analysis, results obtained in the ZET were expressed as fraction of the GMS score at $96 \mathrm{hpf}$ compared to the GMS score of the solvent control $(0.25 \% \mathrm{v} / \mathrm{v} \mathrm{DMSO})$, and are presented as mean \pm standard error of the mean (SEM) of 4 experiments. In vitro concentrationresponse curves from the ZET data were also analysed using the proast web-tool for BMD analysis, based on the PROAST software version 67.0 developed by the Dutch Institute for Public Health and the Environment (RIVM, The Netherlands) (Slob, 2019), in which the benchmark concentration (BMC) at a predefined benchmark response (BMR) was calculated using a fitted dose-response curve. For these analyses, concentration-response data for the GMS were used. For both DES and E2 a decrease of $5 \%$ in GMS and a decrease of $5 \%$ in the survival were defined as the BMR (BMR05) for calculating the corresponding BMC (BMC05). The model with the lowest BMC outcome was selected to calculate the BMC05 (Supplementary materials). For TI calculation, both LD50 and EC50 values were determined from the concentration response curves obtained in the ZET using the same PROAST web-tool for BMD analysis. To this purpose, the BMR was set to $50 \%$, representing the concentration causing either $50 \%$ cumulative mortality or lethality (LD50) or $50 \%$ teratogenic-related effects (EC50), such as pericardial edema formation. 
To assess for statistical differences of treatment effects, multiple paired t-tests between the treatments and the solvent control were performed using GraphPad Prism 5.0 (California, US).

\section{Results}

\subsection{In vitro developmental toxicity of E2 and DES in the ZET}

Figure 1 shows the effect of DES and E2, in the ZET. As shown in Figure 1, exposure to either E2 (A) or DES (B) induced concentration-dependent effects on the GMS score and the embryo survival in the ZET (scored at $96 \mathrm{hpf}$ ). BMD analysis for GMS indicated a 2.8-fold higher potency for DES compared to E2 as reflected by the BMC05 values of 0.63 and $1.77 \mu \mathrm{M}$, respectively. The concentrationdependent effects on the survival at $96 \mathrm{hpf}$ are shown in Figure 1 and related results of the BMD analysis provide BMC05 values of 1.5 and $4.7 \mu \mathrm{M}$ for DES (B) and E2 (A), respectively, indicating that based on this endpoint DES is, 3-fold more potent than E2, in the ZET. Results of the BMD analysis are presented in the supplementary materials.

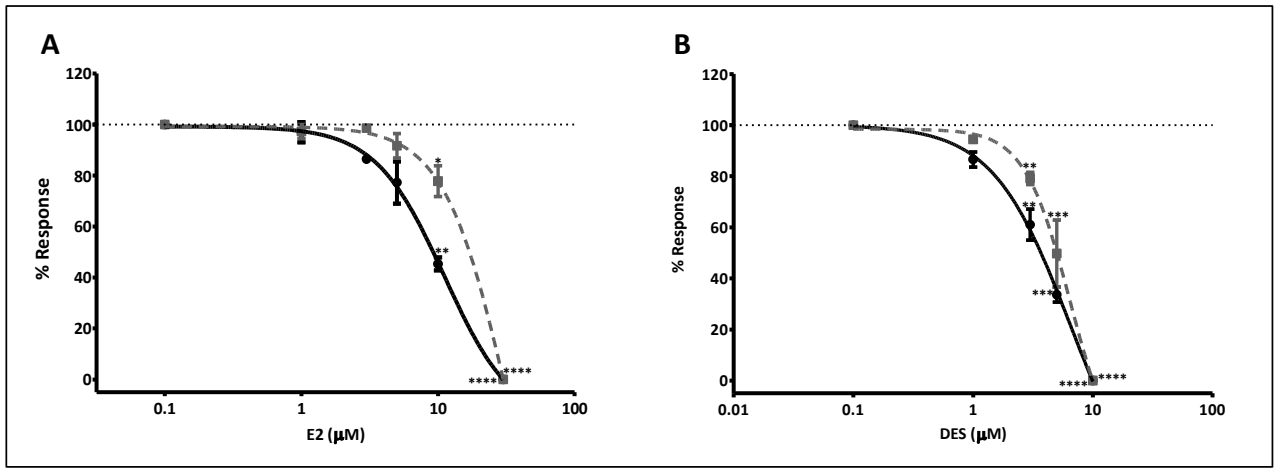

Figure 1. Concentration-dependent effects of E2 (A) and DES (B) in the ZET on GMS score (black line with filled circles) and survival (grey dotted line with filled squares). Results obtained from $0.25 \% \mathrm{v} / \mathrm{v}$ DMSO (solvent control) is illustrated by the dotted line. The statistical analysis that indicates a significant difference of results between the compound tested and solvent control at **** $p<0.0001 ; * * p<0.001 ; * * p<0.01 ; * p<0.05$.

\section{Malformations and teratogenicity in zebrafish embryos and larvae}

In addition to the GMS, the teratogenicity of E2 and DES was evaluated for some specific teratogenic endpoints with emphasis on those endpoints that have been shown to be specifically affected upon exposure to teratogens, as described by Beekhuijzen et al. (2015). The teratogenic endpoints 
described by Beekhuijzen et al. (2015) are malformation of the head, malformation of the sacculi, malformation of the tail, malformation of the heart, deformed body shape and yolk deformation (Beekhuijzen et al., 2015). The outcome for these individual endpoints at $96 \mathrm{hpf}$, including induction of pericardial and yolk sac edema are presented in Figures 2 and 3. Figure 2 shows that no induction of pericardial edema was observed in embryos exposed to E2 (up to $10 \mu \mathrm{M}$ ), except for the embryos exposed to the highest concentrations (10 and $30 \mu \mathrm{M})$. Interestingly, and in contrast to E2, DES induced pericardial edema in a concentration-dependent manner with significant differences compared to the solvent control already at 3 and $5 \mu \mathrm{M}$ (Figures 3 and 4). Furthermore, DES induced several other morphological effects not observed for E2, including short tail, curved tail and yolk sac edema (Figure 5).

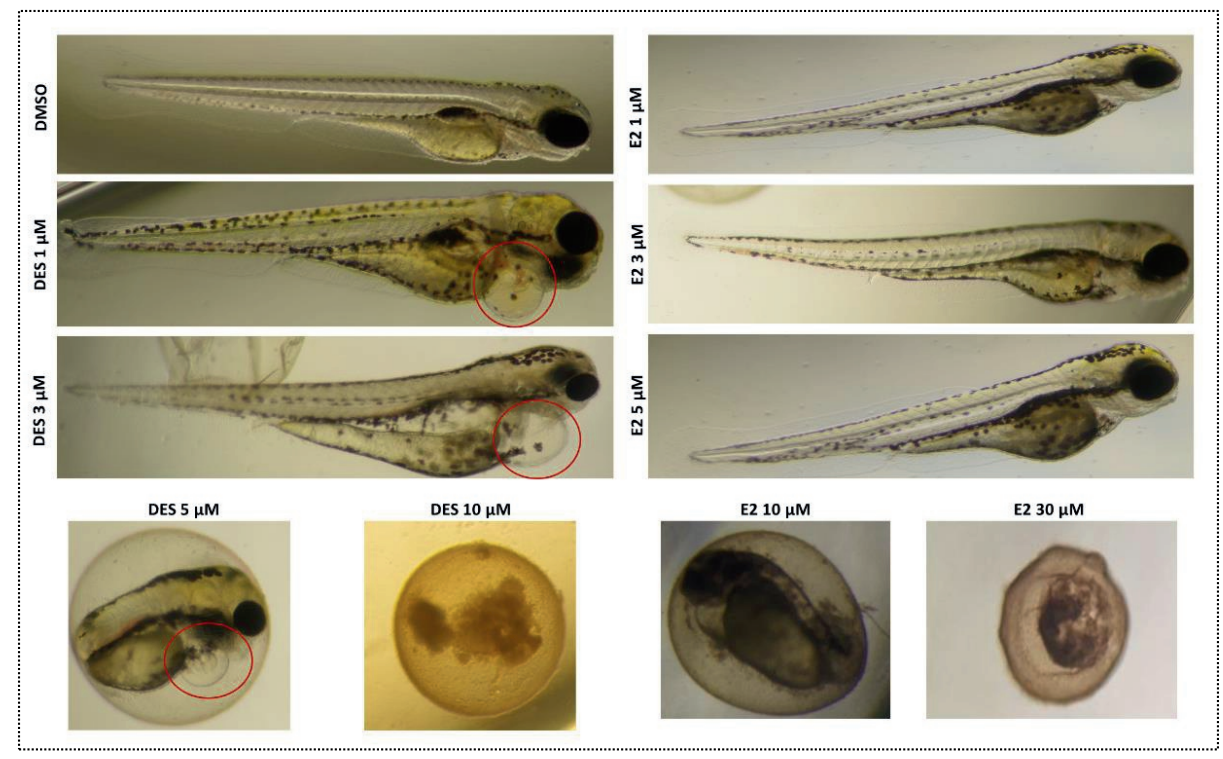

Figure 2. Representative images of morphological analysis of zebrafish embryos exposed to different concentrations of E2 and DES showing DES-induced pericardial edema (structure in circle), which is not observed upon exposure to $E 2$. 


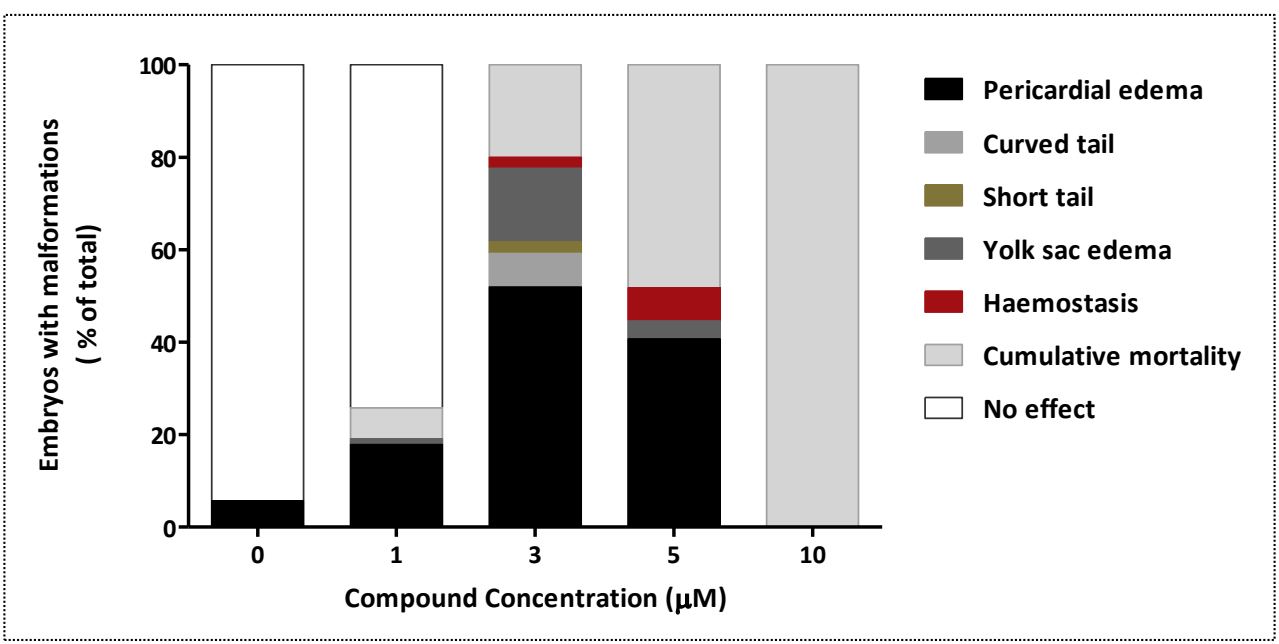

Figure 3. Concentration-dependent adverse developmental effects of DES in the ZET. Colouring within the bars illustrating different teratogenic endpoints scored including pericardial edema, malformation in tail (short and curved tail), yolk sac edema, haemostasis and cumulative mortality.

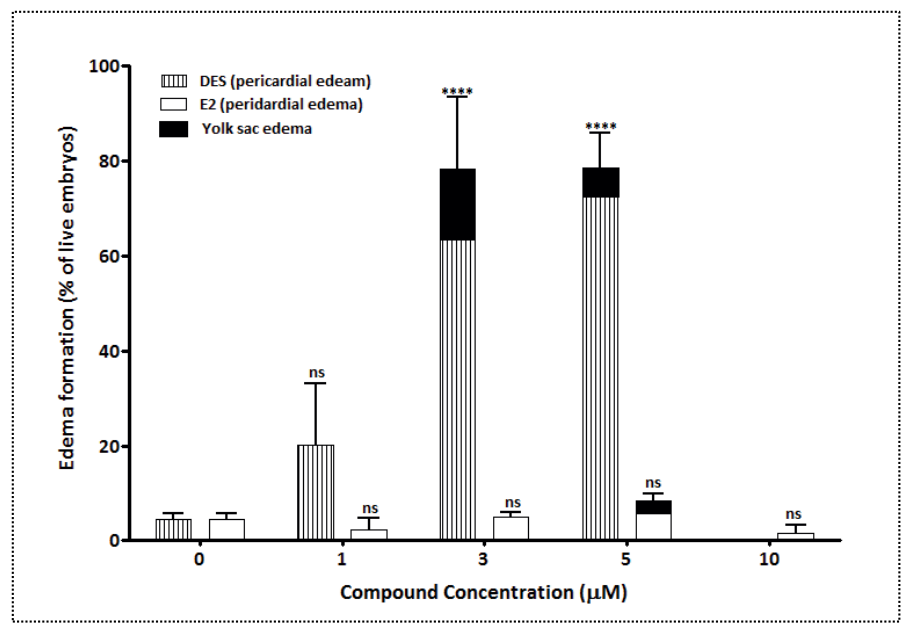

Figure 4. Concentration-dependent effect of DES and E2 on edema (pericardial and yolk sac (black bars)) formation in zebrafish embryos. For the statistical analysis, $* * * * p<0.0001, n s$ is non-significant. 


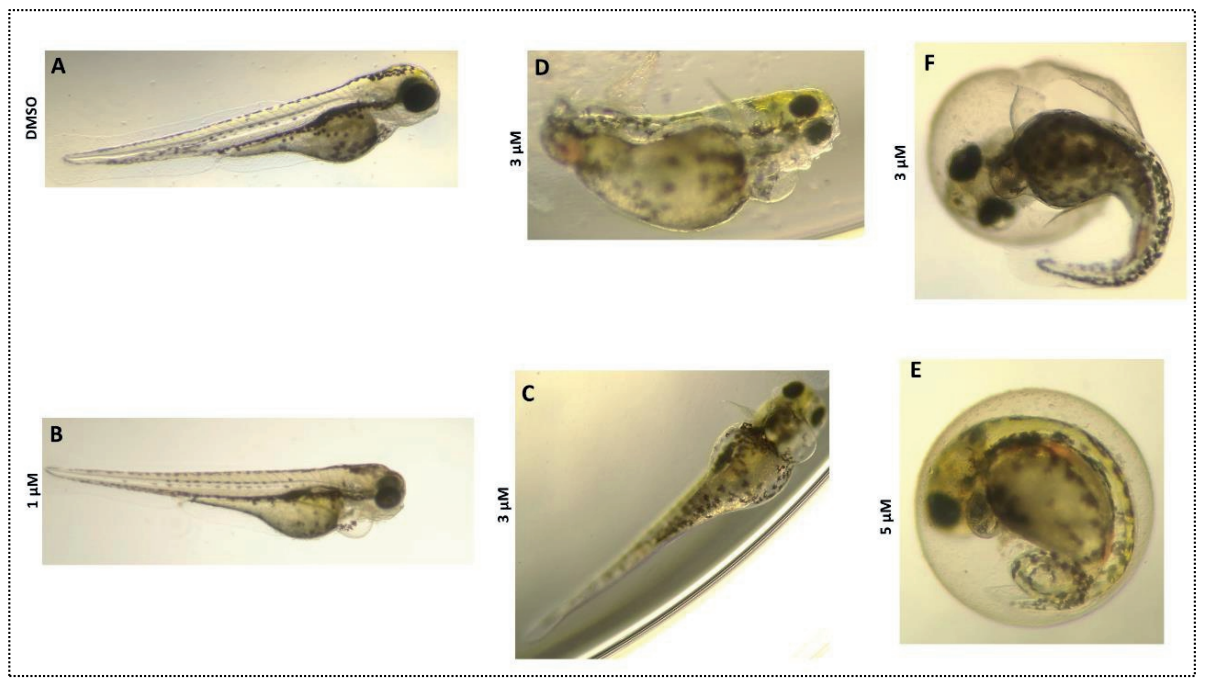

Figure 5. Presentation of A) normal embryos at 96 hpf (without phenotypic changes) and of adverse developmental effects observed mostly for DES but not E2-exposed zebrafish embryos in the ZET, including B) pericardial edema formation, C) deformed head with small eyes, and a deformed body shape with yolk sac edema, D) the "Short Tail" phenotype with a tail shorter than normal with haemostasis in the tail and yolk sac edema, E) chorion phenotype representing embryos that are still located in their chorion with yolk sac edema and haemostasis, and F) down curved tail, where the tail is oriented downward compared to the horizontal orientation/deformed body shape.

Regarding the teratogenicity classification, 3 teratogenic endpoints were observed in zebrafish embryos exposed to DES including malformation of the heart (pericardial edema), malformation of the tail (short and curved tail) and yolk deformation (yolk sac edema), while none of these teratogenic endpoints were observed to a significant extent upon exposure to E2 as upon exposure to E2 no concentration-dependent adverse effects, nor a statistically significantly effect different from the solvent control were observed. Furthermore, it is worth mentioning that an BMC50 could only be defined for the DES-induced pericardial edema scoring, but not for the other two aforementioned endpoints due to the presence of unhatched embryos at $96 \mathrm{hpf}$. In other words, it is hard to evaluate the malformation of the tail and body for the unhatched zebrafish embryo. Based on the pericardial edema as a teratogenic endpoint, a TI of 3.5 was obtained for DES by dividing the LC50 (BMC50) of the survival (cumulative mortality) $(8.8 \mu \mathrm{M})$ by the BMC50 of the pericardial edema formation $(2.5 \mu \mathrm{M})$. Given that E2 did not induce this adverse effect a TI for E2 could not be established. 


\subsection{Effect of the ER $\alpha$ antagonist fulvestrant on DES-induced developmental toxicity in zebrafish embryos}

To first establish a non-toxic concentration of the ER $\alpha$ antagonist fulvestrant in the ZET, the developmental effects and the in vitro teratogenic potential of fulvestrant in the ZET were evaluated. The results obtained (Figure $6 \mathrm{~A}$ ) indicate that fulvestrant does not affect the GMS score up to $3 \mu \mathrm{M}$, inducing no malformations or deformations. At $10 \mu \mathrm{M}$ the GMS score decreased without mortality being observed, while the highest concentration of $30 \mu \mathrm{M}$ resulted in cumulative mortality (at 96 hpf) for all exposed zebrafish embryos. Based on these results, a concentration of $3 \mu \mathrm{M}$ fulvestrant was selected to investigate the effect of the ER $\alpha$ antagonist on DES-induced developmental toxicity in the ZET because at this concentration fulvestrant did not interfere with the zebrafish development. Furthermore, $3 \mu \mathrm{M}$ is considerably (> 3000 times) higher than the IC50 for antagonist activity of fulvestrant to the $E R \alpha$, which amounts to 0.8 to $0.9 \mathrm{nM}$ as reported in the literature (Wakeling et al., 1991; Weir et al., 2016). Figure 6B presents the results obtained when DES was tested in the ZET in the absence or presence of $3 \mu \mathrm{M}$ fulvestrant. These results reveal that DESinduced pericardial and yolk sac edema formation in zebrafish embryos is significantly reduced in the presence of the ER $\alpha$-antagonist fulvestrant at $3 \mu \mathrm{M}$, although at higher concentrations of DES ( 3 and $5 \mu \mathrm{M})$ inhibition was not complete.

A

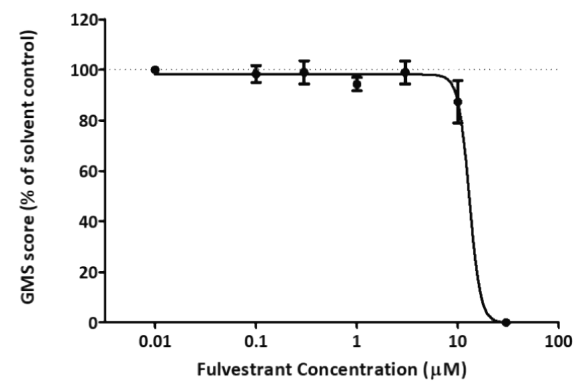

B

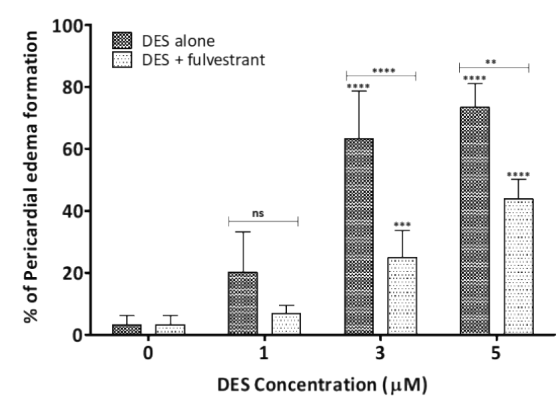

Figure 6. A) Concentration-dependent effect of fulvestrant in the ZET (scored at $96 \mathrm{hpf}$ ) based on the decrease in GMS score (GMS solvent control set at 100\%) and B) fulvestrant-mediated inhibition of the DES-induced pericardial edema formation tested in the absence or presence of $3 \mu \mathrm{M}$ fulvestrant. Edema formation is 
presented as percentage of surviving embyros. For the statistical analysis, ${ }^{* * * *} p<0.0001 ; * * * p<0.001 ; * * p$ $<0.01$.

\section{Discussion}

DES has been reported to induce developmental toxicity in vivo including embryo mortality and malformations, with an important role for its ER $\alpha$ agonist activity in the underlying mode of action (Wardell et al., 1982; Cornwall et al., 1984; Nagao et al., 2013; Nagao and Yoshimura, 2009; Odum et al., 2002). However, no in vivo developmental toxicity data have been reported for the endogenous ER $\alpha$ agonist E2. In our previous study, also in vitro data from the EST appeared to capture the differential effect of DES and E2 showing DES to be active in inducing in vitro developmental toxicity, while E2 was not since it appeared to be active only at cytotoxic concentrations (Adam et al., 2019a). The EST data also revealed that the DES-induced in vitro developmental toxicity was counteracted by the ER $\alpha$ antagonist fulvestrant thus demonstrating that the EST captured the role of ER $\alpha$ in the mode of action of DES. However, compared to other developmental toxicants tested in the EST, the assay seemed to underpredict the developmental toxicity potency of DES, possibly because the EST does not capture late events in the developmental process. Therefore, given that the ZET may be better able to detect late developmental effects, the aims of the present study were (1) to study the developmental toxicity of DES and E2 in the ZET and assess whether the ZET better predicts the in vivo DES-induced developmental toxicity, and (2) to determine the applicability of the ZET to capture the role of ER $\alpha$ in the developmental toxicity of DES, in order to investigate the potential of the ZET as a tool to study the role of ER $\alpha$ in developmental toxicity of estrogenic compounds.

Notable adverse developmental effects, including edema (pericardial and yolk sac), and dorsal curvature were observed in the DES-exposed zebrafish embryos, in addition to a concentrationdependent response for cumulative mortality and GMS. E2 appeared to be less active in the ZET, showing an induction of growth retardation and embryo mortality only starting at $10 \mu \mathrm{M}$. These findings are partially in line with a previous study reporting E2-induced malformation and mortality in zebrafish embryos at $10 \mu \mathrm{M}$ (Kishida et al., 2001; Ren et al., 2012). In contrast to E2, DES induced in 
vitro developmental toxicity, as measured in the ZET, reflected by cumulative mortality, growth retardation and pericardial edema formation (scored at $96 \mathrm{hpf}$ ) occurring in a concentrationdependent manner, starting at $1 \mu \mathrm{M}$. Other teratogenic effects than edema formation, including deformed head, deformed tail (i.e. short and curved-tail), haemostasis and yolk sac edema were also recorded in zebrafish embryos exposed to DES (Figures 3 and 5). These teratogenic effects of DES corroborate previously reported findings that DES altered heart development and function of zebrafish embryos (Campinho and Power, 2013). In this study, DES classified to be a teratogenic compound with a TI of 3.5, while E2 could not be classified as teratogenic, based on the fact that E2 did not induce malformations in the ZET at the tested concentrations, while effects on the GMS score coincided with mortality.

Additional experiments of the present study investigated the role of $E R \alpha$ in the developmental toxicity induced by DES in the ZET. Activation and disruption of the ER $\alpha$ pathway might contribute to disruption of embryonic development (Bondesson et al., 2015; Greco et al., 1993). Strong relationships between ER $\alpha$ activation and the adverse developmental effects of DES have been reported before. It has been reported for example that ER $\alpha$ is essential for DES to induce phenotypic changes in the reproductive tract (malformed reproductive tract) and alterations of several genes that are involved in regulation of embryonic development (Block et al., 2000; Couse et al., 2001; Couse and Korach, 2004; Ma et al., 1998; Miller et al., 1998). Also in the EST, a role for ER $\alpha$ in the developmental toxicity of DES has been elucidated (Adam et al., 2019a). With respect to the ZET, the results of the present study corroborate a role for ER $\alpha$ in the DES-induced developmental toxicity, as demonstrated by the fact that the ER $\alpha$ antagonist fulvestrant significantly counteracted the DESinduced pericardial edema formation. Fulvestrant at $3 \mu \mathrm{M}$ fully prevented edema formation induced by $1 \mu \mathrm{M}$ DES, while the effect was only partially prevented at 3 and $5 \mu \mathrm{M}$ DES. This partial effect of fulvestrant might be due to the relative ER $\alpha$ affinity of the two ligands, DES and fulvestrant, and their internal concentration at the relevant target organ. Comparison of the relative ER $\alpha$ binding affinities of DES and fulvestrant reveal the EC50 values for binding of DES and fulvestrant to be similar (Blair et 
al., 2000; Wakeling et al., 1991; Weir et al., 2016), so the competition may no longer be effective at equimolar concentrations (as now observed). Interestingly, when ER $\alpha$ activity was blocked in the EST by addition of fulvestrant, $0.15 \mu \mathrm{M}$ fulvestrant was able to fully block the DES-induced inhibition of ES-D3 cell differentiation (Adam et al., 2019a). The differences between the fulvestrant-mediated inhibition of DES-induced developmental toxicity in the EST and ZET assays could be due to differences in kinetics of fulvestrant and/or DES in the two model systems resulting in different concentrations at the cellular location of relevance, and/or to the fact that the EST detects other developmental stages than the ZET (Pera and Trounson 2004).

The partial, but not full, inhibition of DES-induced edema formation, in the presence of fulvestrant, in the ZET may also be due to the fact that in addition to ER $\alpha$-mediated effects also other modes of action contribute to the DES-induced developmental toxicity. Likewise, other developmental and teratogenic compounds, including for example thalidomide have been reported to induce their teratogenic effects by a combination of different mechanisms (Wani et al., 2017). For DES, the interaction with the retinoic acid receptors may for example play a role in its developmental toxicity, since it has been observed that DES upregulates CYP26A1 and CYP26B1 genes in vitro (Adam et al., 2019b). These two genes and the corresponding proteins are known to be involved in metabolism and elimination of retinoic acid, while their expression level has been identified as a marker for the developmental toxicity of some other developmental toxicants (Dimopoulou et al., 2016; Loudig et al., 2000; Luijten et al., 2010; Thatcher and Isoherranen, 2009). The notion that other than only ER $\alpha$ mediated pathways contribute to the DES-induced developmental toxicity is also supported by the fact that the endogenous estrogen E2 is not reported to be a developmental toxicant in in vivo and in vitro assays, as shown in the present study using the ZET and in a previous study using the EST (Adam et al., 2019a).

The present study shows that effect concentrations of DES in the ZET are in the low micromolar range. Since limited data are available to perform a correlation analysis between in vitro effect 
concentrations in the ZET and in vivo effect doses in rodents, we could not directly assess whether the ZET better predicts the in vivo developmental toxicity in a quantitative way than the (ES-D3 cell differentiation assay of the) EST (Adam et al., 2019). However, given that effect concentrations of DES in the EST are also in the low $\mu \mathrm{M}$ range, and given that also for other chemicals (for example azole fungicides (de Jong et al., 2011), glycol ether metabolites (Hermsen et al., 2011)) effect concentrations are quite similar in the ZET as in the EST, it is concluded that the ZET is not more sensitive than the EST to detect developmental toxicity of DES. This may be related to the fact that these two in vitro assays do not reflect repeated dose toxicity and/or epigenetic effects that may play a role in the mode of action of DES-induced developmental toxicity in vivo (Titus-Ernstof et al., 2010; Bromer et al., 2009).

Altogether, it is concluded that the ZET can detect the in vitro developmental toxicity of DES and reveal differences between DES and E2. Furthermore, the present study also confirms the role of ER $\alpha$ in developmental toxicity of DES in the ZET, while the ZET does not outperform the EST in terms of the assay sensitivity.

\section{Acknowledgements}

This work was supported by Wageningen University and Research.

\section{Conflict of interest}

The authors declare that there are no conflict of interest. 


\section{References}

Adam, AHB, Zhang M, de Haan, LHJ, van Ravenzwaay, B., Louisse, J., and Rietjens, I.M. C. M. C. (2019a). The in vivo developmental toxicity of diethylstilbestrol (DES) in rat evaluated by an alternative testing strategy. Archives of Toxicology 93 (7), 2021-2033.

Adam, A. H. B., de Haan, L. H. J., Estruch, I. M., Hooiveld, G. J. E. J., Louisse, J., and Rietjens, I. M. C. M. (2019b). Estrogen receptor alpha $(E R \alpha)$-mediated coregulator binding and gene expression discriminates the toxic ER $\alpha$ agonist diethylstilbestrol (DES) from the endogenous ERaagonist 17 $\beta$ estradiol (E2). (submitted).

Beekhuijzen, M., de Koning, C., Flores-Guillen, M. E., de Vries-Buitenweg, S., Tobor-Kaplon, M., van de Waart, B., and Emmen, H. (2015). From cutting edge to guideline: A first step in harmonization of the zebrafish embryotoxicity test (ZET) by describing the most optimal test conditions and morphology scoring system. Reproductive Toxicology 56, 64-76.

Blair, R. M., Fang, H., Branham, W. S., Hass, B. S., Dial, S. L., Moland, C. L., Tong, W., Shi, L., Perkins, R., and Sheehan, D. M. (2000). The estrogen receptor relative binding affinities of 188 natural and xenochemicals: structural diversity of ligands. Toxicological sciences 54(1), 138-53.

Block, K., Kardana, A., Igarashi, P., and Taylor, H.S. (2000). In utero diethylstilbestrol (DES) exposure alters Hox gene expression in the developing mullerian system. FASEB J 14(9), 1101-1108.

Bondesson, M., Hao, R., Lin, C.Y., Williams, C., and Gustafsson, J.A. (2015). Estrogen receptor signaling during vertebrate development. Biochimica Biophysica Acta 1849(2), 142-151.

Bromer JG, Wu J, Zhou Y, Taylor HS (2009) Hypermethylation of homeobox A10 by in utero diethylstilbestrol exposure: an epigenetic mechanism for altered developmental programming. Endocrinology 150(7):3376-3382.

Busquet, F., Strecker, R., Rawlings, J. M. et al. (2014). OECD validation study to assess intra- and interlaboratory reproducibility of the zebrafish embryo toxicity test for acute aquatic toxicity testing. Regul Toxicol Pharmacol 69, 496-511

Campinho, M. A., and Power, D. M. (2013). Waterborne exposure of zebrafish embryos to micromole concentrations of ioxynil and diethylstilbestrol disrupts thyrocyte development. Aquatic toxicology 140-141, 279-287.

Cornwall, G. A., Carter, M. W., and Bradshaw, W. S. (1984). The Relationship between Prenatal Lethality or Fetal Weight and Intrauterine Position in Rats Exposed to Diethylstilbestrol, Zeranol,

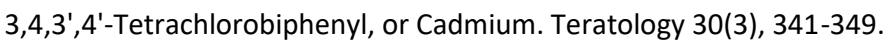

Couse, J. F., and Korach, K. S. (2004). Estrogen receptor-alpha mediates the detrimental effects of neonatal diethylstilbestrol (DES) exposure in the murine reproductive tract. Toxicology 205(1-2), 5563.

Couse, J.F., Dixon, D., Yates, M., et al (2001). Estrogen receptor-alpha knockout mice exhibit resistance to the developmental effects of neonatal diethylstilbestrol exposure on the female reproductive tract. Developmental Biology 238(2), 224-238. 
de Jong, E., Barenys, M., Hermsen, S. A., Verhoef, A., Ossendorp, B. C., Bessems, J. G., and Piersma, A. H. (2011). Comparison of the mouse Embryonic Stem cell Test, the rat Whole Embryo Culture and the Zebrafish Embryotoxicity Test as alternative methods for developmental toxicity testing of six 1,2,4triazoles. Toxicology and Applied Pharmacology 253(2), 103-11.

Dimopoulou, M., Verhoef, A., van Ravenzwaay, B., Rietjens, I. M., and Piersma, A. H. (2016). Flusilazole induces spatio-temporal expression patterns of retinoic acid-, differentiation- and sterol biosynthesis-related genes in the rat Whole Embryo Culture. Reproductive Toxicology 64, 77-85.

Genschow, E., Spielmann, H., Scholz, G., Pohl, I., Seiler, A., Clemann, N., Bremer, S., and Becker, K. (2004). Validation of the embryonic stem cell test in the international ECVAM validation study on three in vitro embryotoxicity tests. Alternatives to laboratory animals : Alternatives to Laboratory Animals 32(3), 209-44.

Greco, T. L., Duello, T. M., and Gorski, J. (1993). Estrogen receptors, estradiol, and diethylstilbestrol in early development: the mouse as a model for the study of estrogen receptors and estrogen sensitivity in embryonic development of male and female reproductive tracts. Endocrine Reviews 14(1), 59-71.

Herbst, A. L., and Anderson, D. (2015). Diethylstilbestrol (DES) Pregnancy Treatment: A Promising Widely Used Therapy with Unintended Adverse Consequences. AMA journal of ethics 17(9), 865-70.

Hermsen, S. A., van den Brandhof, E. J., van der Ven, L. T., and Piersma, A. H. (2011). Relative embryotoxicity of two classes of chemicals in a modified zebrafish embryotoxicity test and comparison with their in vivo potencies. Toxicology in vitro : an international journal published in association with BIBRA 25(3), 745-53.

Hill, A. J., Teraoka, H., Heideman, W., and Peterson, R. E. (2005). Zebrafish as a model vertebrate for investigating chemical toxicity. Toxicological Sciences 86(1), 6-19.

IARC. A review of human carcinogens. Part A: Pharmaceuticals. IARC Working Group on the Evaluation of Carcinogenic Risks to Humans. International Agency for Research on Cancer, 2012 100:1-403.

Kamelia, L., Brugman, S., de Haan, L., Ketelslegers, H., Rietjens, I. and Boogaard, P. (2019) "Prenatal developmental toxicity testing of petroleum substances using the zebrafish embryotoxicity test", ALTEX - Alternatives to animal experimentation, 36(2), 245-260.

Lee, H. Y., Inselman, A. L., Kanungo, J., and Hansen, D. K. (2012). Alternative models in developmental toxicology. Systems Biology in Reproductive Medicine 58(1), 10-22.

Loudig, O., Babichuk, C., White, J., Abu-Abed, S., Mueller, C., and Petkovich, M. (2000). Cytochrome P450RAI(CYP26) promoter: a distinct composite retinoic acid response element underlies the complex regulation of retinoic acid metabolism. Molecular Endocrinology 14(9), 1483-97.

Luijten, M., van Beelen, V. A., Verhoef, A., Renkens, M. F., van Herwijnen, M. H., Westerman, A., van Schooten, F. J., Pennings, J. L., and Piersma, A. H. (2010). Transcriptomics analysis of retinoic acid embryotoxicity in rat postimplantation whole embryo culture. Reproductive Toxicology 30(2), 33340. 
Ma, L., Benson, G.V., Lim, H., Dey, S.K., Maas, R.L. (1998). Abdominal B (AbdB) Hoxa genes: regulation in adult uterus by estrogen and progesterone and repression in mullerian duct by the synthetic estrogen diethylstilbestrol (DES). Developmental Biology 197(2), 141-154.

Miller, C., Degenhardt, K., Sassoon, D.A. (1998). Fetal exposure to DES results in de-regulation of Wnt7a during uterine morphogenesis. (1995). Teratogen update: carcinogenesis and teratogenesis associated with exposure to diethylstilbestrol (DES) in utero. Teratology 51(6), 435-45.

Nagao, T., and Yoshimura, S. (2009). Early embryonic losses in mice induced by diethylstilbestrol. Congenital Anomalies 49(4), 269-73.

Nagao, T., Kagawa, N., Saito, Y., and Komada, M. (2013). Developmental effects of oral exposure to diethylstilbestrol on mouse placenta. Journal of applied toxicology : JAT 33(11), 1213-21.

Newbold, R. R. (2004). Lessons learned from perinatal exposure to diethylstilbestrol. Toxicology and Applied Pharmacology 199(2), 142-50.

OECD. (2013). OECD Guidelines for Testing of Chemicals No.236: Fish Embryo Acute Toxicity (FET) Test. Adopted 26 July 2013.

Odum, J., Lefevre, P. A., Tinwell, H., Van Miller, J. P., Joiner, R. L., Chapin, R. E., Wallis, N. T., and Ashby, J. (2002). Comparison of the developmental and reproductive toxicity of diethylstilbestrol administered to rats in utero, lactationally, preweaning, or postweaning. Toxicological sciences : an official journal of the Society of Toxicology 68(1), 147-63.

Panzica-Kelly, J. M., Zhang, C. X., and Augustine-Rauch, K. (2012). Zebrafish embryo developmental toxicology assay. Methods in molecular biology 889, 25-50.

Pera, M. F., and Trounson, A. O. (2004). Human embryonic stem cells: prospects for development. Development 131(22), 5515-25.

Piersma, A. H., Genschow, E., Verhoef, A., Spanjersberg, M. Q., Brown, N. A., Brady, M., Burns, A., Clemann, N., Seiler, A., and Spielmann, H. (2004). Validation of the postimplantation rat wholeembryo culture test in the international ECVAM validation study on three in vitro embryotoxicity tests. Alternatives to laboratory animals : ATLA 32(3), 275-307.

Prins, G.S., Birch, L., Couse, J.F., Choi, I., Katzenellenbogen, B., and Korach, K.S. (2001). Estrogen imprinting of the developing prostate gland is mediated through stromal estrogen receptor alpha: studies with alphaERKO and betaERKO mice. Cancer Research 61(16), 6089-6097

Reed, C. E., and Fenton, S. E. (2013). Exposure to diethylstilbestrol during sensitive life stages: a legacy of heritable health effects. Birth defects research. Part C, Embryo today : reviews 99(2), 13446.

Ren, X., Lu, F., Cui, Y., Wang, X., Bai, C., Chen, J., Huang, C., and Yang, D. (2012). Protective effects of genistein and estradiol on PAHs-induced developmental toxicity in zebrafish embryos. Human \& experimental toxicology 31(11), 1161-9. 
Selderslaghs, I. W., Blust, R. and Witters, H. E. (2012). Feasi-bility study of the zebrafish assay as an alternative method to screen for developmental toxicity and embryotoxicity using a training set of 27 compounds. Reproductive Toxicology 33, 142-154.

Sipes, N. S., Martin, M. T., Reif, D. M., Kleinstreuer, N. C., Judson, R. S., Singh, A. V., Chandler, K. J., Dix, D. J., Kavlock, R. J., and Knudsen, T. B. (2011). Predictive models of prenatal developmental toxicity from ToxCast high-throughput screening data. Toxicological sciences : an official journal of the Society of Toxicology 124(1), 109-27.

Slob W (2019) PROAST: software for dose-response modeling and benchmark dose analysis. https://proastweb.rivm.nl/

Spielmann, H., Genschow, E., Brown, N.A., Piersma, A.H., Verhoef, A., Spanjersberg, M.Q., Huuskonen, H., Paillard, F., Seiler, A., 2004. Validation of the rat limb bud micromass test in the international ECVAM validation study on three in vitro embryotoxicity tests. ATLA 32, 245-274.

Spielmann, H., Seiler, A., Bremer, S., Hareng, L., Hartung, T., Ahr, H., Faustman, E., Haas, U., Moffat, G. J., Nau, H., et al. (2006). The practical application of three validated in vitro embryotoxicity tests. The report and recommendations of an ECVAM/ZEBET workshop (ECVAM workshop 57). Alternatives to Laboratory Animals. ATLA 34(5), 527-38.

Thatcher, J. E., and Isoherranen, N. (2009). The role of CYP26 enzymes in retinoic acid clearance. Expert opinion on drug metabolism \& toxicology 5(8), 875-86.

Titus-Ernstof, L., Troisi R, Hatch EE et al (2010) Birth defects in the sons and daughters of women who were exposed in utero to diethylstilbestrol (DES). Int J Androl 33(2), 377-384.

von Schilling, B. (1980). On the Teratogenic Action of Diethylstilbestrol and Other Exogenous Sexual Hormones. In Functional Morphologic Changes in Female Sex Organs Induced by Exogenous Hormones (G. Dallenbach-Hellweg, Ed.) doi: 10.1007/978-3-642-67568-3_3, pp. 17-28. Springer Berlin Heidelberg, Berlin, Heidelberg.

Wakeling, A. E., Dukes, M., and Bowler, J. (1991). A potent specific pure antiestrogen with clinical potential. Cancer Research 51(15), 3867-73.

Wani, T. H., Chakrabarty, A., Shibata, N., Yamazaki, H., Guengerich, F. P., and Chowdhury, G. (2017). The Dihydroxy Metabolite of the Teratogen Thalidomide Causes Oxidative DNA Damage. Chemical Research in Toxicology 30(8), 1622-1628.

Wardell, R. E., Seegmiller, R. E., and Bradshaw, W. S. (1982). Induction of prenatal toxicity in the rat by diethylstilbestrol, zeranol, 3,4,3',4',-tetrachlorobiphenyl, cadmium, and lead. Teratology 26(3), 229-37.

Weir, H. M., Bradbury, R. H., Lawson, M., Rabow, A. A., Buttar, D., Callis, R. J., Curwen, J. O., de Almeida, C., Ballard, P., Hulse, M., et al. (2016). AZD9496: An Oral Estrogen Receptor Inhibitor That Blocks the Growth of ER-Positive and ESR1-Mutant Breast Tumors in Preclinical Models. Cancer Research 76(11), 3307-18. 


\section{Supplementary materials 1 . Teratogenic endpoints assessed in the zebrafish embryo/larva}

Table 1. The teratogenic endpoints that assessed in the zebrafish embryo to help in the teratogenicity classification are described in the following table.

\begin{tabular}{|l|l|}
\hline \multicolumn{1}{|c|}{ Teratogenic endpoints } & \multicolumn{1}{|c|}{ Description parameters } \\
\hline $\begin{array}{l}\text { Malformation of the } \\
\text { head }\end{array}$ & $\begin{array}{l}\text { Missing structures such as the jaw and the } \\
\text { eyes. Uneven eye size or abnormal eye shape, } \\
\text { abnormal head shape, edema etc. }\end{array}$ \\
\hline $\begin{array}{l}\text { Malformation of the } \\
\text { sacculi/otoliths }\end{array}$ & $\begin{array}{l}\text { Missing structures, duplicated structures or uneven size or } \\
\text { abnormal shape. }\end{array}$ \\
\hline Malformation of the tail & Kinked tail or malformed tail fins \\
\hline $\begin{array}{l}\text { Malformation of the } \\
\text { heart }\end{array}$ & Irregular shape due to edema or aplasia. Abnormal heartbeat. \\
\hline Deformed body shape & $\begin{array}{l}\text { Scoliosis, rachischisis, absence, indistinct or malformed } \\
\text { morphology of the notochord or (one or more) somites. }\end{array}$ \\
\hline Yolk deformation & Edema or malformations. \\
\hline
\end{tabular}

Supplementary material 2. Results from concentration-response modeling of the data on zebrafish embryo test (ZET) of DES and E2

\subsection{Results from BMD analysis of the data on ZET of DES and E2 based on the GMS data}

Table 2. Results from BMD analysis of the data on ZET of DES based on the GMS data. The table presents the benchmark concentration (BMCO5) for a BMR of a $5 \%$ decrease in the GMS compared to the solvent control with characteristics of the model fit.

\begin{tabular}{|c|c|c|c|c|c|c|}
\hline \multirow{2}{*}{ Model type } & \multirow{2}{*}{ BMR type } & \multirow{2}{*}{ Log likelihood } & \multirow{2}{*}{ Model accepted? } & \multirow{2}{*}{ BMC } & \multicolumn{2}{|c|}{ BMC } \\
\hline & & & & & $\mathrm{BMCL}$ & BMCU \\
\hline LVM: Expon. m3- & $5 \%$ & -35.6 & Yes & 0.63 & 0.244 & 1.4 \\
\hline
\end{tabular}

LVM: Expon. m3-

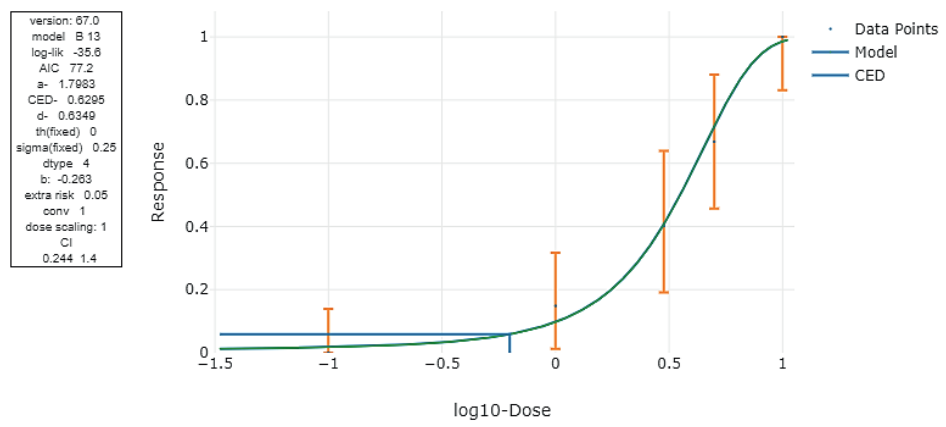


Table 3. Results from BMD analysis of the data on ZET of E2 based on the GMS data. The table presents the benchmark concentration (BMC5) for a BMR of a $5 \%$ decrease in the GMS compared to the solvent control with characteristics of the model fit.

\begin{tabular}{|c|c|c|c|c|c|c|}
\hline \multirow{2}{*}{ Model type } & \multirow{2}{*}{ BMR type } & \multirow{2}{*}{ Log likelihood } & \multirow{2}{*}{ Model accepted? } & \multirow{2}{*}{ BMC } & \multicolumn{2}{|c|}{ BMC } \\
\hline & & & & & BMCL & BMCU \\
\hline LVM: Expon. m3- & $5 \%$ & -32.82 & Yes & 1.77 & 0.746 & 3.11 \\
\hline
\end{tabular}

LVM: Expon. m3-

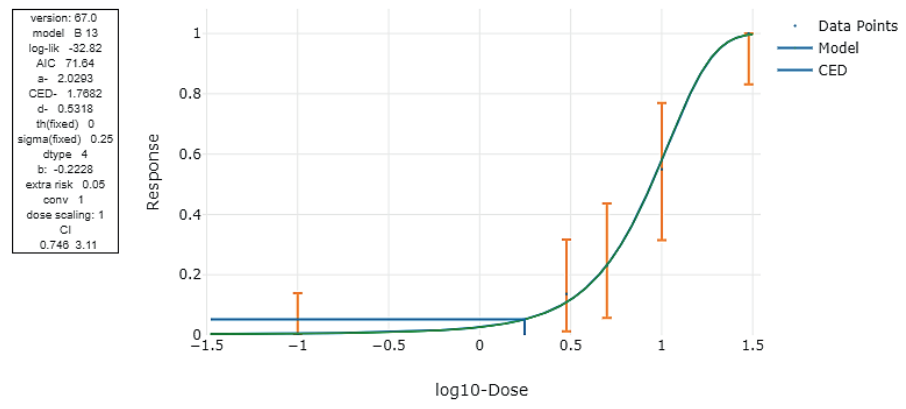

\subsection{Results from BMD analysis of the data on ZET of DES and E2 based on the accumulative} mortality data

Table 4. Results from BMD analysis of the data on ZET of DES based on the accumulative mortality (survival) data. The table presents the benchmark concentration (BMCO5) for a BMR of a $5 \%$ increase in the accumulative mortality compared to the solvent control with characteristics of the model fit.

\begin{tabular}{|c|c|c|c|c|c|c|}
\hline \multirow{2}{*}{ Model type } & \multirow{2}{*}{ BMR type } & \multirow{2}{*}{ Log likelihood } & \multirow{2}{*}{ Model accepted? } & \multirow{2}{*}{ BMC } & \multicolumn{2}{|c|}{ BMC } \\
\hline & & & & & BMCL & BMCU \\
\hline LVM: Expon. m3- & $5 \%$ & -29.95 & Yes & 1.5 & 0.8 & 2.8 \\
\hline
\end{tabular}

LVM: Expon. m3-

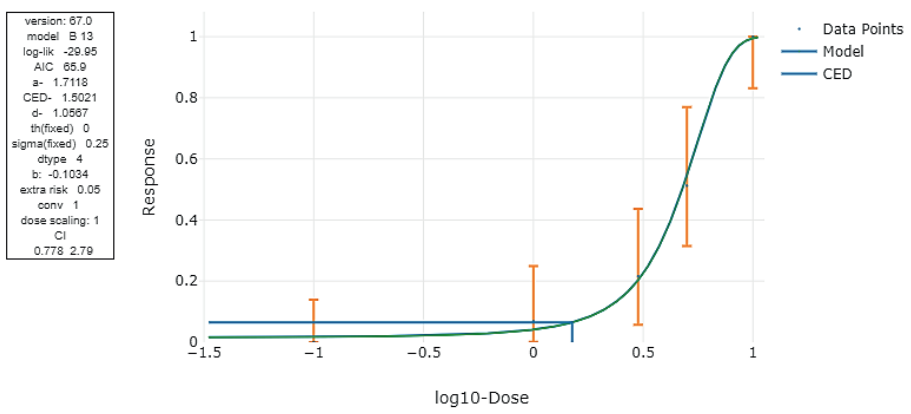


Table 5. Results from BMD analysis of the data on ZET of DES based on the accumulative mortality (survival) data. The table presents the benchmark concentration (BMC50) for a BMR of a $50 \%$ increase in the accumulative mortality compared to the solvent control with characteristics of the model fit.

\begin{tabular}{|c|c|c|c|c|c|c|}
\hline \multirow{2}{*}{ Model type } & \multirow{2}{*}{ BMR type } & \multirow{2}{*}{ Log likelihood } & \multirow{2}{*}{ Model accepted? } & \multirow{2}{*}{ BMC } & \multicolumn{2}{|c|}{ BMC } \\
\hline & & & & & BMCL & BMCU \\
\hline LVM: Expon. m3- & $50 \%$ & -32.82 & Yes & 8.8 & 7 & 11.5 \\
\hline
\end{tabular}

LVM: Expon. m3-

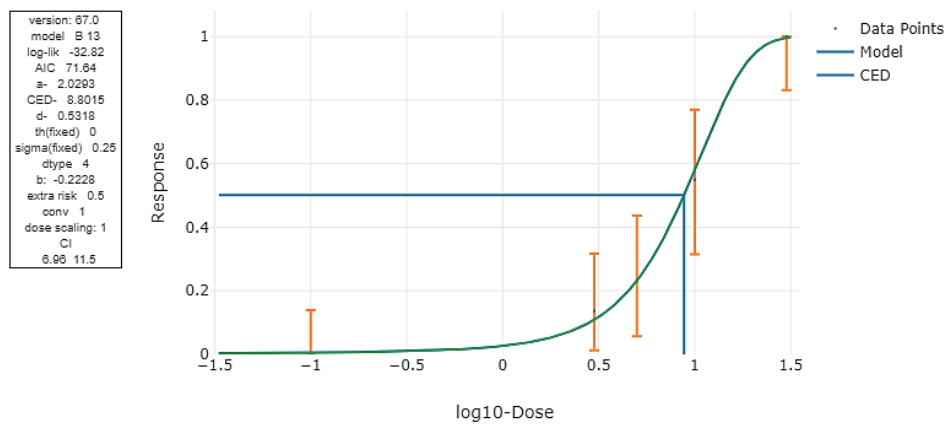

Table 5. Results from BMD analysis of the data on ZET of E2 based on the accumulative mortality (survival) data. The table presents the benchmark concentration (BMC5) for a BMR of a $5 \%$ increase in the accumulative mortality compared to the solvent control with characteristics of the model fit.

\begin{tabular}{|c|c|c|c|c|c|c|}
\hline \multirow{2}{*}{ Model type } & \multirow{2}{*}{ BMR type } & \multirow{2}{*}{ Log likelihood } & \multirow{2}{*}{ Model accepted? } & \multirow{2}{*}{ BMC } & \multicolumn{2}{|c|}{ BMC } \\
\hline & & & & & BMCL & $\mathrm{BMCU}$ \\
\hline LVM: Expon. m3- & $5 \%$ & -21.43 & Yes & 4.7 & 2.8 & 8.5 \\
\hline
\end{tabular}

LVM: Expon. m3-

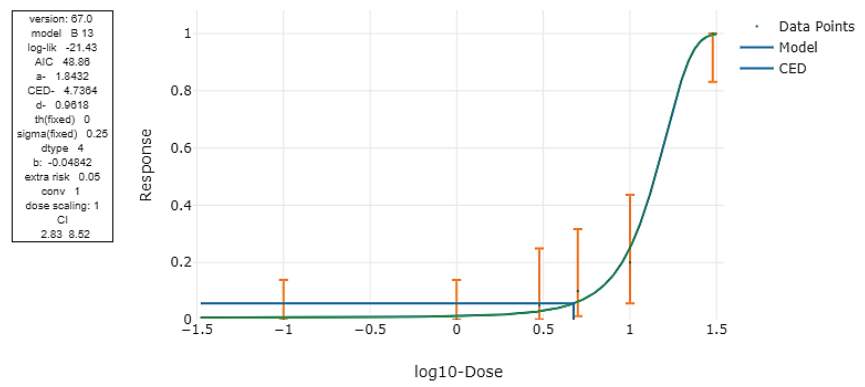




\subsection{Results from BMD analysis of the data on ZET of DES based on the edema formation data}

Table 6. Results from BMD analysis of the data on ZET of DES based on the edema formation data. The table presents the benchmark concentration (BMC50) for a BMR of a $50 \%$ increase in the edema formation compared to the solvent control with characteristics of the model fit.

\begin{tabular}{|c|c|c|c|c|c|c|}
\hline \multirow{2}{*}{ Model type } & \multirow{2}{*}{ BMR type } & \multirow{2}{*}{ Log likelihood } & \multirow{2}{*}{ Model accepted? } & \multirow{2}{*}{ BMC } & \multicolumn{2}{|c|}{ BMC } \\
\hline & & & & & BMCL & BMCU \\
\hline LVM: Expon. m3- & $50 \%$ & -29.95 & Yes & 2.5 & 1.55 & 3.77 \\
\hline
\end{tabular}

LVM: Expon. m3-
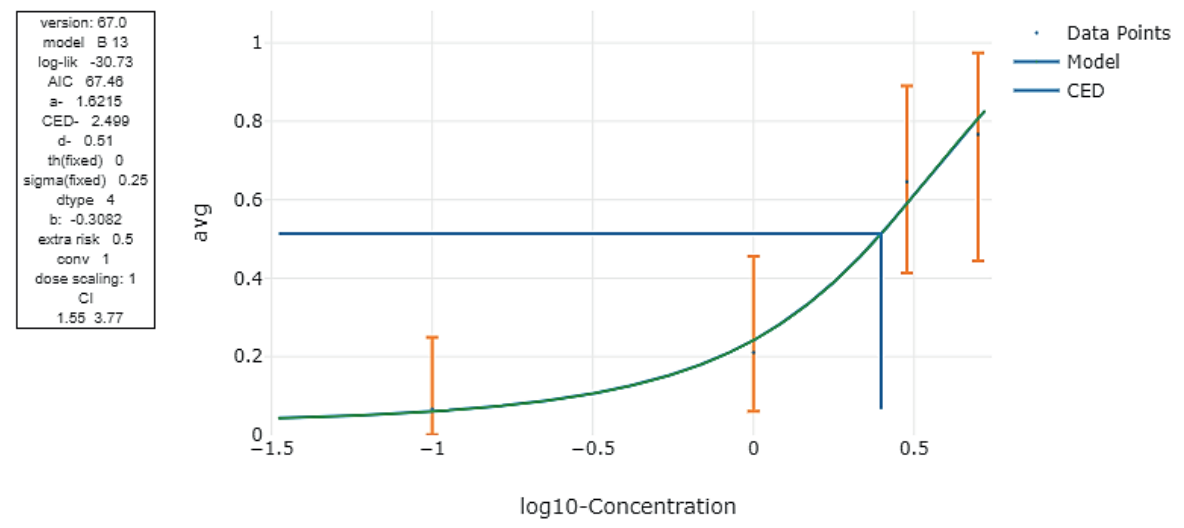
Assessment of the in vitro developmental toxicity of diethylstilbestrol and estradiol in the zebrafish 
CHAPTER 5

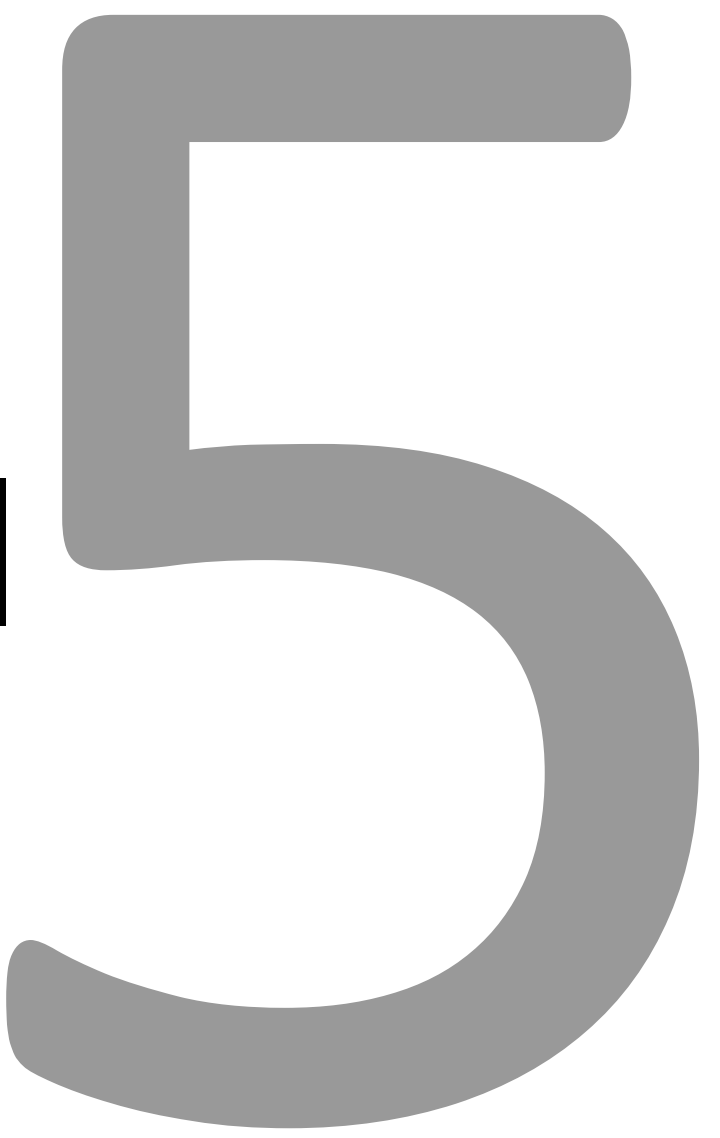


Physiologically based kinetic modellingfacilitated comparison of internal female dose levels of diethylstilbestrol and $17 \beta$-estradiol, to study a potential role of kinetics in the differences in their developmental toxicity

Aziza Hussein Bakheit Adam, Mengying Zhang, Albertus Spenkelink, Sebas Wesseling, Jochem Louisse and Ivonne MCM Rietjens 


\section{Abstract}

Diethylstilbestrol (DES) is a synthetic estrogen and proven human teratogen, while the endogenous estrogen $17 \beta$-estradiol (E2) does not show such adverse effects. It has been reported that both compounds have a similar mode of action in different in vitro systems with only minor differences. Therefore, the aim of the present study was to investigate whether differences in kinetics may play a role in the differential effects on development by DES and E2. To obtain insight in these possible differences in kinetics, physiologically based kinetic (PBK) models for DES and E2 in non-pregnant and pregnant women were developed and used to investigate potential dose-dependent differences in plasma concentrations. The models predicted the kinetics of DES and E2 in pregnant women to be comparable. The median therapeutic doses of DES as given to pregnant women were predicted to result in plasma concentrations that were almost 200-fold higher than endogenous E2 concentrations during pregnancy. It is concluded that the PBK models developed enable quantification of dose-dependent plasma concentrations of DES and E2 in non-pregnant and pregnant women and reveal that differences in effects on development between E2 and DES may at least in part be due to differences in internal exposure levels. 


\section{Introduction}

Diethylstilbestrol (DES) is a synthetic hormone that was first prescribed in the 1940s to 1970s for pregnant women to prevent miscarriage and premature delivery, and to women in general for the treatment of menstrual problems and cancer (IARC 2012; Reed and Fenton 2013). However, in later studies it was concluded that these claimed beneficial effects were not observed, while even adverse effects were reported (IARC 2012; Newbold 2006; Reed and Fenton 2013). The adverse health effects in women and their offspring exposed to DES included developmental toxicity, and an increased risk for developing cancer and reproductive tract abnormalities (Giusti et al. 1995; IARC 2012). Similar developmental toxicity effects of DES have been found in experimental animals including rats and mice (Cornwall et al. 1984; Nagao and Yoshimura 2009; Wardell et al. 1982).

DES is structurally similar to the endogenous hormone $17 \beta$-estradiol (E2) and it has been suggested that DES mimics the effects of E2 (Watanabe et al. 2003). E2 as well as DES exert their biological effect via estrogen receptors (ERs) and they induce similar responses in many in vitro assays that relate to ER $\alpha$-mediated activities (Adam et al. 2019c). Furthermore, the developmental toxicity of DES and E2 has been evaluated in in vitro alternative assays for developmental toxicity including the embryonic stem cell test (EST) and the zebrafish embryo toxicity (ZET) assay, confirming the role of ER $\alpha$ but revealing a higher potency of DES than of E2 (Adam et al. 2019a; Adam et al. 2019b).

The endogenous hormone E2 plays as a key role in embryonic development and has other relevant functions in the reproductive system (Bondesson et al. 2015; Albrecht and Pepe. 2010). During pregnancy, E2 contributes to uterine growth and facilitates mammary gland development (Bennink 2008). This regulation is strictly controlled by the body during embryo development (Bondesson et al. 2015). However, this strict regulation can be altered or disturbed by xenoestrogenic compounds including for example DES.

Previous studies on E2- and DES-induced biological effects revealed small, albeit relevant differences in their ER $\alpha$-mediated responses (Adam et al. 2019c). However, given the substantial similarities in 
the responses, it was hypothesised in the present study that part of the in vivo differences in effects on development may originate from differences in the actual internal dose levels of these two estrogens during pregnancy and/or DES treatment. Therefore the present study aimed to develop physiologically based kinetic (PBK) models for E2 and DES to gain insight in dose-dependent internal plasma concentrations and to enable comparison of realistic exposure regimens.

\section{Materials and methods}

\subsection{Materials}

Dimethyl sulfoxide (DMSO), DES, E2, adenosine 3'-phosphate 5'-phosphosulfate (PAPS) lithium salt hydrate, alamethicin, magnesium chloride, and sodium phosphate were purchased from SigmaAldrich (Zwijndrecht, the Netherlands), reduced nicotinamide adenine dinucleotide phosphate (NADPH), uridine 5'-diphosphoglucuronic acid (UDPGA), acetyl coenzyme A (acetyl CoA) sodium salt, were purchased from Carbosynth Limited (Berkshire, UK). The pooled liver S9 fraction was a pool made from five human female (age 20 - 45 years) liver S9 fractions (Xenotech), which were purchased through Tebu-bio (Heerhugowaard, the Netherlands).

\subsection{Development of PBK models describing DES and E2 kinetics in (pregnant) women}

Two PBK models were developed for each compound, including one for non-pregnant women and also one for pregnant women, the first one being required for model validation because no kinetic data on these estrogens are available in pregnant women. Upon validation of the model for nonpregnant women, this model was modified to include the parameters for pregnant women. A schematic representation of the PBK model developed for E2 and DES is shown in Fig. 1. The model is based on the PBK models developed and evaluated before for E2 and DES in rats and humans (Adam et al. 2019a; Zhang et al., 2018). The model includes separate compartments for blood, liver, fat, rapidly perfused tissue (e.g. heart, lung, brain) and slowly perfused tissue (e.g. skin, muscle, bone). Additionally, a compartment for the intestines is included, to describe the intestinal transition of the chemicals. To describe small intestinal transition, the intestinal compartment was divided in 7 sub- 
compartments over which the chemical transition was described. For the placental transfer it was assumed that the maternal blood concentration equals the fetal blood concentration. This assumption was made based on the fact that DES and E2 are known to rapidly cross the primate placenta in rhesus monkeys and enter the fetal circulation in a similar way (Shah and McLachlan 1976).

The values for physiological and anatomical parameters for non-pregnant and pregnant women were taken from literature and are presented in table 1 (Abduljalil et al. 2012; Brown et al. 1997; Dallmann et al. 2017; Kararli, 1995: Hosseinpour and Behdad, 2008). Physiological parameter values related to pregnant women were used for the beginning of the pregnancy (first trimester; gestational age 12-13 weeks), the period during which most of the miscarriages occur during the first trimester of pregnancy (Akolekar et al. 2011). This also best reflects the period when DES was prescribed to prevent miscarriage and premature delivery, causing its developmental toxicity and malformations (IARC 2012; Reed and Fenton 2013).

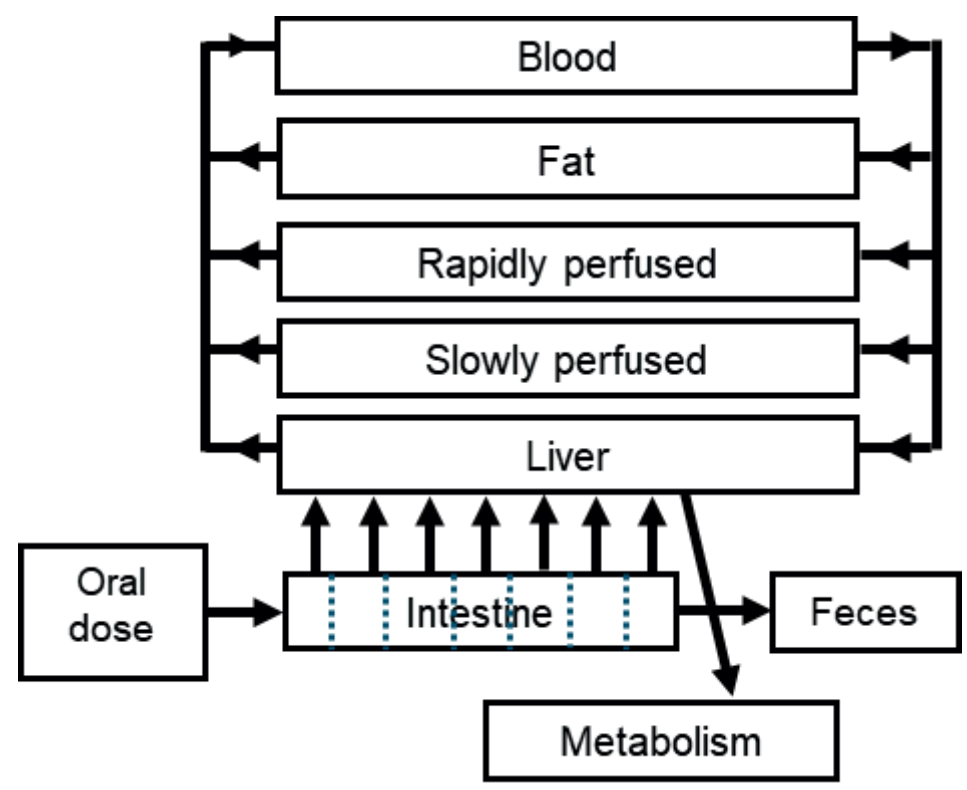

Fig. 12. Schematic diagram of the PBK model for DES and E2 in humans. 


\subsection{Determination of intestinal absorption parameters}

The apparent permeability coefficient in the Caco-2 model (Papp,Caco-2) was used to derive the absorption rate constant $(\mathrm{ka})$ for uptake of the parent compound from the intestines into the liver. For DES the Papp,Caco-2 value was estimated based on the quantitative structure-activity relationship (QSAR) approach of Hou et al. (2004). The chemical-dependent input parameter of this approach is the polar surface area (PSA), which is 40.46 for DES (Hou et al. 2004). The in vitro Log Papp value was estimated using the formula: Log (Papp, in vitro $)=-4.28-0.011 \times$ PSA, resulting in a Papp value of $18.8 \times 10^{-6} \mathrm{~cm} / \mathrm{s}$ for DES. The Papp value for E2 in the Caco-2 model is reported to amount to $17 \times 10^{-6} \mathrm{~cm} / \mathrm{s}$ (Yazdanian et al. 1998). These Papp,Caco-2 values for E2 and DES were used to calculate the in vivo Papp value using the following equation: Log Papp, in vivo $=0.7524 \times \log$ Papp,in vitro -0.5441 (Sun et al. 2002). Then, the intestinal absorption rate constant (ka, L/h) was determined using the estimated in vivo Papp value (expressed in $\mathrm{dm} / \mathrm{h}$ ) times the intestinal surface area (SA, in $\mathrm{dm}^{2}$ ) of each sub-compartment (Adam et al., 2019a and Zhang et al. 2018). The surface area for human small intestine was assumed to amount to $72 \mathrm{dm}^{2}$ and the volume to $9 \mathrm{~L}$, based on a radius of $2.5 \mathrm{~cm}$ (Kararli, 1995) and a small intestine length of $460 \mathrm{~cm}$ (Hosseinpour and Behdad, 2008).

\subsection{Determination of tissue/blood partitioning parameters}

The tissue/blood partition coefficients of DES and E2 were estimated based on the quantitative property-property relationship (QPPR) approach of DeJongh et al. (1997). The input parameter of this approach is the octanol-water partition coefficient (Pow), the Log Pow of DES and E2 are 5.07 and 4.01 respectively (Hansch et al. 1995 and Selassie et al. 1999). The calculated partition coefficients of DES and E2 are presented in Table 1.

The assumptions were made that the estrogenic effects of DES and E2 are caused by the parent compound, not by the metabolites, and that clearance of both DES and E2 mainly depends on hepatic clearance. This hepatic clearance of both parent compounds was determined in incubations 
with pooled female human liver S9 fractions, as described below. The PBK model codes for nonpregnant and pregnant women, respectively, are described in supplementary material 1 and 2 for E2 and supplementary material 3 and 4 for DES. The PBK model equations were coded and numerically integrated in Berkeley Madonna 8.3.18 (UC Berkeley, CA, USA), using the Rosenbrock's algorithm for stiff systems.

\subsection{Determination of the model parameter value for hepatic clearance}

The in vitro hepatic intrinsic clearance $\left(\mathrm{CL}_{\text {int }}\right)$ was determined using a substrate depletion approach, and these data were scaled to the in vivo situation to describe the hepatic clearance of the parent compound in the PBK model. The $\mathrm{CL}_{\text {int }}$ of DES and E2 were determined in incubations with liver S9 fractions derived from female humans in the presence of relevant co-factors (NADPH, UDPGA, PAPS, and acetyl CoA) for phase I and II metabolism, in line with the method previously developed (Adam et al. 2019; Zhang et al., 2018; Zhang et al., 2019). One requirement of the substrate depletion approach is that the initial concentration of the parent compound should be below the MichaelisMenten constant $(\mathrm{Km})$ for the respective conversions so that substrate depletion is still apparently linear with the substrate concentration. This implies that the PBK models may not adequately describe the in vivo kinetics at doses that result in liver concentrations (available for metabolism) substantially higher than the $\mathrm{Km}$, since saturation of metabolism is not included in the model. In the current study, the test concentrations of DES and E2 were $3 \mu \mathrm{M}$, which is 3.3-fold below the DES concentration reported to inhibit UDP-glucuronosyltransferases (UGTs) activity (Zhu et al. 2016). To determine the hepatic clearance, $3 \mu \mathrm{M}$ DES or E2 (final concentration) was incubated with $0.5 \mathrm{mg} / \mathrm{ml}$ liver S9, 3 mM NADPH, 5 mM UDPGA, $0.2 \mathrm{mM}$ PAPS, $0.5 \mathrm{mM}$ acetyl CoA, $5 \mathrm{mM} \mathrm{MgCl}$, and 0.025 $\mathrm{mg} / \mathrm{ml}$ alamethicin in $0.1 \mathrm{M}$ potassium phosphate $(\mathrm{pH}$ 7.4). The final concentration of DMSO in the incubation mixtures was $0.5 \%$. The total incubation volume was $100 \mu \mathrm{L}$. The incubation time points were $0,2,4,6,8,10,15,20,25,30,35,40$ and 45 minutes. To terminate the reaction, $50 \mu \mathrm{L}$ ice-cold acetonitrile $(A C N)$ were added to the mixture and the Eppendorf tubes were put on ice for $30 \mathrm{~min}$. Subsequently, tubes were centrifuged at 15,000 rpm for $10 \mathrm{~min}$ (CT 15RE, Hitachi Koki Co., Ltd) and 
the supernatant was collected for UPLC analysis. For each incubation time point, a corresponding control incubated in the absence of co-factors was included. For all incubations, three independent replicates were performed. The ratio of remaining compound between incubation samples ( $\left.\mathrm{C}_{\text {compound }}\right)$ and the corresponding control (incubation without co-factors, $\mathrm{C}_{\text {control) }}$ ) was calculated for all the incubation time points. The elimination curve of the parent compound $\left[\ln \left(\mathrm{C}_{\text {compound }} / \mathrm{C}_{\text {control }}\right)\right]$ against incubation time thus obtained was used to quantify the elimination rate constant $\left(\mathrm{k}\right.$ in $\left.\mathrm{min}^{-1}\right)$, which is the absolute value of the slope of the linear part of the elimination curve. This elimination rate constant was used to calculate the in vitro clearance $\left(\mathrm{CL}_{\text {int, in vitro }}\right)$ using the following equation: $\mathrm{CL}_{\text {int, in }}$ vitro $(\mu \mathrm{L} / \mathrm{min} / \mathrm{mg}$ protein $)=$ incubation volume $(\mu \mathrm{L}) /$ protein amount in the mixture $($ mg protein $) \times$ elimination rate constant ( $k$ in $\min ^{-1}$ ) (Obach 1999; Sjogren et al. 2009). The in vitro $\mathrm{CL}_{\text {int }}$ value of the parent compound was then scaled to the whole liver, assuming the $\mathbf{S 9}$ protein concentration in human liver to be $72 \mathrm{mg}$ protein/g liver (Chiu and Ginsberg 2011).

For the hepatic clearance for the PBK model for pregnant women, the values thus obtained for nonpregnant women were used since $\mathrm{S} 9$ fractions from pregnant women to perform similar experiments were unavailable.

\subsection{Ultra -performance liquid chromatography (UPLC) Analysis}

A UPLC H_Class system (Waters Acquity) equipped with a Waters BEH C18 $(1.7 \mu \mathrm{m}, 2.1 \times 50 \mathrm{~mm})$ column was used. The temperature was set at $40{ }^{\circ} \mathrm{C}$ for the column and $5^{\circ} \mathrm{C}$ for the samples. The injection volume was $3.5 \mu \mathrm{L}$ and the flow rate was $0.3 \mathrm{ml} / \mathrm{min}$. The mobile phase consisted of nanopure water as solvent $A$ and $A C N$ as solvent $B$. The gradient started at $65 \%$ solvent $A$, changed to $50 \%$ solvent $A$ in the next $2 \mathrm{~min}$, decreased to $0 \%$ solvent $A$ in $1 \mathrm{~min}$, and was kept at these conditions for another $2 \mathrm{~min}$. Then, the gradient was changed to the initial conditions in $2 \mathrm{~min}$ and kept at these conditions for $1 \mathrm{~min}$. The total running time was $8 \mathrm{~min}$. The quantification of DES and E2 in each incubation was achieved by integrating the peak area at $245 \mathrm{~nm}$ for DES and $200 \mathrm{~nm}$ for 
E2 and comparison of the peak areas to the peak areas of a calibration curve made using the commercially available reference compounds.

\subsection{PBK model evaluation}

To evaluate the performance of the PBK model developed, the predicted time-dependent blood concentrations of E2 were compared to the time-dependent blood concentrations of E2 in premenopausal females reported in the literature upon oral E2 exposure. For DES, no kinetic data for premenopausal females were found, but a similar PBK model developed previously for rats was shown to perform adequately for DES (Adam et al 2019a).

Furthermore, a sensitivity analysis was performed to identify the PBK model parameters that are most influential for the model prediction of the maximum blood concentration $\left(C_{\max }\right)$ of DES and E2. In line with previous studies (Adam et al. 2019a, Zhang et al., 2018), normalized sensitivity coefficients $(\mathrm{SC})$ were calculated according to the following equation: $S C=\left(\mathrm{C}^{\prime}-\mathrm{C}\right) /\left(\mathrm{P}^{\prime}-\mathrm{P}\right) \times(\mathrm{P} / \mathrm{C})$, with $C$ and $C^{\prime}$ representing the initial and modified values of the model output, and $P$ and $P^{\prime}$ the initial and modified parameter values (Evans and Andersen 2000). A 5\% increase of parameter value was chosen to assess the effect of a change in parameter on the prediction of $C_{\max }$. Each parameter was individually analysed by changing one parameter value at a time and keeping the others the same. The sensitivity analysis was conducted for oral exposure to a single dose of $0.114,5.0$ and $50 \mathrm{mg} / \mathrm{kg}$ bw, $0.114 \mathrm{mg} / \mathrm{kg}$ bw being the dose that was applied in the in vivo kinetic study for E2, and 5.0 and $50 \mathrm{mg} / \mathrm{kg}$ bw being dose levels in the range of the prescribed doses when using DES as a drug.

\section{Results}

\subsection{Development of a PBK model for DES and E2 in non-pregnant and pregnant women}

The developed PBK model codes for respectively non-pregnant and pregnant women are presented in supplementary material 1 and 2 for E2, and 3 and 4 for DES. The values for physiological and anatomical parameters were taken from literature (Abduljalil et al 2012; Brown et al. 1997; Dallmann 
et al. 2017; Kararli, 1995: Hosseinpour and Behdad, 2008), and are presented in Table 1. The parameters that were changed for the model at 13 weeks of pregnancy were body weight, increasing by approximately $6 \%$, fat content increasing by $11 \%$ resulting in proportionally decreased $\%$ for other tissues, and the cardiac output reported to increase by $8 \%$ (Abduljalil et al. 2012). Due to the lack of data and because we parametrize our model at 13 weeks of pregnancy, most of the parameters remained unchanged.

Table 1. Parameters used in the PBK model for DES and E2 in non -pregnant and pregnant women

\begin{tabular}{|c|c|c|}
\hline Parameters & Values & Values \\
\hline \multicolumn{3}{|c|}{ Physiological parameters } \\
\hline \multirow{2}{*}{ Body weight (kg) } & non-pregnant & pregnant \\
\hline & 58 & 62 \\
\hline \multicolumn{3}{|c|}{ Tissue volumes (\% of body weight) } \\
\hline & non-pregnant & Pregnant \\
\hline Liver & 2.6 & 2.6 \\
\hline Fat & 32.7 & 36.3 \\
\hline Rapidly perfused tissue & 6.8 & 6.8 \\
\hline Slowly perfused tissue & 50 & 46.4 \\
\hline Blood & 7.9 & 7.9 \\
\hline $\begin{array}{l}\text { Cardiac output }\left(\mathrm{L} \cdot \mathrm{h}^{-1} \cdot \mathrm{kg} \text { bw- }\right. \\
0.74)\end{array}$ & 312 & 337 \\
\hline \multicolumn{3}{|c|}{ Tissue blood flows (\% of cardiac output) } \\
\hline & non-pregnant & Pregnant \\
\hline Liver & 22.7 & 22.7 \\
\hline Fat & 5.2 & 5.2 \\
\hline Rapidly perfused tissue & 53 & 53 \\
\hline Slowly perfused tissue & 19.1 & 19.1 \\
\hline \multicolumn{3}{|c|}{ In vitro clearance $\left(\mathrm{CL}_{\text {int }}\right)$} \\
\hline & non-pregnant & Pregnant \\
\hline $\mathrm{E} 2 \mathrm{Cl}_{\text {int }}(\mu \mathrm{l} / \mathrm{min} / \mathrm{mg}$ protein $)$ & $128 \pm 8.0$ & $128 \pm 8.0$ \\
\hline DES Clint $(\mu \mathrm{l} / \mathrm{min} / \mathrm{mg}$ protein) & $160 \pm 20$ & $160 \pm 20$ \\
\hline \multicolumn{3}{|c|}{ Tissue/blood partition coefficients for both (pregnant and non-pregnant) } \\
\hline & E2 & DES \\
\hline
\end{tabular}




\begin{tabular}{|l|c|c|}
\hline Liver & 8.3 & 8.8 \\
\hline Fat & 113 & 114 \\
\hline Rapidly perfused tissue & 7.2 & 11.2 \\
\hline Slowly perfused tissue & 5.1 & 5.4 \\
\hline
\end{tabular}

In vitro clearance $\left(\mathrm{CL}_{\text {int }}\right)$ were determined in the present study

\subsection{Determination of model parameter values for hepatic clearance}

In vitro studies were performed to determine the in vitro $\mathrm{CL}_{\text {int }}$ values for $\mathrm{E} 2$ and $\mathrm{DES}$ by measuring their depletion over time in incubations with female human liver S9 (derived from non-pregnant females with ages $<45)$ using an initial substrate concentration of $3 \mu \mathrm{M}$. The depletion curves are presented in figure 2 and show a time-dependent decrease in the concentrations of DES and E2. The hepatic CLint values derived from these data for E2 and DES in non-pregnant women, are listed in table 1. Given that S9 liver tissue fractions of pregnant women were not available, the hepatic clearance for pregnant women was assumed to be similar to that derived for non-pregnant women.

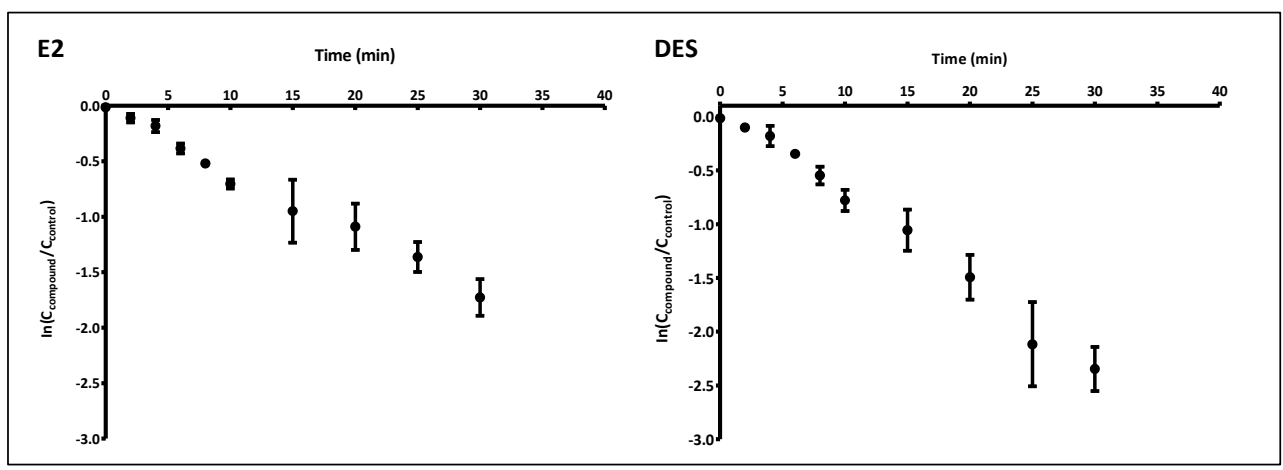

Fig. 13. The substrate depletion curves of $E 2$ and DES in incubations with human female liver S9 fraction and the co-factors NADPH, UDPGA, PAPS and acetyl. Symbols represent the average $\operatorname{In}\left(C_{\text {compound }} / C_{\text {control }}\right)$ at different incubation time points $(n=3)$. The data until 10 minutes were used to determine the $k$ values.

\subsection{PBK model evaluation}

To evaluate the model predictions, the predicted time-dependent blood concentrations of E2 were compared with available in vivo kinetic data reported in the literature. Figure 3 presents the time- 
dependent blood concentration of E2 obtained from in vivo studies in which premenopausal women were exposed to oral doses of E2 amounting to $0.029,0.057$ and $0.114 \mathrm{mg} / \mathrm{kg}$ bw (symbols), compared to the predicted time-dependent blood concentration curves (lines) (Fig. 3). The results show that the developed PBK model can predict the $\mathrm{C}_{\max }$ concentration of $\mathrm{E} 2$ upon oral exposure within an order of magnitude accuracy.

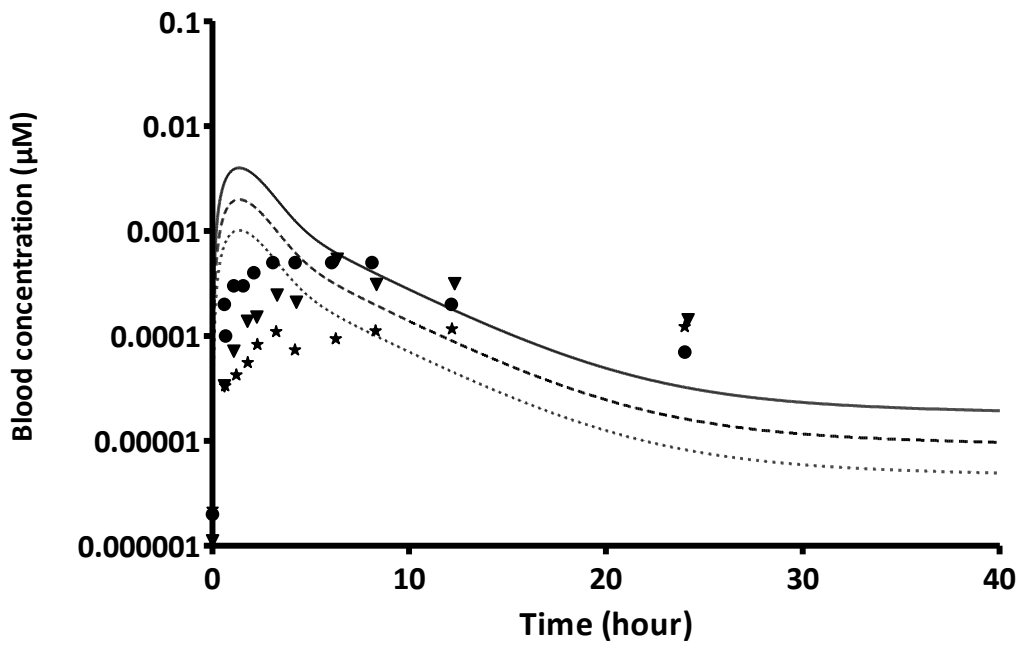

Fig. 3. Predicted and observed blood concentration of E2 in women upon oral administration of E2 to premenopausal women. Symbols represent the reported average blood concentrations when premenopausal females were exposed to E2 from the human in vivo study of Kuhnz (Kuhnz et al. 1993). Lines represent PBK model-based predictions of blood concentrations. Dose levels are as follows: $0.029 \mathrm{mg} / \mathrm{kg}$ bw/day (stars, dotted line), $0.057 \mathrm{mg} / \mathrm{kg} \mathrm{bw/day} \mathrm{(triangle,} \mathrm{dashed} \mathrm{line)} \mathrm{and} 0.114 \mathrm{mg} / \mathrm{kg} \mathrm{bw/day} \mathrm{(circles,} \mathrm{straight} \mathrm{line).}$

For further evaluation of the model, a sensitivity analysis was performed. This sensitivity analysis was performed for the prediction of the $C_{\max }$ upon oral exposure to doses of $0.114 \mathrm{mg} / \mathrm{kg}$ bw (Kuhnz et al. 1993), or of 5.0 or $50 \mathrm{mg} / \mathrm{kg}$ bw. The last two doses were chosen within the prescribed therapeutic doses range for DES. The normalized sensitivity coefficient (SC) for parameters with an absolute SC value higher than 0.1 are displayed in Fig. 4 . The results indicate that, among all the influential 
parameters, the prediction of the $C_{\max }$ of both E2 and DES by the PBK model is most sensitive to parameters of the fraction of blood flow to the liver ( $Q L C)$, the fraction of liver tissue (VLC), the hepatic clearance (CLintS9), the S9 protein concentration in human liver (S9P), the estimated in vivo $P_{\text {app }}$ value, the volume of the intestinal sub-compartment (Vin) and the intestinal surface area for the intestinal sub-compartment (SAin). The results also reveal that the influential parameters do not change with the dose, or with the compound.

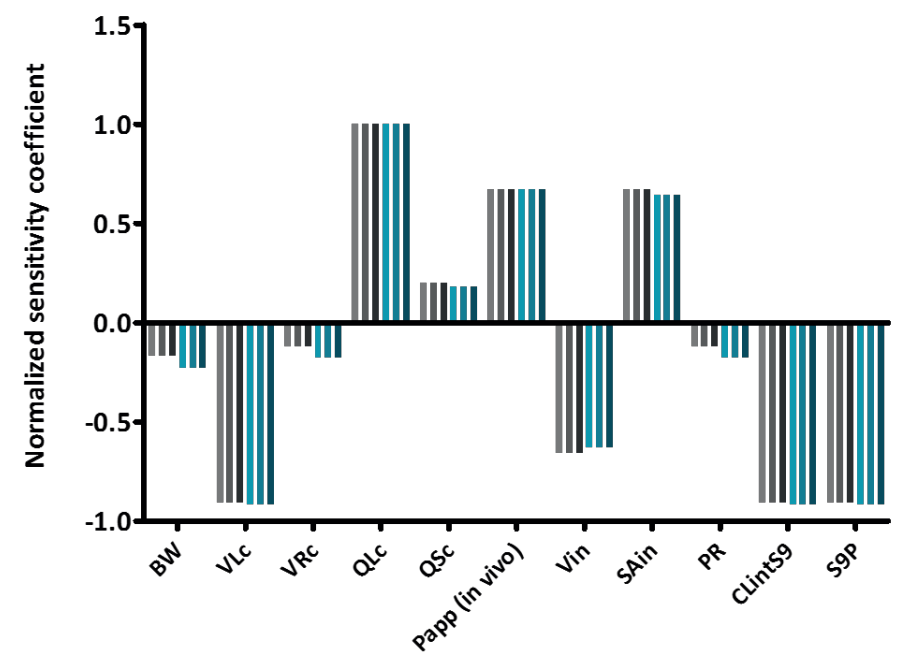

Figure 4. Normalized sensitivity coefficients of PBK model parameters for the prediction of $C_{\max }$ of the parent compound in blood after oral administration of $0.114,5$ or $50 \mathrm{mg} / \mathrm{kg} \mathrm{bw}$ E2 (light, middle and dark grey) and DES (light, middle and dark blue). All model parameters with normalized sensitivity coefficients higher than 0.1 are shown. $B W=$ body weight, $V L c=$ fraction of liver tissue, $V R c=$ fraction of rapidly perfused tissue, $Q L c=$ fraction of blood flow to liver, QSC = fraction of blood flow to slowly perfused tissue, Papp in vivo = apparent intestinal permeability coefficient in vivo, Vin = intestine volume for intestinal sub-compartment, SAin = intestinal surface area for intestinal sub-compartment, $P R=$ rapidly perfused tissue/blood partition coefficient, $C L i n t=$ experimental hepatic clearance of parent compound, $S 9 P=S 9$ protein concentration in human liver.

\subsection{PBK model predictions of blood concentration $\left(C_{\max }\right)$ of $E 2$ and DES}

In a next step the PBK model was adjusted for pregnant woman using the parameters indicated in table 1 and used to simulate the dose-dependent blood concentration of DES and E2 at different oral 
dose levels. The results obtained reveal that predicted blood concentrations for E2 and DES increased linearly with the dose being generally 1.2 -fold higher for E2 than for DES with a $C_{\max }$ of 0.04 to $35 \mu \mathrm{M}$ E2 and 0.03 to $27.7 \mu \mathrm{M}$ DES at oral doses ranging from 0.01 to $1000 \mathrm{mg} / \mathrm{kg}$ bw (Fig 5). According to data available from the National Cooperative Diethylstilbestrol Adenosis (DESAD) project, the median therapeutic doses of DES were $3650 \mathrm{mg}$ (range $6-62100 \mathrm{mg}$ ) for women (IARC 2012). The doses of DES that were prescribed to pregnant women with a body weight of $62 \mathrm{~kg}$, thus varied from 0.1 up to values as high as $1002 \mathrm{mg} / \mathrm{kg} / \mathrm{bw}$ with a median dose of $59 \mathrm{mg} / \mathrm{kg} / \mathrm{bw}$. Using forward dosimetry the PBK models can predict the corresponding Cmax values of DES (Figure 5). The figure reveals that at these dose levels the internal maximum blood concentration of DES is predicted to amount to 0.003 up to $28 \mu \mathrm{M}$ with a value of $1.7 \mu \mathrm{M}$ at the median dose. Furthermore, Figure 5 also reveals, using reverse dosimetry, that the external dose level of E2 that would be required to achieve realistic endogenous E2 levels during the 13 week gestation (9.5 nM) amount to 0.3 $\mathrm{mg} / \mathrm{kg} / \mathrm{bw}$. This endogenous level of E2 at 13 week pregnancy was calculated based on the equation: [estradiol] $(\mathrm{ng} / \mathrm{ml})=0.06+0.0558 \mathrm{GA}+0.0103 \mathrm{GA}^{2}$ ) with $\mathrm{GA}$ (gestational age) being 13 weeks (Abduljalil et al. 2012; Morel et al. 2016). In this way the figure clearly reveals that therapeutic dose levels of DES resulted in substantially higher internal DES concentrations than realistic endogenous E2 concentrations at 13 weeks if pregnancy. At the reported low therapeutic DES dose levels ( 0.1 $\mathrm{mg} / \mathrm{kg} \mathrm{bw}$ ) similar internal concentrations of DES compared to endogenous E2 are expected to be reached, while at the median DES doses described $(59 \mathrm{mg} / \mathrm{kg}$ bw) internal DES concentrations are expected to be about 2 orders of magnitude higher than the endogenous E2 concentrations. 


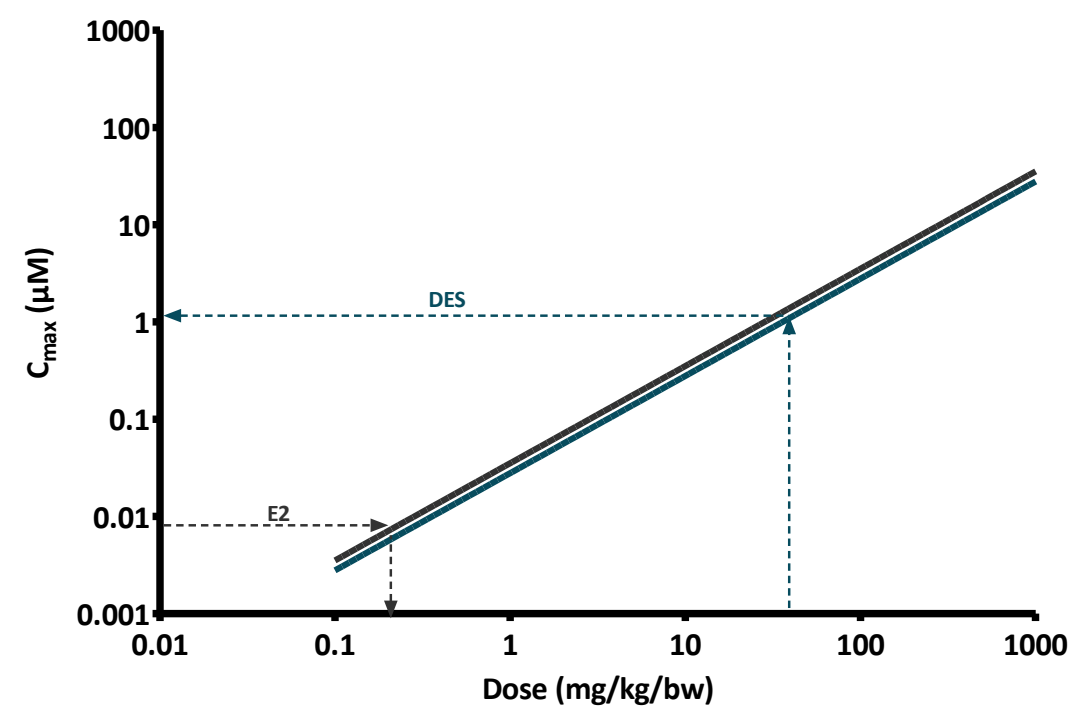

Figure 5. PBK model-based prediction of dose-dependent plasma $C_{\max }$ of E2 (grey) and DES (blue) in pregnant women at oral doses ranging from 0.1 up to $1000 \mathrm{mg} / \mathrm{kg} / \mathrm{bw}$. The median doses of DES that were prescribed for pregnant women and realistic endogenous $E 2$ level are indicated while the dotted lines and arrows represent for DES; forward dosimetry to predict the internal concentrations resulting from the external dose levels, and for E2; reverse dosimetry to predict the external dose levels that would result in the reported endogenous level of E2.

\section{Discussion}

The aim of the present study was to develop PBK models for E2 and DES in (non-)pregnant women to obtain insight in possible dose-dependent differences in internal dose levels of DES and E2, in order to elucidate to what extent such differences in kinetics may play a role in the different potential of these estrogens to induce developmental toxicity. Endogenous E2 exposure occurring naturally during pregnancy does not result in developmental toxicity while use of DES as a drug to prevent miscarriage or premature delivery is well known to result in developmental toxicity (IARC 2012). To investigate whether differences in expected internal dose levels resulting from different sources and levels of exposure during pregnancy may contribute to the different outcomes of exposure to these 
estrogens during pregnancy became of interest, because studies on differences in ER $\alpha$-mediated cellular responses towards E2 and DES showed only minor differences between DES and E2 (Adam et al. 2019c).

To enable comparison of E2 and DES kinetics, first PBK models for non-pregnant women for E2 and DES were developed and evaluated. Subsequently, the PBK models were adjusted for pregnant women and used to i) translate therapeutic dose levels of DES to internal exposure concentrations by forward dosimetry and to ii) translate realistic endogenous E2 levels to corresponding external dose levels by reverse dosimetry. Evaluation of the PBK models obtained against reported data on blood concentrations of E2 revealed that the model could predict the blood $C_{\max }$ levels within one order of magnitude. The results of the present study indicate that substantially lower therapeutic doses of DES than the ones that were applied could already have resulted in internal levels of DES similar to endogenous levels of E2. To reach similar concentrations as endogenous E2, DES doses in the range of $0.1-0.16 \mathrm{mg} / \mathrm{kg} / \mathrm{bw}$ would be required, which is in the range of the lowest therapeutic dose levels applied, but actually 3 orders of magnitude below the upper range of therapeutic DES doses administered to pregnant women (IARC 2012). The results also reveal that DES and E2 show similar kinetics in humans and that the differences in the relevant internal dose levels should rather be ascribed to the relatively high doses used in DES therapy. The realistic endogenous internal E2 concentrations during pregnancy were found to be almost 200 -fold lower than the predicted plasma concentration of DES $(1.6 \mu \mathrm{M})$ at the median prescribed dose of $59 \mathrm{mg} / \mathrm{kg}$ bw. It remains to be elucidated why in therapeutic use of DES such high dose levels were applied, especially because also at that time it was known that during pregnancy, the production of E2 is strictly regulated (Bondesson et al. 2015) by the body to avoid plasma concentrations of E2 that could affect fetal development.

Comparison of the results of the present study to results from a similar study on kinetics of DES and E2 in rats (Adam et al. 2019a; Zhang et al. 2018) also provides insight in species differences in kinetics 
of DES and E2. This inter-species comparison, revealed that clearance of DES is 2.8 -fold lower while that of E2 is 2-fold higher in humans compared to rats, pointing at subtle species differences in clearance of these estrogens.

Considering that the blood concentration of DES will be a key parameter determining developmental toxicity in vivo, any factors that influence this parameter may influence sensitivity to developmental toxicity between individual women. Based on the sensitivity analysis, the plasma concentration of E2 and DES is highly influenced by the fraction of blood flow to the liver (QLC), the fraction of liver tissue (VLc), the hepatic clearance (CLintS9), S9 protein concentration in human liver (S9P), the estimated in vivo Papp value, the volume for the intestinal sub-compartment (Vin) and the intestinal surface area for the intestinal sub-compartment (SAin).

The internal dose levels predicted for DES and E2 can also be compared to concentration-response curves as obtained in in vitro developmental toxicity assays including the EST and ZET as reported in our previous studies (Adam et al 2019a; Adam et al 2019b). This reveals that at dose levels of DES in the range of 49.4 to $1000 \mathrm{mg} / \mathrm{kg}$ bw, the internal concentrations will readily reach concentrations in the range of 1 to $100 \mu \mathrm{M}$ shown to cause in vitro developmental toxicity.

It should be noted that internal concentrations predicted at dose levels above $0.25 \mathrm{mg} / \mathrm{kg}$ seem to exceed the range of $3 \mu \mathrm{M}$ where clearance was likely linear. Whether at these higher internal concentrations clearance of DES and E2 is still linear and not saturating remains to be established. However when kinetics would saturate at these higher dose levels the internal Cmax values would even be higher than what has now been predicted in Figure 5, resulting in even more substantial differences in internal dose levels upon high dose DES therapy as compared to endogenous E2 levels.

It is also of interest to note that only a limited number of parameters were available to define the PBK models for pregnant women, keeping many parameters similar to what was defined for the premenopausal women (Table 1). However, based on the outcome of the sensitivity analysis, and the fact that the respective parameters can be expected to change in both the E2 and DES model in a 
similar way, it can be concluded that changes in additional parameters upon pregnancy are not likely to influence the outcomes to such an extent that they will overrule the 2 to 3 orders of magnitude difference in internal dose levels now elucidated for the endogenous E2 versus the internal DES levels at therapeutic dose levels.

Finally, in addition to kinetics and the internal dose levels, developmental toxicity of a compound depends also on toxicodynamics including the mode of toxic action, and the window of exposure during which in a pregnancy the adverse effect can be induced. Our previous studies revealed that E2 and DES showed high similarity in the mode of action with some minor albeit significant differences related to some epigenetic effects induced by DES but not E2, including downregulation of histone deacetylation genes (HDAC7 and HDAC10) and genes for DNA methylation (HIST1H2BE) (Adam et al. 2019c). In addition to the remarkable difference in expected internal dose levels at therapeutic dose levels of DES compared to endogenous E2 levels, these differences in epigenetic effects may add to the adverse effects observed in the offspring and subsequent generations of the pregnant women exposed to DES during pregnancy (IARC 2012). It has been reported that aberrant DNA methylation was implicated in DES-induced reproductive developmental abnormalities and tumor formation (Newbold et al. 2006; Sato et al. 2009). In addition, sons and daughters of women who were exposed in utero to DES also showed increased numbers of birth defects, showing transgenerational effects that may be epigenetically regulated (Titus-Ernstoff et al. 2010). Thus, even at similar internal dose levels subtle differences between E2 and DES may remain.

Altogether, it is concluded that the PBK modeling-based approach enabled a clear assessment of the dose-dependent internal dose levels of E2 and DES. The results thus obtained indicate that differences between DES and E2 in developmental toxicity might to a large extent be ascribed to the differences between the internal dose levels resulting from endogenous formation of E2 and the high therapeutic dose level of DES administered. Given the high potency of DES as an estrogen, with a 
potency similar or even somewhat higher than E2, it remains to be elucidated why such relatively high therapeutic dose levels of DES have been applied.

\section{Conflict of interest statement}

The authors declare that there are no conflicts of interest.

\section{References}

Abduljalil K, Furness P, Johnson TN, Rostami-Hodjegan A, Soltani H (2012) Anatomical, physiological and metabolic changes with gestational age during normal pregnancy: a database for parameters required in physiologically based pharmacokinetic modelling. Clin Pharmacokinet 51(6):365-96.

Abramson FP, Miller HC (1982) Bioavailability, distribuation and pharmacokinetics of diethylstilbestrol produced from stilphostrol. The Journal of Urology 128 (6): 1336-1339.

Adam AHB, Zhang M, de Haan LHJ, van Ravenzwaay B, Louisse J, Rietjens IMCM (2019a) The in vivo developmental toxicity of diethylstilbestrol (DES) in rat evaluated by an alternative testing strategy. Arch Toxicol 93(7):2021-2033.

Adam AHB, de HaanLHJ, Kamelia L, Louisse J, Rietjens IMCM (2019b) Assessment of the role of Estrogen receptor alpha in the developmental toxicity of diethylstilbestrol (DES) compared to estradiol (E2) using zebrafish. Submitted.

Adam AHB, de Haan LHJ, Estruch IM, Hooiveld GJEJ, Louisse J, Rietjens IMCM (2019c) Estrogen receptor alpha $(E R \alpha)$-mediated coregulator binding and gene expression discriminates the toxic $E R \alpha$ agonist diethylstilbestrol (DES) from the endogenous ERaagonist 17 $\beta$-estradiol (E2). Submitted.

Akolekar R, Bower S, Flack N, Bilardo CM, Nicolaides KH (2011) Prediction of miscarriage and stillbirth at 11-13 weeks and the contribution of chorionic villus sampling. Prenat Diagn 31(1):38-45

Albrecht ED and Pepe GJ (2010) Estrogen regulation of placental angiogenesis and fetal ovarian development during primate pregnancy. Int J Dev Biol 54(2-3): 397-408.

Bennink HJTC (2008) Reprint of are all estrogens the same?. Maturitas 61(1-2): 195-201.

Bondesson M, Hao R, Lin CY, Williams C, Gustafsson JA (2015) Estrogen receptor signaling during vertebrate development. Biochim Biophys Acta 1849(2):142-151.

Boonpawa R, Spenkelink A, Punt A, Rietjens IMCM (2017) In vitro-in silico-based analysis of the dosedependent in vivo oestrogenicity of the soy phytoestrogen genistein in humans. Br J Pharmacol. 174(16):2739-2757.

Brown RP, Delp MD, Lindstedt SL, Rhomberg LR, Beliles RP (1997) Physiological parameter values for physiologically based pharmacokinetic models. Toxicol Ind Health 13(4):407-484. 
Bruce Chabner; Dan Louis Longo (1996). Cancer Chemotherapy and Biotherapy: Principles and Practice. Lippincott-Raven Publishers. p. 186. ISBN 978-0-397-51418-2.

Chiu WA, Ginsberg GL (2011) Development and evaluation of a harmonized physiologically based pharmacokinetic (PBPK) model for perchloroethylene toxicokinetics in mice, rats, and humans. Toxicol Appl Pharmacol 253(3):203-234.

Cornwall GA, Carter MW, Bradshaw WS (1984) The relationship between prenatal lethality or fetal weight and intrauterine position in rats exposed to diethylstilbestrol, zeranol, 3,4,3', $4^{\prime}$ tetrachlorobiphenyl, or cadmium. Teratology 30(3):341-349.

Dallmann A, Ince I, Meyer M, Willmann S, Eissing T, Hempel G (2017) Gestation-Specific Changes in the Anatomy and Physiology of Healthy Pregnant Women: An Extended Repository of Model Parameters for Physiologically Based Pharmacokinetic Modeling in Pregnancy. Clin Pharmacokinet (2017) 56:1303-1330.

DeJongh J, Verhaar HJ, Hermens JL (1997) A quantitative propertyproperty relationship (QPPR) approach to estimate in vitro tissue-blood partition coefcients of organic chemicals in rats and humans. Arch Toxicol 72(1):17-25.

Evans MV, Andersen ME (2000) Sensitivity analysis of a physiological model for 2,3,7,8tetrachlorodibenzo-p-dioxin (TCDD): assessing the impact of specific model parameters on sequestration in liver and fat in the rat. Toxicol Sci 54(1):71-80.

Giusti RM, Iwamoto K, Hatch EE (1995) Diethylstilbestrol revisited: a review of the long-term health efects. Ann Intern Med 122(10):778-788.

Hansch C, Leo A, Hoekman D (1995) Exploring QSAR: hydrophobic, electronic, and steric constants. American Chemical Society, Washington, DC.

Hennry EC, Miller RK (1986) Comparison of the disposition of diethylstilbestrol and estradiol in the fetal rat: Correlation with teratogenic potency. Biochemical Pharmacology 35(12): 1993-2001.

Hosseinpour M, Behdad A (2008) Evaluation of small bowel measurement in alive patients. Surg Radio Anat 30, 653-5.

Hou TJ, Zhang W, Xia K, Qiao XB, Xu XJ (2004) ADME evaluation in drug discovery. 5. Correlation of Caco-2 permeation with simple molecular properties. J Chem Inf Comput Sci 44(5):1585-1600.

IARC (2012) A review of human carcinogens. Part A: Pharmaceuticals. IARC Working Group on the Evaluation of Carcinogenic Risks to Humans, 100:1-403.

Kararli TT (1995) Comparison of the gastrointestinal anatomy, physiology, and biochemistry of humans and commonly used laboratory animals. Biopharm Drug Dispos 16: 351-380

Kemp HA, Read GF, Fahmy DR, Pike AW, Gaskell SJ, Queen K, Harper ME, Griffiths K (1981) Measurement of Diethylstilbestrol in Plasma from Patients with Cancer of the Prostate. Cancer Research 41: 4693-4697 
Kuhnz W, Gansau C, Mahler M (1993) Pharmacokinetics of estradiol, free and total estrone, in young women following single intravenous and oral administration of 17 beta-estradiol. Arzneimittelforschung 43(9):966-73

Morel Y, Roucher F, Plotton I, Goursaud C, Tardy V, Mallet D (2016) Evolution of steroids during pregnancy: Maternal, placental and fetal synthesis. Annales d'Endocrinologie77(2016)82-89

Nagao T, Yoshimura S (2009) Early embryonic losses in mice induced by diethylstilbestrol. Congenit Anom 49(4):269-273

Newbold RR, Padilla-Banks E, Jefferson, WN (2006) Adverse effects of the model environmental estrogen diethylstilbestrol are transmitted to subsequent generations. Endocrinology 147(6), 11-17

Obach RS (1999) Prediction of human clearance of twenty-nine drugs from hepatic microsomal intrinsic clearance data: an examination of in vitro half-life approach and nonspecifc binding to microsomes. Drug Metab Dispos Biol Fate Chem 27(11):1350-1359

Price TM, Blauer KL, Hansen M, Stanczyk F, Lobo R, Bates GW (1997) Single-dose pharmacokinetics of sublingual versus oral administration of micronized 17 beta-estradiol. Obstet Gynecol 89(3), 340-5.

Reed, C. E., and Fenton, S. E. (2013). Exposure to diethylstilbestrol during sensitive life stages: a legacy of heritable health effects. Birth defects research. Part C, Embryo today: reviews 99(2), 134-46

Roy D, Bernhardt A, Strobel HW, Liehr JG (1992) Catalysis of the oxidation of steroid and stilbene estrogens to estrogen quinone metabolites by the beta-naphthofavone-inducible cytochrome P450 IA family. Arch Biochem Biophys 296(2):450-456

Sato K. Fukata H, Kogo Y, Ohgane J, Shiota K, Mori C (2009) Neonatal exposure to diethylstilbestrol alters expression of DNA methyltransferases and methylation of genomic DNA in the mouse uterus. Endocrine journal 56(1): 131-9.

Selassie CD, Shusterman AJ, Kapur S, Verma RP, Zhang LT, Hansch C (1999) On the toxicity of phenols to fast growing cells. A QSAR model for a radical-based toxicity. J Chem Soc Perk T 2(12):2729-2733

Shah HC and McLachlan JA (1976) The fate of diethylstilbestrol in the pregnant mouse. Journal of Pharmacology and Experimental Therapeutics 197 (3): 687-696

Sjogren E, Lennernas H, Andersson TB, Grasjo J, Bredberg U (2009)The multiple depletion curves method provides accurate estimates of intrinsic clearance (CLint), maximum velocity of the metabolic reaction (Vmax), and Michaelis constant $(\mathrm{Km})$ : accuracy and robustness evaluated through experimental data and Monte Carlo simulations. Drug Metab Dispos 37(1):47-58.

Sun D, Lennernas H, Welage LS et al (2002) Comparison of human duodenum and Caco-2 gene expression profiles for 12,000 gene sequences tags and correlation with permeability of 26 drugs. Pharm Res 19(10):1400-1416

Titus-Ernstoff L, Troisi R, Hatch EE, Palmer JR, Hyer M, Kaufman R, Adam E, Noller K, Hoover RN (2010) Birth defects in the sons and daughters of women who were exposed in utero to diethylstilbestrol (DES). Int J Androl 33(2):377-84 
Tracy TS, Venkataramanan R, Glover DD, et al. Temporal changes in drug metabolism (CYP1A2, CYP2D6 and CYP3A activity) during pregnancy. Am J Obstet Gynecol 2005 Feb; 192 (2): 633-9.

Wardell RE, Seegmiller RE, Bradshaw WS (1982) Induction of prenatal toxicity in the rat by

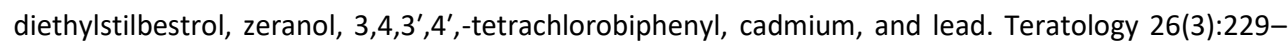
237

Warita K, Mitsuhashi T, Sugawara T, Tabuchi Y, Tanida T, Wang ZY, Matsumoto Y, Yokoyama T, Kitagawa H, Miki T, et al. (2010) Direct effects of diethylstilbestrol on the gene expression of the cholesterol side-chain cleavage enzyme (P450scc) in testicular Leydig cells. Life sciences 87(9-10), 281-285.

Watanabe H, Suzuki A, Kobayashi M, Lubahn DB, Handa H, Iguchi T (2003) Similarities and differences in uterine gene expression patterns caused by treatment with physiological and non-physiological estrogens. Journal of Molecular Endocrinology 31(3): 487-497.

Yazdanian M, Glynn SL, Wright JL, Hawi A (1998) Correlating partitioning and Caco-2 cell permeability of structurally diverse small molecular weight compounds. Pharm Res 15(9):1490-1494

Zhang M, van Ravenzwaay B, Fabian E, Rietjens IMCM, Louisse J (2018)Towards a generic physiologically based kinetic model to predict in vivo uterotrophic responses in rats by reverse dosimetry of in vitro estrogenicity data. Arch Toxicol 92(3):1075-1088

Zhu L, Xiao L, Li W, Zhang Y, Han W, Zhu Y, Ge G, Yang L (2016) Human UDP-Glucuronosyltransferases $1 \mathrm{~A} 1,1 \mathrm{~A} 3,1 \mathrm{~A} 9,2 \mathrm{~B} 4$ and $2 \mathrm{~B} 7$ are Inhibited by Diethylstilbestrol. Basic \& Clinical Pharmacology \& Toxicology, 2016, 119, 505-511 


\section{Supplementary material 1}

; Date: November 2019

; Purpose: General PBK model for 17?-estradiol

; Species: Human (female)

; Compiled by: Aziza Hussein

; Organization: Wageningen University

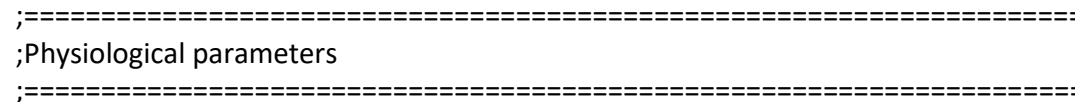

;tissue volumes

$\mathrm{BW}=58\{\mathrm{Kg}\} \quad ;$ body weight human (variable, dependent on study)

$\mathrm{VFC}=0.327 \quad ;$ fraction of fat tissue

reference: (Brown et al., 1997).

$\mathrm{VLC}=0.026 \quad$; fraction of liver tissue

reference: (Brown et al., 1997).

$\mathrm{VBc}=0.079 \quad ;$ fraction of blood

$\mathrm{VRC}=0.068 \quad ;$ fraction of rapidly perfused tissue

reference: (Brown et al., 1997).

$\mathrm{VSc}=0.5$

reference: (Brown et al., 1997).

; fraction of slowly perfused tissue

reference: (Brown et al., 1997).
$\{\mathrm{L}$ or $\mathrm{Kg}\}$
$\{\mathrm{L}$ or $\mathrm{Kg}\}$
$\{\mathrm{L}$ or $\mathrm{Kg}\}$
$\{\mathrm{L}$ or $\mathrm{Kg}\}$
$\mathrm{VF}=\mathrm{VFc} * \mathrm{BW}$
$\{\mathrm{L}$ or $\mathrm{Kg}\}$
; volume of fat tissue (calculated)
$\mathrm{VL}=\mathrm{VLC} * \mathrm{BW}$
; volume of liver tissue (calculated)
; volume of blood (calculated)
$\mathrm{VR}=\mathrm{VRc} * \mathrm{BW}$
; volume of richly perfused tissue
(calculated)
$\mathrm{VS}=\mathrm{VSc} * \mathrm{BW}$

(calculated)

;blood flow rates

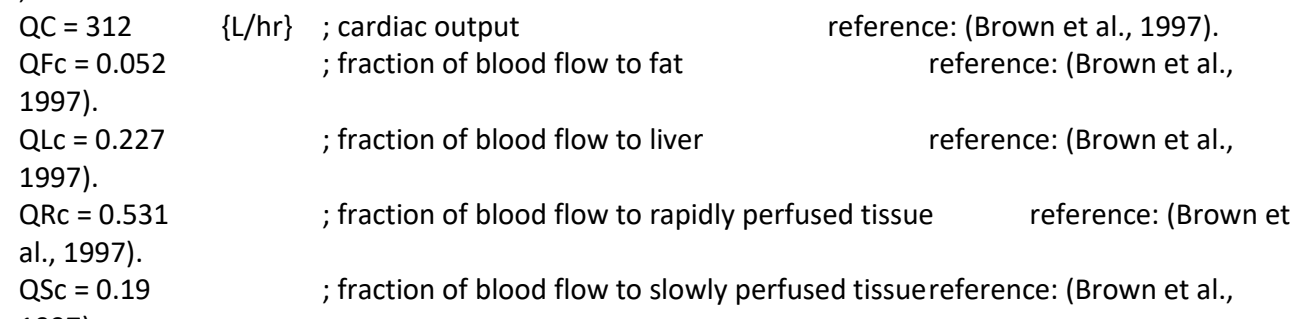

1997).

$\begin{array}{lll}Q F=Q F c^{*} Q C & \{L / h r\} & ; \text { blood flow to fat tissue (calculated) } \\ Q L=Q L c^{*} Q C & \{L / h r\} & ; \text { blood flow to liver tissue (calculated) } \\ Q R=Q R c^{*} Q C & \{L / h r\} & ; \text { blood flow to rapidly perfused tissue (calculated) } \\ Q S=Q S c^{*} Q C & \{L / h r\} & ; \text { blood flow to slowly perfused tissue (calculated) }\end{array}$

; Intestinal lumen volumes, surfaces, absorption rates, transfer rates
Vin $=1.29$
; volume for each compartment of intestines $\{L\}$
SAin $=10.3$
; surface area $\{\mathrm{dm} 2\}$
kin $=2.19$
; transfer rate to next compartment within the intestines $\{/ \mathrm{hr}\}$
Papp $=0.055$
; apparent intestinal permeability coefficient in vivo $\{\mathrm{dm} / \mathrm{hr}\}$
kabin1 $=$ Papp*SAin
; absorption rate constant $\{\mathrm{L} / \mathrm{hr}\}$
$\operatorname{Vin} 1=\operatorname{Vin}$
; volume of intestine compartment $1\{\mathrm{~L}\}$ 


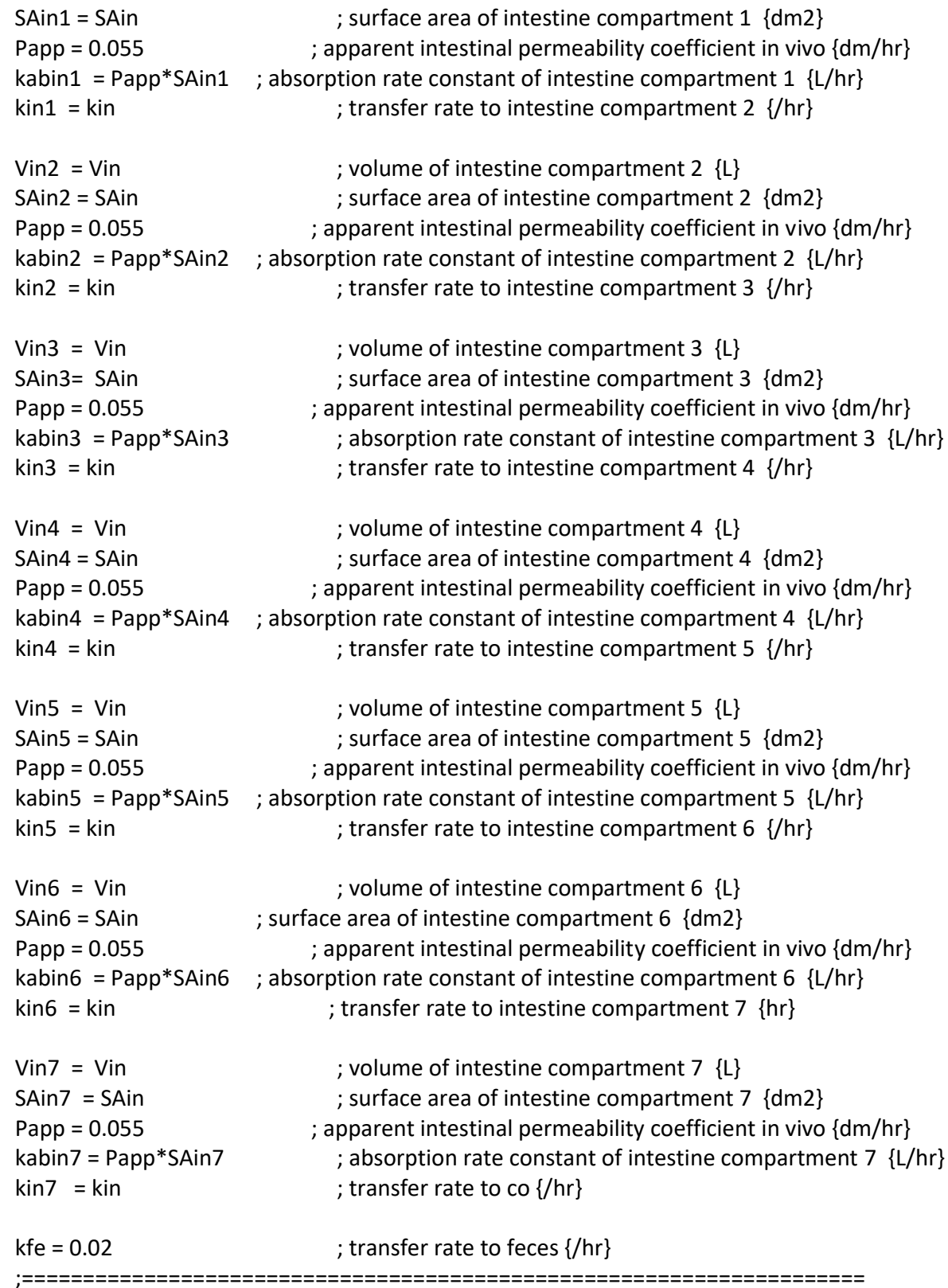

;Partition Coefficients

$\mathrm{PF}=112.72$

;fat/blood partition coefficient calculated using QPPR of DeJongh et al. (1997)

$\mathrm{PL}=8.32$

;liver/blood partition coefficient calculated using QPPR of DeJongh et al. (1997) 
$\mathrm{PR}=7.24$

; rapidly perfused tissue/blood partition coefficient calculated using QPPR of DeJongh et al. (1997)

PS $=5.14$

;slowly perfused tissue/blood partition coefficient calculated using QPPR of DeJongh et al. (1997)

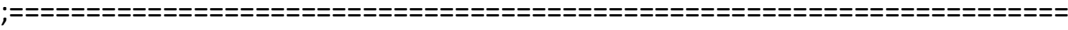

;Kinetic parameters

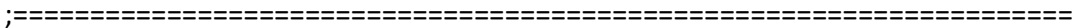

;Metabolism liver

;metabolism of 17 ?-estradiol, scaled maximum rate of metabolism

CLint $=S 9 P * V L *(C L i n t S 9 * 60 * 1 E-6) \quad\{L / h r\} \quad$;Hepatic clearance

CLintS9 = $128 \quad\{\mathrm{ul} / \mathrm{min} / \mathrm{mg}$ protein $\} \quad$;Hepatic clearance derived from S9 fraction;

$\mathrm{S9P}=72 * 1000 \quad\{\mathrm{mg} / \mathrm{kg}\} \quad ; \mathrm{mg}$ protein in $\mathrm{kg}$ liver

;reference: (Chiu and Ginsberg, 2011)

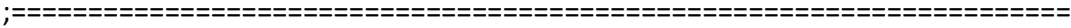

;Run settings

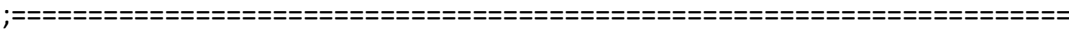

;Molecular weight

$\mathrm{MW}=272.38$

; Molecular weight 17?-oestradiol

;oral dose

ODOSEmg1 $=0.25 \quad\{\mathrm{mg} / \mathrm{kg} \mathrm{bw}\} \quad ;$ ODOSEmg1 $=$ given oral dose $\mathrm{in} \mathrm{mg} / \mathrm{kg} \mathrm{bw}$

ODOSEumol2 $=$ ODOSEmg $1 * 1 \mathrm{E}-3 / \mathrm{MW} * 1 \mathrm{E} 6 \quad\{\mathrm{umol} / \mathrm{kg}$ bw $\}$

;ODOSEumol2 = given oral dose recalculated to $\mathrm{umol} / \mathrm{kg}$ bw

ODOSEumol=ODOSEumol2*BW; $\quad$; ODOSEumol $=$ umol given oral

;IV dose

IVDOSEmg1 = $0 \quad\{\mathrm{mg} / \mathrm{kg} \mathrm{bw}\} \quad$; IVDOSEmg1 = given IV dose in $\mathrm{mg} / \mathrm{kg}$ bw

IVDOSEumol2 = IVDOSEmg1*1E-3/MW*1E6 \{umol/ $\mathrm{kg} \mathrm{bw}\}$

;IVDOSEumol2 = given oral dose recalculated to $u \mathrm{~mol} / \mathrm{kg}$ bw

IVDOSEumol=IVDOSEumol2*BW ～; IVDOSEumol = umol given IV

;time

Starttime $=0 \quad ;$ in $\mathrm{hr}$

Stoptime $=50 \quad ;$ in hr

DTMIN = 1e-6 ; minimum integration time (DT)

DTMAX $=0.0015 \quad$; maximum integration time (DT) 


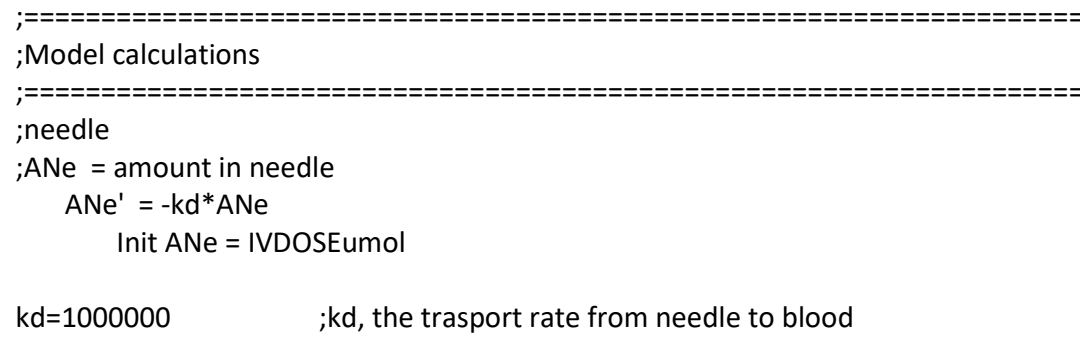

; intestines, divided in 7 compartments

;Ain1 = Amount 17?-oestradiol in intestine compartment 1 (umol)

Cin1 $=$ Ain1/Vin1

Ain $1^{\prime}=-\operatorname{kin} 1 *$ Ain 1

Init Ain1 = ODOSEumol

;Ain2 = Amount 17?-oestradiol in intestine compartment 2 (umol)

$\operatorname{Cin} 2=\operatorname{Ain} 2 / \operatorname{Vin} 2$

Ain2' $=$ kin1*Ain1 - kin2*Ain2 - kabin2*Cin2

Init Ain2 $=0$

;Ain3 = Amount 17?-oestradiol in intestine compartment 3 (umol)

Cin3 $=$ Ain3/Vin3

Ain3' $=$ kin2*Ain2 - kin3*Ain3 - kabin3*Cin3

Init Ain3 $=0$

;Ain4 = Amount 17?-oestradiol in intestine compartment 4 (umol)

Cin4 $=$ Ain4/Vin4

Ain4' $=$ kin3*Ain3 - kin4*Ain4 - kabin4*Cin4

Init Ain4 $=0$

;Ain5 = Amount 17?-oestradiol in intestine compartment 5 (umol)

Cin5 $=$ Ain5/Vin5

Ain5' $=$ kin4*Ain4 - kin5*Ain5 - kabin5* Cin5

Init Ain5 $=0$

;Ain6= Amount 17?-oestradiol in intestine compartment 6 (umol)

Cin6 $=$ Ain6/Vin6

Ain6' $=$ kin5*Ain5 - kin6*Ain6 - kabin6* Cin6

Init Ain6 $=0$

;Ain7= Amount 17?-oestradiol in intestine compartment 7 (umol)

Cin7 $=$ Ain7/Vin7

Ain7' $=$ kin6*Ain6 $-\operatorname{kin} 7 *$ Ain7 $-\operatorname{kabin} 7{ }^{*} \operatorname{Cin} 7$

Init Ain7 = 0

$; A c o=$ Amount 17 ?-oestradiol in colon (umol)

Aco' $=$ kin7*Ain7- kfe*Aco

Init Aco $=0$

ACco' $=$ kin7 $*$ Ain7 
Init $\mathrm{ACCO}=0 ;$ cumulative amount reaching colon

$;$;eces
$; A F A=$ amount 17 ?-oestradiol in feces (umol)
AFe' $=$ kfe*Aco
Init AFe $=0$

;liver compartment

$; A L=$ Amount 7?-oestradiol in liver tissue, umol

$A L^{\prime}=Q L^{*}(C B-C V L)+\operatorname{kabin} 2 * \operatorname{Cin} 2+\operatorname{kabin} 3 * \operatorname{Cin} 3+\operatorname{kabin} 4 * \operatorname{Cin} 4+\operatorname{kabin} 5 * \operatorname{Cin} 5+\operatorname{kabin} 6 * \operatorname{Cin} 6+$ kabin7*Cin7 - AMint'

Init $\mathrm{AL}=0$

$\mathrm{CL}=\mathrm{AL} / \mathrm{VL}$

$\mathrm{CVL}=\mathrm{CL} / \mathrm{PL}$

;AMint = amount 17?-oestradiol metabolized

AMint' $=$ CLint ${ }^{*} \mathrm{CVL}\{$ umol $/ \mathrm{min}\}$

init AMint $=0$

; ;-----------------------

$; A F=$ Amount 17?-oestradiol in fat tissue (umol)

$A F^{\prime}=Q^{*}(C B-C V F)$

Init $A F=0$

$\mathrm{CF}=\mathrm{AF} / \mathrm{VF}$

$\mathrm{CVF}=\mathrm{CF} / \mathrm{PF}$

;tissue compartment richly perfused tissue

$; A R=$ Amount 17 ?-oestradiol in rapidly perfused tissue (umol)

$A R^{\prime}=Q R^{*}(C B-C V R)$

Init $A R=0$

$\mathrm{CR}=\mathrm{AR} / \mathrm{VR}$

$C V R=C R / P R$

;tissue compartment slowly perfused tissue

;AS = Amount 17?-oestradiol in slowly perfused tissue (umol)

$A S^{\prime}=Q S^{*}(C B-C V S)$

Init $A S=0$

$\mathrm{CS}=\mathrm{AS} / \mathrm{VS}$

$\mathrm{CVS}=\mathrm{CS} / \mathrm{PS}$

; blood compartment

$; A B=$ Amount 17?-oestradiol in blood (umol)

$A B^{\prime}=\left(k d^{*} A N e+Q F^{*} C V F+Q L^{*} C V L+Q S^{*} C V S+Q R^{*} C V R-Q C^{*} C B\right)$

Init $A B=0$

$C B=A B / V B$

$A \cup C^{\prime}=C B \quad ; u^{\prime}{ }^{*}{ }^{*} \mathrm{~min} / \mathrm{L}$

Init $A \cup C=0$ 


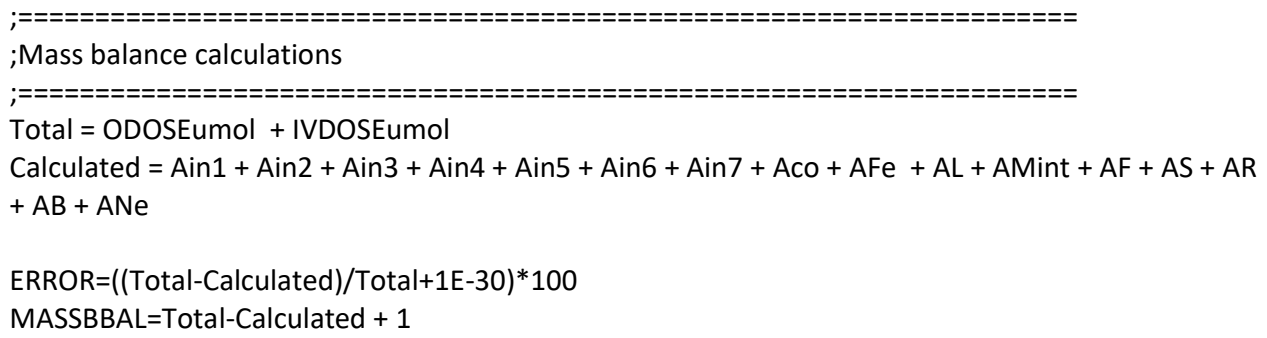

\section{Supplementary material 3}

; Date: November 2019

; Purpose: General PBK model for DES

; Species: Human (female)

; Compiled by: Aziza Hussein

; Organization: Wageningen University

;======================
;Physiological parameters

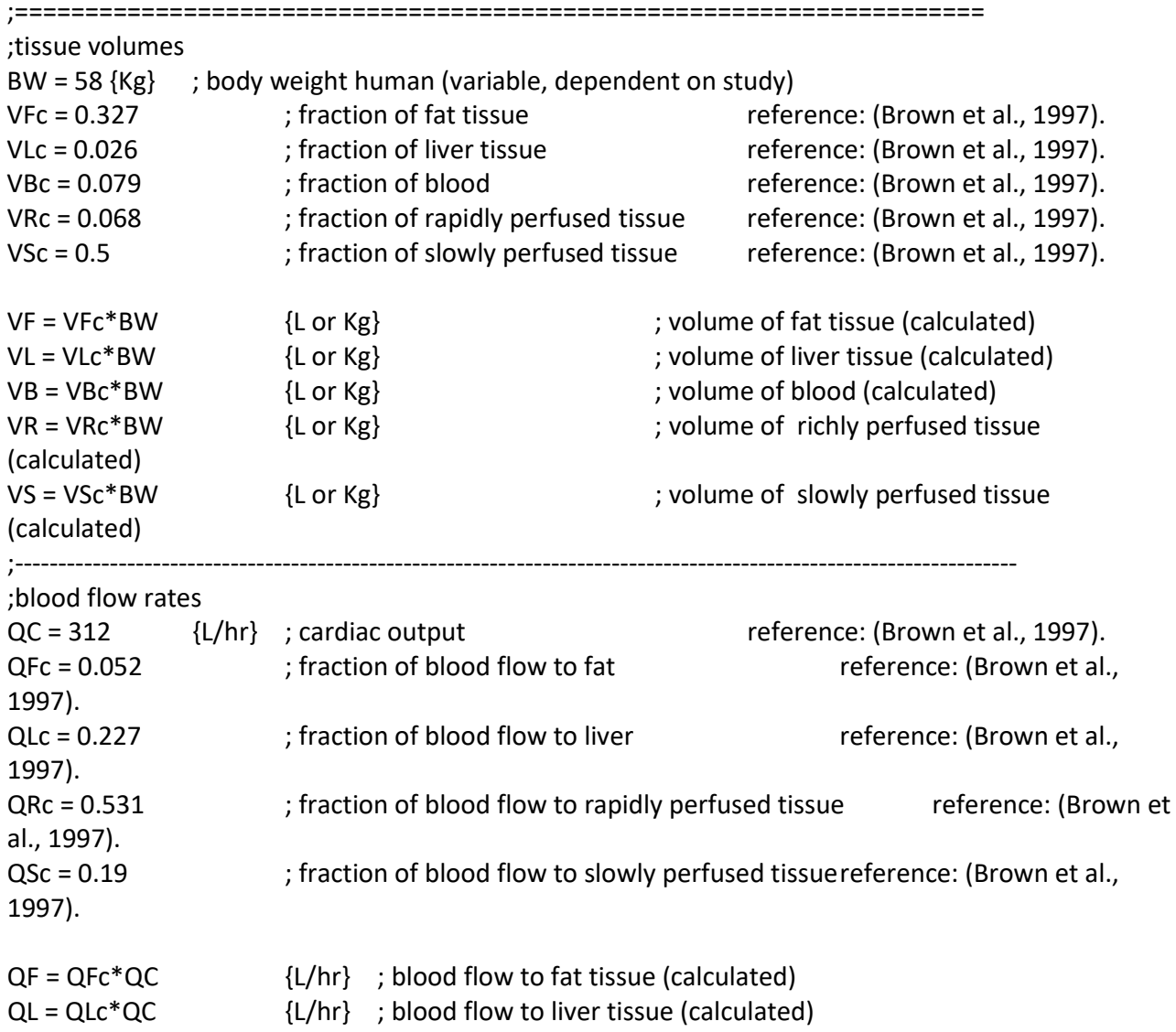


$\begin{array}{lll}\mathrm{QR}=\mathrm{QRc} * \mathrm{QC} & \{\mathrm{L} / \mathrm{hr}\} & ; \text { blood flow to rapidly perfused tissue (calculated) } \\ \mathrm{QS}=\mathrm{QSc} * \mathrm{QC} & \{\mathrm{L} / \mathrm{hr}\} & ; \text { blood flow to slowly perfused tissue (calculated) }\end{array}$

; Intestinal lumen volumes, surfaces, absorption rates, transfer rates
Vin4 = Vin

SAin4 $=$ SAin

Papp $=0.058$

kabin4 $=$ Papp*SAin4

kin4 $=$ kin

Vin5 $=$ Vin

SAin5 $=$ SAin

Papp $=0.058$

kabin5 $=$ Papp*SAin5

kin5 $=$ kin

$\operatorname{Vin} 6=$ Vin

SAin6 $=$ SAin

Papp $=0.058$

kabin6 $=$ Papp*SAin6

kin6 $=$ kin

$\operatorname{Vin} 7=$ Vin

SAin7 = SAin

Papp $=0.058$

kabin7 = Papp*SAin7
; volume for each compartment of intestines $\{L\}$

; surface area $\{\mathrm{dm} 2\}$

; transfer rate to next compartment within the intestines $\{/ \mathrm{hr}\}$ ;apparent intestinal permeability coefficient in vivo $\{\mathrm{dm} / \mathrm{hr}\}$

; absorption rate constant $\{\mathrm{L} / \mathrm{hr}\}$

; volume of intestine compartment $1\{\mathrm{~L}\}$

; surface area of intestine compartment 1 dm2\}

; apparent intestinal permeability coefficient in vivo $\{\mathrm{dm} / \mathrm{hr}\}$

; absorption rate constant of intestine compartment $1\{\mathrm{~L} / \mathrm{hr}\}$

; transfer rate to intestine compartment $2\{/ \mathrm{hr}\}$

; volume of intestine compartment $2\{\mathrm{~L}\}$

; surface area of intestine compartment $2\{\mathrm{dm} 2\}$

; apparent intestinal permeability coefficient in vivo $\{\mathrm{dm} / \mathrm{hr}\}$

; absorption rate constant of intestine compartment $2\{\mathrm{~L} / \mathrm{hr}\}$

; transfer rate to intestine compartment $3\{/ \mathrm{hr}\}$

; volume of intestine compartment $3\{\mathrm{~L}\}$

; surface area of intestine compartment 3 \{dm2\}

;apparent intestinal permeability coefficient in vivo $\{\mathrm{dm} / \mathrm{hr}\}$

; absorption rate constant of intestine compartment $3\{\mathrm{~L} / \mathrm{hr}\}$

; transfer rate to intestine compartment 4 //hr\}

; volume of intestine compartment $4\{\mathrm{~L}\}$

; surface area of intestine compartment 4 \{dm2\}

;apparent intestinal permeability coefficient in vivo $\{\mathrm{dm} / \mathrm{hr}\}$

; absorption rate constant of intestine compartment $4\{\mathrm{~L} / \mathrm{hr}\}$

; transfer rate to intestine compartment $5\{/ \mathrm{hr}\}$

; volume of intestine compartment $5\{\mathrm{~L}\}$

; surface area of intestine compartment $5\{\mathrm{dm} 2\}$

; apparent intestinal permeability coefficient in vivo $\{\mathrm{dm} / \mathrm{hr}\}$ ; absorption rate constant of intestine compartment $5\{\mathrm{~L} / \mathrm{hr}\}$

; transfer rate to intestine compartment $6\{/ \mathrm{hr}\}$

; volume of intestine compartment $6\{\mathrm{~L}\}$

; surface area of intestine compartment 6 \{dm2\}

;apparent intestinal permeability coefficient in vivo $\{\mathrm{dm} / \mathrm{hr}\}$

; absorption rate constant of intestine compartment $6\{\mathrm{~L} / \mathrm{hr}\}$

; transfer rate to intestine compartment $7\{\mathrm{hr}\}$

; volume of intestine compartment $7\{\mathrm{~L}\}$

; surface area of intestine compartment 7 \{dm2\}

;apparent intestinal permeability coefficient in vivo $\{\mathrm{dm} / \mathrm{hr}\}$

; absorption rate constant of intestine compartment $7\{\mathrm{~L} / \mathrm{hr}\}$ 


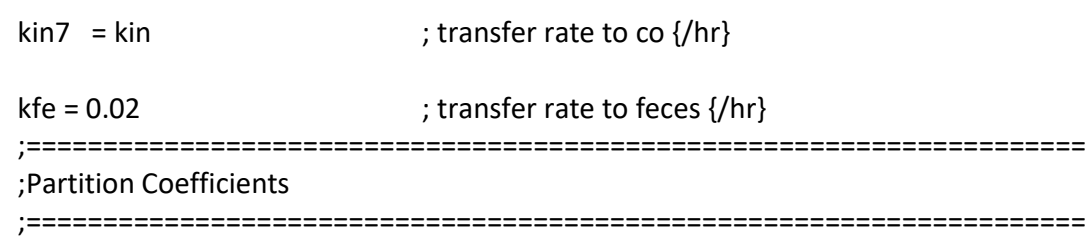

PF $=113.81 \quad$;fat/blood partition coefficient calculated using QPPR of DeJongh et al. (1997)

$\mathrm{PL}=8.84 \quad$;liver/blood partition coefficient calculated using QPPR of DeJongh et al. (1997)

$P R=11.23 \quad$;rapidly perfused tissue/blood partition coefficient calculated using QPPR of DeJongh et al. (1997)

PS = 5.44 ;slowly perfused tissue/blood partition coefficient calculated using QPPR of DeJongh et al. (1997)

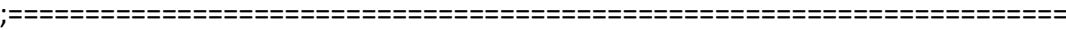

;Kinetic parameters

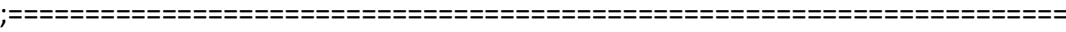

;Metabolism liver

;metabolism of diethylstilbestrol, scaled maximum rate of metabolism

CLint $=$ S9P*VL*(CLintS9*60*1E-6) $\quad\{L / h r\} \quad$; Hepatic clearance

CLintS9 = $160 \quad\{\mathrm{ul} / \mathrm{min} / \mathrm{mg}$ protein $\} \quad ;$ Hepatic clearance derived from S9 fraction;

S9P $=72 * 1000 \quad\{\mathrm{mg} / \mathrm{kg}\} \quad$;mg protein in $\mathrm{kg}$ liver

;reference: (Chiu and Ginsberg, 2011)

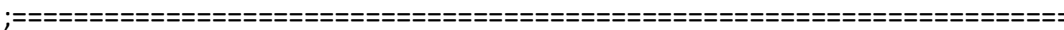

;Run settings

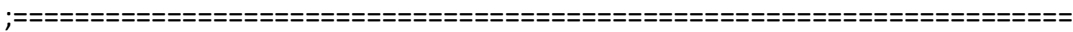

;Molecular weight

MW = 268.35 ; Molecular weight diethylstilbestrol

;oral dose

ODOSEmg1 = $0.25 \quad\{\mathrm{mg} / \mathrm{kg} \mathrm{bw}\} \quad ;$ ODOSEmg1 $=$ given oral dose in $\mathrm{mg} / \mathrm{kg}$ bw

ODOSEumol2 = ODOSEmg $1 * 1 \mathrm{E}-3 / \mathrm{MW} * 1 \mathrm{E} 6 \quad\{\mathrm{umol} / \mathrm{kg} \mathrm{bw}\}$

;ODOSEumol2 = given oral dose recalculated to $\mathrm{umol} / \mathrm{kg}$ bw

ODOSEUmol=ODOSEumol2*BW; $\quad$; ODOSEumol = umol given oral

;IV dose

IVDOSEmg1 = $0 \quad\{\mathrm{mg} / \mathrm{kg} \mathrm{bw}\} \quad ;$ IVDOSEmg1 $=$ given IV dose in $\mathrm{mg} / \mathrm{kg}$ bw

IVDOSEumol2 = IVDOSEmg1*1E-3/MW*1E6 \{umol/ kg bw

;IVDOSEumol2 = given oral dose recalculated to $u \mathrm{~mol} / \mathrm{kg}$ bw 
;time

Starttime $=0 \quad ;$ in $\mathrm{hr}$

Stoptime $=20 \quad ;$ in hr

DTMIN $=1 \mathrm{e}-6 \quad ;$ minimum integration time (DT)

DTMAX $=0.0015 \quad ;$ maximum integration time (DT)

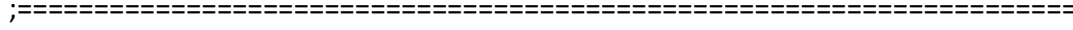

;Model calculations

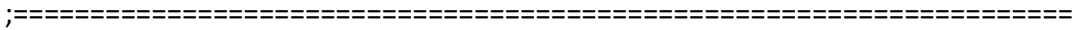

;needle

;ANe = amount in needle

$\mathrm{ANe}^{\prime}=-\mathrm{kd}^{*} \mathrm{ANe}$

Init ANe = IVDOSEumol

$k d=1000000 ; k d$, the trasport rate from needle to blood

;intestines, divided in 7 compartments

;Ain1 = Amount diethylstilbestrol in intestine compartment 1 (umol)

Cin1 $=$ Ain1/Vin1

Ain1' $=-\operatorname{kin} 1^{*}$ Ain 1

Init Ain1 = ODOSEumol

;Ain2 = Amount diethylstilbestrol in intestine compartment 2 (umol)

Cin2 $=$ Ain2/Vin2

Ain2' $=$ kin1*Ain1 - kin2*Ain2 - kabin2*Cin2

Init Ain2 $=0$

;Ain3 = Amount diethylstilbestrol in intestine compartment 3 (umol)

$\operatorname{Cin} 3=$ Ain $3 / \operatorname{Vin} 3$

Ain3' $=$ kin2*Ain2 - kin3*Ain3 - kabin3* $\operatorname{Cin} 3$

Init Ain3 $=0$

;Ain4 = Amount diethylstilbestrol in intestine compartment 4 (umol)

Cin4 $=$ Ain4/Vin4

Ain4' $=$ kin3*Ain3 - kin4*Ain4 - kabin4*Cin4

Init Ain4 $=0$

;Ain5 = Amount diethylstilbestrol in intestine compartment 5 (umol)

Cin5 $=$ Ain $5 /$ Vin 5

Ain5' = kin4*Ain4 - kin5*Ain5 - kabin5*Cin5

Init Ain5 $=0$

;Ain6= Amount diethylstilebstrol in intestine compartment 6 (umol)

Cin6 $=$ Ain6/Vin6

Ain6' = kin5*Ain5 - kin6*Ain6 - kabin6*Cin6 
Init Ain6 $=0$

;Ain7= Amount diethylstilbestrol in intestine compartment 7 (umol)

Cin7 $=$ Ain7/Vin7

Ain7' $=$ kin6*Ain6 - kin7*Ain7 - kabin7* Cin7

Init Ain7 $=0$

$; A c o=$ Amount diethylstilbestrol in colon (umol)

Aco' $=$ kin7*Ain7- kfe*Aco

Init Aco $=0$

$\mathrm{ACCO}^{\prime}=\operatorname{kin} 7^{*}$ Ain 7

Init $\mathrm{ACcO}=0 ;$ cumulative amount reaching colon

; ;eces

;AFA = amount diethylstilbestrol in feces (umol)

$\mathrm{AFe}^{\prime}=\mathrm{kfe}^{*} \mathrm{Aco}$

Init $\mathrm{AFe}=0$

;

;liver compartment

$; A L=$ Amount diethylstilbestrol in liver tissue, umol

$A L^{\prime}=Q L^{*}(C B-C V L)+\operatorname{kabin} 2 * \operatorname{Cin} 2+\operatorname{kabin} 3 * \operatorname{Cin} 3+$ kabin $4 * \operatorname{Cin} 4+\operatorname{kabin} 5 * \operatorname{Cin} 5+\operatorname{kabin} 6 * \operatorname{Cin} 6+$ kabin $7{ }^{*} \operatorname{Cin} 7-$ AMint' $^{\prime}$

Init $A L=0$

$\mathrm{CL}=\mathrm{AL} / \mathrm{VL}$

$\mathrm{CVL}=\mathrm{CL} / \mathrm{PL}$

;AMint $=$ amount diethylstilbestrol metabolized

AMint' $=$ CLint ${ }^{*}$ CVL $\{$ umol/min $\}$

init AMint $=0$

;fat compartment

$; A F=$ Amount diethylstilbestrol in fat tissue (umol)

$A F^{\prime}=Q F^{*}(C B-C V F)$

Init $A F=0$

$\mathrm{CF}=\mathrm{AF} / \mathrm{VF}$

$\mathrm{CVF}=\mathrm{CF} / \mathrm{PF}$

;tissue compartment richly perfused tissue

$; A R=$ Amount diethylstilbestrol in rapidly perfused tissue (umol)

$A R^{\prime}=Q R^{*}(C B-C V R)$

Init $A R=0$

$C R=A R / V R$

$\mathrm{CVR}=\mathrm{CR} / \mathrm{PR}$

; ;issue compartment slowly perfused tissue

;AS = Amount diethylstilbestrol in slowly perfused tissue (umol)

$\mathrm{AS}^{\prime}=\mathrm{QS} \mathrm{S}^{*}(\mathrm{CB}-\mathrm{CVS})$

Init $A S=0$ 
$\mathrm{CS}=\mathrm{AS} / \mathrm{VS}$

$\mathrm{CVS}=\mathrm{CS} / \mathrm{PS}$

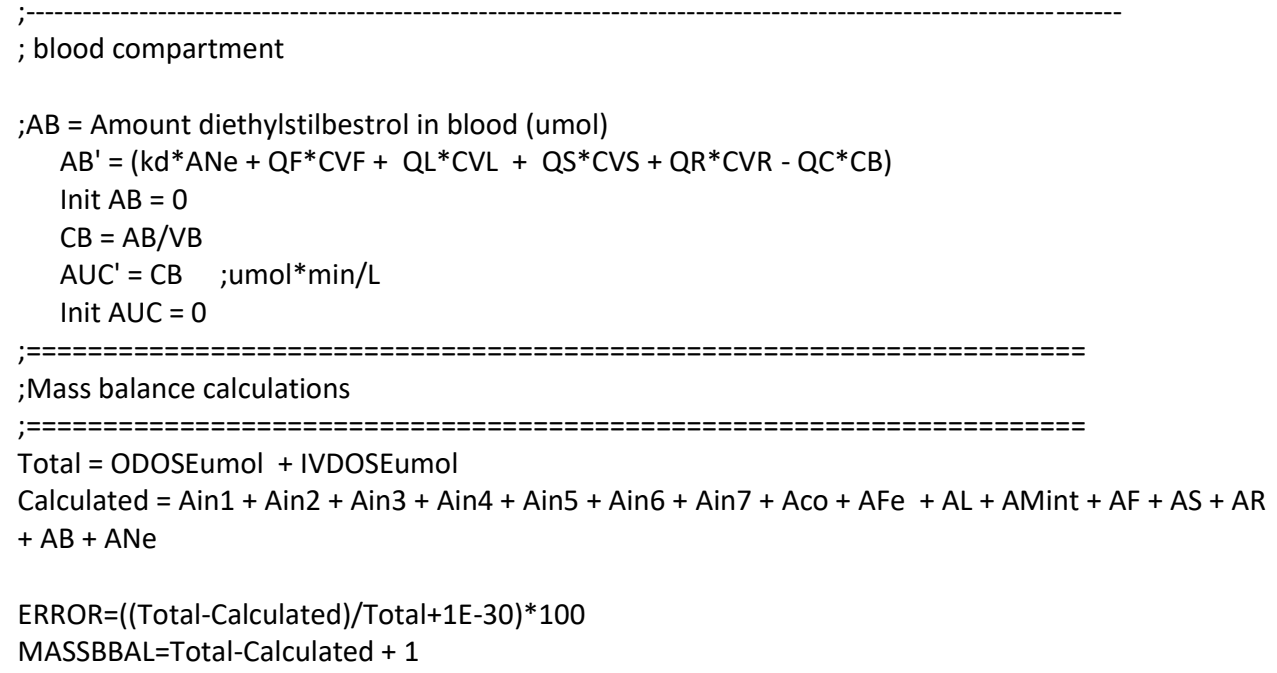

\section{Supplementary material 4}

; Date: November 2019

; Purpose: General PBK model for DES

; Species: Human (pregenant female)

; Compiled by: Aziza Hussein

; Organization: Wageningen University

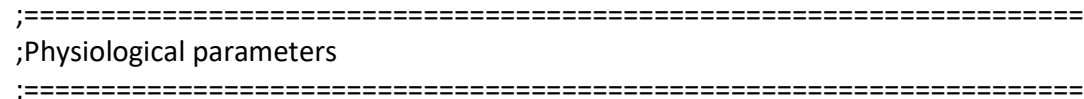

;tissue volumes

$\mathrm{BW}=62\{\mathrm{Kg}\} \quad$; body weight human (variable, dependent on study)

$\mathrm{VFc}=0.363 \quad ;$ fraction of fat tissue

reference: (Brown et al., 1997).

$V L c=0.026 \quad ;$ fraction of liver tissue

reference: (Brown et al., 1997).

$\mathrm{VBC}=0.079$

; fraction of blood

$\mathrm{VRc}=0.068$

; fraction of rapidly perfused tissue

reference: (Brown et al., 1997).

VSC $=0.464$ ; fraction of slowly perfused tissue

reference: (Brown et al., 1997).

reference: (Brown et al., 1997).
$\mathrm{VF}=\mathrm{VFc} * \mathrm{BW}$
$\{\mathrm{L}$ or $\mathrm{Kg}\}$
$\{\mathrm{L}$ or $\mathrm{Kg}\}$
$\mathrm{VL}=\mathrm{VLC} * \mathrm{BW}$
$\{\mathrm{L}$ or $\mathrm{Kg}\}$
$\mathrm{VB}=\mathrm{VBc} * \mathrm{BW}$
$\{\mathrm{L}$ or $\mathrm{Kg}\}$
; volume of fat tissue (calculated)
$\mathrm{VR}=\mathrm{VRc} * \mathrm{BW}$
$\{\mathrm{L}$ or $\mathrm{Kg}\}$
; volume of liver tissue (calculated)
; volume of blood (calculated)
(calculated)
$\mathrm{VS}=\mathrm{VSC} * \mathrm{BW}$
; volume of richly perfused tissue

(calculated)

\section{;blood flow rates}

$\mathrm{QC}=337 \quad\{\mathrm{~L} / \mathrm{hr}\} \quad$; cardiac output

reference: (Brown et al., 1997). 


\begin{tabular}{|c|c|}
\hline $\begin{array}{l}\mathrm{QFc}=0.052 \\
1997) .\end{array}$ & ; fraction of blood flow to fat \\
\hline $\begin{array}{l}\text { QLC }=0.227 \\
1997) .\end{array}$ & ; fraction of blood flow to liver \\
\hline $\begin{array}{l}\text { QRc }=0.531 \\
\text { al., 1997). }\end{array}$ & ; fraction of blood flow to rapidly perfused tissue \\
\hline $\begin{array}{l}\text { QSC }=0.19 \\
1997) .\end{array}$ & ; fraction of blood flow to slowly perfused tissuereference: (Brown et al., \\
\hline$Q F=Q F c * Q C$ & ; blood flow to fat tissue (calculated) \\
\hline$Q L=Q L c * Q C$ & $\{\mathrm{~L} / \mathrm{hr}\} \quad ;$ blood flow to liver tissue (calculated) \\
\hline$Q R=Q R c * Q C$ & $\{\mathrm{~L} / \mathrm{hr}\} \quad ;$ blood flow to rapidly perfused tissue (calculated) \\
\hline$Q S=Q S c * Q C$ & $\{\mathrm{~L} / \mathrm{hr}\} \quad ;$ blood flow to slowly perfused tissue (calculated) \\
\hline
\end{tabular}

; Intestinal lumen volumes, surfaces, absorption rates, transfer rates

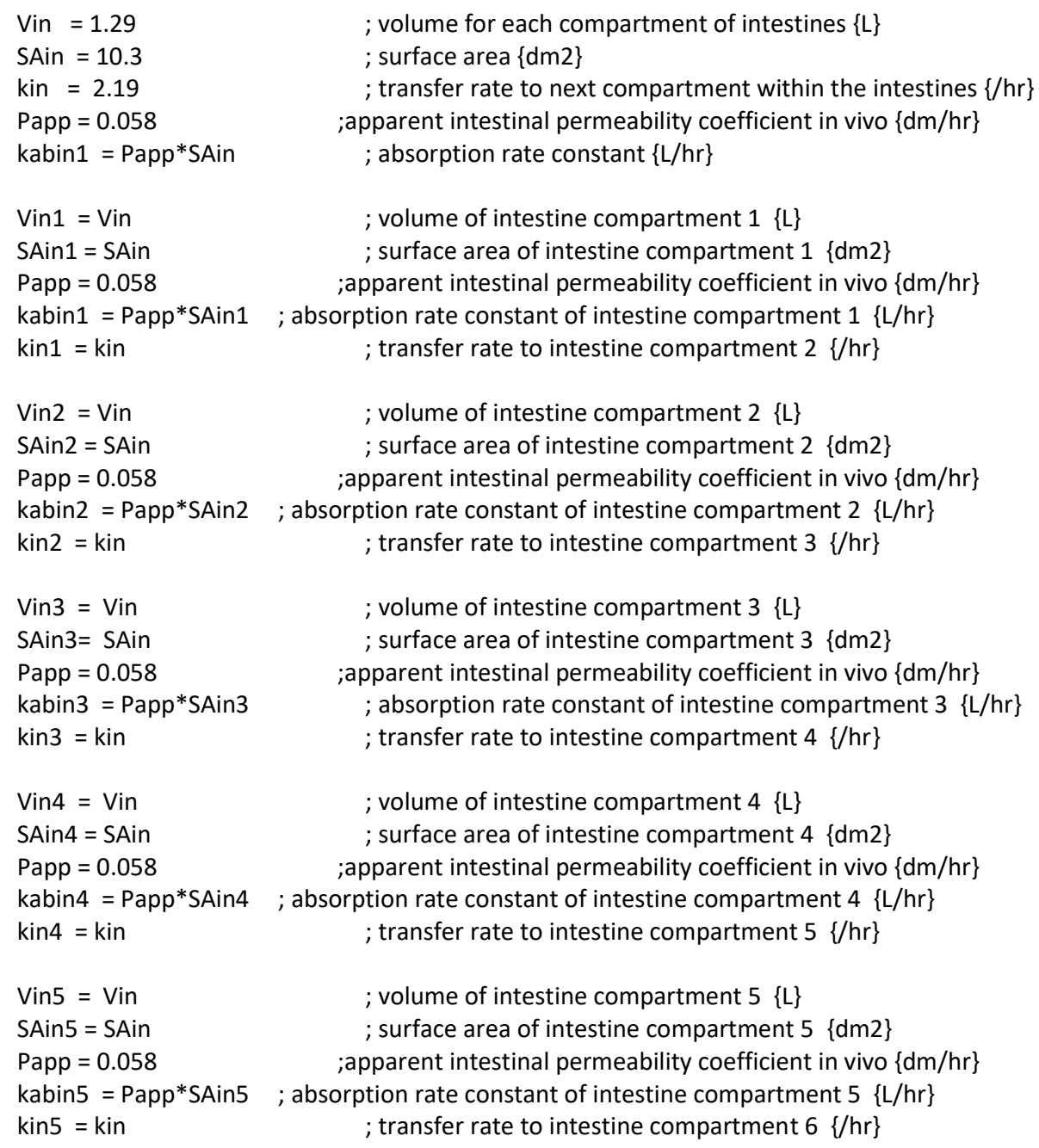


$\operatorname{Vin} 6=$ Vin

SAin6 $=$ SAin

Papp $=0.058$

kabin6 $=$ Papp $*$ SAin6

kin6 $=$ kin

Vin7 $=$ Vin

SAin7 $=$ SAin

Papp $=0.058$

kabin7 $=$ Papp $*$ SAin7

kin7 $=$ kin
; volume of intestine compartment $6\{\mathrm{~L}\}$

; surface area of intestine compartment 6 \{dm2\}

;apparent intestinal permeability coefficient in vivo $\{\mathrm{dm} / \mathrm{hr}\}$

; absorption rate constant of intestine compartment $6\{\mathrm{~L} / \mathrm{hr}\}$

; transfer rate to intestine compartment 7 hr $\}$

; volume of intestine compartment $7\{\mathrm{~L}\}$

; surface area of intestine compartment 7 dm2\}

;apparent intestinal permeability coefficient in vivo $\{\mathrm{dm} / \mathrm{hr}\}$

; absorption rate constant of intestine compartment $7\{\mathrm{~L} / \mathrm{hr}\}$

; transfer rate to co $\{/ \mathrm{hr}\}$

; transfer rate to feces $\{/ \mathrm{hr}\}$

$\mathrm{kfe}=0.02$

$;================$
$;$ Partition Coefficients

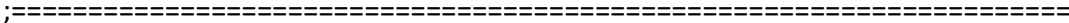

PF $=113.81 \quad$;fat/blood partition coefficient calculated using QPPR of DeJongh et al. (1997)

$\mathrm{PL}=8.84 \quad$;liver/blood partition coefficient calculated using QPPR of DeJongh et al. (1997)

PR $=11.23 \quad$;rapidly perfused tissue/blood partition coefficient calculated using QPPR of DeJongh et al. (1997)

PS = 5.44 ;slowly perfused tissue/blood partition coefficient calculated using QPPR of DeJongh et al. (1997)

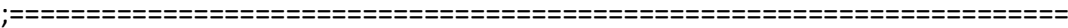

;Kinetic parameters

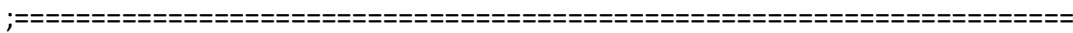

;Metabolism liver

;metabolism of diethylstilbestrol, scaled maximum rate of metabolism

CLint $=$ S9P*VL*(CLintS9*60*1E-6) $\quad\{\mathrm{L} / \mathrm{hr}\} \quad$;Hepatic clearance

CLintS9 $=160 \quad\{\mathrm{ul} / \mathrm{min} / \mathrm{mg}$ protein $\} \quad$;Hepatic clearance derived from S9 fraction;

$\mathrm{S} 9 \mathrm{P}=72 * 1000 \quad\{\mathrm{mg} / \mathrm{kg}\}$

;mg protein in kg liver

;reference: (Chiu and Ginsberg, 2011)

$;=========$
$;$ Run settings

; Molecular weight

$\mathrm{MW}=268.35$

; Molecular weight diethylstilbestrol

;oral dose

ODOSEmg1 $=0.25 \quad\{\mathrm{mg} / \mathrm{kg} \mathrm{bw}\} \quad ;$ ODOSEmg1 $=$ given oral dose in $\mathrm{mg} / \mathrm{kg}$ bw

ODOSEumol2 = ODOSEmg $1 * 1 \mathrm{E}-3 / \mathrm{MW} * 1 \mathrm{E} 6 \quad\{\mathrm{umol} / \mathrm{kg} \mathrm{bw}\}$ 
;ODOSEumol2 = given oral dose recalculated to $\mathrm{umol} / \mathrm{kg}$ bw

ODOSEumol=ODOSEumol2*BW;

; ODOSEumol = umol given oral

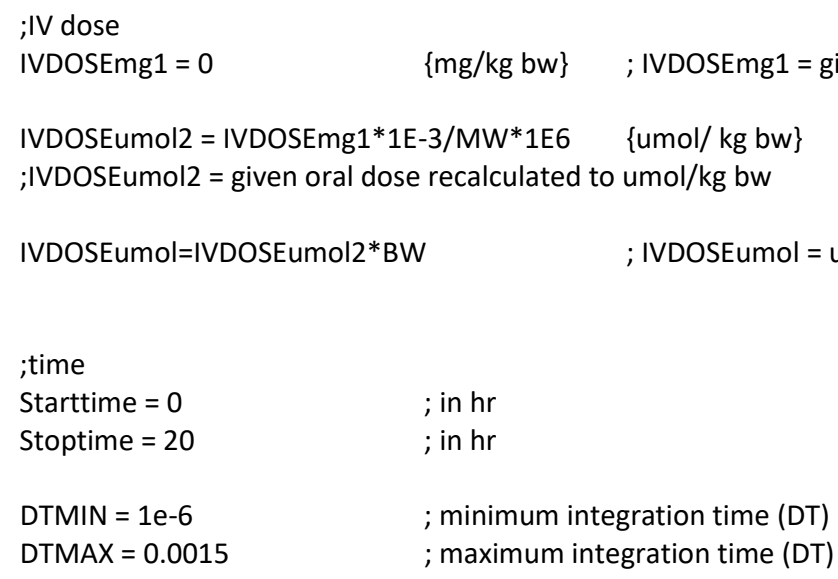

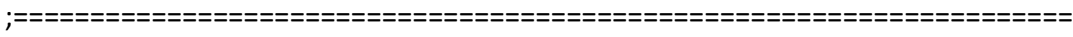

;Model calculations

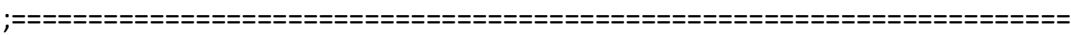

;needle

;ANe = amount in needle

$\mathrm{ANe}^{\prime}=-\mathrm{kd}^{*} \mathrm{ANe}$

Init ANe = IVDOSEumol

$\mathrm{kd}=1000000 \quad ; k d$, the trasport rate from needle to blood

;intestines, divided in 7 compartments

;Ain1 = Amount diethylstilbestrol in intestine compartment 1 (umol)

Cin1 $=$ Ain1/Vin1

Ain1' $=-\operatorname{kin} 1^{*}$ Ain 1

Init Ain1 = ODOSEumol

;Ain2 = Amount diethylstilbestrol in intestine compartment 2 (umol)

$\operatorname{Cin} 2=\operatorname{Ain} 2 / \operatorname{Vin} 2$

Ain2' $=$ kin1*Ain1 - kin2*Ain2 - kabin2*Cin2

Init Ain2 $=0$

;Ain3 = Amount diethylstilbestrol in intestine compartment 3 (umol)

Cin3 $=$ Ain $3 /$ Vin3

Ain3' $=$ kin2*Ain2 - kin3*Ain3 - kabin3*Cin3

Init Ain3 $=0$

;Ain4 = Amount diethylstilbestrol in intestine compartment 4 (umol)

Cin4 $=$ Ain4/Vin4 
Ain4' $=$ kin3*Ain3 - kin4*Ain4 - kabin4*Cin4

Init Ain4 $=0$

;Ain5 = Amount diethylstilbestrol in intestine compartment 5 (umol)

Cin5 $=$ Ain5/Vin5

Ain5' $=$ kin4*Ain4 - kin5*Ain5 - kabin5* Cin5

Init Ain5 $=0$

;Ain6= Amount diethylstilebstrol in intestine compartment 6 (umol)

Cin6 = Ain6/Vin6

Ain6' $=$ kin5*Ain5 - kin6*Ain6 - kabin6* Cin6

Init Ain6 $=0$

;Ain7= Amount diethylstilbestrol in intestine compartment 7 (umol)

Cin7 $=$ Ain7/Vin7

Ain7' $=$ kin6*Ain6 $-\operatorname{kin} 7 * \operatorname{Ain} 7-\operatorname{kabin} 7{ }^{*} \operatorname{Cin} 7$

Init Ain7 $=0$

$; A c o=$ Amount diethylstilbestrol in colon (umol)

Aco' $=$ kin7*Ain7- kfe*Aco

Init $A c o=0$

$\mathrm{ACCO}^{\prime}=\operatorname{kin} 7^{*} \mathrm{Ain} 7$

Init $\mathrm{ACcO}=0 ;$ cumulative amount reaching colon

; $;$ feces

;AFA = amount diethylstilbestrol in feces (umol)

$\mathrm{AFe}^{\prime}=\mathrm{kfe} \mathrm{A}^{*} \mathrm{Aco}$

Init $\mathrm{AFe}=0$

;liver compartment

$; A L=$ Amount diethylstilbestrol in liver tissue, umol

$A L^{\prime}=Q L^{*}(C B-C V L)+$ kabin2*Cin2 + kabin3*Cin3 + kabin4*Cin4 + kabin5*Cin5 + kabin6* Cin6 + kabin7*Cin7 - AMint'

Init $A L=0$

$C L=A L / V L$

$\mathrm{CVL}=\mathrm{CL} / \mathrm{PL}$

;AMint = amount diethylstilbestrol metabolized

AMint' $=$ CLint $*$ CVL $\{$ umol/min $\}$

init AMint $=0$

; $;$ fat compartment

$; \mathrm{AF}=$ Amount diethylstilbestrol in fat tissue (umol)

$A F^{\prime}=Q F^{*}(C B-C V F)$

Init $A F=0$

$\mathrm{CF}=\mathrm{AF} / \mathrm{VF}$

$C V F=C F / P F$

;tissue compartment richly perfused tissue 

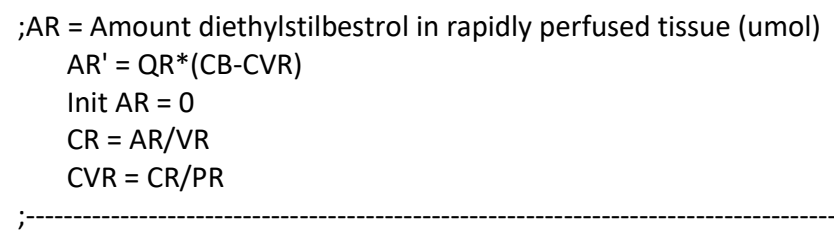

;tissue compartment slowly perfused tissue

;AS = Amount diethylstilbestrol in slowly perfused tissue (umol)

$A S^{\prime}=Q S^{*}(C B-C V S)$

Init $A S=0$

$\mathrm{CS}=\mathrm{AS} / \mathrm{VS}$

$\mathrm{CVS}=\mathrm{CS} / \mathrm{PS}$

; blood compartment

$; A B=$ Amount diethylstilbestrol in blood (umol)

$A B^{\prime}=\left(k d^{*} A N e+Q F^{*} C V F+Q L^{*} C V L+Q S^{*} C V S+Q R^{*} C V R-Q C^{*} C B\right)$

Init $A B=0$

$\mathrm{CB}=\mathrm{AB} / \mathrm{VB}$

$A \cup C^{\prime}=C B \quad ; u^{\prime}{ }^{*} \min / L$

Init $A \cup C=0$

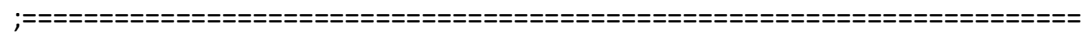

;Mass balance calculations

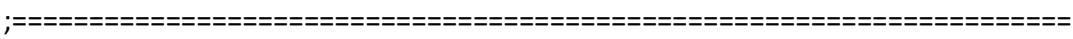

Total $=$ ODOSEumol + IVDOSEumol

Calculated $=$ Ain1 + Ain2 + Ain3 + Ain4 $+A i n 5+A i n 6+A i n 7+A c o+A F e+A L+A M i n t+A F+A S+A R$

$+\mathrm{AB}+\mathrm{ANe}$

ERROR $=(($ Total-Calculated $) /$ Total $+1 \mathrm{E}-30) * 100$

MASSBBAL=Total-Calculated +1 
Physiologically based kinetic modellingfacilitated comparison of internal female dose levels of diethylstilbestrol and $17 \beta$-estradiol, to study a potential role of kinetics in the differences in their developmental toxicity 


\section{CHAPTER 6}

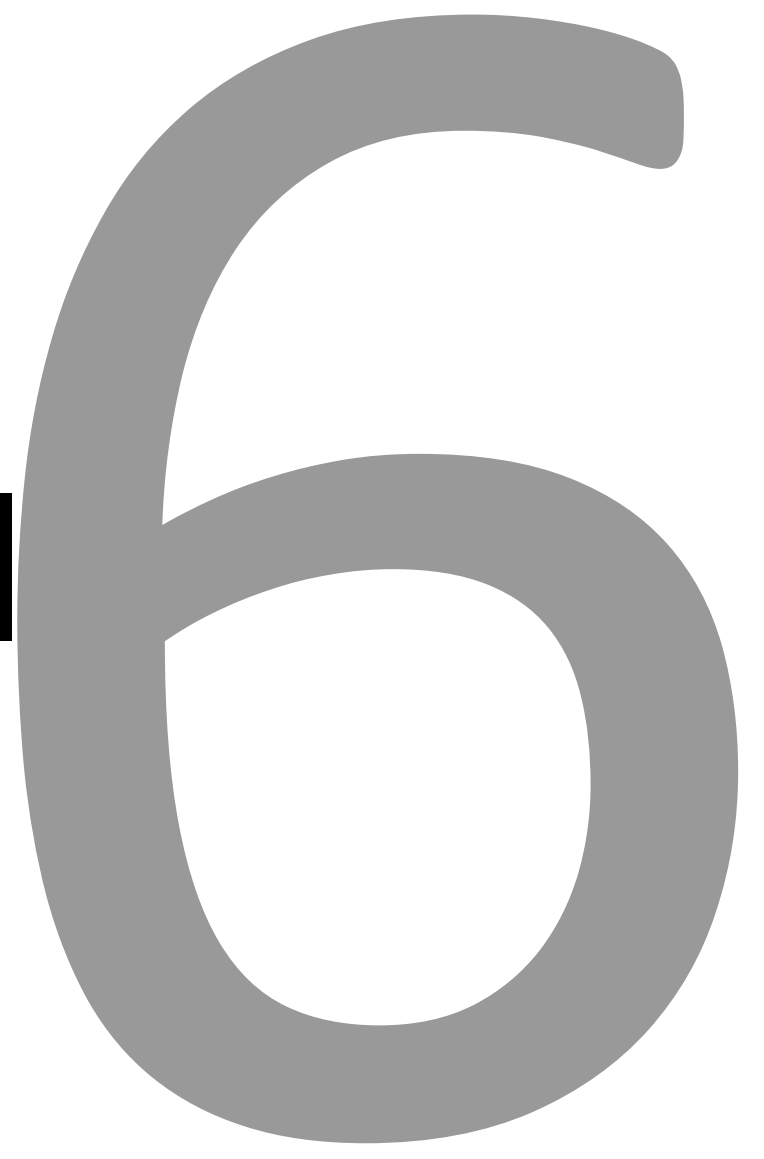


General Discussion 


\section{General discussion}

Diethylstilbestrol (DES) is a synthetic estrogen that has been used between the 1940s and 1970s by pregnant women to prevent miscarriages and premature delivery by stimulating the synthesis of estrogen and progesterone in the placenta (IARC, 2012; Newbold 2008; Reed and Fenton 2013). However, use of DES appeared to cause a wide range of adverse effects, such as clear cell vaginal adenocarcinoma in the daughters of women who took the drug, and developmental and reproductive toxicity (Greenwald et al. 1971; Herbst et al. 1971; Pellizzer et al. 2005; Reed and Fenton 2013; Titus-Ernstoff et al. 2001). These adverse effects have often been attributed to the functional estrogen receptor alpha $(E R \alpha)$, since it has been reported that $E R \alpha$ is needed to induce DES-mediated adverse developmental and reproductive effects in neonates (Chen et al. 2012; Klotz et al. 2000; Couse et al. 2001; Couse and Korach 2004; Prins et al. 2001). The question has been raised why DES behaves differently from the endogenous ER $\alpha$ agonist $17 \beta$-estradiol (E2), even though the molecular dimensions and binding orientations of DES and E2 to the ER $\alpha$ are almost identical (Gonzalez et al. 2019).

The research described in this thesis aimed to investigate the possible differences in the estrogenicity and developmental toxicity between DES and E2, using different in vitro and in silico approaches, focussing on the potential role of possible differences in ER $\alpha$-mediated effects in the underlying mode of action. Accordingly, first the effect of DES and E2 on ER $\alpha$-mediated reporter gene expression, ER $\alpha$-mediated T47D breast cancer cell proliferation, and ER $\alpha$-coregulator interactions and gene expression in T47D cells were evaluated. In addition, the effects of DES and E2 in two alternative developmental toxicity assays (the ES-D3 cell differentiation assay of the embryonic stem cell test (EST) and the zebrafish embyotoxicity test (ZET)) and the potential role of ER $\alpha$ in these effects were evaluated. Finally, possible dose-dependent differences in internal dose levels of DES and E2 were evaluated with help of PBK modelling, in order to elucidate to what extent possible differences in kinetics could play a role in differential in vivo effects of DES and E2. 


\section{Main findings of the thesis}

ER $\alpha$-mediated reporter gene expression, cell proliferation, ER $\alpha$-coregulator interactions and gene expression

Initially, activation of ER $\alpha$-mediated effects by E2 and DES were evaluated using the U2OS ER $\alpha$ reporter gene assay and the T47D cell proliferation assay. DES and E2 showed similar ER $\alpha$-activating potential as illustrated in the U2OS ER $\alpha$ reporter gene assay and the T47D cell proliferation assay. The results obtained for DES and E2 in these models did no differentiate DES from E2. Therefore, ER $\alpha$-coregulator (motif) interactions were studied to assess for possible more subtle differences between DES and E2 regarding ER $\alpha$ activation. A high number of coactivator and corepressor motifs was found to interact with the ER $\alpha$-LBD (ligand binding domain) in a DES and E2 concentrationdependent manner, suggesting that a broad range of coregulator proteins is involved in ER $\alpha$ mediated gene expression by both agonists. Results obtained revealed that DES and E2 induced in general similar ER $\alpha$-LBD coregulator motif interactions, but also showed that for a few coregulator motifs, differences in the ligand-induced coregulator motif interactions with the ER $\alpha$-LBD were observed. Such differences in coregulator binding, albeit limited to only a few coregulators, may in theory result in differences in gene expression patterns.

Next, gene expression in DES- and E2-exposed ER $\alpha$-containing T47D cells was assessed using RNA sequencing to further assess subtle differences in cellular responses induced by DES and E2. General comparison of the gene expression data confirmed that DES and E2 induced remarkably similar gene expression patterns, although close analysis of the data revealed minor, albeit significant differences. In contrast to E2, DES induced significant downregulation of genes involved in histone deacetylation (HDAC7, HDAC10) and DNA methylation (HIST1H2BE) and upregulation of CYP26A1 and CYP26B1, known to be involved in retinoid metabolism (Loudig et al. 2000; Thatcher and Isoherranen 2009). These differences may contribute to the differential in vivo effects reported for DES and E2. 
In the second part of the thesis, the in vitro developmental toxicity of DES and E2 was assessed using two alternative test methods, taking into account the potential role of ER $\alpha$ in the developmental toxicity of DES. First, the effects of E2 and DES in the ES-D3 cell differentiation assay of the embryonic stem cell test (EST) were assessed. The effect concentrations of the EST data for DES were translated into predicted in vivo dose levels causing developmental toxicity using physiologically based kinetic (PBK) modelling-based reverse dosimetry. DES tested positive (at non-cytotoxic concentrations) in the ES-D3 differentiation assay. The DES-induced inhibition of the ES-D3 cell differentiation could be counteracted by the ER $\alpha$ antagonist fulvestrant, indicating that the in vitro ES-D3 cell differentiation assay was able to mimic the role of ER $\alpha$ in the mode of action underlying the developmental toxicity of DES in vivo. E2 was only positive in the EST at cytotoxic concentrations, pointing to a non-specific adverse effect. Although the EST detected DES as a developmental toxicant, the predicted dosedependent in vivo developmental toxicity of DES based on the EST data was 1000-fold underpredicted, indicating that the ES-D3 cell differentiation assay of the EST apparently does not capture the full processes underlying DES-induced developmental toxicity in vivo. As the EST has been reported to capture mainly disturbances in early development, in subsequent experiments, zebrafish embryos were used as a model that also captures disturbances later in the development. Results obtained in the zebrafish embryotoxicity test (ZET) showed that DES induced growth retardation, cumulative mortality and malformations (i.e. induction of pericardial edema) in zebrafish embryos while E2 showed only growth retardation and cumulative mortality with lower potency compared to DES. Furthermore, DES induced pericardial edema formation in zebrafish embryos, which was not observed in E2-exposed zebrafish embryos. This effect could be counteracted by coexposure to fulvestrant, indicating that the ZET was able to capture the role of ER $\alpha$ in the mode of action underlying this developmental toxicity effect of DES in zebrafish. Comparison to in vivo developmental data revealed that the ZET, like the EST, does not fully capture the in vivo potency of DES, as it also underestimates the in vivo potency reported for DES. 
Altogether, the studies on the developmental toxicity of DES and E2 in two alternative test methods show that the EST and the ZET differentiate DES from E2 with respect to the developmental toxicity effects, while confirming the role of ER $\alpha$ in the developmental toxicity of DES. The in vitro assays seemed to underpredict the in vivo developmental toxicity, probably because they do not capture the full mode of action underlying DES-mediated developmental toxicity. This may be related to the fact that both the EST and the ZET do not reflect repeated dose toxicity and/or epigenetic effects that may play a role in the in vivo mode of action of DES (Bromer et al. 2009; Titus-Ernstoff et al. 2010).

Role of toxicokinetics of DES and E2 in their differential in vivo effects

In addition to studies on potential differences in toxicodynamics of E2 and DES, it was considered that differences in the differential effect of DES and E2 might (in part) be due to differences in kinetics. Therefore, PBK models for DES and E2 in non-pregnant and pregnant women were developed and used to investigate potential dose-dependent differences in plasma concentrations of the two ER $\alpha$ agonists. Using forward dosimetry the model for DES predicted that therapeutic doses of DES as given to pregnant women would result in plasma levels that are much higher than endogenous plasma levels for E2. Using reverse dosimetry the model for E2 revealed that predicted dose levels that would result in the endogenous plasma levels of E2 were much lower than the therapeutic dose levels of DES applied as a drug. So although kinetics of DES and E2 appeared to be very similar, differential effects between E2 and DES in vivo may, at least in part, be due to differences in internal exposure levels, resulting from the seemingly extremely high dose levels that were applied when using DES as a drug.

Given these results, obviously also questions for future research remain. In the next sections of this chapter, the implications of the results obtained in the thesis are discussed in some more detail, and recommendations for future studies are presented. More specifically, the topics further discussed include; 
- the potential mechanisms activated by ER agonist activity of DES compared to E2

- the role of coregulators and differential gene expression in the mode of action underlying the differential effects of DES and E2

- the use of alternative testing methods to predict the developmental toxicity of DES (highlighting the potential role of ER $\alpha$ in the developmental toxicity of DES)

- the use of PBK models (considerations and limitations) and the role of kinetics in defining the internal effective dose.

\section{The potential mechanisms activated by ER agonist activity of DES compared to E2}

In the present thesis, focus on the role of ER $\alpha$ in the adverse effects of DES was based on the fact that many studies reported that the adverse effects of DES are mediated through activation of the ER $\alpha$ (Chen et al. 2012; Klotz et al. 2000; Couse et al. 2001; Couse and Korach 2004; Prins et al. 2001). It has been reported that the molecular dimensions and the binding orientation of DES to the ER $\alpha$ are almost identical to those of E2 (Gonzalez et al. 2019). However, E2 is not known for causing the typical adverse effects that have been observed for DES. The adverse effects of DES that are mediated via the ER $\alpha$ include mainly phenotypic changes in the reproductive tract, progressive proliferative lesions, abnormal epithelial cell differentiation in the prostate and alterations of several genes that are involved in regulation of embryonic development (Block et al., 2000; Couse et al., 2001; Couse and Korach, 2004; Ma et al., 1998; Miller et al., 1998). It could be proposed that in addition to ER $\alpha$-mediated effects, other mechanisms may be involved in DES-induced toxicity, since these adverse effects of DES for which ER $\alpha$ involvement has been demonstrated do not cover all the adverse effects reported to be induced by DES. It has been reported that epigenetic changes could be one of the main modes of action of DES-induced adverse effects, which would also be in line with the observation that effects of DES can be passed on to and/or may become only evident in subsequent generations. Sons and daughters of women who were exposed in utero to DES also showed increased numbers of birth defects, showing transgenerational effects that may be epigenetically 
regulated (Titus-Ernstoff et al. 2010). Furthermore, the role of epigenetics in the developmental toxicity of DES follows for example from the fact that it has been reported that female mice exposed to DES in utero had aberrant methylation in the promotor and intron of the hoxa10 gene, a gene of which an adequate expression is critical during embryonic development (Bromer et al. 2009). Clearly future studies should focus on modes of action different from those dependent on ER $\alpha$-mediated effects.

The role of coregulators and differential gene expression in the mode of action underlying the differential effects of DES and E2

Little is known about ER $\alpha$-coregulator interactions induced by DES and to what extent these play a role in the differential effects of the two ER $\alpha$ agonists. The data presented in this thesis show some different ER $\alpha$-LBD-coregulator interactions in the presence of DES compared to E2 and some minor albeit potentially relevant differences in ER $\alpha$-mediated gene expression between both compounds in T47D cells. Coregulators are key intermediates in the transcriptional activation (and repression) of $E R \alpha$, and their overexpression or lack of certain (ligand-dependent) coregulators can modify the effects of a chemical on gene expression and thus its biological effects (Glass and Rosenfeld 2000; Hsia et al. 2010; O'Malley and Kumar 2009). Most of the coregulator motifs that showed specific binding to E2 in the present study, and that were not recruited in the presence of DES, are corepressors that play a role in histone acetylation (e.g. TRRAP). For instance, the corepressors that recruit histone deacetylases (HDACs) to the target gene chromatin keep the chromatin in closed conformation thus shutting off the target gene transcription. The fact that histone deacetylase related genes HDAC7, HDAC10 and HISTIH2BE were significantly downregulated by DES while not by E2 (Chapter 2) and the fact that DES has been reported to induce histone deacetylation in the promoter region of P450scc in TTE1 Leydig cells, while E2 did not induce these changes (Warita et al. 2010), points to specific epigenetic changes induced by DES but not by E2. 
Given the fact that differences were observed between E2 and DES in coregulator (peptide) binding to $E R \alpha$, there are some considerations that should be taken into account in future research in this area. One of these considerations relates to the fact that in this thesis we used the isolated ligand binding domain (LBD) of the ER $\alpha$ to study the coregulator binding to ER $\alpha$ in the presence of $E 2$ and DES. Although the LBD is the main player in the receptor dimerization and coregulator interaction (de Lera et al. 2007), the DNA binding domain (DBD) is in charge of the binding to the estrogen responsive element (ERE) within the genome (Gronemeyer et al. 2004). It remains to be established whether the ligand-induced coregulator interactions of the LBD of ER $\alpha$ would be similar to those observed when using a full length ER $\alpha$. In fact, it has been reported that the DBD of ER $\alpha$ may affect the functioning of the ER $\alpha$ (Ahlbory-Dieker et al. 2009). In addition, gene activation and repression by estrogen-bound ERa rely on an intact DBD in vivo (Ahlbory-Dieker et al. 2009). Therefore, it would be of interest in future research to study the effect of E2 and DES on the coregulator binding of a full length ER $\alpha$ including also ultimate effects on gene expression in vivo. Such an in vivo study would then also validate the differences reported in the present thesis between DES- and E2-induced transcriptomic signatures in the T47D cell model.

Furthermore, use of other techniques to confirm the ligand-induced differential coregulator interactions could be considered. High-throughput glutathione S-transferase (GST) pulldown assays (Goodson et al. 2007), two-hybrid-based methods (Albers et al. 2005), and protein microarrays (Kim et al. 2005) have been shown to provide insights into the interactions of purified full-length coregulators and nuclear receptor (NR) proteins. Given that the coregulator binding data in this thesis were generated using a peptide-based methodology (MARCoNI) not using full length ER $\alpha$ but also not using full length coregulators, indicates a need for further evaluation of the differential coregulator interactions induced by DES and E2 with these complementary technologies. The use of these assays will be crucial to substantiate the differences between E2 and DES reported in the present thesis. Apart from that, the physiological impact of these coregulators at the in vivo level should be considered. The knowledge on the in vivo roles for ER $\alpha$ coregulators is still limited. 
Considering the large number of known coregulators for $E R \alpha$, there is a need for knock out studies to better understand the physiological role of these coregulators and their interaction with ER $\alpha$ in the presence or absence of the ligands. For instance, it has been reported that the knockout of coactivators (NCOAs) causes a range of physiological changes in the knockout mice, including reproductive and metabolic defects (Xu et al. 1998; Xu et al. 2000; Xu and Li 2003; Gehin et al. 2002).

In addition, gene expression in DES- and E2-exposed ER $\alpha$ competent T47D cells was assessed using RNA seq. The T47D cell line is a generally applied model for studying ER $\alpha$-mediated effects, especially because the cells retain several key characteristics specific to the mammary epithelium (Holliday and Speirs, 2011). This thesis shows that DES and E2 induce remarkably similar gene expression patterns in T47D cells, although close analysis of the data revealed minor, albeit significant differences. Several of these differences could be linked to effects of DES on genes related to epigenetic regulation and developmental processes that were not observed for E2. These differences in gene expression between DES and E2 were not described so far in the reported literature. The fact that DES induced significant expression of especially retinoid acid metabolism related genes (CYP26A1 and CYP26AB1), could point at a potential role for disturbance of retinoid acid homeostasis in the mechanism of DES-induced developmental toxicity. DES-mediated upregulation of CYP26A1 and CYP26B1 gene expression, is in line with effects reported for the developmental toxins flusilazole and retinoic acid which have been reported to increase the expression of these genes in a similar manner (Dimopoulou et al. 2016; Luijten et al. 2010). Disturbance of retinoic acid signalling is known to represent an important mode of action in developmental toxicity, especially in induction of malformations (Maden 2000; Tantibanchachai 2014). These differences in transcriptomic signatures between DES and E2 may contribute to the understanding of the molecular events driving the physiological differences between E2 and DES.

Nevertheless, to further support that the effects observed in the T47D cells are not specific for these cells but also observed in other ER $\alpha$ responsive cells experiments were performed in MCF-7 cells, 
validating the differences between DES and E2 in the induction of genes involved in epigenetic mechanisms. Figure 1 present the results obtained and reveals that the differences between DESand E2-mediated downregulation of the histone deacetylase genes (HDAC7 and HDAC10), involved in retinoid acid metabolism (CYP26A1 and CYP26B1) and in the ER-pathway (AXIN2) initially reported in the T47D cells, are also observed in the ER $\alpha$ positive MCF-7 cells. In future studies it would also be of interest to test the effect of DES and E2 on the expression of the genes involved in the retinoic acid pathway (CYP26A1 and CYP26B1) in the EST and ZET.
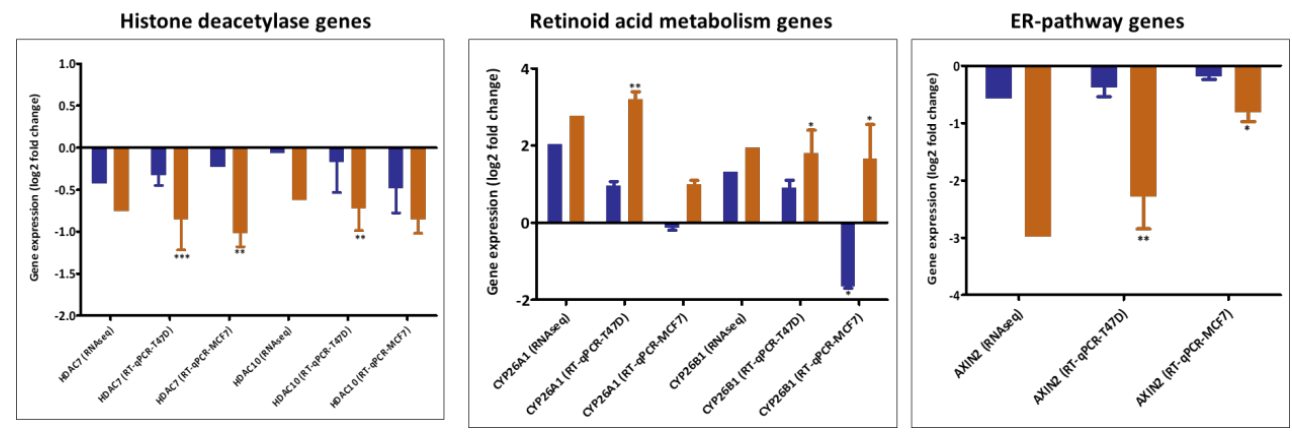

Figure 1. Genes that show differences between DES (orange) and E2 (blue) in T47D and validated in MCF-7 cells. The expression was considered significant if log $2 F C>0.6$ and $p$-value $<0.05$. For these RT-qPCR results, bars represent average \pm SEM from at least three independent experiments. For statistical analysis of the $R T-q P C R$ data, multiple paired t-tests were performed and differences were considered significant if $p$-value $<0.05$

\section{Use of in vitro testing methods to predict developmental toxicity of DES.}

In the second part of the thesis the developmental toxicity of DES compared to E2 was assessed using in vitro testing methods for developmental toxicity. It has been suggested that these alternative in vitro testing methods are promising and will reduce the use of experimental animals, while targeting to mimic the in vivo situation and therefore, improve the human prediction (van der Jagt et al. 2004; Adler et al. 2011). Results of the present thesis show that the developmental toxicity of DES can be detected in both the EST and ZET and that the developmental toxicity effects in these models are mediated via the ER $\alpha$. Comparison of the in vitro potency of DES in the ZET and EST to 
that observed in vivo revealed that both models adequately capture the adverse developmental effects of DES in a qualitative way but do not capture the full potential of DES in a quantitative way. Compared to other developmental toxicants tested in these bioassays, for which the EC50 in the in vitro assays correlated well with the in vivo data, EC50 values for DES in the EST and ZET were higher than what would have been expected based on their in vivo potency. Therefore, the predictive capacity of these in vitro tests for in vivo developmental toxicity of DES is a crucial point to discuss. Combining the in vitro EST-data with PBK modeling-based reverse dosimetry underpredicted the in vivo developmental toxicity of DES in a quantitative way by about three orders of magnitude, although the PBK model adequately predicted the in vivo kinetics of DES. Interestingly, a combination of EST data with PBK modelling has been shown to adequately predict the developmental toxicity for several other (groups of) chemicals, including glycol ethers, retinoic acid, a series of phenols, and tebuconazole (Li et al. 2017; Louisse et al. 2010, 2015, Strikwold et al. 2017). From the results of this thesis, it is clear that the EST is unable to fully reflect the in vivo developmental toxicity of DES as predicted toxic dose levels were 1000-fold lower than reported toxic dose levels in rats. This may indicate that specific molecular events that are relevant for DES-induced developmental toxicity in vivo are lacking in the EST and/or that these are not related to the readout inhibition of cardiac differentiation. The ZET provides more information than the EST, since it not only detects developmental disturbances, but also chemical-induced malformations (teratogenicity). The ZET also differentiated between DES and E2 with respect to their developmental toxicity. Teratogenic effects including edema formation, deformed head, deformed tail (i.e. short and curved-tail), haemostasis and yolk sac edema were recorded in zebrafish embryos exposed to DES but not when the embryos were exposed to E2. These teratogenic effects of DES corroborate previously reported findings that DES altered heart development and function of zebrafish embryos (Campinho and Power, 2013).

Although the EST and ZET did not adequately capture the relatively high potency of DES as a developmental toxicant, they did capture the role of ER $\alpha$ in the developmental toxicity induced by DES. Activation and disruption of the ER $\alpha$ pathway might contribute to disruption of embryonic 
development (Bondesson et al., 2015; Greco et al., 1993; Block et al., 2000; Couse et al., 2001; Couse and Korach, 2004; Ma et al., 1998; Miller et al., 1998). Furthermore, it was observed in the present thesis that when the ER $\alpha$ was blocked with the antagonist fulvestrant, the developmental toxicity of DES in both the EST and the ZET was significantly reduced (Chapter 3 and 4). However, other than only ER $\alpha$-mediated pathways can be expected to contribute to the DES-induced developmental toxicity, which is also supported by the fact that the endogenous estrogen E2 is not reported to be a developmental toxicant in in vivo and in vitro assays, as also shown using the ZET and the EST in the present thesis. For instance, the retinoic acid receptor (RAR) pathway has been shown to play an important role in embryo development by supporting normal growth and differentiation (Kam et al. 2012; Mark et al. 2009; Rhinn and Dolle 2012), and results reported in this thesis pointed at DES interference with RAR pathways via upregulation of CYP26 genes. Given these results and the fact that disturbance of retinoic acid signalling has been frequently implicated in the toxicological mode of action of teratogenic compounds (Collins and Mao 1999; Dimopoulou et al. 2016; Tembe et al. 1996; Turton et al. 1992), it is tempting to speculate that disturbance of RAR pathways may be involved in the possible embryotoxicity of DES. This would be an interesting topic for future research.

Another consideration of interest for future research would be the use of other alternative assays for developmental toxicity that may provide more information and better predict the developmental toxicity of DES in a quantitative way. For instance, the rat Whole Embryo Culture (WEC) assay is a model that has advantages compared to the ZET and EST. The WEC better mimics the in vivo situation by including the complexity of the entire mammalian embryo in terms of morphology and gene expression (Robinson et al. 2012). Furthermore, the WEC allows the continuous monitoring of embryonic development during the gestational days (GD) 10 to 12 , when a major part of organogenesis occurs (New et al. 1976). This is especially of interest given the high level of concordance between human and rodent in vivo development during this embryonic stage (Fang et al. 2010; Irie and Kuratani 2011; Robinson et al. 2012). Thus, the WEC is suggested as a useful tool for studying the teratogenic outcomes of chemicals. It would also be of interest to investigate whether 
the subtle differences in transcriptome signatures reported in the present thesis in the T47D cell model would also be observed in an entire embryo. This might require taking spatial and timedependent distribution of effects into account. Nevertheless, it is suggested that using more than one alternative testing strategy will increase the accuracy of in vivo predictions, while enhancing at the same time the background knowledge on the mechanisms underlying the developmental toxicity of DES.

\section{The use of PBK modelling for pregnancy (considerations and limitations)}

PBK models can be used to study the kinetics and translate external dose levels of a chemical into internal blood or tissue concentrations of the chemical (and its metabolite(s)) by forward dosimetry, or translate internal concentrations to corresponding dose levels using reverse dosimetry. In addition, PBK models can also be used to describe and quantify interspecies and interindividual differences in kinetics (Rietjens et al. 2011). Development of a PBK model requires many physiological parameters related to the species (animal/human) of interest as well as compoundrelated parameters. In the PBK modelling in this thesis it was assumed that the maternal levels of DES are equal to the embryo levels. Since no in vivo toxicokinetic data on DES in pregnant animals are available, it is not known whether this assumption is valid. The underprediction of the in vivo developmental toxicity of DES in a quantitative way may be related (in part) to wrong estimations of embryonic DES concentrations, which may be higher than the maternal plasma levels. There is no accurate source for data required to develop a PBK model for pregnant women. Moreover, considering that pregnant women are exposed to developmental toxicants in different pregnancy weeks, it is also of interest to note that during these weeks the parameters may change substantially. Despite the efforts made to parameterize PBK models for pregnant women (Abduljalil et al. 2012; Dallmann et al 2017; Gargas et al. J2000; ogiraju et al 2017; Alqahtani and Kaddoumi 2015), important knowledge gaps remain in such models that require additional efforts to further increase 
the predictive value of these models. These remaining gaps are discussed in the following paragraphs.

Metabolism/elimination Due to unavailability of liver microsomes or $\mathrm{S9}$ fractions derived from livers of pregnant women, hepatic clearance values in the present study were derived from liver tissue fractions of non-pregnant women (see Chapter 5). The activity of metabolizing enzymes including those involved in phase I or II enzymes has been reported to change during pregnancy. For instance, cytochrome P450 (CYP) enzymes have been reported to change during pregnancy which can affect drug pharmacokinetics (Tracy et al 2005). Moreover, changes in phase II metabolism during pregnancy include increased activity of the conjugating enzyme uridine 5'-diphosphoglucuronosyltransferase (UGT) which leads to increased oral clearance of chemicals (de Haan et al. 2004; He et al. 2007; Luquita et al. 2001; Pacheco et al. 2013; Pennell et al. 2004).

Therefore, differences in metabolic enzyme expression levels could be considered in future research for further refinement of the PBK model for pregnant women. Also potential metabolism in the embryo may be a factors to consider when further refining the models.

Placental transfer In the PBK models that were developed in this thesis, maternal blood concentrations were assumed to be equal to the fetal blood concentrations. This assumption was made based on the fact that DES and E2 are known to rapidly cross the primate placenta in rhesus monkeys and enter the fetal circulation in a similar way (Shah and McLachlan 1976). This is not always the case, as some chemicals may accumulate in the embryo, leading to higher concentrations in the embryos compared to the mothers (Griffiths and Campbell 2014). In contrast, the placenta may also be a barrier for chemicals, so the concentration in the embryo could be lower than that in maternal blood (Griffiths and Campbell 2014). Currently, there are not many in vitro systems that can be used to predict placental transfer. The human choriocarcinoma (BeWo) cell model is one of the transport models that has been used before to study placental transfer of phenols and antifungal compounds and quantify relative differences in placental transfer which were subsequently used to 
improve in vivo predictions (Li et al 2013; Strikwold 2015; Bode et al., 2006; Kazakoff et al., 1995). In addition, human trophoblast and human umbilical vein endothelial cells (HUVECS) have also been used to mimic the placental barrier (Bode et al., 2006; Kazakoff et al., 1995). Furthermore, placental transfer can be estimated using in silico models that can estimate parameter values for placental transfer of chemicals (Hewitt et al., 2007). These models could be of use to define a rate constant for placental transfer enabling description of the embryo as a separate compartment with its own kinetics in the PBK models. This would however also require availability of fetal liver samples to enable description of fetal metabolism and clearance.

In addition to the items to consider when using PBK models for pregnant women discussed above, there are also some items that are of interest to consider when applying reverse dosimetry in general. These include: variability in in vitro and in vivo data, use of average values not taking into account interindividual variability, correction for protein binding, and the use of intra- or extracellular concentrations. When performing reverse dosimetry in order to predict in vivo toxicity based on in vitro concentration-response data, it is first of all important to select an in vitro model and endpoint relevant for the in vivo effect. Given that in vitro assays represent only part of the complexity of the whole developing embryo and its maternal environment, one may question the possibility to develop an in vitro assay that adequately captures all aspects of this important endpoint in toxicity studies. In this thesis the EST was used, which has been used frequently for predicting in vivo developmental toxicity and showed to provide an adequate basis for in vitro to in vivo extrapolation (Li et al. 2017; Louisse et al. 2010, 2015; Strikwold et al. 2017). Concentration-response curves obtained in this in vitro assay can be translated to in vivo dose-response curve by relating the in vitro concentration to the maximum plasma concentration $\left(C_{\max }\right)$ as done in the present thesis (Chapter 3 ). Prior to translation of the in vitro concentration-response curve to the in vivo dose-response curve, it is crucial to consider that only the free fraction of the chemical is expected to induce the effect. This indicates the need for correction for differences in protein binding under the in vitro and in vivo conditions (Gülden and Seibert 2003). The unbound fraction of the chemical can be quantified by 
using different in vitro and in silico methods (Gülden and Seibert 2003; Louisse et al. 2015; van Liempd et al. 2011). Furthermore, a decision has to be made of whether to use intra- or extracellular concentrations for the reverse dosimetry (Rietjens et al. 2019). In the present thesis extracellular concentrations were used for protein binding correction and reverse dosimetry, similar to what was done in previous proofs-of-principle. Some people argue that toxicity will be caused by intra- not extracellular unbound concentrations of the chemical (Mielke et al. 2019). However, correcting for intracellular protein binding is difficult if not impossible, given that upon homogenizing the sample and opening the cells equilibria will change and that extra animal studies would be required to measure tissue concentrations, making the approach less suitable as an alternative testing strategy. Using extracellular unbound concentrations assumes that potential differences between intra- and extracellular protein binding in cells in vitro and in vivo will be limited. It can be even assumed that for most chemicals an equilibrium exists between the unbound concentration in the cell and the unbound concentration outside the cell, indicating that determination of the free fraction of the chemical outside the cell suffices. Upon correcting for the differences in protein binding between the in vitro and in vivo situation, each nominal in vitro concentration can be extrapolated to an in vivo effect dose. In this way the in vitro concentration-response curves from the ES-D3 differentiation assay were translated into in vivo dose-response curves using PBK modelling-based reverse dosimetry (Chapter 3). The predicted in vivo dose-response curves were compared with the reported in vivo data. This points at the issue of the quality of the in vivo data, since for some compounds in vivo dose-response curves also vary substantially, making it difficult to evaluate the adequacy of the predictions made. In the present thesis the PBK model (Chapter $\mathbf{3}$ ) was developed to predict the in vivo developmental toxicity of DES. Due to the lack in vivo developmental toxicity data for DES in rat, only data on embryo death and resorption were available to derive BMD10 values for the comparison with the predicted toxicity values, illustrating that sometimes in vivo data used for the comparison may also have limitations. In addition, where it comes to the use of in vivo data in general, one should be aware that appropriate historical control data can be helpful in the 
interpretation of malformations and variations, especially those that normally occur at very low incidences. Such historical control data may be absent but at the same time essential to be able to evaluate whether adverse findings are relevant indicators of developmental toxicity or not. In the present thesis, only few appropriate in vivo data were found for validation of the DES predictions, and no data on malformation were found. This may point at a limitation of the in vivo data used for validation of the predictions of DES-induced developmental toxicity, since the available in vivo endpoints may not fully match the endpoints of the EST and ZET.

Another point to consider in future studies is interindividual differences. It is well known that interindividual differences in bioactivation and detoxification exist. Obviously using average values for related parameters in the PBK models predicts the actual effects to be expected in vivo only in an average way without taking such interindividual differences into account. It would be an interesting topic for future research to use the potential of the PBK modeling-based reverse dosimetry to quantify interindividual differences in kinetics and resulting predicted in vivo toxicity.

\section{Conclusions}

Altogether, it is concluded that the two estrogens E2 and DES differ in their biological effects related to development in a subtle but significant way. At the cellular level, DES and E2 show high similarities in the molecular pathways that relate to ER $\alpha$-mediated effects with small significant differences that may contribute to the developmental toxicity in part via potential epigenetic effects of DES. The in vitro developmental toxicity assays EST and ZET can discriminate DES from E2 in terms of developmental toxicity, but at the same time do not capture the full mode of action underlying DESinduced developmental toxicity. Finally, it was shown that in addition to the subtle differences in toxicodynamics, substantial differences in internal concentrations (endogenous E2 concentrations compared to predicted DES concentrations in women that took DES as medication), add to the differential in vivo effects of E2 and DES. 


\section{References}

Abduljalil K, Furness P, Johnson TN, Rostami-Hodjegan A, Soltani H (2012) Anatomical, physiological and metabolic changes with gestational age during normal pregnancy: a database for parameters required in physiologically based pharmacokinetic modelling. Clin Pharmacokinet 51(6):365-96.

Adler S, Basketter D, Creton S et al. (2011) Alternative (non-animal) methods for cosmetics testing: current status and future prospects-2010. Archives of Toxicology volume 85, pages367-485.

Ahlbory-Dieker DL, D. Stride B, Leder G, et al. (2009) DNA Binding by Estrogen Receptor- $\alpha$ Is Essential for the Transcriptional Response to Estrogen in the Liver and the Uterus, Molecular Endocrinology 23(10):1544-1555.

Albers M, Kranz H, Kober I, Kaiser C, Klink M, Suckow J, Kern R, Koegl M (2005) Automated yeast twohybrid screening for nuclear receptor-interacting proteins. Mol Cell Proteomics 4(2):205-213.

Alqahtani S, Kaddoumi A (2015) Development of Physiologically Based Pharmacokinetic/Pharmacodynamic Model for Indomethacin Disposition in Pregnancy. PLoS One 2;10(10):e0139762.

Björnström L, Sjöberg M (2005) Mechanisms of Estrogen Receptor Signaling: Convergence of Genomic and Nongenomic Actions on Target Genes. Molecular Endocrinology 19(4):833-842.

Block K, Kardana A, Igarashi P, Taylor HS (2000) In utero diethylstilbestrol (DES) exposure alters Hox gene expression in the developing mullerian system. FASEB J 14(9), 1101-1108.

Bode CJ, Jin H, Rytting E, Silverstein PS, Young AM, Audus KL (2006) In vitro models for studying trophoblast transcellular transport. Methods Mol Med 122, 225-39.

Bondesson M, Hao R, Lin CY, Williams C, Gustafsson JA (2015) Estrogen receptor signaling during vertebrate development. Biochim Biophys Acta 1849(2):142-151.

Bromer JG, Wu J, Zhou Y, Taylor HS (2009) Hypermethylation of homeobox A10 by in utero diethylstilbestrol exposure: an epigenetic mechanism for altered developmental programming. Endocrinology 150(7):3376-82.

Chen M, Yeh CR, Chang HC, et al. (2012) Loss of epithelial oestrogen receptor alpha inhibits oestrogen-stimulated prostate proliferation and squamous metaplasia via in vivo tissue selective knockout models. The Journal of pathology 226(1):17-27.

Collins MD, Mao GE (1999) Teratology of retinoids. Annual review of pharmacology and toxicology 39:399-430.

Couse JF, Dixon D, Yates M, et al. (2001) Estrogen receptor-alpha knockout mice exhibit resistance to the developmental effects of neonatal diethylstilbestrol exposure on the female reproductive tract. Developmental Biology 238(2): 224-238.

Couse JF, Korach KS (2004) Estrogen receptor-alpha mediates the detrimental effects of neonatal diethylstilbestrol (DES) exposure in the murine reproductive tract. Toxicology 205(1-2):55-63. 
Dallmann A, Ince I, Meyer M, Willmann S, Eissing T, Hempel G (2017) Gestation-Specific Changes in the Anatomy and Physiology of Healthy Pregnant Women: An Extended Repository of Model Parameters for Physiologically Based Pharmacokinetic Modeling in Pregnancy. Clin Pharmacokinet (2017) 56:1303-1330.

de Haan G, Edelbroek P, Segers J, Engelsman M, Lindhout D, Devile-Notschaele, M, et al. (2004) Gestation-induced changes in lamotrigine pharmacokinetics: a monotherapy study. Neurology 63, 571-573.

de Lera AR, Bourguet W, Altucci L, Gronemeyer H (2007) Design of selective nuclear receptor modulators: RAR and RXR as a case study. Nat Rev Drug Discov 6(10):811-20.

Dimopoulou M, Verhoef A, van Ravenzwaay B, Rietjens IMCM, Piersma AH. Flusilazole induces spatio-temporal expression patterns of retinoic acid-, differentiation- and sterol biosynthesis-related genes in the rat Whole Embryo Culture. Reproductive toxicology. 2016;64:77-85.

Fang H, Yang Y, Li C, Fu S, Yang Z, Jin G, Wang K, Zhang J, Jin Y (2010) Transcriptome analysis of early organogenesis in human embryos. Dev Cell 19(1):174-84.

Fuentes N, Silveyra P (2019) Estrogen receptor signaling mechanisms. Adv Protein Chem Struct Biol. 116: 135-170.

Gargas ML, Tyler TR, Sweeney LM et al. (2000) A Toxicokinetic Study of Inhaled Ethylene Glycol Monomethyl Ether (2-ME) and Validation of a Physiologically Based Pharmacokinetic Model for the Pregnant Rat and Human. Toxicology and Applied Pharmacology 165, 53-62.

Gehin M, Mark M, Dennefeld C, Dierich A, Gronemeyer H, Chambon P (2002) The function of TIF2/GRIP1 in mouse reproduction is distinct from those of SRC-1 and p/CIP. Mol Cell Biol 22:59235937.

Glass CK, Rosenfeld MG (2000) The coregulator exchange in transcriptional functions of nuclear receptors. Genes \& development 14(2):121-141.

Gonzalez TL, Rae JM, Colacino JA, Richardson RJ (2019) Homology models of mouse and rat estrogen receptor-alpha ligand-binding domain created by in silico mutagenesis of a human template: molecular docking with 17ss-estradiol, diethylstilbestrol, and paraben analogs. Comput Toxicol 10:116.

Goodson ML, Farboud B, Privalsky ML (2007) An improved high throughput protein-protein interaction assay for nuclear hormone receptors. Nucl Recept Signal . 2007;5:e002.

Greco TL, Duello TM, Gorski J (1993) Estrogen receptors, estradiol, and diethylstilbestrol in early development: the mouse as a model for the study of estrogen receptors and estrogen sensitivity in embryonic development of male and female reproductive tracts. Endocr Rev 14(1):59-71.

Greenwald P, Barlow JJ, Nasca PC, Burnett WS (1971) Vaginal cancer after maternal treatment with synthetic estrogens. The New England journal of medicine 285(7):390-2.

Griffiths SK and Campbell JP (2014) Placental structure, function and drug transfer. Continuing Education in Anaesthesia Critical Care \& Pain 15(2):84-89. 
Gronemeyer H, Gustafsson J, Laudet V (2004) Principles for modulation of the nuclear receptor superfamily. Nat Rev Drug Discov 3, 950-964.

Gülden M, Seibert H (2003) In vitro-in vivo extrapolation: estimation of human serum concentrations of chemicals equivalent to cytotoxic concentrations in vitro. Toxicology 189(3):211-22.

He XJ, Yamauchi H, Suzuki K, et al. (2007) Gene expression profiles of drug-metabolizing enzymes (DMEs) in rat liver during pregnancy and lactation. Exp Mol Pathol 83(3):428-34.

Herbst AL, Ulfelder H, Poskanzer DC (1971) Adenocarcinoma of the vagina. Association of maternal stilbestrol therapy with tumor appearance in young women. The New England journal of medicine 284(15):878-81.

Hewitt M, Madden JC, Rowe PH, Cronin MT (2007) Structure-based modelling in reproductive toxicology: (Q)SARs for the placental barrier. SAR QSAR Environ Res 18, 57-76.

Holliday DL, Speirs V (2011) Choosing the right cell line for breast cancer research. Breast Cancer Research 13, 215.

Hsia EY, Goodson ML, Zou JX, Privalsky ML, Chen HW (2010) Nuclear receptor coregulators as a new paradigm for therapeutic targeting. Advanced drug delivery reviews 62(13):1227-1237.

IARC. (2012) A review of human carcinogens. Part A: Pharmaceuticals. IARC Working Group on the Evaluation of Carcinogenic Risks to Humans. International Agency for Research on Cancer 100:1-403.

Irie N, Kuratani S (2011) Comparative transcriptome analysis reveals vertebrate phylotypic period during organogenesis. Nat Commun 2, 248.

Jogiraju VK, Avvari S, Gollen R, Taft DR (2017) Application of physiologically based pharmacokinetic modeling to predict drug disposition in pregnant populations. Biopharm Drug Dispos 38(7):426-438

Kam RK, Deng Y, Chen Y, Zhao H (2012) Retinoic acid synthesis and functions in early embryonic development. Cell \& bioscience 2(1):11.

Kazakoff PW, McGuire TR, Hoie EB, Cano M, Iversen PL (1995) An in vitro model for permeability: assessment of monolayer integrity. In Vitro Cell Dev Biol Anim 31, 846-52.

Kim SH, Tamrazi A, Carlson KE, Katzenellenbogen JA (2005) A proteomic microarray approach for exploring ligand-initiated nuclear hormone receptor pharmacology, receptor selectivity, and heterodimer functionality. Mol Cell Proteomics 4(3):267-277.

Klotz DM, Hewitt SC, Korach KS, Diaugustine RP (2000) Activation of a uterine insulin-like growth factor I signaling pathway by clinical and environmental estrogens: requirement of estrogen receptor-alpha. Endocrinology 141(9):3430-3439.

Li H, van Ravenzwaay B, Rietjens IMCM, Louisse J (2013) Assessment of an in vitro transport model using BeWo b30 cells to predict placental transfer of compounds. Arch Toxicol 87:1661-1669. 
Li H, Zhang M, Vervoort J, Rietjens IMCM, van Ravenzwaay B, Louisse J (2017) Use of physiologically based kinetic modeling-facilitated reverse dosimetry of in vitro toxicity data for prediction of in vivo developmental toxicity of tebuconazole in rats. Toxicol Lett 266:85-93.

Loudig O, Babichuk C, White J, Abu-Abed S, Mueller C, Petkovich M. (2000) Cytochrome P450RAI(CYP26) promoter: a distinct composite retinoic acid response element underlies the complex regulation of retinoic acid metabolism. Molecular endocrinology 14(9):1483-1497.

Louisse J, Bosgra S, Blaauboer BJ, Rietjens IMCM, Verwei M (2015) Prediction of in vivo developmental toxicity of all-trans-retinoic acid based on in vitro toxicity data and in silico physiologically based kinetic modeling. Arch Toxicol 89(7):1135-1148.

Louisse J, de Jong E, van de Sandt JJ et al (2010) The use of in vitro toxicity data and physiologically based kinetic modeling to predict dose-response curves for in vivo developmental toxicity of glycol ethers in rat and man. Toxicol Sci 118(2):470-484.

Luijten M, van Beelen VA, Verhoef A, et al. (2010) Transcriptomics analysis of retinoic acid embryotoxicity in rat postimplantation whole embryo culture. Reproductive toxicology 30(2):333-340

Luquita MG, Catania VA, Pozzi EJ, et al. (2001) Molecular basis of perinatal changes in UDPglucuronosyltransferase activity in maternal rat liver. J Pharmacol Exp Ther 298(1):49-56.

Ma L, Benson GV, Lim H, Dey SK, Maas RL (1998) Abdominal B (AbdB) Hoxa genes: regulation in adult uterus by estrogen and progesterone and repression in mullerian duct by the synthetic estrogen diethylstilbestrol (DES). Developmental Biology 197(2), 141-154.

Maden M (2000) The Role of Retinoic Acid in Embryonic and Post-Embryonic Development. Nutrition Society 59 (2000): 65-73.

Mark M, Ghyselinck NB, Chambon P (2009) Function of retinoic acid receptors during embryonic development. Nuclear receptor signaling 7:e002.

Mielke H, Partosch F, Gundert-Remy U (2019) Letter to the Editor. Arch Toxicol 93, 1465-1466.

Miller C, Degenhardt K, Sassoon DA (1998) Fetal exposure to DES results in de-regulation of Wnt7a during uterine morphogenesis. (1995). Teratogen update: carcinogenesis and teratogenesis associated with exposure to diethylstilbestrol (DES) in utero. Teratology 51(6), 435-45.

New DA, Coppola PT, Cockroft DL (1976) Comparison of growth in vitro and in vivo of postimplantation rat embryos. J Embryol Exp Morphol 36(1): p. 133-44.

Newbold RR (2008) Prenatal exposure to diethylstilbestrol (DES). Fertility and sterility 89(2 Suppl):e55-6.

O'Malley BW, Kumar R (2009) Nuclear receptor coregulators in cancer biology. Cancer Research. 69(21):8217-8222.

Pellizzer C, Bremer S, Hartung T (2005) Developmental toxicity testing from animal towards embryonic stem cells. Altex 22(2):47-57. 
Pennell PB, Newport DJ, Stowe ZN, Helmers SL, Montgomery JQ, Henry TR (2004) The impact of pregnancy and childbirth on the metabolism of lamotrigine. Neurology 62(2):292-295

Pera MF, Trounson AO (2004) Human embryonic stem cells: prospects for development. Development 131(22):5515-5525.

Prins GS, Birch L, Couse JF, Choi I, Katzenellenbogen B, Korach KS (2001) Estrogen imprinting of the developing prostate gland is mediated through stromal estrogen receptor alpha: Studies with alpha ERKO and)beta ERKO mice. Cancer Res 61(20):7704-7705.

Reed CE, Fenton SE (2013) Exposure to diethylstilbestrol during sensitive life stages: a legacy of heritable health effects. Birth defects research Part C, Embryo today : reviews 99(2):134-46.

Rhinn M, Dolle P (2012) Retinoic acid signalling during development. Development 139(5):843-858.

Rietjens IMCM, Louisse J, Punt A (2011) Tutorial on physiologically based kinetic modeling in molecular nutrition and food research. Mol Nutr Food Res 55(6):941-56.

Rietjens, IMCM, Ning J, Chen L. et al (2019) Selecting the dose metric in reverse dosimetry based QIVIVE. Arch Toxicol 93, 1467-1469

Robinson JF, Verhoef A, Piersma AH (2012) Transcriptomic analysis of neurulation and early organogenesis in rat embryos: an in vivo and ex vivo comparison. Toxicol Sci 126(1): p. 255-66.

Ross SA, Peter JM, Ursula CD, Luigi MDL (2000) Retinoids in Embryonal Development. Physiological Reviews 80 (2000): 1022-46.

Shah HC and McLachlan JA (1976) The fate of diethylstilbestrol in the pregnant mouse. Journal of Pharmacology and Experimental Therapeutics 197 (3): 687-696.

Spielmann H, Seiler A, Bremer S, et al (2006) The practical application of three validated in vitro embryotoxicity tests. The report and recommendations of an ECVAM/ZEBET workshop (ECVAM workshop 57). Alternatives to laboratory animals: ATLA 34(5):527-538.

Strikwold M, Spenkelink B, de Haan LHJ, Woutersen RA, Punt A, Rietjens IMCM (2017) Integrating in vitro data and physiologically based kinetic (PBK) modelling to assess the in vivo potential developmental toxicity of a series of phenols. Arch Toxicol 91:2119-2133.

Tantibanchachai C (2014) Retinoids As Teratogens. Embryo Project Encyclopedia (2014-02-28). ISSN: $1940-5030$

Tembe EA, Honeywell R, Buss NE, Renwick AG (1996) All-trans-retinoic acid in maternal plasma and teratogenicity in rats and rabbits. Toxicology and applied pharmacology 141(2):456-472.

Thatcher JE, Isoherranen N (2009) The role of CYP26 enzymes in retinoic acid clearance. Expert opinion on drug metabolism \& toxicology 5(8):875-886.

Titus-Ernstoff L, Hatch EE, Hoover RN, et al. (2001) Long-term cancer risk in women given diethylstilbestrol (DES) during pregnancy. British journal of cancer 84(1):126-33. 
Titus-Ernstoff L, Troisi R, Hatch EE, Palmer JR, Hyer M, Kaufman R, Adam E, Noller K, Hoover RN (2010) Birth defects in the sons and daughters of women who were exposed in utero to diethylstilbestrol (DES). Int J Androl 33(2):377-84

Turton JA, Willars GB, Haselden JN, Ward SJ, Steele CE, Hicks RM (1992) Comparative teratogenicity of nine retinoids in the rat. International journal of experimental pathology 73(5):551-563.

van der Jagt K, Munn S, Tørsløv J, de Bruijn J (2004) Alternative approaches can reduce the use of test animals under REACH. Report EUR. 2; 2004.

van Liempd S, Morrison D, Sysmans L, Nelis P, Mortishire-Smith R (2011) Development and validation of a higher-throughput equi-librium dialysis assay for plasma protein binding. J Lab Autom 16(1):5667

Warita K, Mitsuhashi T, Sugawara T, et al. (2010) Direct effects of diethylstilbestrol on the gene expression of the cholesterol side-chain cleavage enzyme (P450scc) in testicular Leydig cells. Life sciences 87(9-10):281-285.

Xu J, Li Q 2003 Review of the in vivo functions of the p160 steroid receptor coactivator family. Mol Endocrinol 17:1681-1692.

Xu J, Liao L, Ning G, Yoshida-Komiya H, Deng C, O'Malley BW (2000) The steroid receptor coactivator SRC-3 ( $p / C I P / R A C 3 / A I B 1 / A C T R / T R A M-1)$ is required for normal growth, puberty, female reproductive function, and mammary gland development. Proc Natl Acad Sci USA 97:6379-6384. 
CHAPTER 7

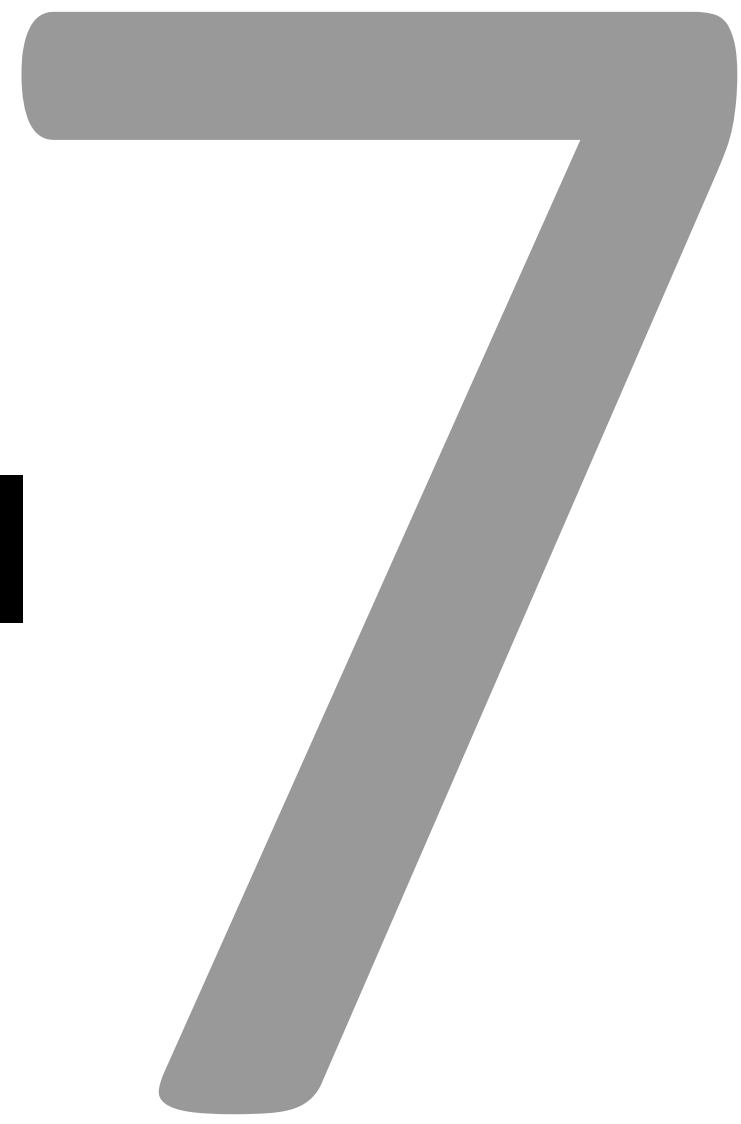


Summary 


\section{Summary}

Diethylstilbestrol (DES) is a synthetic hormone that was first prescribed in the 1940s to 1970s for pregnant women to prevent miscarriage and premature delivery, and to women in general for treatment of menstrual problems and cancer. However, from later studies it was concluded that these claimed beneficial effects were not observed, and even adverse effects were reported, such as clear cell carcinoma, and reproductive and developmental toxicity. Although increased levels of the endogenous hormone $17 \beta$-estradiol (E2) have been reported to increase the chances on developing cancer, such as breast cancer, the typical adverse effects observed for DES were not reported to the same extent for E2, although DES is structurally similar to E2 and it is suggested that DES acts by mimicking the effects of E2. The aim of this thesis was to investigate the differences in estrogenicity and developmental toxicity between DES and E2 using different in vitro and in silico approaches, focussing on the potential role of possible differences in ER $\alpha$-mediated changes in the underlying mode of action.

Chapter 1 provides background information introducing the topic. In addition, the adverse effects related to DES-exposure and the known mechanisms of action of DES are described. The knowledge gaps and principal aim of the thesis are defined and the testing strategies to be used are explained and a general outline of the thesis is provided.

Chapter 2 investigated the possible differences between DES and E2 in induction of ER $\alpha$-mediated cellular effects, including ER $\alpha$-mediated reporter gene expression in the U2OS CALUX assay, ER $\alpha$ mediated cell proliferation, and ER $\alpha$-mediated-coregulator interactions and gene expression in cells of the T47D breast cancer cell line. The results obtained indicate that DES and E2 activate ER $\alpha$ mediated reporter gene transcription and T47D cell proliferation in a similar way. However, minor but significant differences between DES- and E2-induced binding of the ER $\alpha$ to coregulator motifs and in transcriptomic signatures were observed. These differences, including especially E2-induced binding of the ER $\alpha$ with several co-repressor motifs, DES-induced downregulation of genes involved 
in histone deacetylation and DNA methylation, and upregulation of CYP26A1 and CYP26B1, may play a role in the differential in vivo effects reported for DES and E2. Thus, coregulator binding and transcriptomic signatures could discriminate DES from E2.

In Chapter $\mathbf{3}$ an alternative testing strategy to quantitatively predict the in vivo developmental toxicity of DES was evaluated. To this end a physiologically based kinetic (PBK) model was defined that was subsequently used to translate concentration-response data for the in vitro developmental toxicity of DES, obtained in the ES-D3 cell differentiation assay, into predicted in vivo dose-response data for developmental toxicity. Previous studies showed that the PBK modeling-facilitated reverse dosimetry approach is a useful approach to quantitatively predict the developmental toxicity of several developmental toxins. The results obtained in this chapter show that the PBK model adequately predicted DES blood concentrations in rats. Furthermore, the study revealed that DES tested positive in the ES-D3 differentiation assay and that DES-induced inhibition of the ES-D3 cell differentiation could be counteracted by the ER $\alpha$ antagonist fulvestrant, indicating that the in vitro ES-D3 cell differentiation assay was able to capture the role of ER $\alpha$ reported in the mode of action underlying the developmental toxicity of DES in vivo. Finally, the in vitro data were combined with the PBK model to predict a dose-response curve for the in vivo developmental toxicity of DES, and the results clearly showed that this combination did not adequately predict the in vivo developmental toxicity of DES in a quantitative way. Thus, it was concluded that although the EST qualifies DES as a developmental toxin and detects the role of ER $\alpha$ in this process, the ES-D3 cell differentiation assay of the EST apparently does not adequately capture the full mode of action underlying DES-induced developmental toxicity in vivo. This may in part be related to the fact that the ES-D3 cell differentiation assay lacks the complex biological system and the metabolic capacity of an intact organism and/or that the assay may not reflect all modes of action possibly underlying developmental toxicity, including for example epigenetic effects, reported to play an important role in DES-mediated developmental effects. 
Because of these potential limitations of the EST, Chapter 4 assessed the developmental toxicity of DES compared to E2 in the zebrafish embryotoxicity test (ZET). In addition, it was investigated whether the role of the ER $\alpha$ in DES-mediated developmental toxicity could also be demonstrated in the ZET. To this end, the in vitro embryotoxicity of DES and E2 was quantified in the ZET in the absence and presence of the ER $\alpha$ antagonist fulvestrant. Results obtained in the ZET showed that DES induced growth retardation, cumulative mortality and malformations in zebrafish embryos, while E2 showed only growth retardation and cumulative mortality with a lower potency compared to DES. Additionally, DES induced pericardial edema formation in zebrafish embryos, which was not observed in E2-exposed zebrafish embryos. This effect could be counteracted by co-exposure to fulvestrant, indicating that the ZET was able to capture the role of ER $\alpha$ in the mode of action underlying this developmental toxicity effect of DES in zebrafish. Overall, it is concluded that the ZET differentiates between E2 and DES with respect to their developmental toxicity, while confirming the role of ER $\alpha$ in the specific developmental toxicity effects found for DES. Furthermore, like the EST, also the ZET appeared unable to capture the relatively high in vivo potency of DES as a developmental toxicant.

Finally, in Chapter $\mathbf{5}$ of the thesis it was investigated to what extent differences in kinetics and internal dose levels may add to the potential in vivo differences in effects of E2 vs DES on development. It was hypothesised that part of the in vivo differences may originate from differences in the internal dose levels of these two estrogens during pregnancy and/or DES treatment. To enable quantification of dose-dependent internal dose levels, physiologically based kinetic (PBK) models for E2 and DES in pregnant women were defined. The models predicted the kinetics of DES and E2 in pregnant women to be comparable. Therapeutic doses of DES as given to pregnant women were predicted to result in blood levels that are 3 to 4 orders of magnitude higher than endogenous E2 blood levels. It is concluded that the PBK models developed enable quantification of dose-dependent plasma concentrations of DES and E2 in pregnant women and reveal that differences in effects of DES and E2 on development may at least in part be due to differences in internal exposure levels. 
In Chapter 6 an overview and discussion of the results obtained is provided. The chapter also presents remaining data gaps and future perspectives. Altogether, it is concluded that the two estrogens E2 and DES differ in their biological effects related to development in a subtle but significant way. At the cellular level, DES and E2 show high similarities in the molecular pathways that relate to ER $\alpha$-mediated effects with small significant differences that may contribute to the developmental toxicity in part via potential epigenetic effects of DES. The in vitro developmental toxicity assays EST and ZET can discriminate DES from E2 in terms of developmental toxicity, but at the same time do not capture the full mode of action underlying DES-induced developmental toxicity. Finally, it was shown that in addition to the subtle differences in toxicodynamics, substantial differences in internal concentrations (endogenous E2 concentrations compared to predicted DES concentrations in women that took DES as medication), add to the differential in vivo effects of E2 and DES. 


\section{APPENDIX}




\section{Appendix}

Acknowledgements

List of Publications

Curriculum Vitae

Overview of completed training activities 


\section{Acknowledgement}

Researching, executing, and compiling this thesis was a very challenging and rewarding experience for me. I have learned a wealth of knowledge and gained valuable experience through my thesis work. This PhD thesis would not have been possible without the support and encouragement of several special people. Hence, I would like to take this opportunity to show my gratitude to those who have assisted me in numerous ways.

First of all, I would like to express my sincere appreciation to my promotor, Prof. Ivonne Riejtens, who has the substance of a genius: she convincingly guided and encouraged me to be professional and do the right thing even when the road got tough. There were many times where I had reached a 'crossroad' and each time you were there to steer me towards the right path. Without your persistent help, the goal of this project would not have been realized. Thank you so much for taking a chance on me and teaching me that there is always scope for improvement, your leadership has made me more productive and converted all of my skills into strengths. Thank you Ivonne! you know I appreciate you in so many ways.

To Dr. Jochem, thank you so much for giving me the opportunity to work on this project and being my daily supervisor during the last five years for both my master thesis and my PhD. I learned a lot from you on how to do research, but also on how to see things from a broader point of view. You taught me more than I could ever give you credit here. You have shown me, by your example, what a good scientist (and person) should be. I really appreciated your support and critical comments during the years that we were working together.

To former toxicology colleagues and friends: Laura, it has been my pleasure to work with you during my PhD journey. I would also like to thank you for your technical help to finalize my experiments. I am extremely grateful for our friendly chats at the end of our meetings and your personal support in my academic and personal endeavors. Bert and Sebas, thank you so much for your guidance and help throughout the UPLC experiments. It truly has been a very good time in this lab. I am also very grateful to all other teaching and research staff (Nico, Hans, Karsten, Hans) that have taken some time to discuss and enrich my work. Particularly valuable were the corridor chats at the department; the PhD research seminars; and the informal meetings. Tox has provided me with a very stimulating environment in what concerns the extraordinary quality of its academic staff, and that experience will leave marks beyond this thesis.

Special thanks go to all other co-authors for my publications; Ben, thank you so much for your valuable feedback and comments. Guido, thanks for teaching me the omics principles and your valuable help for data analysis. Mengying (modeling girl), thanks a lot for your 
input and help with the PBK models. Lenny, thank you so much for your friendship and your help and contribution to the zebrafish paper. Wish you all the best in your future life.

I would like to thank all my current and previous $\mathrm{PhD}$ colleagues, with whom I have shared moments of deep anxiety but also of big excitement. Their presence was very important in a process that is often felt as tremendously solitaire. Reiko, Sunday, Samantha, Jonathan, Amer, Abdul, Hequn, Marcia, Myrto, Lu, Jia, Mebrahtom, Lenny, Marta, Ashraf, Diego, Mengying, Suparmi, Felecia, Isaac, Katja, Diana, Miaoying, Diana, Ixchel, Kornphimol, Annelies, Shensheng, Menno, Biyao, Jin, Edith, Bohan, Lu Chen, Qianrui, Danlei, Artem. It was enjoyable to work and have so many fun activities with you. Your friendship and support have made Wageningen not only a workplace but also a home away from home. I will always remember the great time we had.

The work presented in this thesis has been critically assessed and approved by an outstanding committee to whom I am more than grateful: Prof. Sander Kersten, Prof. Aldert Piersma, Prof. Majorie van Duursen and Dr. Herman Koeter.

Two person at TOX deserve a very special word of gratitude (my paranymphs): one is Ignacio (Nacho), who has given me valuable support from the beginning of my PhD. Thanks for your encouragement and for helping me dealing with the difficulties of doing a PhD. You are the best Nacho. Georgia (Gogo), who has always been a major source of support when things would get a bit discouraging. Thank you all for everything you have done for me. For the funtime we spent together, sleepless nights that gave us the courage to complete tasks before deadlines and for stimulating discussions. Thank you so much form the bottom of my heart for being a true friend.

To Rozaini, Rung and Nacho (the pocoys) my TOX brother and sisters. The debates, dinners, and running as well as editing advice, bike trips to the forest, and general help and friendship were all greatly appreciated. Thank you for your thoughts, well-wishes/prayers, phone calls, e-mails, texts, skypes, editing advice, and being there whenever I needed you. I love you from the bottom of heart. You are one of the best things that I got in my life.

Also outside the university, there are people that I would like to thank for making my stay in the Netherlands a pleasant and social one. It is my pleasure to thank all my Sudanese and non-Sudanese friends and their families; Sarah and Osman, Nuha, Sahar and Amjed, Nasereldin and Raja, Sharifa and Abdallah, Wafaa, Sanaa, Awatif, Samah, Abdelrahim, Sara, Islam and Asmaa for all great times we had together and all kind considerations to my family and me. 
Special thanks go to my lovely Palestinian friend Nour (second mom of Sofi) for your kind support, sympathy and help during the last stage in my PhD. Thanks for being with Safwan and for taking care of him in the same way I do and more. Thanks for being a true sister for me. I wish you all the best in your entire life. Love you from the bottom of my heart.

My very special thanks go to my dearest, friend and mentor in Sudan Dr. Nazik. She was the one who encouraged me since I started my BSc. Thank you so much for encouraging me to harness my skills and never stop learning.

I cannot forget friends who went through hard times together, cheered me on, and celebrated each accomplishment. Yousra, Saida, Einas, Abeer Thank you so much for being always there for me. Looking forward to meet you soon in Sudan.

I have been blessed with a very loving and supportive family who had a fundamental role in getting me through the PhD process successfully: Thank you for your encouraging me in all of my pursuits and inspiring me to follow my dreams. I would like to acknowledge my parents, who passed away before the completion of my education. I know they would be proud and I will forever be grateful for the knowledge and values they instilled in me. I always knew that they believed in me and wanted the best for me. They teached me that my job in life was to learn, to be happy, and to know and understand myself; only then could I know and understand others.

To my siblings (Khalid, Abo-Aldahab, Samia, Khalda, Sahal, Bashir, Musaab and Rasha), the backbone of my happiness. Thank you so much for your continuous support throughout my life and leaving me free in all my decisions. Without your love and support, I couldn't continue. The greatest gift my parents ever gave me was you. Love you form the bottom of my heart.

To my aunts and uncles, thank you for believing in me and for all your help when I needed it the most. Special thanks to my aunt Aziza, who joined us when I was delivering my son, for giving me unlimited happiness and pleasure.

Yassin, Umelalim, Salwa and Kawther, my cousins abroad, thanks for your constant support and always asking about me and my family. Your calls and chats means a lot to me.

Above everyone else, I really want to express my appreciation especially for my lovely husband, Actham. Thank you for all your love, support, wisdom, patience, sympathy, kindness and help, both emotional and practical, throughout our life in the Netherlands sharing all the ups, the downs, the frustration and the victories of the scientific and social life. Due to above-mentioned reasons, I love and respect you so much and wish you all the best. Thank you for doing this all with me to make our future nicer. 
Heartful thanks goes to my lovely son, Safwan. You were born in Wageningen during my PhD and brought new motivation and joy for Actham and me in our lives. Having you midway during my Ph.D. was certainly not easy for both of us but you made my life wonderful. You are the most important personal gift for me in every perspective. Thank you for being there for me at the end of the day. Your love and laugh are what has gotten me through when I wanted to give up. I'm proud of you sweetie Sofie (otwy).

I would like to thank all people who I might have forgotten to mention here, but it does not mean I did not value them.

Finally, I am grateful to have had the privilege of attending Wageningen university. This experience has afforded me the opportunity to work with some of the best and brightest, and the resources for me to achieve great success. Thank you for this opportunity. 


\section{List of publications}

Adam, A. H.B., Zhang, M., de Haan, L. H. J., van Ravenzwaay, B., Louisse, J., and Rietjens, I.M. C. M. C. (2019). The in vivo developmental toxicity of diethylstilbestrol (DES) in rat evaluated by an alternative testing strategy. Archives of Toxicology 93 (7), 2021-2033.

Adam, A. H. B., de Haan, L. H. J., Estruch, I. M., Hooiveld, G. J. E. J., Louisse, J., and Rietjens, I. M. C. M. (2020). Estrogen receptor alpha (ER $\alpha$ )-mediated coregulator binding and gene expression discriminates the toxic ER $\alpha$ agonist diethylstilbestrol (DES) from the endogenous ERaagonist 17ß-estradiol (E2). Cell Biology and Toxicology (2020).

Adam, A. H. B., Kamelia, L., de Haan, L. H. J., Louisse, J., and Rietjens, I. M. C. M. (2020). Assessment of the in vitro developmental toxicity of diethylstilbestrol and estradiol in the zebrafish embryotoxicity test. Submitted

Adam, A. H.B., Zhang, M., Spenkelink, A., Wesseling S., Louisse, J., and Rietjens, I.M. C. M. (2020). Physiologically based kinetic modelling-facilitated comparison of internal female dose levels of diethylstilbestrol and $17 \beta$-estradiol, to study a potential role of kinetics in the differences in their developmental toxicity. In preparation

Adam, A. H.B., Mustafa, N.E.M., Rietjens, I.M. C. M. C. (2017). Nitrite in processed meat products in Khartoum, Sudan and dietary intake. Food Additives \& Contaminants Part BSurveillance 10 (2), 79-84. 


\section{Curriculum vitae}

Aziza Hussein was born on September $18^{\text {th }}, 1985$ in Nyala, Sudan. Aziza obtained a Bachelor degree in Public and Environmental Health (University of Khartoum), Sudan in 2009. Next, Aziza obtained a MSc in Public and Environmental Health with specialization in Food Hygiene and Safety in 2012. In addition, she worked as a teaching assistant and lecturer at the department of food hygiene and safety in Khartoum University (2009-2013). In 2013, she came to Wageningen University in the Netherlands for her second master study in Food Safety. During her master, Aziza conducted her major and minor MSc thesis at the department of toxicology. In 2015, she started her PhD at the Division of Toxicology, Wageningen University, under the supervision of Prof. Ivonne Rietjens and Dr. Jochem Louisse from the project sponsored by Wageningen University. During her PhD study, she followed several Postgraduate Education courses in Toxicology, which enables her to register as a European Toxicologist. Aziza will start her work again as Assistant professor at the department of Food Hygiene and Safety at Khartoum University, Sudan. 


\section{Overview of completed training activities}

\section{Discipline specific activities}

Molecular Toxicology, Postgraduate Education in Toxicology (PET), Amsterdam, 2016

Cell Toxicology, PET, Leiden, 2016

Toxicogenomics, PET, Maastricht, 2017

Pathobiology, PET, Utrecht, 2017

Laboratory animal science, PET, Utrecht, 2017

Reproductive Toxicology, PET, Utrecht, 2016

Organ Toxicology, PET, Nijmegen, 2018

Mutagenesis \& Carcinogenesis, PET, Leiden, 2017

\section{Conferences}

Society of Toxicology, Poster Presentation, Baltimore, USA, 2019

Nuclear Receptor Research Network (Annual Meeting, Amsterdam, 2016)

The Dutch Society of Toxicology Meeting (NVT) 2016

\section{General courses}

Techniques for Writing and Presenting a Scientific Paper, Wageningen, 2018.

Presenting with impact, Wageningen, 2018

VLAG PhD week, Venlo, 2015

\section{Optional activities}

General Toxicology, Wageningen, 2017

Environmental Toxicology, Wageningen, 2017

Attending scientific presentations at Division of Toxicology, 2015-2019

Preparing PhD research proposal 2015-2018

$\mathrm{PhD}$ representative at TOX department 2015-2016

PhD representative at VLAG 2015-2018 
The research described in this thesis was financially supported by Wageningen university, the Netherlands.

Financial support from Wageningen University for printing this thesis is gratefully acknowledged.

Cover designed by Azraa Eltayeb and Aziza Hussein

Printed by ProefschriftMaken - Digiforce, Vianen, the Netherlands 



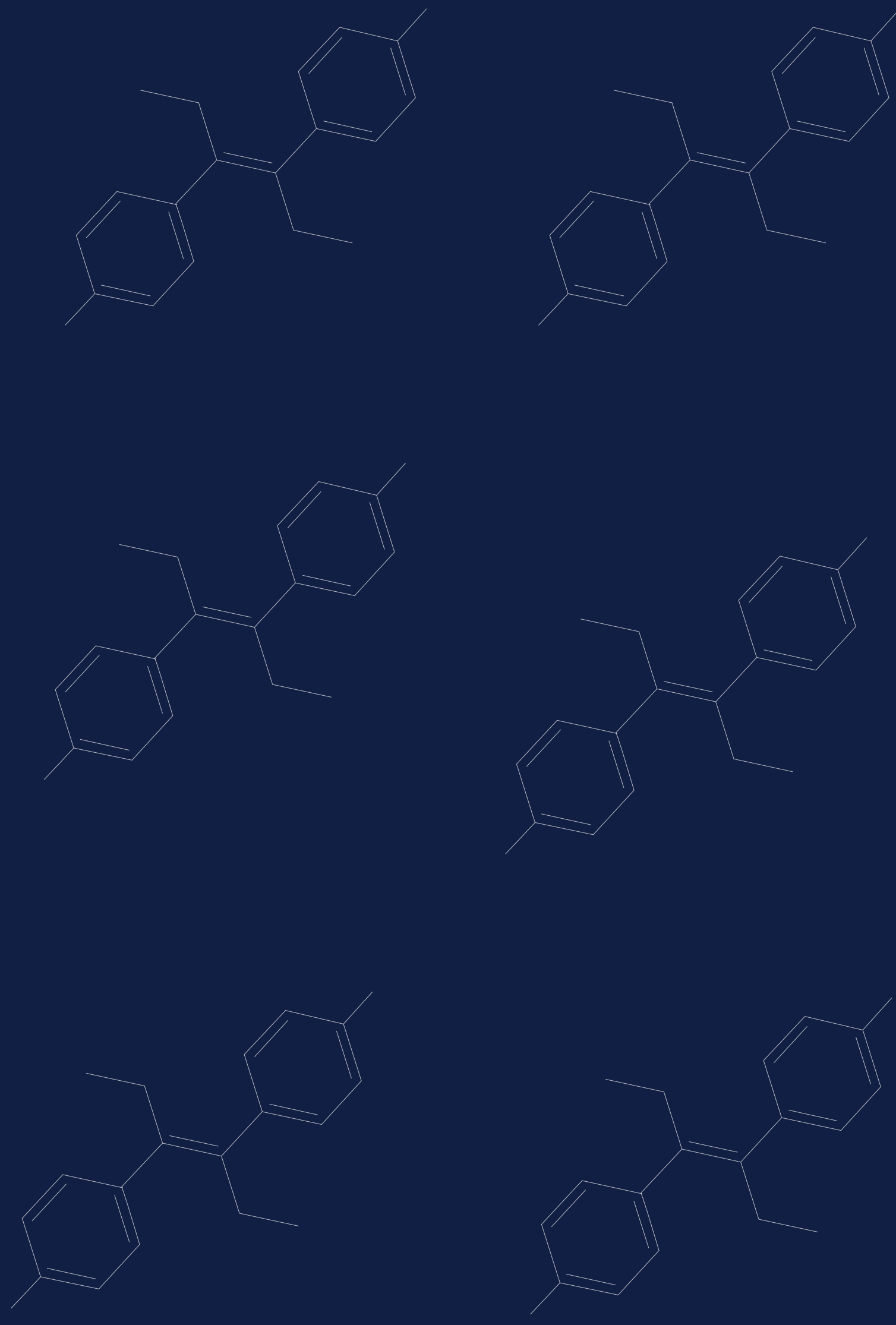